\title{
Reciprocity and cooperation in strategic contexts
}

Citation for published version (APA):

Casoria, F. (2019). Reciprocity and cooperation in strategic contexts. [Doctoral Thesis, Maastricht University]. Maastricht University. https://doi.org/10.26481/dis.20190131fc

Document status and date:

Published: 01/01/2019

DOI:

10.26481/dis.20190131fc

Document Version:

Publisher's PDF, also known as Version of record

\section{Please check the document version of this publication:}

- A submitted manuscript is the version of the article upon submission and before peer-review. There can be important differences between the submitted version and the official published version of record.

People interested in the research are advised to contact the author for the final version of the publication, or visit the DOI to the publisher's website.

- The final author version and the galley proof are versions of the publication after peer review.

- The final published version features the final layout of the paper including the volume, issue and page numbers.

Link to publication

\footnotetext{
General rights rights.

- You may freely distribute the URL identifying the publication in the public portal. please follow below link for the End User Agreement:

www.umlib.nl/taverne-license

Take down policy

If you believe that this document breaches copyright please contact us at:

repository@maastrichtuniversity.nl

providing details and we will investigate your claim.
}

Copyright and moral rights for the publications made accessible in the public portal are retained by the authors and/or other copyright owners and it is a condition of accessing publications that users recognise and abide by the legal requirements associated with these

- Users may download and print one copy of any publication from the public portal for the purpose of private study or research.

- You may not further distribute the material or use it for any profit-making activity or commercial gain

If the publication is distributed under the terms of Article $25 \mathrm{fa}$ of the Dutch Copyright Act, indicated by the "Taverne" license above, 


\section{Reciprocity and Cooperation in Strategic Contexts}


(c) Fortuna Casoria, Maastricht 2019

All rights reserved. No part of this publication may be reproduced, stored in an automated data system, or transmitted in any form or by any means, electronic, mechanical, photocopying, recording or otherwise, without prior permission of the author.

This book was typeset by the author using $\mathrm{AT}_{\mathrm{E}} \mathrm{X}$. 


\title{
Reciprocity and Cooperation in Strategic Contexts
}

\author{
Dissertation \\ to obtain the degree of Doctor at Maastricht University \\ on the authority of the Rector Magnificus Prof. Dr. Rianne M. Letschert, \\ in accordance with the decision of the Board of Deans, \\ to be defended in public on \\ Thursday 31 January 2019, at 10:00 hours.
}

by

Fortuna Casoria 
Assessment Committee: Prof. Dr. Martin Carree (Chair)

Prof. Dr. Randolph Sloof, University of Amsterdam Prof. Dr. Sigrid Suetens, Tilburg University

Dr. Tse-Ling Teh 


\section{Contents}

1 Introduction 1

2 Experimental labor markets and policy considerations: incomplete contracts and macroeconomic aspects 9

2.1 Introduction . . . . . . . . . . . . . . . . . . . . . 10

2.2 Experimental gift-exchange labor markets . . . . . . . . . . 11

2.2.1 Common features across experiments . . . . . . . . . 11

2.2 .2 Fundamental results . . . . . . . . . . . . . 13

2.2.3 Gift-exchange labor markets and policy instruments . . . 18

2.2.4 Robustness and extensions of gift-exchange labor markets 25

2.2.5 Summary . . . . . . . . . . . . . . . 32

2.3 Experimental labor markets in macroeconomics and public finance 33

2.4 Conclusions . . . . . . . . . . . . . . . . . . . . 37

3 Labor market gift-exchange and output market competition 41

3.1 Introduction . . . . . . . . . . . . . . . . . . . . . . 42

3.2 Experimental design . . . . . . . . . . . . . . . . . . . . . . . . . . . . 44

3.2.1 Procedures and parameters . . . . . . . . . . . . 44

3.2.2 Subject pool and payments . . . . . . . . . . . 46

3.2.3 Behavioral predictions and hypotheses . . . . . . . 47

3.3 Results . . . . . . . . . . . . . . . . . . . 52

3.3 .1 Gift-exchange . . . . . . . . . . . . . . . . . 52

3.3 .2 Markets performance . . . . . . . . . . . . 58

3.4 Discussion and conclusions . . . . . . . . . . . . . . . . 61

3.A Saliency of payoffs . . . . . . . . . . . . . . 65

3.A.1 Gift-exchange .................. 65

3.A.2 Markets performance. . . . . . . . . . 68

3.B Additional regressions . . . . . . . . . . . . . . . . 69

3.C Instructions for the Duopoly treatment . . . . . . . . . . 72 
4 Gift-exchange under market liberalization $\quad 77$

4.1 Introduction . . . . . . . . . . . . . . . . . . . 78

4.2 Experimental design $\ldots \ldots \ldots$. . . . . . . . . . . . 81

4.2.1 Procedures and parameters . . . . . . . . . . . 81

4.2.2 Predictions and hypotheses . . . . . . . . . . 84

4.3 Results. . . . . . . . . . . . . . . . . . 87

4.3.1 Effects of market liberalization . . . . . . . . . . 87

4.3.2 Effects of removing competition . . . . . . . . . . . . . . . . . . . . . . . . .

4.4 Summary and conclusions . . . . . . . . . . . . . . . . . . 109

4.A Additional statistical analyses . . . . . . . . . . . . . . 113

4.A.1 Market liberalization - Non-parametric analysis . . . . . . 113

4.A.2 Additional regressions . . . . . . . . . . . . . 115

4.A.3 Removal of competition - Non-parametric analysis . . . 117

4.B Theoretical background . . . . . . . . . . . . . . . . . . 119

4.C Instructions for the MtoD treatment . . . . . . . . . . . . . . 121

5 Do upfront investments increase cooperation? An experimen$\begin{array}{lr}\text { tal approach } & 129\end{array}$

5.1 Introduction . . . . . . . . . . . . . . . . . . 130

5.2 Experimental design . . . . . . . . . . . . . . . . . 133

5.2 .1 Procedures . . . . . . . . . . . . . . . . 135

5.3 Theoretical background . . . . . . . . . . . . . . . . 135

5.3.1 Predictions and hypotheses . . . . . . . . . . . 136

5.4 Results . . . . . . . . . . . . . . . . . . . . . . . . 139

5.4 .1 Investments . . . . . . . . . . . . . . . . . 139

5.4 .2 Cooperation . . . . . . . . . . . . . . . . . 140

5.5 Discussion . . . . . . . . . . . . . . . . . . . . 146

5.5.1 Investments as coordination problem . . . . . . . . . . 146

5.5 .2 Cooperation . . . . . . . . . . . . . . . . . 150

5.6 Summary and conclusions . . . . . . . . . . . . . . . . . 154

5.A Design - number of periods per match . . . . . . . . . 157

5.B Theoretical background . . . . . . . . . . . . . 158

5.C Additional statistical analyses . . . . . . . . . . . . . . 158

5.C.1 Investments . . . . . . . . . . . . . . . 158

5.C.2 Cooperation . . . . . . . . . . . . . . . 159

5.C.3 Discussion- Cooperation . . . . . . . . . . . 167 


\section{List of Figures}

2.1 Flow diagram of the Riedl and van Winden (2001, 2007, 2012) economy . . . . . . . . . . . . . . . . 34

3.1 Total and consumers surplus as a function of $\gamma$ for the three levels

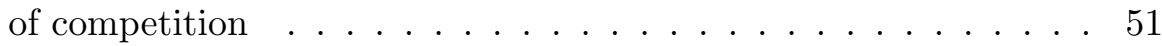

3.2 Average wage and effort over time . . . . . . . . . . 52

3.3 Wage and effort distributions . . . . . . . . . . . . . . . 54

3.4 Average effort for different wage intervals . . . . . . . . . . . 55

3.1 Average wage and effort over time . . . . . . . . . . . . 66

3.2 Average effort for different wage intervals . . . . . . . . . . . 66

4.1 Cumulative distribution functions of wage offers . . . . . . . . 90

4.2 Cumulative distribution functions of effort levels . . . . . . . . . 91

4.3 Average wage over time . . . . . . . . . . . . . . . . 92

4.4 Relation between wage offers and effort levels . . . . . . . . . . . 94

4.5 Average quantities produced and sold over time . . . . . . . . . . 99

4.6 Cumulative distribution functions of wage offers (top panels) and effort levels (bottom panels) . . . . . . . . . . . . . 103

4.7 Average wage over time . . . . . . . . . . . . . . . . . . 103

4.8 Relation between wage offers and effort levels . . . . . . . . . . . 118

5.1 Distribution of investments . . . . . . . . . . . . . . . . 140

5.2 Average cooperation by treatment . . . . . . . . . . . . . . 141

5.3 Average cooperation by treatment and investment category . . . 142

5.4 Distribution of investments . . . . . . . . . . . . . . . . 147

5.5 Coordination on the same investment category . . . . . . . . . 148

5.6 Investment choices given miscoordination in previous match . . . 148

5.7 Individual average payoffs . . . . . . . . . . . . . . . . . 149

5.8 Risk dominance and cooperation, by investment level . . . . . . . 167

5.9 Cooperation and SizeBAD . . . . . . . . . . . . . . 167

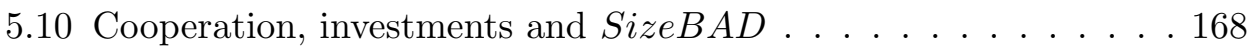





\section{List of Tables}

2.1 Effort levels and costs of effort _ . . . . . . . . . . . . . 12

2.2 Average wage, average effort, and gift-exchange relation for selected studies . . . . . . . . . . . . . . . . . . 19

3.1 Average wages and effort in each treatment . . . . . . . . 53

3.2 Wage-effort relation across output market conditions . . . . . . 57

3.3 Average quantities produced and sold . . . . . . . . . . . . . 59

3.4 Efficiency measures (averages) . . . . . . . . . . . . . . . 59

3.5 Average aggregate quantities . . . . . . . . . . . . 61

3.1 Average wages and effort . . . . . . . . . . 66

3.2 Wage-effort relation . . . . . . . . . . . . . 67

3.3 Average quantities produced and sold . . . . . . . . . . . 68

3.4 Efficiency measures (averages) . . . . . . . . . . . . . . 68

3.5 Wage-effort relation in each treatment - OLS panel regressions . 69

3.6 Wage-effort relation in each treatment - Tobit panel regressions . 70

3.7 Wage-effort relation across output market conditions - Tobit . . . 71

4.1 Standard theory equilibrium predictions . . . . . . . . . . 84

4.2 Average wages and effort . . . . . . . . . . . . . . 88

4.3 Effects on wages and effort of market liberalization . . . . . . . 89

4.4 Contingency tables I - Wage . . . . . . . . . . . . . . . 90

4.5 Contingency tables II - Effort . . . . . . . . . . . . . . 91

4.6 Time dynamics - Wages . . . . . . . . . . . . . . . . 93

4.7 Wage-effort relation - MtoD . . . . . . . . . . . . . . 96

4.8 Wage-effort relation - MtoQ . . . . . . . . . . . . . . . 97

4.9 Average market outcomes . . . . . . . . . . . . . . . . . . 98

4.10 Effects on quantity produced and sold of market liberalization . . 99

4.11 Effects on surpluses of market liberalization . . . . . . . . . . 100

4.12 Average surplus shares (in \%) . . . . . . . . . . . . . . . . 101

4.13 Average wages and effort . . . . . . . . . . . . . 102 
4.14 Time dynamics - Wages . . . . . . . . . . . . . . . . . . 104

4.15 Wage-effort relation - DtoM . . . . . . . . . . . . . 106

4.16 Wage-effort relation - QtoM . . . . . . . . . . . . . . 107

4.17 Average market outcomes . . . . . . . . . . . . . . . . 108

4.18 Average surplus shares . . . . . . . . . . . . . . . . . 109

4.19 Wilcoxon tests - $p$-values . . . . . . . . . . . . . 113

4.20 Wage-effort relation - MtoD, control for risk and reciprocity attitudes . . . . . . . . . . . . . . . . . 115

4.21 Wage-effort relation - MtoQ, control for risk and reciprocity attitudes . . . . . . . . . . . . . . . 116

4.22 Wilcoxon tests - p-values . . . . . . . . . . . . . 117

4.23 Contingency tables I - Wage . . . . . . . . . . . . . 117

4.24 Contingency tables II - Effort . . . . . . . . . . . . . 117

5.1 Prisoner's dilemma game payoff matrix . . . . . . . . . . . . . 133

5.2 Prisoner's dilemma payoff matrix . . . . . . . . . . . . . . 136

5.3 Average investments . . . . . . . . . . . . . . . . . . . . . 140

5.4 Average cooperation rates by a subject's and opponent's investment categories . . . . . . . . . . . . . . . . . 145

5.5 Effects on cooperation of SPE, RD, SizeBAD and investments . 153

5.6 Number of periods across matching groups . . . . . . . . . 157

5.7 Treatment effects, investments . . . . . . . . . . . . . 158

5.8 Percentage of cooperation by treatment . . . . . . . . . . 159

5.9 Effects of investment treatment on the probability to cooperate . 159

5.10 Differences in cooperation between NoInv and Endo . . . . . . . 160

5.11 Effects of investments on the probability to cooperate, by investment category . . . . . . . . . . . . . . . 160

5.12 Differences in cooperation between Endo and Exo . . . . . . . . . 161

5.13 Endo versus Exo . . . . . . . . . . . . . . . . . . 162

5.14 Within treatment differences in cooperation rates, across investment category . . . . . . . . . . . . . . . . . . 163

5.15 Differences in cooperation between Short and Long . . . . . . . . 164

5.16 Effects of $\delta$ on the probability to cooperate . . . . . . . 165

5.17 Effects of $\delta$ on the probability to cooperate . . . . . . 166 




\section{Chapter 1}

\section{Introduction}

While difficult to achieve, cooperation is frequently observed and sustained among humans. As free-riding incentives are ubiquitous in social life, the fact that cooperation emerges so often among unrelated individuals is seen by social scientists as a puzzle. After all, in a world believed to be exclusively populated by homines oeconomici, only defection (as expression of self-interest) can be expected from others. Experimental evidence now abounds showing that in many strategic interactions individuals do not quite behave like a homo oeconomicus should: they seem to care about fairness, do cooperate, and are willing to punish defectors, even at a personal cost and in the absence of benefits to the punisher. Since deviations from the canonical model have important consequences for policy making (such as the optimal design of institutions and contracts, or the conditions for successful collective action), economists and social scientists have been trying for decades to explain how cooperation among individuals occurs and can be sustained.

A prominent tradition in economics identifies the main condition for cooperation to evolve in the concept of reciprocity, the propensity of agents to respond kindly to kind actions, and with hostility to unkind actions. Reciprocity mechanisms, however, still appeal to individuals' selfishness: self-interested agents are able to sustain cooperation because repeated interactions generate, through reciprocal altruism and reputation building, benefits for the cooperators (Trivers [1971], Axelrod and Hamilton [1981], Axelrod [1984]). This insight has its formal representation in the game-theoretic result known as the folk theorem (Fudenberg and Maskin [1986], Fudenberg et al. [1994]), according to which if a) information is public and accurate (for the threat of punishment to be effective), b) the number of players is small (so that cooperation/defection can be easily monitored), and $c$ ) the shadow of the future is long enough (i.e. individuals are patient enough for defection to not be too tempting), then high levels 
of cooperation can be attained.

This sort of self-serving or weak reciprocity has been strongly criticized. The three conditions mentioned above, the critics argue, make the folk theorem hardly applicable to real life situations, where, for example, one-shot interactions are frequent and information is often inaccurate. Moreover, weak reciprocity and the embodied self-regarding motives cannot explain behaviors that are regularly observed in experiments, which instead support the idea that individuals have other regarding preferences (they care about their and others' payoffs) and care about how outcomes are generated (not just about the outcomes per se). In ultimatum games, for example, respondents frequently reject positive offers to punish what are considered unfair proposals (Güth et al. [1982], Camerer [2003], Hennig-Schmidt et al. [2008]); in public goods games, players contribute and punish low contributors even on the final round of the game, when there is no prospect of future gains (Fehr and Gächter [2000], Gächter et al. [2008]); in different settings, subjects cooperate and punish in one-shot and anonymous interactions, and cooperate and punish less when they play against a computer rather than a person (Blount [1995], Fehr and Gächter [2002b], Charness [2004], Falk et al. [2008], Balafoutas et al. [2014]).

These established results are interpreted as reflecting what has been termed strong reciprocity, the behavioral predisposition to cooperate conditionally on others' cooperation, and to punish those who violate cooperative norms, even at a cost to themselves (Gintis [2000]). Strong reciprocity, and the interaction between strongly reciprocal and self-regarding individuals, have been long considered as main drivers of the observed patterns of cooperation (Fehr and Gintis [2007]). Fehr and Gintis [2007], for example, explain the decrease of cooperation in public goods games without punishment with the tendency of strongly reciprocal subjects to initially cooperate if they believe that others will also cooperate, and to stop cooperating to punish self-regarding group members as they are observed to free ride throughout the game. Conversely, when a punishment opportunity is made available, strong reciprocators can punish the defectors directly, creating an economic incentive for the self-regarding subjects to cooperate, [and] will also cooperate because they need not fear others' defection, as the self-regarding individuals are disciplined (p. 50).

Considerations of fairness and reciprocity not only induce cooperation in social settings, but also proved to affect market outcomes. In particular, the idea that reciprocity plays a role in (contractually incomplete) labor markets was first suggested by Akerlof [1982] and further developed in Akerlof and 
Yellen [1988, 1990]. Akerlof [1982] builds on observational data and models of social exchange theorists such as Homans [1958] and Blau [1964], who had hypothesized long before that prices in social exchanges were not solely determined by supply and demand forces, but that reciprocity norms are likely to affect the formation of such prices. According to Blau [1964], differently from economic transactions, social exchange entails "unspecified obligations", favors whose nature cannot be stipulated in advance. And since there is no way to assure an appropriate return for a favor, social exchange requires trusting others to discharge their obligations. Moreover, [...] an internalized norm of reciprocity would make [one] feel guilty if he fails to discharge his obligations; [...] people usually discharge their social obligations, even though there is no binding contract that can be enforced. These are the principles behind Akerlof [1982]'s model, where he presents his view of the labor contract as a "partial gift-exchange".

Akerlof [1982] argues against the economists' view of labor as a factor of production similar to capital, emphasizing that while the latter can be used to a capitalist's wishes, the willing cooperation of labor itself must usually be obtained for the firm to make the best use of the labor services (p. 545). Since effort is typically not (fully) contractible or enforceable by a third party, firms find it advantageous to pay more than the market-clearing wage (the fair wage) since workers are willing to exert higher effort in response. Firms and workers voluntarily exchange gifts (i.e. wage and effort in excess of the minimum required), implying that the terms of the labor contract are, at least partially, determined by reciprocity norms that emerge endogenously.

The gift-exchange model has spurred an extensive body of experimental research. Since Fehr et al. [1993] first implemented the gift-exchange game, the hypothesis of a reciprocal relationship between the wage offered by firms and the effort exerted by workers has been tested under a broad variety of conditions. It is a well-established result that a positive relationship between wages and effort exists, and that employers are willing to offer wages higher than the prevailing minimum to elicit higher effort. In Chapter 2, we review the main results related to the existence of this positive wage-effort relation, in the lab and in the field. We also report on studies that have tried to assess the implication of these findings for policy making, and on studies that have checked the robustness of gift-exchange and showed that, while it survives many experimental variations, there are some environmental factors under which it has difficulties to emerge. In the second part of the chapter, we survey a 
small experimental literature that explores labor issues in macroeconomics, and focuses on the relation between labor taxation and unemployment. Results show that increasing labor taxes to balance budget deficits negatively affects overall economic performance, and that shifting the tax burden from labor to sales or production might alleviate this effect. In particular, it is found that shifting taxation from labor to consumption increases effort provision.

Interestingly, all the results on labor market gift-exchange have been obtained in partial equilibrium settings where firms are assumed to operate in isolation as monopolists on the output market. While this has been a useful restriction to generate clean results, evidence supporting the existence of reciprocal firm-worker relationships might be misleading. Since firms operate both on the labor and the product market, the existing literature on gift-exchange fails to capture potential interaction effects between these two markets. Moreover, it ignores any potential effects of market institutions on behavior reported in recent studies. Some scholars show that markets may foster or be compatible with fairness, trust and cooperation norms (Henrich et al. [2001, 2010], Bowles [2011], Huck et al. [2012], Bartling et al. [2015b]), while others find that competition can have adverse effects on such norms and be detrimental to pro-social behavior (Bowles [1998], Shleifer [2004], Cai and Liu [2009], Brandts et al. [2009], Falk and Szech [2013a], Brandts and Riedl [2016]).

In Chapter 3 and Chapter 4, we add to the gift-exchange literature by studying whether product market competition among firms affects reciprocity norms within firms in a labor market characterized by incomplete contracts. We use a modified, three-stage version of the gift-exchange game. In the first two stages, a standard bilateral gift-exchange game is played: first, each firm makes a wage offer to the worker she has been paired with; then, each worker is informed of the wage offer, and chooses an effort level. A worker's effort level determines the output produced by the firm, who, in the third stage, decides on how much of her capacity is brought to the market.

In Chapter 3, we compare three treatments that exclusively differ in the competitiveness of the output market, so that (labor and output) market conditions other than the number of firms active in the market do not change across treatments. Our results show that, in all markets, average wages and effort are strictly positive, and both decrease with the number of firms in the market. Moreover, in each market institution gift-exchange relationships emerge, so that wages and effort are positively correlated. Most importantly, even though increasing output market competition calls for lower wages, this positive re- 
lation is largely unaffected by competition, proving gift-exchange as a quite stable behavioral pattern. Consequently, more competition generates higher total surplus, and leads to a redistribution of surplus from firms to workers and consumers.

The effects of product market competition on reciprocal wage-effort relationships are studied further in Chapter 4. Here, we look at output market competition from a different perspective. We use a within-subject design and study firms and workers' behavior when output market conditions change from a setting where competition is absent to a setting characterized by the presence of competition, with all the other aspects of the economic environment being held constant. More specifically, product markets with different degrees of competitiveness follow one another, while competition in the labor market stays unchanged. We control for order effects in two additional treatments where competition is removed rather than introduced. We find that wages and effort respond to the intensity of output market competition: they increase with market liberalization, and decrease when competition is removed. Consequently, the more competitive a market is, the higher is the total generated surplus. In all markets a positive relationship between wage offers and effort levels emerges, and this relationship is robust to market liberalization. Our results show that reciprocity is rather constant across market institutions when competition increases. We do not find consistent and significant differences in reciprocity across markets when competition is removed.

The strong reciprocity theory supports the idea that a punishment mechanism is necessary for cooperation to flourish and be sustained. Since the seminal studies of Yamagishi [1986] and Ostrom et al. [1992], a large number of studies have been conducted to investigate the effects of punishment on cooperation in different social dilemma games. Important insights are that subjects in many experimental settings are willing to punish free-riders at their own cost, and that punishment can increase and maintain cooperation at higher levels than observed without punishment, even in one-shot interactions and when the sanctions are purely symbolic (Fehr and Gächter [2000, 2002b], Masclet et al. [2003], Fehr and Fischbacher [2004], Noussair and Tucker [2005], Gächter et al. [2008], Egas and Riedl [2008], Gächter and Herrmann [2009], Reuben and Riedl [2013]). However, more careful analyses have shown that punishment by itself is insufficient. On the one hand, punishment is in itself a public good and poses a second-order free rider problem: individuals who cooperate but do not punish benefit from cooperators who choose to punish. On the other 
hand, punishment has potentially negative effects, too. Laboratory experiments have shown that punishment might decrease welfare (Dreber et al. [2008], Egas and Riedl [2008], Burnham [2015]), lead to retaliation and counter-punishment (Nikiforakis [2008], Hopfensitz and Reuben [2009], Nikiforakis and Engelmann [2011], Bone et al. [2016]), or evolve into anti-social punishment, where cooperators are punished alongside free riders (Cinyabuguma et al. [2006], Nikiforakis [2008], Gächter and Herrmann [2009]).

Recent experimental literature has investigated whether these issues might be solved by giving individuals the opportunity to choose the rules governing the use of punishment. Research shows that individuals behave more cooperatively if the punishment regime is chosen endogenously than if the same regime is imposed exogenously. This effect has been found with formal (Tyran and Feld [2006], Ertan et al. [2009], Dal Bó et al. [2010], Putterman et al. [2011], Markussen et al. [2014a], Kamei et al. [2015]) and informal (Sutter et al. [2010], Markussen et al. [2014a]) punishment institutions, in the case of third-party punishment (Marcin et al. [2016]), and after controlling for individuals' institutional preferences (Dal Bó et al. [2010], Kamei [2016]).

In all these studies, subjects are presented with different institutions and decide, through voting, on the rules that will govern their interactions. However, putting an institution to the vote does not imply it will be adopted. In Botelho et al. [2005], for instance, most of the experimental subjects voted against the punishment institution; in Dal Bó et al. [2010], almost half of the subjects voted against a policy that could foster cooperation. Tyran and Feld [2006] also show that if an institution is democratically rejected, cooperation is lower as compared to when there is no institution. Moreover, the focus is mostly on formal and informal sanctions, so that subjects choose whether and how much to punish free-riders. In many circumstances, however, individuals cannot choose or vote for an enforcement institution. Even if institutional arrangements exist, cooperation is not always easily enforced. This is the case, for instance, when there is no supranational institution with coercive power, or, for groups where individuals, even though willing to cooperate, are not willing to punish (as for instance in Sutter et al. [2010]).

In Chapter 5, we study whether individuals are able to create themselves situations that are favorable to cooperation in settings where an enforcement mechanism lacks and cooperation is not easily sustained voluntarily. We investigate whether upfront investments help promoting cooperation in a social dilemma, and whether this effect depends on the investments being endogenous 
(chosen by the participants) or exogenous (imposed by the experimenter). Such investments are a cost that individuals have to incur before deciding whether to cooperate or not, and increase the payoff resulting from the choice to cooperate. The social dilemma situation we consider is an infinitely repeated prisoners' dilemma game, which captures the tension at the heart of social dilemmas in a simple form. We find that cooperation rarely emerges in treatments where investments are not possible, for both low and high probabilities of continuation. Introducing endogenous investment opportunities boosts overall cooperation levels. If low investments are endogenous, cooperation is lower than when the same investments are exogenous. When investments are high, cooperation is not statistically significantly different between the endogenous and the exogenous conditions. This is consistent with low investments being interpreted as a signal for unwillingness to cooperate, triggering non-cooperative choices. On the other hand, high investments increase cooperation independent of the mode of implementation, and seem not to serve as signal for willingness to cooperate. Interestingly, even though investments have the potential to foster cooperation, participants in our experiment frequently choose not to invest, or low investments. The investment decision entails a coordination problem, in that individuals would like to invest if others invest as well. Our subjects do not seem to be able to solve such coordination problem. 


\title{
Chapter 2
}

\section{Experimental labor markets and policy considerations: incomplete contracts and macroeconomic aspects}

\begin{abstract}
This chapter focuses on experimental labor markets investigating two aspects that are important for a better understanding of labor market relations and their consequences for labor market policies. The first part of the chapter is dedicated to papers that assess the prevalence of reciprocal considerations in incomplete labor contracts. The second part summarizes the relatively small but growing experimental literature exploring labor market issues in macroeconomics and public finance studying the interaction between taxation and labor market outcomes.
\end{abstract}

Based on Fortuna Casoria and Arno Riedl (2013), Journal of Economic Surveys, $27: 398-420$. 


\section{$2.1 \quad$ Introduction}

Experimental economics' focus on the functioning of labor markets has been growing over the years and the advantages of applying experimental economics methods to labor economics have been extensively discussed (see, e.g., Fehr et al. [2009], Charness and Kuhn [2011]). Experiments allow for tight control over the many environmental factors that can affect behavior and render causal relations easier to infer. The possibility of controlling these factors implies the possibility of varying them and studying whether and to what degree the enforced changes affect decisions. This feature seems to be particularly suitable to analyze labor markets, where a large amount of labor-related available data are circumstantial, implying that it becomes difficult to exactly discern which factors play which role in the realization of outcomes.

The experimental labor economics literature is quite extensive with a wide range of issues addressed and this chapter does neither intend nor pretend to cover the experimental labor literature in all its breath. We rather focus on two aspects that are important for a better understanding of labor market relations and their consequences for labor market policies. The first part of the survey is dedicated to papers that assess the prevalence of reciprocal considerations in incomplete labor contracts. The second part summarizes the relatively small but growing experimental literature exploring labor issues in macroeconomics and public finance studying the interaction between taxation and labor market outcomes. Readers interested in other aspects explored in experimental labor economics, such as work incentives or multitask problems, arbitration, job search, or gender differentials, are referred to the excellent reviews of Charness and Kuhn [2011] and Fehr et al. [2009].

Labor relations are often contractually incomplete in the sense that effort is typically not (fully) contractible or enforceable by a third party. This feature leaves room for reciprocal motivations to play a role in the work process as workers' general job attitudes become important (Fehr and Falk [1999]). The gift-exchange game, first implemented and introduced into the literature by Fehr et al. [1993], was designed to mimic precisely this situation. It tests the gift-exchange hypothesis of efficiency wage theory (Akerlof [1982], Akerlof and Yellen [1988, 1990]), according to which there is a positive (i.e., reciprocal) relationship between the wages offered by firms and the effort exerted by workers. In a gift-exchange market wage offers are binding, while workers can discretionarily choose the amount of effort they exert. Experimental evidence has shown that a positive relation between wages and effort indeed emerges in 
such markets. Next to providing a survey of the main results related to the existence of this positive wage-effort relation, we also report on those studies that have tried to assess the implication of these findings for policy making. In addition, the robustness of the positive wage-effort relation is surveyed showing that while it survives many institutional variations and experimental conditions, there are also some environmental factors under which gift-exchange has difficulties to emerge.

The possibility of using laboratory experiments to better understand the functioning of markets has been mostly utilized for studying causal relationships at the micro level. However, lab experiments can also be a valuable research tool for gaining insights into the effects of alternative labor policies or institutions at a macro level. Indeed, the main strengths of the experimental method, control and replication, can be very useful in the domain of macroeconomics, which traditionally relies on circumstantial field data which may suffer from data non-availability, endogeneity, or measurement error. This implies that the causal impact of a given variable, for example, an increase of a labor tax, on economic performance may be difficult to assess. Experimental labor economics can be useful in such a macroeconomics context and help to overcome some of these problems. The second part of this survey focuses on the small but growing literature of laboratory labor market experiments in macroeconomics and public finance.

\subsection{Experimental gift-exchange labor markets}

\subsubsection{Common features across experiments}

Most experiments described in this section are based on similar implementations of the gift-exchange game. At the beginning of an experimental session, subjects are randomly assigned the roles of either firms or workers and they keep their role during the whole session. In the first stage, firms offer a contract specifying the wage. In some experiments workers have to accept what is offered while in others the contract may be rejected in favor of some outside option. In the second stage, workers decide on the level of effort they want to exert, which is costly to them but profitable to the firm. Often this two-stage game is repeated for several periods with the same or changing firm-worker pairs. In the wage formation (first) stage commonly one of three institutions is explored: bilateral bargaining, one-sided auction, or double auction markets.

In bilateral bargaining, a firm is exogenously and randomly matched with a worker either only at the beginning of the experiment or at the beginning of 
each period. In each period, a firm proposes a wage only to the worker with whom it has been matched.

In one-sided auction markets, firms publicly announce their wage offers, which can be accepted by any worker. Firms are allowed to revise their offers, often according to an improvement rule, until they are accepted or the market closes.Workers cannot make counteroffers. In double auction markets both, firms and workers, can submit and accept wage offers at any time during the trading period. In both market institutions, after a wage contract is concluded the involved firm and the worker are removed from the market for that trading period. Firms and workers who do not strike a contract receive some reservation earnings. In the most common implementation at most one contract per period can be concluded and often there is an excess supply of labor.

In the basic implementation of the second stage, the worker's costly effort choice, firms can neither punish nor reward workers for their choice. Further, all institutional features are public knowledge, including the number of firms, workers, and periods, the matching mechanism, the feasible effort levels, the costs of effort, the wage range, and the payoff functions. Wage offers may be public or private depending on the chosen market institution, but a worker's effort choice is always private information. That is, it is only revealed to the firm with which the worker has concluded a contract. Identities of trading partners are usually not revealed.

\section{Effort levels and cost function}

Most studies reviewed here adopt one of two effort-cost schedules. In one version, $\operatorname{costs} c(e)$ are increasing and convex in effort $e$ as, for example, in Table 2.1. In the other common version costs are linear in effort.

Table 2.1: Effort levels and costs of effort

\begin{tabular}{lcccccccccc}
\hline Effort e & 0.1 & 0.2 & 0.3 & 0.4 & 0.5 & 0.6 & 0.7 & 0.8 & 0.9 & 1 \\
Cost c $(e)$ & 0 & 1 & 2 & 4 & 6 & 8 & 10 & 12 & 15 & 18 \\
\hline
\end{tabular}

\section{Payoff functions}

Regarding the payoff functions for firms and workers there are also two commonly implemented versions. Firms' payoff function is often a version of

$$
\pi^{F}=(v-w) e+k
$$




$$
\pi^{F}=v-w+k
$$

where $v$ denotes an exogenously given redemption value, $w$ the wage, $e$ the effort chosen by the worker, and $k$ some lump-sum transfer.

Workers' payoff function is mostly implemented as the difference between the accepted wage, $w$, the incurred effort cost, $c(e)$, and some fixed costs or transfer $c_{0}$ :

$$
\pi^{W}=w-c(e)-c_{0}
$$

The parameter values are chosen such that under the assumption of material self-interest workers will never choose an effort level higher than the minimum effort, irrespective of the accepted wage. Rational and profit-maximizing firms will anticipate this and, hence, offer the lowest positive wage satisfying workers' participation constraint. The predicted outcome is thus low wages, low efforts, and most importantly no positive relationship between wages and effort levels. Alternatively, the gift-exchange hypothesis (Akerlof [1982]) postulates a positive correlation between wage offers and effort provision and, in consequence, higher than minimum wages and higher than minimum effort levels. ${ }^{1}$

\subsubsection{Fundamental results}

This section reviews some of the seminal gift-exchange labor market experiments and summarizes by now well-established empirical results on the wageeffort relation. First, early experiments are presented, where the gift-exchange hypothesis is tested in one-shot encounters. In these experiments firms and workers meet essentially only once, leaving no or little room for reputation concerns. Next, we survey papers where reputation may play a role due to repeated interactions between the same firm-worker pair. Finally, we present evidence on the role of negative reciprocity and wage attribution on the functioning of gift-exchange labor markets.

\section{Gift-exchange in one-shot interactions}

Evidence on the presence of gift-exchange in experimental labor markets dates back to Fehr et al. [1993] who have been the first to use the above described

\footnotetext{
${ }^{1}$ The gift-exchange wage-effort relationship can be rationalized by assuming outcome-based social preferences (e.g., Fehr and Schmidt [1999], Bolton and Ockenfels [2000]), intention-based reciprocal motives (Rabin [1993], Dufwenberg and Kirchsteiger [2004]), and a mixture of both (Levine [1998], Falk and Fischbacher [2006]).
} 
setup to test for the validity of the fair wage-effort hypothesis. They model the labor market as a one-sided auction and frame it in good market terms: buyers and sellers who choose prices and quality, respectively. The authors observe clear evidence in favor of the gift-exchange hypothesis as wages and efforts are strongly positively correlated. Consequently, wages and effort are clearly above their respective minimum level and also do not show any tendency to decline with repetition.

In a second paper, Fehr et al. [1998b] check whether observed high wages are due to firms' unconditional preference to pay high wages or due to workers' willingness to reciprocate high wages with high effort levels. They compare two different treatments (reciprocity treatment and control treatment), which differ only in that in the control treatment effort levels are exogenously fixed at the lowest effort level, eliminating opportunities for gift-exchange, whereas in the reciprocity treatment workers are free in their effort choices. Since subjects participated in both treatments, it could be tested if the same firms change behavior or not. It is found that the very same firms which pay rather high wages when workers can reciprocate significantly lower their offers when the effort is fixed by the experimenter. This shows that it is mostly not firms' unconditional preference to pay high wages but that those are induced by experienced and anticipated low-effort responses to low wages and, consequently, low profits.

Fehr et al. [1998a] are the first to study the effect of competition among workers on wages. They conduct three different treatments: a one-sided auction, called gift-exchange market, a bilateral gift-exchange (BGE), where firms and workers are exogenously matched, and a complete contract market (CCM), where the maximum effort level is exogenously enforced. By comparing the wages in CCM and gift-exchange market it could be assessed whether the high wages in the latter as found by Fehr et al. [1993, 1998b] are indeed attributable to gift-exchange. Comparing wages in bilateral gift-exchange, where competition in the labor market cannot play any role, with those in gift-exchange market shows to what extent competition affects wage levels. The authors find that high wages are reciprocated by high efforts, both in gift-exchange market and bilateral gift-exchange, with no tendency for this positive correlation to decline over time. Importantly, already after a few periods wages in gift-exchange market and bilateral gift-exchange coincide, indicating that labor market competition does not affect wage formation. However, wages in giftexchange market are significantly above wages in CCM, where firms constantly try to stipulate lower wages. This indicates that in gift-exchange market firms 
anticipate workers' reciprocal responses and that payment of noncompetitive wages generates higher profits. In consequence, firms are unwilling to enforce low wages when there is room for workers to reciprocate with effort.

\section{Gift-exchange and reputation}

Employment relationships are seldom characterized by one-shot transactions. Rather employers and employees often interact repeatedly over time, which creates incentives for reciprocation, even for materially selfish workers provided that they can expect (future) material gains from it. This potential reputation effect has been first explored in Gächter and Falk [2002]. They compare behavior in a one-shot (OS) treatment and a repeated game (RG) treatment, where the same firm-worker pairs interact repeatedly. In line with earlier results they find that wages and effort levels are clearly above their minimum values. Importantly, for similar wages in the two treatments, workers are more reciprocal in RG than in one-shot: this shows that repeated interaction and reputation incentives strengthen the positive wage-effort relation. An individual level analysis further suggests that even selfish workers have a strong incentive to act reciprocally, because providing high effort in response to high wage offers improves reputation and gives access to attractive wage offers.

Brown et al. [2004] implement three treatment conditions in order to investigate how contractual incompleteness affects the nature of market interactions and the formation of relational contracts. In all treatments, the market for contracts is organized as a one-sided auction where contracts consist of a wage, a desired effort level, and the firm's ID number. In the complete contracts treatment $(\mathrm{C})$, a firm's desired effort level is exogenously enforced by the experimenter. Under the incomplete contract condition (ICF), the worker can choose any effort in the feasible range. In both these treatments, firms and workers have fixed ID numbers throughout the whole experimental session implying that a firm can address its contract offer to a specific worker in consecutive periods. In the third incomplete contract treatment (ICR), firms and workers are randomly assigned a new ID number in each period, ruling out the possibility of entering long-term relations. In each trading period firms can make private or public offers, where private offers are only transmitted to the worker with whom a firm wants to trade while public offers can be observed and accepted by any worker in the market.

The authors find that in $\mathrm{C}$ traders are indifferent to their trading partners' identities, whereas firms strongly prefer to trade with the same worker over 
many consecutive periods in ICF. In the former case, contract offers are mostly public offers and the majority of trades take place in one-shot (OS) transactions. In contrast, in the latter case, trades are usually privately initiated and bilateral relationships emerge. In $\mathrm{C}$ firms pay relatively low wages and appropriate the largest share of the gains from trade, whereas in ICF they pay high wages and earnings from trade are distributed rather equally. Effort is significantly higher in ICF, while in ICR, average effort drops and workers choose the minimal effort level in most cases. An important insight from this paper is that firms use high wages, together with the threat of firing, to discipline selfish workers. They adopt a policy of contingent contract renewal where relatively high effort levels are rewarded with a new contract, while relations with workers providing low effort are terminated with high probability.

Brown et al. [2012] implement the same three treatments in a market characterized by excess demand for labor, to check whether relational contracts emerge even in the absence of the unemployment threat. What they find is that bilateral relations between firms and workers do emerge in these markets, with wages and effort higher in ICF than in ICR and C, but are more difficult to be sustained over time. Stronger competition among firms and the lower number of long-term relationships do not affect market performance, though: aggregate effort in ICF is almost identical to that under excess supply of labor. A main reason for that is that higher wages due to excess labor demand induces workers to provide more effort.

\section{Gift-exchange, negative reciprocity, and wage attribution}

Some of the results surveyed above have been questioned because they are obtained in an environment that may favor workers' opportunity to exhibit positive reciprocity, that is, by responding to high wages with high effort levels. However, negative reciprocity, the willingness to incur costs to punish unkind actions, may also have a role in the wage formation with potential opposite effects, as low effort responses to low wages may unravel into even lower wages and efforts.

To study the role of negative reciprocity, Fehr and Falk [1999] compare double auction labor markets where effort is endogenous (main treatment) to others where effort is exogenously fixed (control treatment), with excess supply of workers in both cases. What distinguishes this experiment is the implementation of a modified cost function, according to which a selfish money-maximizing worker should always choose the maximum effort level, because lower levels are 
more costly. Results from the main treatment show that workers indeed react to low wage offers by choosing non-maximal effort levels. This negatively reciprocal behavior leads firms to pay higher wages in the main treatment, even if workers underbid each other's wage offers. In contrast, in the control treatment wages tend to decrease over time and come close to the competitive equilibrium level. These findings show that firms may be reluctant to push wages down toward the competitive level, if workers have the opportunity to punish them via their effort choices. Workers' negative reciprocity generates wages that are downwardly rigid.

Charness [2004] explores bilateral gift-exchange under three experimental conditions that differ in the wage-generating mechanism. First, wages are determined by the firm, second they are generated by a draw from a bingo cage, and, third, by an assignment by a third party, the experimenter. In all cases, workers are informed whether the received wage has been assigned by either the firm or one of the external processes. In all treatments, there is a positive relationship between wages and effort levels. However, at low wages, the effort level is lower when the wage is chosen by a firm than when it is exogenously generated, suggesting the presence of negative reciprocity. That is, workers never provide costly effort when a low wage can be attributed to the firm's intention but do so when the low wage comes from an exogenous source. At high wage levels, there is essentially no difference in effort levels across treatments. ${ }^{2}$

The results from Charness [2004] suggest that the mechanism according to which wages are formed has a non-negligible impact on workers' performances. Maximiano et al. [2013] make an important step in investigating this conjecture by studying wage attribution by means of a more complex gift-exchange environment, where ownership and control are separated. Specifically, owners do not directly set a worker's wage and the manager, who actually determines the wage, does not bear the full wage costs and does also not fully benefit from workers' higher efforts. The authors consider four treatments. The bilateral condition is a standard bilateral gift-exchange setting, with a firm consisting of a single owner-manager who is directly responsible for choosing the worker's wage. In the two trilateral conditions ( $\mathrm{TC} 0$ and $\mathrm{TC} 25),{ }^{3}$ the firm is owned by a shareholder, who claims most of the firm's profit, but controlled by a manager, who chooses the worker's wage. In the fourth treatment, wages are randomly

\footnotetext{
${ }^{2}$ Pereira et al. [2006] also find some evidence for negative reciprocity which may be caused by a framing effect similar to those observed in dictator allocation experiments (List [2007], Bardsley [2008]).

${ }^{3}$ In TC0 the manager is paid a fixed wage and in TC25 condition the manager earns $25 \%$ of the firm's profit.
} 
determined by the experimenter (cf. Charness [2004]). In all treatments, a gift-exchange wage-effort relationship is found. The higher the wage offered, the higher the average effort level chosen by workers, irrespective of the firm's composition and whether the manager receives part of the profits or not. Importantly, the wage-effort relationship is steepest when wages are determined by a member of the firm. The finding that the wage-effort relationship does not differ among the three endogenous treatments indicates that workers are not particularly sensitive to how ownership and control are divided within the firm, but are reciprocal toward the firm as a whole.

Table 2.2 shows the average wage, the average effort and the estimated wage-effort relation for some prominent papers surveyed in section 2.2.2.

\subsubsection{Gift-exchange labor markets and policy instruments}

Despite the robustness and prevalence of gift-exchange wage-effort relationships, still relatively few experimental studies investigate policy implications of it. Among others, questions that could be asked are: Are (un)employment policies similarly (in)effective in gift-exchange and complete contract markets? Do optimal and redistributive tax policies have the predicted effects in giftexchange labor markets? Here, we survey the experimental studies asking such important policy implications of gift-exchange in labor markets.

\section{Taxation}

Riedl and Tyran [2005] are the first to examine whether and to what extent statutory tax incidence affects the performance of efficiency-wage markets and whether Tax Liability Side Equivalence ${ }^{4}$ (tax LSE) holds in gift-exchange labor markets. Theory predicts that tax LSE also holds in gift-exchange labor markets as long as participants are only concerned with net wages and profits. Yet, if workers make their effort choices on the basis of gross wages and consider taxation as exogenous to the gift-exchange relation, tax LSE breaks down. This alternative hypothesis is suggested by a study of Kerschbamer and Kirchsteiger [2000] who show that tax LSE may break down in bilateral bargaining environments.

In a one-sided auction environment, Riedl and Tyran [2005] implement two treatments, differing in the sequence of two distinct tax regimes. In one regime the tax is levied on firms while in the other regime workers are obliged to pay the tax. Each regime lasts for 16 trading periods.

\footnotetext{
${ }^{4}$ Tax LSE states that "the statutory incidence (i.e., who legally pays a tax) is irrelevant for economic incidence (i.e., who bears the tax burden)" (Riedl and Tyran [2005]).
} 
Table 2.2: Average wage, average effort, and gift-exchange relation for selected studies

\begin{tabular}{|c|c|c|c|}
\hline & Average wage & Average effort & Gift-exchange \\
\hline \multirow[t]{2}{*}{ Fehr et al. (1993) } & 72 & 0.4 & 0.0078 \\
\hline & {$[26,126]$} & {$[0.1,1]$} & OLS \\
\hline \multicolumn{4}{|l|}{ Fehr et al. (1998b) } \\
\hline $\mathrm{CT}$ & $\begin{array}{c}215 \\
{[210,290]}\end{array}$ & - & \\
\hline \multirow[t]{2}{*}{ RT } & 74 & 0.36 & 0.0087 \\
\hline & {$[30,110]$} & {$[0.1,1]$} & Tobit \\
\hline \multicolumn{4}{|l|}{ Falk and Gächter (2002) } \\
\hline \multirow[t]{2}{*}{$\mathrm{RG}$} & 57.60 & 0.47 & 0.0111 \\
\hline & {$[20,120]$} & {$[0.1,1]$} & Tobit \\
\hline \multicolumn{4}{|l|}{ Brown et al. (2004) } \\
\hline \multirow[t]{2}{*}{$\mathrm{C}$} & 33.30 & 9.3 & - \\
\hline & {$[1,100]$} & {$[1,10]$} & \\
\hline \multirow[t]{2}{*}{ ICF } & 40.10 & 6.9 & 0.14 \\
\hline & {$[1,100]$} & {$[1,10]$} & OLS \\
\hline \multirow[t]{2}{*}{ ICR } & 24.30 & 3.3 & 0.11 \\
\hline & {$[1,100]$} & {$[1,10]$} & OLS \\
\hline \multicolumn{4}{|l|}{ Fehr and Falk (1999) } \\
\hline $\mathrm{CC}$ & $\begin{array}{c}34.96 \\
{[20,120]}\end{array}$ & - & \\
\hline \multicolumn{4}{|l|}{ Charness (2004) } \\
\hline Wage offer by employer & $\begin{array}{c}54.87 \\
{[20,120]}\end{array}$ & $\begin{array}{c}0.312 \\
{[0.1,1]}\end{array}$ & $\begin{array}{l}0.012 \\
\text { Tobit }\end{array}$ \\
\hline Wage offer by random & $\begin{array}{c}56.97 \\
{[20,120]}\end{array}$ & $\begin{array}{c}0.344 \\
{[0.1,1]}\end{array}$ & $\begin{array}{c}0.0088 \\
\text { Tobit }\end{array}$ \\
\hline Wage offer by third party & $\begin{array}{c}57.87 \\
{[20,120]}\end{array}$ & $\begin{array}{c}0.317 \\
{[0.1,1]}\end{array}$ & $\begin{array}{c}0.0085 \\
\text { Tobit }\end{array}$ \\
\hline \multicolumn{4}{|l|}{ Maximiano et al. (2013) } \\
\hline $\mathrm{BC}$ & $\begin{array}{c}61.45 \\
{[0,100]}\end{array}$ & $\begin{array}{c}2.41 \\
{[1,10]}\end{array}$ & $\begin{array}{c}0.0283 \\
\mathrm{RE}\end{array}$ \\
\hline TC0 & $\begin{array}{c}67.24 \\
{[0,100]}\end{array}$ & $\begin{array}{c}2.77 \\
{[1,10]}\end{array}$ & $\begin{array}{c}0.0378 \\
\mathrm{RE}\end{array}$ \\
\hline TC25 & $\begin{array}{c}49.29 \\
{[0,100]}\end{array}$ & $\begin{array}{c}2.76 \\
{[1,10]}\end{array}$ & $\begin{array}{c}0.0039 \\
\mathrm{RE}\end{array}$ \\
\hline ВСexo & $\begin{array}{c}64.50 \\
{[0,100]}\end{array}$ & $\begin{array}{c}3.07 \\
{[1,10]}\end{array}$ & $\begin{array}{c}0.0118 \\
\mathrm{RE}\end{array}$ \\
\hline
\end{tabular}

Note: Brackets indicate the range of possible values; the variable "gift-exchange" measures the increase of effort for an infinitesimal increase in wage; OLS = ordinary least square regression; Tobit $=$ Tobit regression; $\mathrm{RE}=$ random effects regression. 
The main results are that gift-exchange emerges and that tax LSE holds in the gift-exchange labor markets under study. None of the analyzed variables, net wages, worker efforts, and net earnings, significantly differs between regimes, not even in the short run. Net wages are almost the same in both tax regimes right from the very beginning. Similarly, workers' earnings as well as firms' profits are not different across nor within treatments, thus clearly supporting tax LSE.

\section{Competition and wage rigidity}

A main implication of gift-exchange is that wages may be downwardly rigid because firms have no incentive to lower wages as this would lead to low performance of workers and, hence, to low profits. As mentioned above, evidence for that has been provided by Fehr and Falk [1999] who investigate wage formation in a double auction market, which is considered as particularly competitive (see, e.g., Davis and Holt [1993]). Brandts and Charness [2004] analyze whether giftexchange is affected by the relative number of firms and workers on the market. They implement a market with excess supply of labor and a market with excess supply of firms, with wage formation in a one-sided auction. They find that wage and effort are positively correlated and that this relation is not affected by competitive pressure. Specifically, wages do not significantly differ across treatments and are generally quite high. Hence, overall the gift-exchange relation appears to be robust to increased competition on the labor market.

\section{Minimum wage legislation}

Experimental evidence shows that changes in the level of the minimum wage strongly affect what is perceived by individuals as a fair wage, causing important effects on reservations wages, actual wages, and employment levels.

Brandts and Charness [2004] are the first to study the effect of a minimum wage on behavior of firms and workers in a gift-exchange context with excess supply of workers. They find that the imposition of a minimum wage has an adverse effect on effort exerted by workers. Although the relationship between wage and effort remains significantly positive, the impact on effort provision is negative. At all wages effort levels are lower with than without a minimum wage.

Falk et al. [2006] look at the effects of a minimum wage in an economy with complete contracts, where workers provide either zero effort, if they reject a wage offer, or automatically provide maximum effort, if they accept a wage offer. They find that, when minimum wages are introduced, workers' en- 
dogenous reservation wages increase to above the level of the minimum wage. This suggests that being paid exactly the minimum wage is viewed as unfair by workers. In addition, the introduction and removal of a minimum wage have asymmetric effects. If existing minimum wages are removed reservation wages only marginally decrease and remain substantially above those prevailing before the introduction of the minimum wage.

Owens and Kagel [2010] find partly contrasting results. They observe that the introduction of the minimum wage results in an increase in average wages but also that dropping the minimum wage leads to a decrease in both average wages and average effort. When a minimum wage is introduced the effects on effort levels differ depending on the wage rate. At lower wage rates and, in particular, in the neighborhood of the minimum wage, a reduction in effort is detected, while no systematic effects on effort levels are found for higher wages.

Overall the evidence of the effect of minimum wages on provided effort is mixed. Importantly, however, the surveyed studies show that on the one hand, the minimum wage increases average wages inducing reciprocal workers to exert more effort. On the other hand, the minimum wage may alter subjects' fairness perceptions perhaps due to a reference point effect (Kahneman and Tversky [1979], Abeler et al. [2011]). Consequently, wages considered fair when there is no minimum wage tend to be perceived as less fair once there is a minimum wage. The net effect of the minimum wage on effort turns out to be ambiguous and depends on the relative size of these two counteracting effects (Fehr et al. [2009]).

\section{Sick pay}

Duersch et al. [2012] experimentally study the interaction of sick pay provision and gift-exchange between firms and workers. The authors modify the standard gift-exchange design to specifically test two hypotheses: the "gift-exchange hypothesis", which claims that workers uniformly reciprocate sick pay, and the "selection hypothesis", according to which sick pay favors the matching between those firms who offer sick pay and those workers who appreciate and reciprocate it. In each of 10 periods, employers have to choose from a menu of five contracts each consisting of a wage, $w$, which is paid if the worker shows up for work, and a sick pay, $s$, which is paid otherwise. Workers' lowest effort is equivalent to (pretending to) being sick and not showing up at the workplace. Importantly, the lowest effort may also happen for reasons outside the workers' accountability. Firms, however, can only verify if workers show up or not. Two 
main treatments are compared. In treatment $M$ (Monopsony) firms and workers are exogenously and anonymously matched in each period. In treatment $\mathrm{S}$ (Selection) firms compete for workers and are given the possibility of hiring more than one worker.

Gift-exchange results are replicated. Moreover, offering sick pay also increases effort. However, the experimental data also show that offering sick pay contracts is not always the most profitable option for firms. In M firms sometimes even suffer losses. Interestingly, when firms have to compete for workers they earn the highest profit when choosing a contract that offers only a partial sick pay. Firms realize this and most frequently choose the contract consisting of a partial sick pay. In both treatments, sick pay contracts induce self-selection and attract more reciprocal workers. In conclusion, in the presence of gift-exchange the effectiveness of sick pay is driven by competition in the labor market.

\section{Deferred compensation}

Huck et al. [2011] experimentally test Lazear [1979] model of deferred compensation and examine the relationship between a firm's wage offer and worker's effort provision in a three-period game. ${ }^{5}$ Four treatments are implemented.

In the main Full Commitment Treatment (FCT), firms can fully commit to future wage offers. In FCT results are mixed for both, firms and workers. Deferred compensation is observed but not all firms offer the predicted wage pattern and some workers shirk although they are incentivized not to do. In order to better understand that pattern, the authors conduct two control treatments. In the No Commitment Treatment (NCT), firms can only make non-binding promises about future payments. In the computer firm treatment (CFT), firms' wage offers are generated by a computer in order to control for the effect of outcome inequality. When there is no commitment device workers' effort and efficiency are low, as predicted. Workers do not believe wage promises and do not reciprocate to promised high future wages. Actual wages are indeed lower than promised ones. Nevertheless, there is evidence for giftexchange but mainly within a period. Therefore, the authors conclude that the best strategy to induce high effort is not to offer a low wage early and promise a high wage later but offer a high wage right at the beginning. In the Reputation

\footnotetext{
${ }^{5}$ In deferred compensation contracts workers are underpaid in early years of their career and overpaid in later years. Theoretically, they induce higher effort because future payments within the firm always exceed future payment elsewhere (Lazear [1979]). However, since firms can renege on future payments, the optimality of deferred contracts depends on the existence of an effective commitment mechanism.
} 
Treatment (RT), firms' past history on wage promises and actual wages is made available to workers, in order to check for reputation effects. The authors find that actually paying high wages to old workers has indeed a reputation effect and reputation may work as a commitment device.

\section{Gift-exchange, incentive schemes, and contract enforcement}

Laboratory gift-exchange experiments show that reciprocity is effectively increasing worker effort when contracts are incomplete. In the field, also material incentives are used to mitigate the enforcement problem. Therefore, the question of how explicit performance incentives and gift-exchange interact with each other has been subject of several studies.

Fehr et al. [1997] conduct three treatments involving competitive markets with more workers than firms. In each treatment, firms specify a wage, a desired effort level, and a fine imposed if a worker is detected shirking. In the no-reciprocity-treatment (NRT) contract terms are exogenously enforced by the experimenter; in the weak-reciprocity-treatment (WRT) workers who accept a contract choose an effort level, and a random device determines whether the firms are able to verify shirking; the strong-reciprocity- treatment (SRT) has an additional third stage in which firms can also respond reciprocally, by costly rewarding or punishing workers after they observe actual effort choices.

The results from WRT show that firms' behavior is affected by reciprocity considerations, as the number of generous offers is significantly higher than in the NRT. Nevertheless, shirking is also quite prevalent. In SRT firms demand and succeed in enforcing much higher effort levels than in WRT. They punish workers who shirk and reward both those who provide the desired or more effort. In response workers reciprocate high wages with high efforts. This leads to a higher aggregate monetary payoff, meaning that both workers and firms are better off in SRT.

Fehr and Gächter [2002a] examine the possibility that explicit incentives may create a hostile atmosphere of threat and distrust undermining reciprocitybased extra effort. They conduct a gift-exchange experiment under two treatments, a trust treatment (TT), which resembles a standard gift-exchange game under the one-sided auction trading rules and an incentive treatment (IT) where firms can punish shirking workers.

In TT firms offer higher wages and demand higher effort levels than in IT, resulting in higher actual average effort. The authors observe that the lower effort levels in IT are not caused by lower wage offers but that low wages are 
a response to the reduction of the workers' willingness to reciprocate. Further, the data show that efficiency is lower in IT, due to the reduced effort levels. The authors conjecture that the negative incentive effect is due to framing the material inventive as punishment, which workers may perceive as unkind. To test this, an additional bonus treatment (BT) where a shirking worker, instead of paying a fine, does not receive a bonus if caught shirking, is conducted. The incentive structure is exactly the same in IT and BT. Nevertheless, large behavioral differences are observed in IT and BT. With the material incentive framed as bonus, effort levels are significantly higher than when it is framed as punishment.

Fehr et al. [2007] compare the performance of three types of contracts. In the incentive contract the principal offers a wage, a required effort level, and a fine paid in case the agent is caught shirking. If the principal invests in a verification technology, agents' effort choices are observed with the exogenous probability $p=1 / 3$. In the trust contract, the principal offers a fixed wage to the agent and asks for high effort in return. Lastly, the bonus contract is similar to the trust contract, except that the principal announces that $\mathrm{s} /$ he might pay a bonus if the agent exerts more effort than required. The authors conduct a bilateral gift-exchange experiment with two treatments. In the trustincentive treatment (TI) principals could choose between the trust contract and the incentive contract and in the bonus-incentive treatment (BI) all three contracts could be chosen. In TI it is found that incentive contracts are chosen by most principals and increasingly preferred over time as they perform better from the firm's perspective. Workers' effort levels and principals' payoffs are higher with incentive contracts than with trust contracts. In stark contrast, in the BI treatment bonus contracts are chosen much more often than the incentive contracts and the trust contract is never chosen. Hence, on the one hand, in TI fairness concerns are not powerful enough to contradict standard theory prediction that incentive contracts are preferred to trust contracts. On the other hand, when a non-binding promise to pay bonuses is introduced, the results contrast with what standard theory postulates.

In a subsequent paper, Fehr and Schmidt [2007] wonder whether combining a bonus and an incentive contract helps improving efficiency. Principals can choose between a pure bonus contract and a combined contract, which therefore offers both a fine paid in case of detected shirking and a voluntary bonus. Still, the authors find that the vast majority of principals prefer the pure bonus contract, which also turns out to be more efficient. These results seem to 
support the idea that, in many cases, explicit negative incentives may crowd out intrinsic motivation, as agents might perceive a fine as a hostile act and the choice of monitoring the agents as a signal of distrust.

Eriksson and Villeval (2012) study whether symbolic but costly reward ("respect" in the authors' words) for high effort affects gift-exchange. They find that the majority of employers do not send symbolic rewards. More symbolic rewards are sent when there is competition on the labor market than when it is balanced and they are mainly used to initiate longer-term relationships. Interestingly, receiving rewards induce higher efforts only when the market is balanced.

Fehr et al. [1996] study incentive effects on efforts in a different environment. Specifically, they test whether the predictions of the shirking version of the efficiency wage hypothesis (Shapiro and Stiglitz [1984]), namely that higher wages and lower effort requirements reduce shirking, are borne out by the data. In the Efficiency Wage Experiments (EWE) firms with different production technologies offer contracts consisting of a wage, a required effort level, and a penalty levied on the worker in case caught shirking. The results are then compared to a Market Clearing Experiment (MCE), where the incentive to pay efficiency wages is removed by allowing the imposition of a higher penalty. In the EWE it is observed that firms make a rational and selfish use of penalties, meaning that the great majority of the chosen penalties meet the standard theoretical predictions. However, wage offers and demanded effort levels tend to lie below the predicted values, suggesting that firms' choices might be affected by risk aversion. In the MCE the market converges to the predicted values.Most importantly, the authors find support for the efficiency wage hypothesis as an increase in wage offers reduces the probability of shirking and firms try to pay job rents to induce workers not to shirk. Finally, it is shown that the existence of efficiency wages leads to involuntary unemployment.

\subsubsection{Robustness and extensions of gift-exchange labor markets}

Gift-exchange labor market experiments have been conducted under many environmental conditions and the strong positive relationship between wage and effort has been confirmed by a large number of papers. There are, however, some conditions where gift-exchange may break down. The experiments summarized in this section propose extensions of the basic gift-exchange game design and try to assess whether and to what extent changes in the environmental features affect gift-exchange. 


\section{Gift-exchange, multi-worker firms, and social comparisons}

The external validity of experimental results gathered in relatively simple environments is a challenge for experimental economics in general and for giftexchange labor market experiments in particular. For instance, the mostly used implementation of gift-exchange markets, where employment relationships involve one employer and one employee, may limit the validity of results for cases where employers can hire more than one worker.

Maximiano et al. [2007] compare a standard one-employer-one-worker (11) bilateral gift-exchange game with one in which each firm has four workers (1-4). In the latter case, the firm has to pay the same wage to all workers, who then simultaneously decide how much effort to provide without knowing the effort choices of their co-workers. In both treatments, workers choose, on average, a higher effort level the higher the offered wage and the difference between treatments is small and statistically not significant. Hence, overall the wage-effort relation is robust to an increased number of workers within a firm.

The previous paper is mainly concerned with the relationship between agents at different levels in the firm hierarchy. Charness and Kuhn [2007] examine how the horizontal relationship between workers and the observation of each other's wages may affect effort choices. They match two workers with different productivity levels (high and low) with one firm. Workers know that their productivity is different from their co-workers' but they do not know the direction of this difference. Firms can offer their workers different wages. The authors also vary, in a within-subjects design, whether wage offers are public (both workers know both wages) or private (workers know only their own wage). The data show that when a co-worker's wage is secret workers' effort choices respond very strongly to their own wage. Interestingly, the same holds when workers are informed of their co-workers' wage before choosing their own effort. Hence, workers seem to be mainly concerned with their own wage offer and horizontal comparisons are either not important or wage differences are perceived as justified because of the productivity differences.

Gächter and Thöni [2010] analyze horizontal pay comparison effects when workers are equally productive. In contrast to Charness and Kuhn [2007], they find that a worker who is paid less than a co-worker significantly reduces his/her effort relative to a situation where equal wages are paid. Gächter and Thöni [2010] further analyze whether the observed pay comparison effects actually come from wage differences or are due to an aversion to intentional wage discrimination. In an additional treatment, a random device chooses workers' 
wages on behalf of firms. It turns out that disadvantageous wage discrimination does not result anymore in reduced effort levels and, hence, intentionality is the source of reduced efforts in case of unequal wages.

Gächter et al. [2012] go a step further and investigate whether the possibility to compare both, pay and effort, influences reciprocal behavior. In a threeperson gift-exchange game, the employer chooses a wage, which can be different for different workers. In the experiment employees first observe both wages and then choose sequentially an effort level. The worker who moves second (Employee 2), therefore, also receives information about the co-worker's effort choice. The authors find that in this setting pay comparisons do not affect effort choices. However, for a given wage combination, a worker's effort depends on the co-worker's effort decision. Employee 2 exerts high effort if Employee 1 does so and tends to choose low effort if the co-worker also chooses low effort. Hence, on average reciprocity toward the employer is weakened when effort comparison is possible.

Nosenzo [2013] studies pay comparison effects in a gift-exchange game where one employer is matched with two symmetric employees, and compares effort choices under three treatments: in the "pay secrecy" treatment each employee only knows his/her own wage; the two "public wages" treatments, where both wages are known to both employees, differ in how wages are determined. In one treatment the employer can choose both wages, while in the other one wage is set exogenously. The data show that information about co-workers' wages can be detrimental for effort provision. In the pay secrecy treatment effort levels are higher than in the other two treatments because with public wages employees who are paid less exert less effort. Interestingly, this holds even when co-workers' wages are chosen exogenously.

In Abeler et al. [2010], two agents are matched with one principal who chooses a wage only after having observed the effort simultaneously chosen by the agents in the first stage of a gift-exchange game. In one treatment the principal has to pay the same wage to both agents, while in a second treatment she can set different wages for the two agents. The authors find that in the equal wage treatments effort levels are significantly lower than when agents are paid individually, suggesting that agents perceive equal wages for unequal performance as unfair. In the individual wage treatment principals seem to anticipate that and pay higher wages to agents who exert higher effort. Moreover, when wages are set equal by the employer, employees who initially work hard tend to reduce effort to the level of their low-performing co-workers. 
The opposite occurs when workers are paid individually: those workers who initially exert low effort align with the high performers.

Siang et al. [2011] also test for horizontal comparisons in a bilateral giftexchange game, under both random and fixed matching, where workers are provided with either quantitative or qualitative information about the average wage in the market. ${ }^{6}$ Overall, it is found that information about average wages has a decreasing effect on both wage and effort in the random-matching treatments, and the opposite effect under the fixed matching protocol.

\section{Framing}

Charness et al. [2004] investigate whether providing experiment participants with a comprehensive payoff table has an effect on gift-exchange. They run a standard gift-exchange game under two different conditions. In both conditions subjects are given the payoff functions and in one treatment subjects are, in addition, given a complete payoff table reporting firms and workers' payoffs for all combinations of wages and effort. The authors find that the provision of such a table, although superfluous for subjects to be able to compute payoffs, does affect behavior. Gift-exchange is observed in both treatments but the inclusion of the payoff table decreases wages and effort. Further, with the payoff table the wage-effort relationship seems to be weakened over time, especially toward the end of the experiment suggesting strategic effort choices. The authors propose two main explanations for the lowered gift-exchange but leave the ultimate reason open. On the one hand, working through the table and focusing on it may have led workers somehow to regard their effort choices and firms' wage decisions as not linked to each other. On the other hand, the payoff table might have made the distributional consequences more salient, as firms' marginal benefit resulting from an increased effort decreases as wage increases, which might induce lower effort.

\section{Stake levels}

Fehr et al. [2014] study the effect of high stakes on gift-exchange. They conduct two treatments of the gift-exchange market a normal-stake condition and a highstake condition, where in the latter the stake level was 10 times higher than in the normal-stake condition, and (Russian) subjects' earnings amounted on average to up to three monthly incomes. The introduction of high stakes does not weaken the wage effort relationship. Wages are above the competitive level

\footnotetext{
${ }^{6}$ More precisely, workers are informed whether the employer offers a wage which is $5 \%$ larger or smaller than the average wage across markets.
} 
and quite similar for normal and high stakes. The impact of increased stakes on effort is negligible as well. A comparison of behavior under normal stakes with Austrian subjects show that the reported results are not due to Russian subjects' characteristics. Overall, the results indicate that market institutions are more important in shaping behavior than stake size.

\section{Market size}

The issue of how market size might affect behavior in a gift-exchange environment is addressed in Brandts et al. [2010]. In the small market there are 7 traders ( 5 workers and 2 firms), while the large market has 21 trading agents (15 workers and 6 firms). In each market trades occur through two different market institutions: double auctions (DA) or bilateral negotiations (BN). The experiment lasts 30 periods in which during the first 10 rounds, subjects trade only through DA. In the successive 20 periods, at the beginning of each period, firms choose whether to enter the DA or privately negotiate with a worker. The worker, in turn, indicates whether or not s/he is willing to enter the BN. Thereafter, the game proceeds with wage offers and subsequent effort decisions. The authors report that gift-exchange is robust to the variation of the number of traders in the market. In both treatments effort and wages are positively correlated and wages and efforts in BN are higher than in DA. In both treatments aggregate surplus is considerably higher in periods 11-30 (when DA and $\mathrm{BN}$ coexist in the markets) than in the first 10 periods (with only DA). Hence, the market institution is more important in shaping behavior than the market size.

\section{Transparency}

In many employment relationships the amount of effort exerted by the workers is not perfectly observable by the employer, a factor that is ignored in standard gift-exchange experiments. The question arises if workers would still be reciprocal in a situation where hidden actions are possible and, consequently, if it is still profitable for firms to offer generous wages.

Irlenbusch and Sliwka [2005] address this issue by investigating how transparency of effort choices affects gift-exchange. In their experiment, a firm's payoff is given by the sum of a worker's effort and a random component. Two treatments are conducted. In the revealed-effort treatment, firms are perfectly informed about both components of their payoff, whereas in the hidden-effort treatment, firms only observe their payoff without any further detail. Their results show that the positive wage-effort relation is present in both treatments, 
but it is much stronger in the revealed effort treatment. When exploring the results in more detail the authors find that actual effort levels are similar across treatments, but that wages in the hidden effort treatment are higher. The hidden effort treatment is also characterized by much more heterogeneity in agents' behavior. It seems that some agents take advantage of the principal not being able to observe their effort while others are willing to exert even more than the efficient effort level in order to signal their willingness to reciprocate.

\section{Subject pool}

Hannan et al. [2002] conducted two experiments with two different U.S. subject pools, MBAs and undergraduate students to explore the effect of work experience. They also compared their behavior to that of Austrian students in Fehr et al. [1998b] in order to investigate whether characteristics of the U.S. society (e.g., a more individualistic approach to work) leads to different results in terms of gift-exchange. The implemented gift-exchange labor markets consist of one-sided auctions and firms were either of high or low productivity. When comparing U.S. students, MBAs, and Austrian students, the authors find that all three subject pools exhibit reciprocal preferences, but that U.S. students are less reciprocal than MBAs and Austrian students. Similarly, MBAs' wage offers are found to be considerably higher than those of U.S. students. In order to explore whether U.S. students' weaker gift-exchange is due to not being familiar with gift-exchange labor markets, the authors conduct another treatment where firms have to submit also a desired effort level. In comparison to the first experiment U.S. students exert more effort, which suggest that different work experiences of undergraduates and MBAs may account for differences in their effort responses.

\section{Gift-exchange in field experiments}

Some papers study gift-exchange in the field and provide evidence that social preferences identified in the laboratory map into fieldwork environments.

Gneezy and List [2006] hire people to perform two real-effort tasks, one involving work in a library and the other involving door-to-door fund-raising. In both cases, the participants know that it is a one-time employment. Two treatments per task are conducted. In both treatments a fixed wage per hour is promised. In the first one the promised wage is paid (noGift) and in the second, after the task has been explained, participants are told that they will be actually paid a higher wage (Gift). Consistent with the laboratory evidence, in the early hours of the task higher wages are reciprocated by higher effort 
levels, as effort in the Gift treatment is markedly higher than in the noGift treatment. This effect, however, vanishes over time. After a few hours, effort levels in the two treatments are statistically indistinguishable.

Kube et al. [2012] analyze how strongly workers reciprocate monetary and non-monetary gifts with higher productivity in a real-effort task. They hire students to enter data into a computer. In the benchmark treatment all students are paid an announced wage. In the cash treatment participants receive a monetary gift, while in the bottle treatment they are given a thermos bottle of equivalent monetary value. They also run additional control treatments. In one of them, the bottle's market price is explicitly mentioned, to rule out the possibility that workers might overestimate its market value. In the choice treatment, conducted to elicit preferences for receiving cash or the bottle, subjects can choose between the bottle and the money. Finally, in the origami treatment that is run to test whether the time and effort invested in the provision of gifts matter, the firm gives the workers money in the form of an origami.

The results show that the nature of gifts determines the strength of reciprocal behavior. The cash gift has only a statistically insignificant impact on workers' productivity, while the bottle starkly increases workers' performance and the effect remains large throughout the experiment. This result is closely replicated in the treatment where subjects are informed about the price of the bottle. Further, when workers can choose between gifts, almost all of them opt for the cash gift and workers' output is the same than in the no choice bottle treatment and, thus, higher than in the no choice money treatment. This suggests that time and effort the firm spends for a gift matter for the workers. Intriguingly, the data show that workers reciprocate a money gift of the same value as in the cash treatment but presented in origami form with an output level that is $30 \%$ higher.

In Kube et al. [2013] workers are hired by a university library to catalog books. In the baseline treatment, workers are paid the announced wage. In two other treatments, workers are informed, right before performing their task, that they would be paid either less or more than announced, respectively. They find that, while unexpected wage cuts severely and persistently reduce productivity, analogous wage increases do not lead to higher output levels.

Hennig-Schmidt et al. [2010] hire students for updating a database. Next to the baseline treatment, where all workers are paid the same wage, the authors perform some treatments where workers receive an unexpected pay raise and some others where workers are also informed about the wage increase of a peer 
group. They observe that neither increases in the own wage nor information on peers' wages seem to affect workers' effort. Hence, contrary to most laboratory and other field experiments no positive wage-effort relation is observed. The authors complement the analysis with a real-effort lab experiment, where employees either receive a flat wage or are exposed to an unexpected wage increase under two conditions, differing in whether the information about the employer's surplus from work effort is available or not. In the absence of surplus information there seems to be no positive relation between wage and effort. However, when surplus information is provided this relation is observed. In fact, the positive wage-effort relation is quite steep and a pay raise is profitable for employers. This result suggests that workers being aware of the employer's surplus may be crucial for reciprocal inclinations to come into play.

\subsubsection{Summary}

Laboratory gift-exchange experiments have identified some broad regularities. Reputation incentives (help) discipline workers and induce them to provide higher effort (Gächter and Falk [2002], Brown et al. [2004, 2012]). Effort responds to the mechanism underlying the wage formation process, at least at low wages, with stronger reactions when (low) wages are intentional (Charness [2004]), but not to the internal composition of the firm (Maximiano et al. [2013]). Effort decisions are affected by the introduction or the removal of a minimum wage. An increased minimum wage may induce more effort through higher wages. However, it also shifts subjects' reference point with counterproductive effects on effort once the minimum wage is dropped (Brandts and Charness [2004], Falk et al. [2006], Owens and Kagel [2010]).

Evidence on the effect of explicit incentives on effort provision is a bit mixed. On the one hand, the possibility for principals to punish or reward agents seems to increase effort levels (Fehr et al. [1997]). On the other hand, a decision by a principal to monitor or punish an agent can create an atmosphere of distrust and undermine gift-exchange, while nonbinding promises to pay bonuses for workers' performance can induce more effort and outperform explicit incentive contracts (Fehr and Gächter [2002a], Fehr et al. [2007], Fehr and Schmidt [2007]). In case of deferred compensation contracts, however, unenforceable promises about future payments can reduce effort (Huck et al. [2011]).

Duersch et al. [2012] show that sick pay provision increases effort and attracts more reciprocal workers, even though offering sick pay contracts is a profitable option for firms only when they have to compete for workers. 
Workers' effort choices can be driven by pay comparison considerations. When workers are characterized by different productivity levels wage differences do not affect effort decisions, suggesting that unequal wages for unequal performance are not perceived as unfair. A detrimental effect on effort is found when workers are all equally productive and principals offer different wages (Charness and Kuhn [2007], Abeler et al. [2010], Gächter and Thöni [2010], Gächter et al. [2012], Nosenzo [2013]). Workers' behavior can depend on coworkers' effort decisions when both effort and pay comparison information are made available (Gächter et al. [2012]).

The way decision tasks are presented in the laboratory may also affect behavior. The provision of a complete payoff table, for instance, significantly decreases wages and effort (Charness et al. [2004]). Impact of increased stakes on effort seems negligible (Fehr et al. [2014]) and so is the effect of the number of traders in the market (Brandts et al. [2010]). Effort choices may differ across subject pools (Hannan et al. [2002]).

Field experiments show that gift-exchange identified in the laboratory to a large extent map into field work environments (Gneezy and List [2006]). Effort also responds to the nature of gifts as workers exert more effort in response to a non-monetary gift (Kube et al. [2012]). Laboratory results that pay comparison information may have little influence on effort choices are confirmed in the field (Hennig-Schmidt et al. [2010]). Finally, there is also strong field evidence of negative reciprocity when wages are cut (Kube et al. [2013]).

\subsection{Experimental labor markets in macroeconomics and public finance}

Laboratory experiments can be a valuable research tool for investigating aggregate economic phenomena. In this section we survey papers that try to assess the impact of taxation on economic performance, mainly focusing on the relation between (labor) taxation and unemployment. In a series of studies, Riedl and Van Winden [2001, 2007, 2012] show the existence of a vicious circle in the interaction between wage taxes and unemployment and suggest that shifting the tax burden from labor to sales or production can alleviate the unemployment-boosting effect of taxes. Blumkin et al. [2012] test the response of labor supply to various forms of taxation and argue that shifting taxation from labor to consumption increases labor supply, while Ortona et al. [2008] find the same effect on effort provision coming from destining taxes to insure subjects against risk and to finance public goods. 
Riedl and Van Winden [2001] are the first to use laboratory experiments to investigate the nexus between labor taxation and unemployment in a fullfledged economy. In particular, they study the effects of a wage tax (WT) system to finance unemployment benefits on the performance of an economy, mainly in reaction to tax adjustments due to a budget deficit or surplus. The economy under consideration is graphically depicted in Figure 2.1.

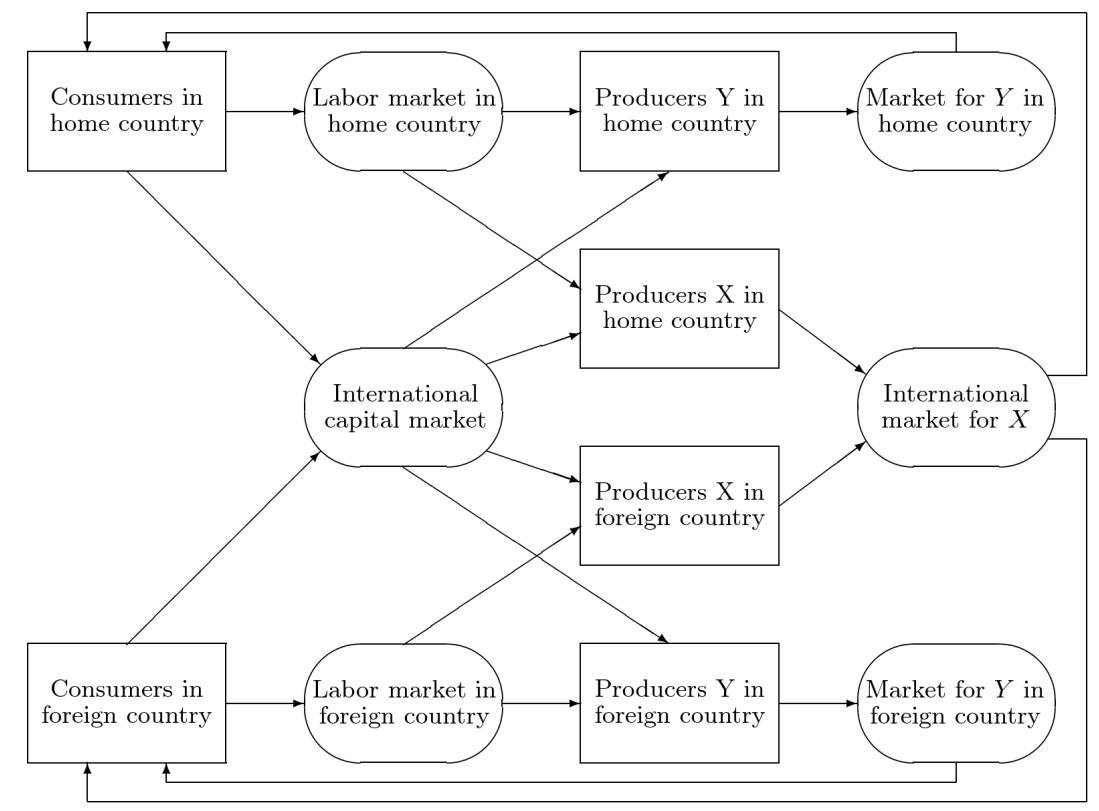

Figure 2.1: Flow diagram of the Riedl and van Winden (2001, 2007, 2012) economy

It consists of two countries, a small "home" country and a large "foreign" country, where two inputs, capital $K$ and labor $L$, and two outputs, $X$ and $Y$, can be traded. In each country, goods $X$ and $Y$ are produced in two separate sectors with the help of inputs $L$ and $K$. These inputs are, respectively, traded on a local labor market (separate in each country) and on an international capital market. Similarly, the market for commodity $X$ is international, while the market for commodity $Y$ is local. Consumers derive utility from leisure, the unsold units of labor, and the consumption of $X$ and $Y$. They are endowed with some units of labor and capital, and they obtain an unemployment benefit for each unsold unit of their labor endowment. The government finances these benefits with the help of a tax on employed labor paid by producers. Two tax regimes are implemented in each country. During the first part of the experimental session, wage taxes are held constant. During the second part, the wage tax rate is adjusted to the previous period's deficit or surplus in the government budget. 
Riedl and Van Winden [2001] find that in the constant tax regime both countries experience a budget deficit in all periods, which does not decrease over time. They also show that, while unemployment levels converge to the equilibrium values, nominal wages are very low in both countries. A thorough analysis of consumers and producers behavior shows that the former supply too much labor at given prices, while the latter have a tendency to employ too few labor units. This supports the so-called risk-compensated price-mechanism hypothesis, which was first detected in pure commodity markets by Noussair et al. [1995]. When producers make their input decisions market conditions, prevailing at the time consumers buy their products, are usually unknown, meaning that producers face uncertainty about the revenues they can make by selling their products. Given this price uncertainty, risk-averse producers demand less labor than predicted in equilibrium. Producers and consumers combined behavior leads to an upward trend of unemployment rates and drive nominal wages down, which explains the observed budget deficit. In the dynamic tax regime, an initial considerable increase in the tax rates is observed as the previous periods' budget is not balanced. Increased taxes help to decrease the budget deficit over time. However, it comes at the cost of strong negative effects on the performance of the economy as a whole. In both countries unemployment rates increase and real GDP sharply decreases.

In Riedl and Van Winden [2007], the same setup is used to compare a closed with an international economy. Overall, the data confirm the earlier results. When the tax rate is constant, in all economies a budget deficit occurs already in early periods. The same excess supply of labor is observed, which is accompanied by producers' reluctance to buy inputs and a downward trend of wages. Together this accounts for the observed budget deficits. Once the dynamic tax regime is introduced, in all economies the deficit becomes smaller due to higher tax rates but the unemployment level increases, an effect that is due to the low employment of both factors (because of price uncertainty), which is exacerbated for labor through the wage tax.

These findings show that there exists a vicious circle in the interaction between wage tax and unemployment. This strongly suggests that shifting taxation from labor to consumption or sales may have beneficial effects on both production and employment. To explore this, Riedl and Van Winden [2012] introduce a sales-tax-cum-labor-subsidy (STLS) system in the above described economy and compared it to a pure wage tax system. Two treatments are implemented. In the baseline treatment, in both the home country and the 
foreign country unemployment benefits are financed with a wage tax. In the alternative treatment, in the home country the wage tax system is substituted by the STLS system while the wage tax system prevails in the foreign country. Next to shifting the tax from labor to sales, in the STLS system producers also receive a subsidy equal to the unemployment benefit for each unit of labor they employ. Again, a constant tax regime is followed by a regime where the tax rate adjusts to previous periods' budget surpluses.

In the constant tax regime basically all quantities and prices as well as economic performance indicators, such as unemployment rate and real GDP, weakly converge to the theoretically predicted equilibrium values. In the small country the unemployment rate is initially higher when the STLS system is effective but tends to decrease over time, despite high sales taxes. Such a development is not observed under the wage tax system. Moreover, declining unemployment under the STLS system is associated with an increase in the budget surplus of the small country, while wage taxes are systematically accompanied by budget deficits. A similar pattern is observed for the real GDP. At the end of the constant tax regime the economies under the wage tax system face budget deficits, while budget surpluses are generated in the small country under the STLS system. Consequently, the transition to the variable tax regime is characterized by an increase in wage tax rates and by a decrease in sales taxes. The increasing tax rates in the wage tax system lead to increasing unemployment and a decrease in real GDP, while at the same time the burden from the budget deficit merely weakens. In stark contrast, in the alternative tax system the initial decline in sales tax rates reduces unemployment and boosts real GDP. In addition, the budget immediately balances and stabilizes over time. Overall, Riedl and Van Winden [2012]'s results show that the STLS system leads to a significantly better economic performance compared to the wage tax system. These differential results are mainly driven by producers' reluctance to incur upfront costs when they are uncertain about output prices. Importantly, producers seem to perceive uncertainty differently under the two tax systems because receiving a labor subsidy and paying taxes according to sales revenues basically gives producers the opportunity to share their risk with the government.

Blumkin et al. [2012] experimentally test the equivalence between consumption and wage taxes in a real-effort experiment where subjects have to decide how to allocate their time between labor and leisure. Subjects receive income according to their performance in a real-effort task, which they are then asked to 
allocate between two consumption goods. They also receive a payment for each unit of leisure consumed. The experiment consists of three parts: the first two are meant to measure and control for subjects' productivity and pretax laborleisure preferences, respectively. Finally, in the third part in one treatment a labor income tax (IT) and in the other treatments a theoretically equivalent consumption tax (CT) is introduced.

Although theoretically equivalent, worker-consumers may work more and consume less leisure in presence of a consumption tax because of money illusion. That is, individuals may tend to think in nominal and not in real terms (for empirical evidence on money illusion see, e.g., Fehr and Tyran [2001]). In that case labor income taxes and consumption taxes may be perceived differently when the labor supply decision has to be made. When subjects make their decision the labor income tax is salient whereas the consumption tax is not. In consequence, subjects would work more in the consumption tax treatment than in the income tax treatment. This is indeed what the authors find. Specifically, those worker-consumers who reduce their labor supply when a tax is introduced, reduce it significantly more in the income tax treatment. In line with Riedl and Van Winden [2012], this result suggests that shifting taxation from labor to consumption might potentially lead to welfare improvements, with higher utility for individuals and unchanged government tax revenues. ${ }^{7}$

Ortona et al. [2008] investigate the relation between labor supply and taxation when tax revenues are used for the production of public goods. They conduct a real-effort experiment and compare the labor supply in two states of the world. In a so-called state of nature (SN) there is a certain risk to lose part of the earned income and there are no taxes, insurance, and public goods. In a welfare state (WS treatment, the same risk is partially insured and a proportional income tax and a public good exist. Their main result is that subjects work more under WS than under SN, which suggests that the fact that the returns from taxes are used to protect subjects against risk and provide public goods does not reduce labor supply and possibly increases it.

\subsection{Conclusions}

Laboratory experiments have entered labor economics and the generated results have significantly increased our knowledge on a variety of aspects. In this chapter we have surveyed part of this literature and concentrated on two main

\footnotetext{
${ }^{7} \mathrm{~A}$ related salience effect of taxation is also found for consumer goods by Chetty et al. [2009].
} 
areas. The first part has been devoted to the behavioral consequences of contractual incompleteness in a gift-exchange environment and in the second part more macroeconomics-oriented experiments have been presented, which mainly focus on the interaction between taxation and labor market performance.

Many employment relations are often contractually incomplete in terms of effort that workers are required to exert. In such contexts, workers' reciprocal inclinations play an important role in determining the overall surplus and profit of the firm. Laboratory experiments provide abundant evidence that a sizable share of people exhibits fairness concerns and show that reciprocity often can substitute for the absence of a formal contract enforcement device. It is now a well-established result that a positive relationship between the wages offered by firms and the effort exerted by workers exists, and that employers are actually willing to offer wages higher than the prevailing minimum to elicit higher effort.

The importance of gift-exchange in employer-employee relations has several policy implications. For instance, it has been shown that gift-exchange wages turn out to be downwardly rigid, speaking to Bewley [1999]'s book title "Why wages don't fall during a recession". A consequence is that the introduction of a minimum wage may have unintended effects as it has been shown that a minimum wage may change workers' reference point of a fair wage and, hence, affect their effort provision. Further, the interaction between reciprocal inclinations and various incentive schemes has to be carefully taken into account as it does not necessarily hold that explicit incentives will have unambiguous positive effects on effort. In fact, explicit incentives may crowd out intrinsic motivation as agents may consider a fine or a punishment as a hostile act or being monitored as a signal of distrust, which may induce lower effort levels.

The positive relationship between wage and effort has been confirmed under a broad range of conditions. Nevertheless, the generalizability of gift-exchange results to more complex field environments has sometimes been questioned. Recently, scholars have started to study situations where employers can hire more than one worker, focusing in particular on the interplay between reciprocity and wage and effort comparisons. Overall also in these studies gift-exchange is observed. However, the strength of it may hinge on details of the environment. For instance, effort comparisons seem to have a stronger impact on workers' effort choices than wage comparisons.

Also, only recently field experiments have been used to investigate giftexchange. The empirical results of the few studies are overall verifying the laboratory results, although some find only a weak wage-effort relationship. In 
the field, it seems that a wage cut has stronger effects than a wage increase and non-monetary gifts have a stronger effect than purely financial ones. An important open question is also the longevity of gift-exchange. As field experiments are almost always less controlled than laboratory setups, it is not clear yet what precisely is behind the larger variation in outcomes in field settings. It seems clear that much more research is required to filter out the institutional details that enhance or hamper gift-exchange in work relationships in the field.

The second part of this survey has been dedicated to the relatively small but important set of experiments aimed at assessing the impact of fiscal policies on the labor market and more general economic performance. These results show the existence of a vicious circle in the interaction between wage taxes and unemployment, because increasing labor taxes to balance budget deficits strongly and negatively affect overall economic performance. The findings suggest that shifting the tax burden from labor to sales or production might alleviate this effect. This research also explores conditions under which imposing a tax might foster effort provision. For instance, it is found that shifting taxation from labor to consumption increases labor supply. Overall, the number of laboratory experiments explicitly aiming at labor market questions traditionally belonging to macroeconomics and public finance is still very small. Interestingly, it is precisely these more traditional areas in economics that lately have been criticized by a skeptical public opinion. More experimental research in the laboratory (as well as the field) investigating such important questions as the perception of salience of different forms of labor taxation and the behavioral equivalence of theoretically equivalent policy interventions could be very informative for these fields too. Moreover, most of the experimental labor research takes place in a partial equilibrium setting where labor relationships and labor markets are assumed to operate on an isolated island. This has been an important and useful restriction in order to generate first clean results. Now the evidence and our knowledge have accumulated so much that time seems ripe to make the step out of the partial world and investigate more general market interactions in labor relations as it has already been done in international trade and other interactive markets experiments (Lei and Noussair [2007], Noussair et al. [1995, 2007]). 


\title{
Chapter 3
}

\section{Labor market gift-exchange and output market competition}

\begin{abstract}
In this chapter we study gift-exchange in labor relations when firms have to compete on the output market. Workers and firms are engaged in a contractually incomplete relationship where firms offer wages and workers respond with effort. Effort determines the output quantity firms can bring to the market. We study three different output market competition scenarios: monopoly, duopoly, and quadropoly. We derive theoretical predictions for standard selfish preferences as well as for reciprocal preferences using a reduced form model. In line with the reciprocity model, our experimental results show that wages and effort respond to the intensity of output market competition and decrease with increasing competition. Importantly, the wage-effort relationship is largely unaffected by competition, showing that reciprocal firm-worker relations are not destroyed when firms face competition. In consequence, more competition theoretically and empirically increases efficiency but leads to a redistribution of surplus from firms to workers and consumers.
\end{abstract}

Based on a joint work with Ronald Peeters and Arno Riedl. 


\subsection{Introduction}

There is by now overwhelming evidence that in contractually incomplete labor markets, where worker effort is typically not enforceable, workers respond to high(er) wages by exerting high(er) effort. ${ }^{1}$ All these results, however, are so far obtained in partial equilibrium settings where firms are assumed to operate in isolation as monopolists on the output market. The literature on gift-exchange, therefore, fails to capture spillover effects between product and labor markets: the possibility that a competitive environment external to the labor relationship might affect the labor relationship itself has been so far neglected. As a consequence, it also fails to capture potential effects that different market institutions might have on behavior.

This study is based on the idea that "economic institutions [might] influence the structure of social interactions and thus the evolution of norms", shape individuals' preferences and induce specific behaviors (Bowles [1998]). The results on this influence are, so far, rather ambiguous. While some studies show that markets do not erode, but even foster, or are compatible with, the emergence of norms like fairness and cooperation (Henrich et al. [2001, 2010], Bowles [2011], Bartling et al. [2015b]), some others argue that, instead, social preferences or moral considerations become negligible in competitive markets. ${ }^{2}$ Starting with Smith [1962], markets experiments have demonstrated that the neoclassical model predicts well outcomes on perfectly competitive markets. In their study on cross-cultural ultimatum games, Roth et al. [1991] put forward the hypothesis that concerns about fairness are context-dependent and might be diminished by increasing competition. Bowles [1998] argues that competition leads people to behave as if they were purely self-interested, and Shleifer [2004] discusses how competition favors the spread of behaviors commonly labeled as unethical (such as corruption or child labor). ${ }^{3}$

Few studies have tackled the question of how competition interacts with reciprocity. Bauernschuster et al. [2013]'s work explicitly deals with this issue:

\footnotetext{
${ }^{1}$ See, among others, Fehr et al. [1993, 1998b, 1997, 1998a], Brandts and Charness [2004], Brown et al. [2004, 2012], Maximiano et al. [2013]; for recent surveys on gift-exchange experiments, see Fehr et al. [2009], Charness and Kuhn [2011], Casoria and Riedl [2013].

${ }^{2}$ Schmidt [2011] argues that social preferences can be ignored only when two conditions are fulfilled, namely separability of preferences and completeness of contracts. In his view, social considerations do matter when contracts are incomplete, as they "transform a market relationship that is governed by competition into a bilateral relationship that is governed by trust and reciprocity", p. 228.

${ }^{3}$ See also Frey et al. [1996], Vohs et al. [2006], Cai and Liu [2009], Brandts et al. [2009], Falk and Szech [2013a,b], Brandts and Riedl [2016] for further discussions on the corrupting effects of market interaction.
} 
they analyze one-shot trust games and focus on whether reciprocity is reduced through any potentially detrimental effects of competition (among trustors) on trust and trustworthiness. Gift-exchange experiments designed to investigate how reciprocity is affected by competition, on the other hand, pivot on (the effects of) changes in labor demand and supply: that is, competition is represented as an imbalance between the number of firms and workers in the market (Fehr et al. [1993, 1998a,b], Brandts and Charness [2004], Brandts et al. [2010]). While the former find that, once competition among trustors is introduced, trustees lower their return ratios, and interpret this result as reciprocity crowding out, the latter show that competition has a limited impact and that firms' and workers' behavior is mostly unaffected.

To the best of our knowledge, this is the first study that investigates the impact of output market competition on reciprocity norms in the context of a contractually incomplete labor relationship. Specifically, we experimentally study the interaction between labor market gift-exchange and output market competition in a modified version of the gift-exchange game. In the first two stages, a standard bilateral gift-exchange game is played: first, each firm makes a wage offer to the worker she has been paired with. Then, each worker is informed of the wage offer, and chooses an effort level. The chosen effort level determines the output produced by the firm, who, in the third and final stage, has to choose how much of her capacity she wants to bring to the market. We compare three treatments that differ in the competitiveness of the output market. In the baseline treatment (Monopoly treatment), the firm does not face any competitors when selling her products. In the Duopoly treatment two firms compete in a Cournot fashion on the output market, and in the Quadropoly treatment four firms compete on the output market.

One crucial feature of our design is that market conditions other than the number of firms active in the market do not change across treatments. In particular, the market demand is kept fixed across market conditions. While a larger market may imply, in many cases, a larger market demand, here the idea is to simulate a geographically closed market and study the impact of industry concentration on market performance within that market, thereby gaining information on what the consequences are of the entry of new firms in that market. In this case, ceteris paribus, aggregate demand unlikely increases just because of new entrants.

We derive theoretical predictions for standard selfish preferences as well as for reciprocal preferences. In particular, for the latter we use a reduced form 
gift-exchange model which assumes the existence of a linear relation between wage and effort. We show that, under the assumption of a constant wage-effort relation across market conditions and for a sufficient level of reciprocity, wages and effort are decreasing in the level of output market competition. Moreover, for a given level of reciprocity, larger markets produce and sell more, which leads to higher efficiency.

Our main experimental results are that, in all treatments, average wages and effort are strictly positive, and both decrease with the number of firms in the market. In each treatment, wages and effort are positively related, indicating that gift-exchange is robust to output market competition. Most importantly, even though increasing output market competition calls for lower wages, this positive relation is manifested in all markets across treatments. Moreover, the very level of reciprocity is not affected by the (increased) competitiveness of the output market, proving gift-exchange as a quite stable behavioral pattern.

In line with previous market experiments, but in a setting with incomplete contracts, we find that the higher the competitiveness of the market, the greater, on average, the amount of quantity produced and sold at the aggregate level, which implies higher efficiency. More competition, however, leads to a redistribution of surplus from firms to workers and consumers. In particular, firms reap most of the total surplus in the Monopoly treatment, while their share considerably decreases in the Quadropoly treatment. This is due to the substantial increase in the consumers' surplus, and to the relatively less sizable increase in workers' surplus.

\subsection{Experimental design}

We investigate the interaction of labor market gift-exchange and output market competition in three treatments where we vary the level of competition in the output market. In all treatments each firm can hire exactly one worker and the firm-worker relation is characterized by incomplete contracts with the possibility of wage-effort gift-exchange. A firm-worker pair produces output of a homogeneous good that can be sold on the output market by the firm. In the Monopoly treatment, the firm does not face any competitors when selling her products. In the Duopoly treatment two firms compete in a Cournot fashion on the output market and in the Quadropoly treatment four firms compete on the output market. 


\subsubsection{Procedures and parameters}

In each treatment, subjects are randomly assigned the roles of either firm or worker and matched to form firm-worker pairs. Neither the role nor the pair subjects are in changes during the experiment. In the Duopoly and Quadropoly treatments firms are randomly matched in order to compete on output markets. Once formed, markets are kept fixed during the experiment; that is, each firm faces the same competitor(s) throughout. Each treatment runs over 25 periods, and each period consists of three stages.

In the first stage, each firm $i$ makes a binding wage offer $w_{i} \in\{0,1, \ldots, 100\}$ to the worker with whom she has been paired. In order to avoid any situation where the market structure happened to be endogenously determined, workers cannot reject a wage offer.

In the second stage, after having been informed on their own wage $w_{i}$, workers choose their effort level $e_{i} \in\{0,1, \ldots, 10\}$. Higher effort levels imply higher effort costs for the worker, according to the linear cost function

$$
c\left(e_{i}\right)=2 e_{i}
$$

Next, the chosen effort level determines the quantity produced by the firm, with higher effort levels producing more output. The production function is given by

$$
\bar{q}_{i}=\frac{80}{n}+20 e_{i}
$$

where $n$ is the number of firms in the market. The role of the constant term in the production function is twofold. First, it guarantees that firms always produce some units of the homogeneous good, which would otherwise prevent them from competing on the output market. Secondly, as we show below, the division by the number of firms in the market ensures fair across treatments comparisons on aggregate market outcomes when standard preferences (i.e., own payoff considerations) are assumed.

Lastly, in the third stage, firms choose $q_{i} \in\left\{0,1, \ldots, \bar{q}_{i}\right\}$; that is, how much of the produced quantity they want to sell on the market. The total amount put on the market determines the price, according to the inverse demand function

$$
p(Q)=\max \{400-Q, 0\}
$$

where $Q=\sum_{i} q_{i}$ is the total quantity sold on the market.

In each period, a firm's payoff is given by:

$$
\pi_{i}=\frac{p(Q) q_{i}}{200}-w_{i}+70 .
$$


Firms' revenues are discounted in order to bring payoffs of firms and workers closer to each other, so to minimize inequity aversion issues that might arise in case of large payoff differences.

A worker's payoff depends on the wage offer and the cost associated with the effort level chosen:

$$
u_{i}=w_{i}-c\left(e_{i}\right)+70 .
$$

The lump sum of 70 in both payoff functions is needed to avoid the possibility that behavior is influenced by loss aversion. ${ }^{4}$

Interactions take place anonymously: subjects are informed that they will never learn the trading partners' identity. In all sessions, the number of firms and workers in the market, the matching mechanism and all market parameters and functions are common knowledge. Actual payoffs, wages paid and effort levels are known only to the involved firm-worker pair. The quantity each firm produces is public knowledge in her market: at the end of the second stage, firms receive information about their own produced quantity and the quantity produced by each competitor in a fixed order. At the end of each period, firms also learn the quantity sold by each firm in their market (in a fixed order) and the market price. The fact that how much each firm produces and sells is common knowledge in the market ensures that the information about market performance available to firms is exactly the same in all three treatments. A worker is only informed about the market performance of the firm $\mathrm{s} /$ he has been paired with.

\subsubsection{Subject pool and payments}

The computerized experiment was programmed and conducted with z-Tree (Fischbacher [2007]). All sessions were run at the BEElab, the experimental laboratory at Maastricht University. Students were recruited via ORSEE (Greiner [2015]), and each of them participated in only one treatment. A total of 144 subjects took part in the experiment: 32 subjects in the Monopoly treatment (16 independent observations), 48 in the Duopoly treatment (12 independent observations) and 64 in the Quadropoly treatment (8 independent observations).

\footnotetext{
${ }^{4}$ Without the lump sum payment, firms can easily make losses in the Quadropoly treatment, where aggregate sales quickly go beyond the level that yields a market price of zero, rendering zero revenue at a possibly positive wage. However, the lump sum may decrease saliency of the earnings in the experiment. Therefore, to verify that behavior is not unduly affected by the lump sum payment, we ran one session of the Monopoly treatment with a higher exchange rate of Experimental Currency Units (ECU) into Euros (and a show-up fee) but without lump sum. We did not find any differences in behavior compared with the original Monopoly treatment (see Appendix 3.A).
} 
Each session lasted 90 minutes, on average. Before the session started, each subject had to read a set of written instructions, and to solve a number of exercises to make sure that everybody understood the experimental procedures. The experiment started only after all subjects had correctly answered all comprehension questions. Subjects had access to an on-screen calculator during the experiment.

The experiment was ended by a questionnaire. We elicited participants' reciprocity and risk attitudes, and checked for differences across treatments. Subjects do not differ in their (average) positive and negative reciprocal attitudes across treatments (Kruskal-Wallis (KW) tests, $p=0.4272$ for positive reciprocity, and $p=0.6717$ for negative reciprocity). ${ }^{5}$ As for risk preferences, we find some differences between treatments (KW significant at $10 \%$ level). ${ }^{6}$ In particular, in the Monopoly treatment participants report, on average, less willingness to take risks than subjects that interact in the Duopoly treatment (5.68 vs. $6.70 ;$ Dunn's test (DT): $p=0.0792$ ) and than those who participate in the Quadropoly treatment (5.68 vs. 6.62; DT: $p=0.0796)$. No statistically significant differences in risk attitudes between the Duopoly and the Quadropoly treatments are detected (DT: $p=0.4653$ ).

Participants were paid privately and individually at the end of the experimental session. Earnings were converted into real money at the exchange rate of $150 \mathrm{ECU}=1$ euro. Subjects earned, on average, $€ 25$ in the Monopoly treatment, $€ 19$ and $€ 15$ in the Duopoly and Quadropoly treatments, respectively.

\subsubsection{Behavioral predictions and hypotheses}

Assuming common knowledge of rationality and selfishness of all players, since effort is costly to workers and unenforceable, workers will choose the minimum effort level, irrespective of the wage offered. Firms anticipate this and offer the lowest possible wage. Hence, the predicted subgame perfect Nash equilibrium

\footnotetext{
${ }^{5}$ In order to assess individual reciprocal inclinations, we asked six questions about positive and negative reciprocity. Following Dohmen et al. [2008, 2009], subjects were requested to indicate on a 7-step scale (where 1 means "fully applies to me" and 7 "does not apply to me at all") to what extent each of the following statements accurately describes them: 1) If someone does me a favor, I am prepared to return it; 2) If I suffer a serious wrong, I will take revenge as soon as possible, no matter what the costs; 3) If somebody puts me in a difficult position, I will do the same to him/her; 4) I go out of my way to help somebody who has been kind to me before; 5) If somebody offends me, I will offend him/her back; 6) I am ready to undergo personal costs to help somebody who helped me before.

${ }^{6}$ To measure risk attitudes we use answers to the question: How do you see yourself: Are you generally a person who is fully prepared to take risks or do you try to avoid taking risks? Please tick a box on the scale, where the value 0 means: "not at all willing to take risks" and the value 10 means: "very willing to take risks".
} 
outcome is zero effort, zero wage and no (positive) relation between wage offers and effort levels. This prediction on wages and effort levels holds for all levels of competition on the output market.

Given the implemented production function, standard theory predicts no differences across treatments in terms of market outcomes. In each treatment, the individual equilibrium output is $q_{i}=\bar{q}_{i}=\frac{80}{n}$, and the total equilibrium output is $Q_{n}=\bar{Q}_{n}=80$. Consequently, the equilibrium market price is $p_{n}=$ 320 and the equilibrium surpluses are $W S_{n}=0$ for the workers, $F S_{n}=128$ for the firms, and $C S_{n}=16$ for the consumers, all aggregating in a total surplus equal to $T S_{n}=144$ in each market. ${ }^{7}$

On the basis of these standard theoretical predictions we formulate the following null hypotheses:

Hypothesis 1 (Standard theory).

(i) There is no (positive) relation between wage offers and effort levels.

(ii) Wages and effort levels are equal to zero for all levels of competition.

(iii) All surpluses are identical for all levels of competition.

The alternative view of the gift-exchange hypothesis (Akerlof [1982]), corroborated by a vast evidence on experimental gift-exchange labor markets, ${ }^{8}$ suggests instead the existence of a positive relation between wage and effort, and predicts that wage offers above some reference wage are reciprocated by above minimum effort levels. Therefore, we expect strictly positive wages and effort in all treatments.

We develop our benchmark theoretical predictions by means of a reduced form gift-exchange model, which simply conjectures the existence of a linear relation between wage and effort. ${ }^{9}$ More specifically, we assume that, in all firms in the market,

$$
e_{i}\left(w_{i}\right)=\gamma_{n} w_{i}
$$

where $\gamma_{n}$ is our reciprocity parameter when $n$ firms compete on the market.

\footnotetext{
${ }^{7}$ To equitably compare treatments with each other, and avoid surpluses to be inflated by the lump sums, we calculated the surpluses generated in each market by subtracting 70 from both firms' profits and workers' earnings.

${ }^{8}$ See Fehr et al. [2009], Charness and Kuhn [2011], Casoria and Riedl [2013] for recent surveys on gift-exchange experiments.

${ }^{9}$ Over the years, several models have been developed to rationalize social behavior. In particular, the kind of behavior emerging in gift-exchange labor markets can be captured and explained by distributional models (Fehr and Schmidt [1999], Bolton and Ockenfels [2000]), reciprocity or intention-based theories (Rabin [1993], Dufwenberg and Kirchsteiger [2004]), and by models combining both approaches (Levine [1998], Falk and Fischbacher [2006]). In our context, the application of any of the above-mentioned models would needlessly complicate the calculations to derive the equilibrium, without providing further insights.
} 
In equilibrium, firms bring full capacity to the market (i.e., $\left.q_{i}=\bar{q}_{i}\right) .{ }^{10}$ Assuming symmetry among rival firms (and aggregate sales being low enough to produce a positive price), firm $i$ 's profit function is given by

$$
\pi_{i}=\frac{\left[400-\left(\frac{80}{n}+20 \gamma_{n} w_{i}\right)-(n-1)\left(\frac{80}{n}+20 \gamma_{n} w_{j}\right)\right]\left[\frac{80}{n}+20 \gamma_{n} w_{i}\right]}{200}-w_{i}
$$

Solving this for the profit maximizing wage $w_{i}$, yields the reaction function

$$
w_{i}\left(w_{j}\right)=\frac{32 \gamma_{n}-\frac{8}{n} \gamma_{n}-1-2(n-1) \gamma_{n}^{2} w_{j}}{4 \gamma_{n}^{2}} .
$$

Assuming symmetry with the rival firms (i.e., $w_{i}=w_{j}, i \neq j$ ), gives the symmetric Nash equilibrium wage

$$
w_{i}=\frac{16-\frac{4}{n}-\frac{1}{2 \gamma_{n}}}{(n+1) \gamma_{n}}
$$

Notice that the wage is nonnegative if and only if $\gamma_{n} \geq \frac{n}{8(4 n-1)}$. So, $\gamma_{n} \geq \frac{1}{24}$ is a sufficient condition for nonnegative wages (and hence effort levels) for all levels of output market competition. Results from previous gift-exchange experiments allow us to assume that this condition on $\gamma$ is easily satisfied. Indeed, once one has taken into account the different scales used in different experimental settings to define the range of effort levels, the reported estimates of the wage-effort relation are very close to, and typically above, the value of $\frac{1}{24} \cdot{ }^{11}$

Equation 3.9 implies that the wage is increasing in $\gamma_{n}$ up to the level $\gamma_{n}=\frac{n}{4(4 n-1)}$ and decreases in $\gamma_{n}$ beyond that level. So, $\gamma_{n}>\frac{1}{12}$ is a sufficient condition for wages being declining in $\gamma_{n}$ for all levels of output market competition.

From the wage we obtain the following effort levels and production capacities and sales:

$$
e_{i}=\frac{16-\frac{4}{n}-\frac{1}{2 \gamma_{n}}}{(n+1)} \quad \text { and } \quad q_{i}=\bar{q}_{i}=\frac{400 \gamma_{n}-10}{(n+1) \gamma_{n}}
$$

\footnotetext{
${ }^{10}$ Since all firms know the prevailing conditions in their market, each firm is able to calculate the quantity that maximizes her profit. Given that the relations $\bar{q}_{i}=\frac{80}{n}+20 e_{i}\left(w_{i}\right)$ and $e_{i}\left(w_{i}\right)=\gamma_{n} w_{i}$ are common knowledge, each firm is in principle also able to exactly calculate what effort needs to be elicited, and thus what wage to offer, for the equilibrium quantity to be produced. This implies that, in equilibrium, there is no excess capacity.

${ }^{11}$ In the gift-exchange experimental literature, regression results of effort on wage show that the wage coefficients generally lie in the range between 0.04 and 0.1 (see, for instance, Casoria and Riedl [2013]). Our experimental estimates support the assumption that $\gamma_{n} \geq \frac{1}{24}$ (see Table 3.2).
} 
and the following market quantities and prices:

$$
Q_{n}=\bar{Q}_{n}=\frac{n\left(400 \gamma_{n}-10\right)}{(n+1) \gamma_{n}} \quad \text { and } \quad p_{n}=\frac{400 \gamma_{n}+10 n}{(n+1) \gamma_{n}} .
$$

Effort levels, individual quantities (capacity and sales) and aggregate quantities are unambiguously increasing in $\gamma_{n}$, even in spite of the decline in wages beyond $\gamma_{n}=\frac{n}{4(4 n-1)}$. Prices are unambiguously declining in $\gamma_{n}$.

This all results in the following surpluses for workers, firms and consumers:

$$
\begin{aligned}
W S_{n} & =\frac{-64 n \gamma_{n}^{2}+16 \gamma_{n}^{2}+34 n \gamma_{n}-8 \gamma_{n}-n}{2(n+1) \gamma_{n}^{2}} \\
F S_{n} & =\frac{1600 n \gamma_{n}^{2}+8 n^{2} \gamma_{n}-64 n \gamma_{n}+8 \gamma_{n}+n}{2(n+1)^{2} \gamma_{n}^{2}}, \text { and } \\
C S_{n} & =\frac{1600 n^{2} \gamma_{n}^{2}-80 n^{2} \gamma_{n}+n^{2}}{4(n+1)^{2} \gamma_{n}^{2}}
\end{aligned}
$$

all aggregating towards a total surplus of

$$
T S_{n}=\frac{1472 n^{2} \gamma_{n}^{2}+3104 n \gamma_{n}^{2}+32 \gamma_{n}^{2}+4 n^{2} \gamma_{n}-76 n \gamma_{n}-n^{2}}{4(n+1)^{2} \gamma_{n}^{2}} .
$$

The workers' surplus is increasing in $\gamma_{n}$ up to $\gamma_{n}=\frac{n}{17 n-4}$ and is declining afterwards. The firms' surplus follows the opposite trend: up to $\gamma_{n}=\frac{n}{4\left(-n^{2}+8 n-1\right)}$ it is declining, and beyond that level it is increasing in $\gamma_{n}$. Consumer surplus and total surplus are unambiguously increasing in $\gamma_{n}$ for all levels of output market competition.

In case the posited relation between wage and effort $\left(\gamma_{n}\right)$ were to be constant over all levels of output market competition (i.e., $\gamma_{n}=\gamma$ for all $n$ ), the comparative statics predictions with respect to the level of competition are unambiguous for wages and effort levels. For low values of $\gamma$, more competition leads to higher wages and effort levels; but, beyond certain levels of $\gamma$, higher levels of output market competition generate lower wages and effort levels. For the levels of competition implemented in our experiment (i.e., $n=1,2,4$ ), the monopoly results in higher wages and effort levels compared to the duopoly and quadropoly if $\gamma$ exceeds $\frac{1}{16}$ and $\frac{1}{20}$, respectively. At all feasible values of $\gamma$ (i.e. $\gamma \geq \frac{1}{24}$ such that wages are nonnegative), the quadropoly always produces lower wages and effort levels as compared to the duopoly. All other values produce an unambiguous ranking over levels of competition. Individual quantities are declining in $n$, the aggregate quantity is increasing in $n$, yielding market prices to be declining in $n$. Moreover, apart from firms' surplus that is declining in $n$, all other surpluses (workers', consumer and total) are increasing in $n$. 
Our alternative reduced-form reciprocity hypothesis is formulated while assuming a constant level of reciprocity for all levels of output market competition, and for sufficient levels of reciprocity $\left(\gamma \geq \frac{1}{16}\right)$, as we deem the occurrence of low levels of reciprocity quite unlikely: ${ }^{12}$

Hypothesis 2 (Reciprocity independent of output market competition).

(i) There is a positive relation between wage offers and effort levels (by model assumption).

(ii) Wages and effort levels are positive and decreasing in the level of competition.

(iii) Apart from the firms' surplus that is declining, all other surpluses (workers', consumer, and total) are increasing in the level of competition.

If, as Bowles [1998] argues, the more an experimental setting approximates the idealized competitive market the less other-regarding behaviors will be observed, then $\gamma_{n}$ (reciprocity) might be decreasing in the level of output market competition. This would imply lower wages and effort, and, consequently, lower produced quantities and higher prices as competition increases. A decreasing $\gamma_{n}$, hence, might result in a less efficient equilibrium allocation as output market competition increases. For instance, assuming $\gamma_{1}=0.1$ in Monopoly and $\gamma_{4}=0.045$ in Quadropoly, the total surplus would be $T S_{1}=236.75$ and $T S_{4}=227.65$, respectively. Similarly, the consumers surplus would be $C S_{1}=56.25$ in Monopoly and $C S_{4}=50.57$ in Quadropoly. Figure 3.1 shows how the total and the consumers surpluses change with $\gamma$.

Firms surplus is always decreasing in the number of firms in the market, independent of how $\gamma$ changes with different levels of output market competition. For workers surplus, instead, there is no unambiguous ranking. When reciprocity is decreasing in $n$, there is only a very small range of values of $\gamma$ for which a Monopoly would generate a higher worker surplus than a Duopoly, and a Duopoly a higher workers surplus than a Quadropoly. We hence formulate the following hypothesis:

Hypothesis 3 (Reciprocity crowded out by output market competition).

Total and consumer surplus might decrease with an increasing level of competition.

\footnotetext{
${ }^{12}$ While the hypotheses over surpluses holds for all levels of $\gamma$ at which wages are nonnegative, the ranking over wages, and therefore effort, differs if the condition $\gamma \geq \frac{1}{16}$ is not satisfied. Specifically, wages are the highest in duopoly and the lowest in quadropoly if $\gamma<\frac{1}{16}$. If, instead, $\gamma<\frac{1}{20}$, then monopoly is the market with the lowest wages. As Table 3.2 shows, however, in our experiment $\gamma$ always exceeds $\frac{1}{16}$.
} 


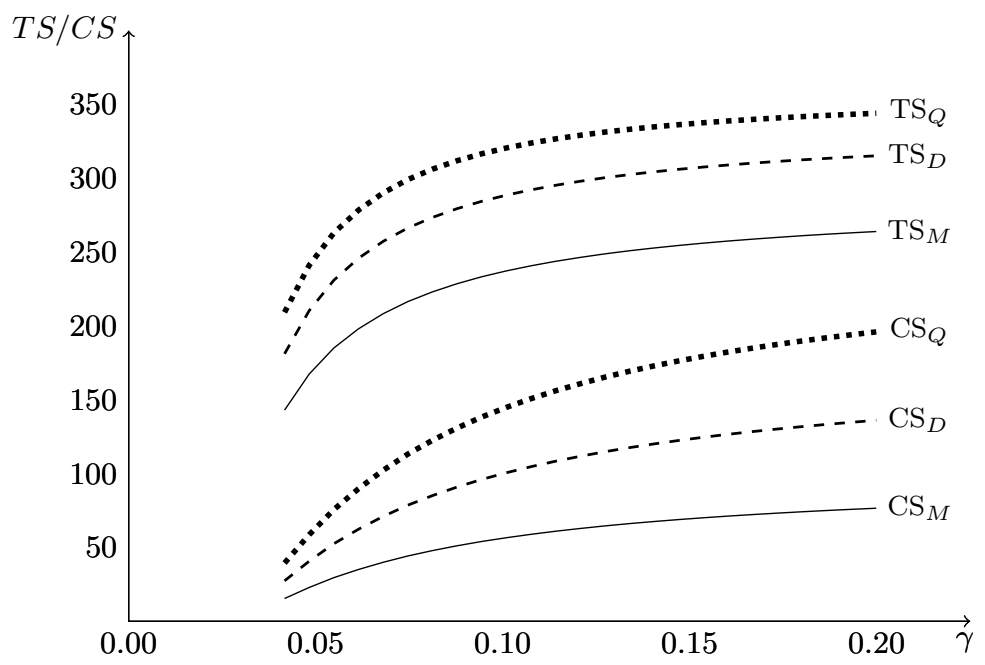

Figure 3.1: Total and consumers surplus as a function of $\gamma$ for the three levels of competition

\subsection{Results}

In this section we present our main results. We first focus on the wage-effort relation and how it develops in each treatment. Next, we report on market outcomes: we describe how markets perform in terms of both quantities produced and sold, and generated welfare. In both cases we give special emphasis to treatment differences, in order to investigate the impact of different degrees of output market competition on gift-exchange and market performance.

\subsubsection{Gift-exchange}

Figure 3.2 shows the evolution of the average wage (left panel) and average effort (right panel) over time, in the three treatments. In all treatments, both wage offers and effort levels are substantially above zero. Wages in Monopoly and Duopoly are relatively high as compared to wages in Quadropoly, and this gap, only due to the higher market competition, does not lessen over time. Similarly, effort levels are lower in the Quadropoly treatment and quite similar in the Monopoly and Duopoly treatments, where they almost overlap from period 15 on. We observe a drop in wages and effort in the last period of all treatments, with the only exception of the Quadropoly, where both wages and effort seem to rather level off.

Figure 3.3 depicts the distribution of wages and effort levels, aggregated over all rounds, for each treatment, and shows heterogeneity. When looking at the wage offers (Figure 3.3 - left panels), their distribution seems to be rather differ- 


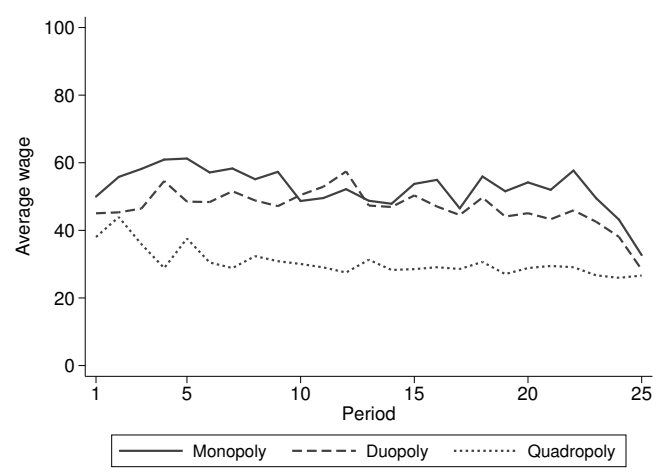

(a) Average wage

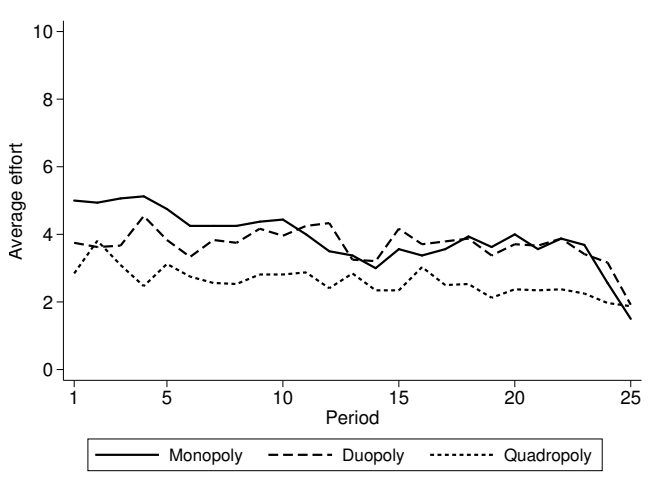

(b) Average effort

Figure 3.2: Average wage and effort over time

ent across treatments. Zero is the most frequent wage offer in the Quadropoly treatment (about $20 \%$ of the observations - panel 3.3e). The mode is around 50 in the Duopoly treatment (15\% - panel 3.3c), whereas in the Monopoly treatment wage offers seem to be quite spread over the whole domain. KolmogorovSmirnov (KS) tests reject the hypothesis of equality of distributions $(p<0.001$ in all pairwise comparisons). As for the effort levels (Figure 3.3 - right panels), the mode is 0 in each treatment $(23 \%, 16 \%$ and $27 \%$ of the observations in Monopoly, Duopoly and Quadropoly, respectively). Moreover, the mass at the highest effort levels 8-10 seem to be decreasing in the level of competition. Effort distributions are statistically different across treatments, according to KS tests (M vs. D: $p=0.035 ; \mathrm{M}$ vs. $\mathrm{Q}$ and $\mathrm{D}$ vs. Q: $p<0.001$ ).

Table 3.1 reports wages and effort in each treatment, averaged over markets.

Table 3.1: Average wages and effort in each treatment

\begin{tabular}{lccc}
\hline \hline & Monopoly & Duopoly & Quadropoly \\
\cline { 2 - 4 } Average wage & 52.5 & 46.8 & 30.5 \\
Average effort & 3.9 & 3.7 & 2.6 \\
\hline
\end{tabular}

All averages are taken over markets.

The average wage offer in the Monopoly treatment is $52.5,12 \%$ higher than the average wage in Duopoly (46.8) and almost $72 \%$ higher than the average wage in Quadropoly (30.5). A joint comparison of average wages across treatments reveals that there are statistically significant differences (Kruskal-Wallis $(\mathrm{KW}): p<0.001)$. Dunn's tests (DT) reveal that the average wage is significantly different in all pair-wise comparisons $(p<0.001) .{ }^{13}$

\footnotetext{
${ }^{13}$ Throughout the chapter, Dunn's tests are two-tailed and use market averages as units of observations. $p$-values are adjusted using the Benjamini-Hochberg method.
} 
Monopoly

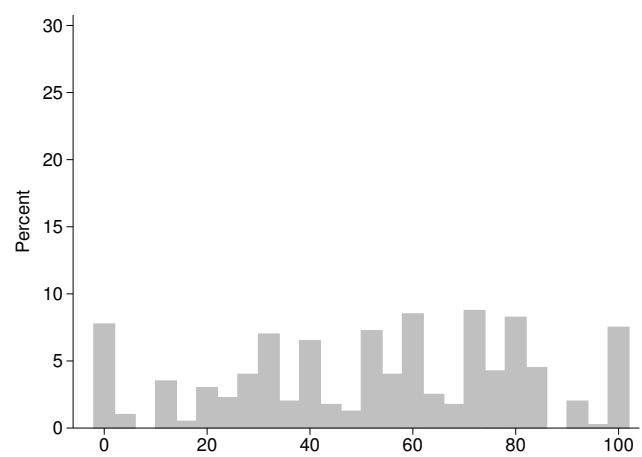

(a) Wage

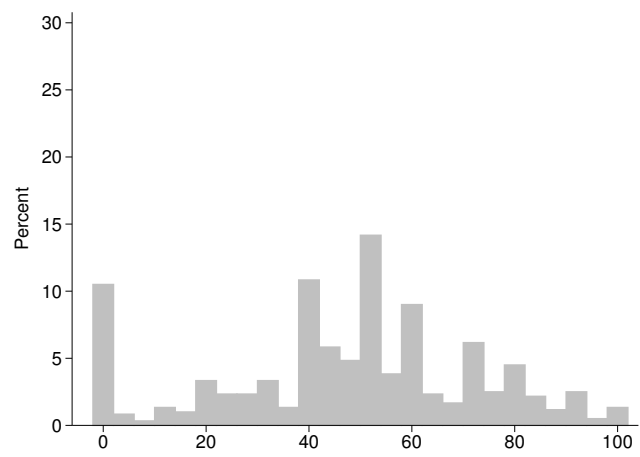

(c) Wage

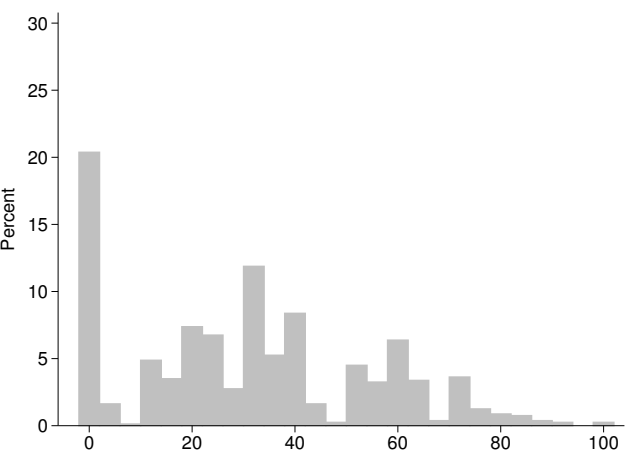

(e) Wage

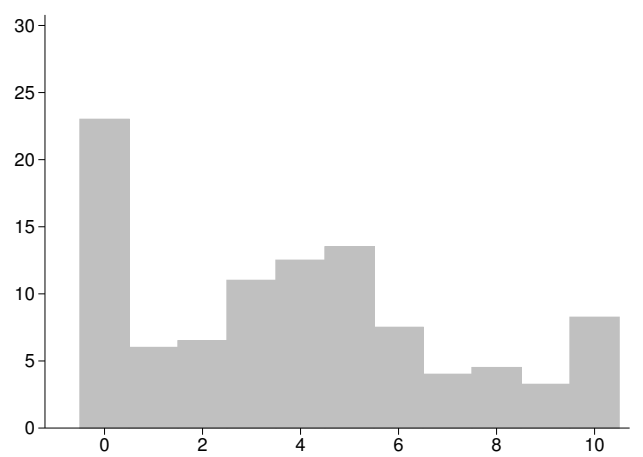

(b) Effort

Duopoly

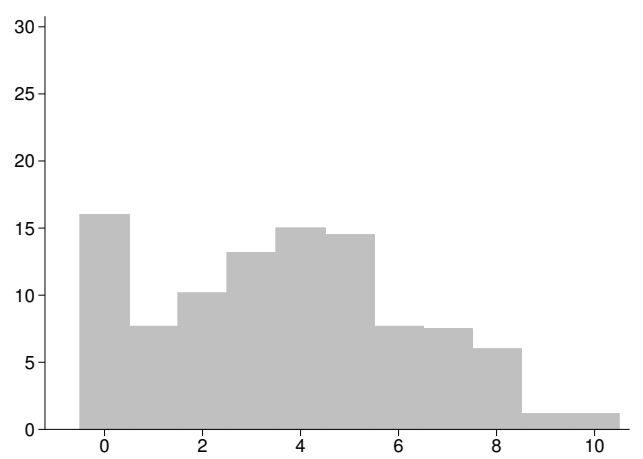

(d) Effort

Quadropoly

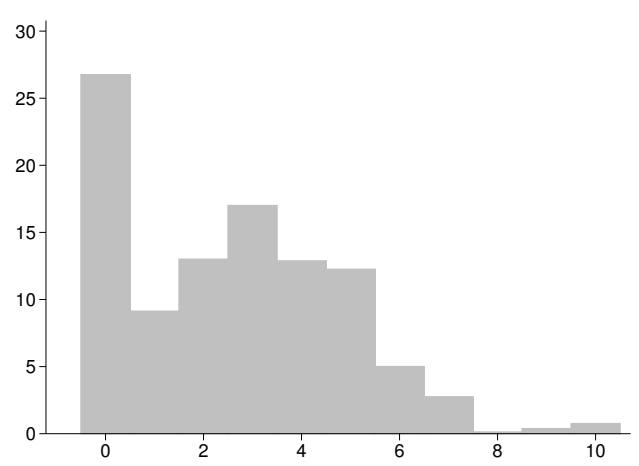

(f) Effort

Figure 3.3: Wage and effort distributions 
Consistent with this pattern of wages are effort levels. Effort in Monopoly is, on average, slightly higher than in Duopoly (3.9 vs. 3.7) and $50 \%$ higher than in Quadropoly (3.9 vs. 2.6). Kruskal-Wallis test results show that differences in average effort are statistically significant across treatments when jointly considered $(p<0.001)$. In pair-wise comparisons, differences in effort between Monopoly and Duopoly are not statistically significant (DT: $p=0.2998$ ), while the hypothesis of equality of effort can be rejected in the comparisons Monopoly against Quadropoly (DT: $p<0.001)$ and Duopoly against Quadropoly (DT: $p<0.001)$.

Result 1 (Wages and effort). On average, wage offers and effort levels are both substantially above zero. Wages and effort respond to the intensity of output market competition and tend to decrease with increasing competition.

Next, we study in detail whether a wage-effort relation emerges in the analyzed markets and, if so, whether it is affected by the level of output market competition. Figure 3.4 depicts, for each treatment, the average effort for different wage intervals. A positive (reciprocal) wage-effort relation is clearly discernible: in each treatment, higher wage offers trigger higher effort levels, on average. Moreover, for each wage interval, average effort does not appear to be substantially different across treatments.

To formally test for gift-exchange, we perform a panel linear regression analysis with effort as the dependent variable, and wage, treatment dummies and interaction terms of the latter as main explanatory variables. Results are shown in Table 3.2, column (1). We also control for period effects, and whether the wage and effort in the previous period, together with receiving a lower wage than in the previous period, have any influence on current effort levels (Table 3.2, columns (2), (3) and (4)). In all regressions, the Monopoly treatment serves as reference group and we use bootstrapped clustered robust standard errors, where resampling clusters are defined over markets. ${ }^{14}$

In specification (1), intercepts increase with market competition; however, treatment dummies ('Duopoly' and 'Quadropoly') are not significant, indicating that the intercepts in Duopoly and Quadropoly are not statistically different from the intercept in Monopoly. Moreover, the Wald test shows that the treatment dummies 'Duopoly' and 'Quadropoly' are not statistically different from each other $(p=0.5307)$. Taken together, these results suggest that the effort

\footnotetext{
${ }^{14}$ The same regressions were performed with clustered instead of bootstrapped standard errors. We did not find any difference besides the negative time trend becoming somewhat more significant.
} 


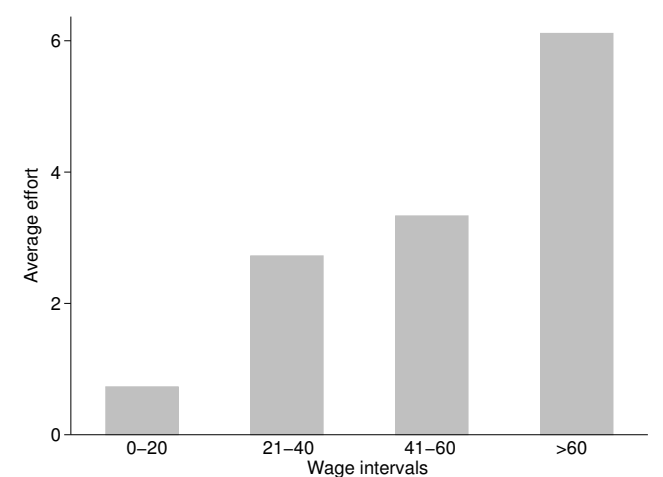

(a) Monopoly

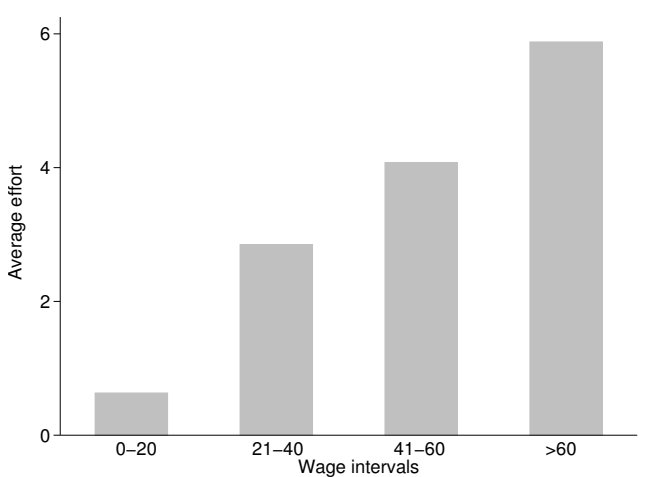

(b) Duopoly

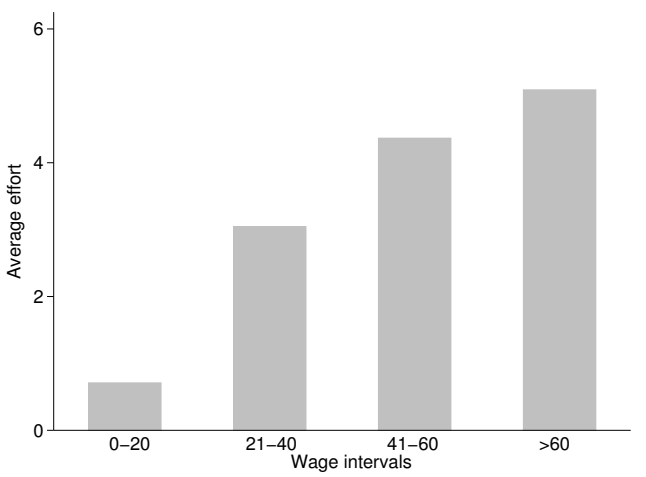

(c) Quadropoly

Figure 3.4: Average effort for different wage intervals

level chosen when the offered wage is zero is quite similar across treatments.

In the Monopoly treatment, the coefficient for wage is positive and highly statistically significant (at the $0.1 \%$ level). As the reciprocity hypothesis maintains, workers exert higher effort the higher the wage they are paid. Interaction terms of wage and treatment dummies are introduced to capture any differences in the wage-effort relation across treatments. This relation seems to be the steepest in Monopoly. However, the differences are modest and none of the interaction terms is significant: this indicates that the wage-effort relation in the two competitive settings and in Monopoly are not different from each other. Since no differences are found between the wage coefficients of Duopoly and Quadropoly (Wald test, $p=0.6764$ ), this allows us to conclude that the wage-effort relationship is rather constant across treatments. We examined the statistical significance of the wage-effort relationship also separately for each treatment. Results show that, for each level of output market competition, wage positively and significantly correlates with effort (see Table 3.5 in Ap- 
Table 3.2: Wage-effort relation across output market conditions

\begin{tabular}{|c|c|c|c|c|}
\hline Effort in period $t$ & (1) & $(2)$ & $(3)$ & $(4)$ \\
\hline Constant & $\begin{array}{r}-0.407 \\
(0.423)\end{array}$ & $\begin{array}{c}0.453 \\
(0.566)\end{array}$ & $\begin{array}{c}0.367 \\
(0.411)\end{array}$ & $\begin{array}{c}0.571 \\
(0.431)\end{array}$ \\
\hline Duopoly & $\begin{array}{c}0.586 \\
(0.524)\end{array}$ & $\begin{array}{r}-0.280 \\
(0.688)\end{array}$ & $\begin{array}{r}-0.099 \\
(0.510)\end{array}$ & $\begin{array}{r}-0.020 \\
(0.516)\end{array}$ \\
\hline Quadropoly & $\begin{array}{c}0.805 \\
(0.454)\end{array}$ & $\begin{array}{c}0.123 \\
(0.635)\end{array}$ & $\begin{array}{c}0.190 \\
(0.435)\end{array}$ & $\begin{array}{c}0.130 \\
(0.464)\end{array}$ \\
\hline Wage $_{t}$ & $\begin{array}{l}0.082^{\text {*** }} \\
(0.006)\end{array}$ & $\begin{array}{l}0.079^{* * *} \\
(0.007)\end{array}$ & $\begin{array}{l}0.075^{* * *} \\
(0.008)\end{array}$ & $\begin{array}{c}0.067^{* * *} \\
(0.009)\end{array}$ \\
\hline Duopoly $\times$ Wage $_{t}$ & $\begin{array}{c}-0.007 \\
(0.007)\end{array}$ & $\begin{array}{c}-0.004 \\
(0.008)\end{array}$ & $\begin{array}{c}0.002 \\
(0.011)\end{array}$ & $\begin{array}{c}-0.005 \\
(0.011)\end{array}$ \\
\hline Quadropoly $\times$ Wage $_{t}$ & $\begin{array}{r}-0.010 \\
(0.007)\end{array}$ & $\begin{array}{r}-0.007 \\
(0.008)\end{array}$ & $\begin{array}{c}0.011 \\
(0.013)\end{array}$ & $\begin{array}{c}0.011 \\
(0.014)\end{array}$ \\
\hline Period $t$ & & $\begin{array}{c}-0.053^{* *} \\
(0.019)\end{array}$ & $\begin{array}{r}-0.017 \\
(0.009)\end{array}$ & $\begin{array}{r}-0.018^{*} \\
(0.009)\end{array}$ \\
\hline Duopoly $\times$ Period $t$ & & $\begin{array}{c}0.054^{*} \\
(0.023)\end{array}$ & $\begin{array}{c}0.016 \\
(0.013)\end{array}$ & $\begin{array}{c}0.014 \\
(0.012)\end{array}$ \\
\hline Quadropoly $\times$ Period $t$ & & $\begin{array}{c}0.041 \\
(0.022)\end{array}$ & $\begin{array}{c}0.002 \\
(0.011)\end{array}$ & $\begin{array}{c}0.001 \\
(0.011)\end{array}$ \\
\hline Effort $_{t-1}$ & & & $\begin{array}{l}0.628^{\text {*** }} \\
(0.076)\end{array}$ & $\begin{array}{l}0.615^{\text {*** }} \\
(0.071)\end{array}$ \\
\hline 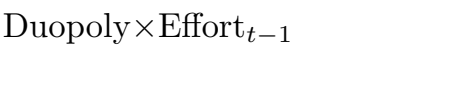 & & & $\begin{array}{c}-0.043 \\
(0.130)\end{array}$ & $\begin{array}{c}-0.019 \\
(0.121)\end{array}$ \\
\hline Quadropoly $\times$ Effort $_{t-1}$ & & & $\begin{array}{c}-0.181 \\
(0.098)\end{array}$ & $\begin{array}{c}-0.173 \\
(0.092)\end{array}$ \\
\hline Wage $_{t-1}$ & & & $\begin{array}{c}-0.051^{* * *} \\
(0.011)\end{array}$ & $\begin{array}{c}-0.044^{* * *} \\
(0.010)\end{array}$ \\
\hline Duopoly $\times$ Wage $_{t-1}$ & & & $\begin{array}{c}0.001 \\
(0.014)\end{array}$ & $\begin{array}{c}0.010 \\
(0.013)\end{array}$ \\
\hline${\text { Quadropoly } \times \text { Wage }_{t-1}}$ & & & $\begin{array}{c}0.001 \\
(0.016)\end{array}$ & $\begin{array}{c}0.002 \\
(0.016)\end{array}$ \\
\hline Disappointment & & & & $\begin{array}{r}-0.467 \\
(0.320)\end{array}$ \\
\hline Duopoly $\times$ Disappointment & & & & $\begin{array}{r}-0.574 \\
(0.346)\end{array}$ \\
\hline Quadropoly $\times$ Disappointment & & & & $\begin{array}{c}0.032 \\
(0.337)\end{array}$ \\
\hline
\end{tabular}

Number of observations

1800

1728

${ }^{*} p<0.05,{ }^{* *} p<0.01,{ }^{* * *} p<0.001$. Duopoly $=1$ for Duopoly treatment, 0 otherwise. Quadropoly $=1$ for Quadropoly treatment, 0 otherwise. Disappointment $=1$ if 1 if $w_{t}<w_{t-1}, 0$ otherwise. Bootstrapped robust standard errors, clustered over markets, in parentheses. 
pendix 3.B). Moreover, the estimated coefficients for the wage are quite similar across the three treatments. ${ }^{15}$

Specification (2) shows qualitatively similar results. Again, the wage-effort relation in Monopoly does not significantly differ from the wage-effort relation in Duopoly and Quadropoly, and the same holds for the difference between reciprocity in Duopoly and in Quadropoly (Wald test, $p=0.6278$ ). Effort somewhat decreases over time in the Monopoly treatment, but not in Duopoly and Quadropoly (see also Figure 3.2b). Time effects are indeed smaller in bigger markets, with this difference being significant only between Monopoly and Duopoly (the Wald test for the comparison Duopoly against Quadropoly yields $p=0.4484)$.

The effort exerted in the previous period positively affects effort in the current period (specification (3)), with this effect diminishing as output market competition increases, even though not significantly so (Wald test, D vs. Q, $p=0.2853)$. The opposite is found relative to the wage received in the previous period, which negatively correlates with the effort exerted in the current period. ${ }^{16}$ This might be interpreted as reflecting a sort of disappointment effect for receiving in $t$ a lower wage than in $t-1$. To find support for this interpretation, in specification (4) we ran the same regression as in (3) but used as an additional control variable the dummy 'Disappointment', which assumes value 1 if $w_{t}<w_{t-1}$ and 0 otherwise. We find a negative coefficient, indicating indeed that a decrease in wages from one period to the next lowers the effort in $t$. This effect is not significant when comparing the Monopoly with the Duopoly and Quadropoly treatment. However, it is stronger in Duopoly than in Quadropoly (Wald test, $p=0.0035) .{ }^{17}$

Result 2 (Gift-exchange). A positive wage-effort relationship exists in all experimental markets. This relationship is largely unaffected by competition, showing that gift-exchange firm-worker relations are not mitigated by higher output market competition.

\footnotetext{
${ }^{15}$ Both the complete model with treatment dummies and the separate models for each treatment were assessed also using Tobit to take into account the censoring of effort levels. Results are reported in Tables 3.6 and 3.7 in Appendix 3.B. Differences between OLS and Tobit estimates are negligible, and not robust across different model specifications.

${ }^{16}$ The effect of lagged wage is negative in all treatments, with no significant differences across them. The Wald test for the Duopoly against Quadropoly comparison yields $p=0.9949$.

${ }^{17}$ This lack of significance may be due to the lagged wage variable capturing part of the disappointment effect. When running the same regression without $w_{t-1}$, the coefficient for 'Disappointment' is negative (-1.498) and highly significant, at the $0.01 \%$ level. This effect is negative but not significantly different in Duopoly and Quadropoly, and still stronger in Duopoly than in Quadropoly (Wald test, $p=0.0301$ ).
} 


\subsubsection{Markets performance}

Table 3.3 presents the total quantities produced and sold, averaged over all periods and markets, in each treatment. The average generated waste (quantities that firms produce but do not sell) is also reported.

Table 3.3: Average quantities produced and sold

\begin{tabular}{lccc}
\hline \hline & Monopoly & Duopoly & Quadropoly \\
\cline { 2 - 4 } Average quantities produced & 158.1 & 227.5 & 288.0 \\
Average quantities sold & 137.6 & 203.2 & 256.5 \\
Average waste (\%) & 10.2 & 7.81 & 8.33 \\
\hline
\end{tabular}

All averages are taken over markets. Since each market represents one independent observation, averages are calculated over samples of 16 observations for Monopoly, 12 observations for Duopoly and 8 for Quadropoly.

The aggregate quantity produced increases with the number of firms in the market, and so does the aggregate quantity sold. Treatment differences are all statistically significant, in terms of both quantity produced and sold. Firstly, treatments differ with respect to firms' stock size when jointly compared (KW: $p=0.0001$ ) as well as in all pairwise comparisons (DT: $p<0.001$ in all cases). Similarly, the number of units put on the market is statistically different across treatments in all comparisons (KW: $p=0.0001$; DT: $p<0.001$ ). The Monopoly is the market that generates the largest gap between quantity produced and quantity sold (almost $13 \%$ of the output is not brought to market). The difference is statistically significant for the Monopoly-Duopoly comparison (DT: $p=0.0017$ ), and for the Duopoly-Quadropoly comparison (DT: $p=0.0009$ ).

Table 3.4 reports market averages of firms' profits and workers' earnings, and of the total welfare (which also takes into account consumers' surplus) generated in each treatment. ${ }^{18}$ Firm profits are highest in Monopoly and lowest in Quadropoly, with these differences being all statistically significant (KW: $p=0.0001 ; \mathrm{DT}: p<0.001$ in all pair-wise comparisons). The opposite holds for worker earnings, with statistically significant differences across treatments (KW: $p=0.0001$; DT: $p<0.001$ in all pair-wise comparisons). When considering firms and workers together, Duopoly generates the highest average joint surplus. The hypothesis of equality of joint surplus across treatments can be rejected according to KW test results $(p=0.0001)$. Differences are significant in all pair-wise comparisons (DT: $p<0.001)$.

\footnotetext{
${ }^{18}$ The lump-sum profits and earnings of 70 are not taken into account in order not to inflate surpluses in the competitive markets.
} 
Table 3.4: Efficiency measures (averages)

\begin{tabular}{lccc}
\hline \hline & Monopoly & Duopoly & Quadropoly \\
\cline { 2 - 4 } Firms surplus & 115.7 & 93.7 & 48.6 \\
Workers surplus & 44.7 & 78.9 & 101.4 \\
Total surplus & 213.9 & 282.1 & 321.1 \\
\hline
\end{tabular}

In each market, firms' and workers' surpluses and, consequently, the total surplus are calculated by subtracting the lump sum of 70 from both firms and workers' payoff functions.

Overall, when taking into account also the consumers' surplus, Quadropoly turns out to generate the highest total surplus (321.1 on average), while Monopoly produces the least (213.9). All treatment differences are statistically significant (KW: $p=0.0001$; DT: $p<0.001$ in all pair-wise comparisons). Experimental results relative to markets performance, hence, go along with the predictions of the reciprocity hypothesis. The reciprocity model explains market behavior with more accuracy than the model with standard preferences does.

Result 3 (Market performance). Efficiency differences do emerge in the studied markets, and are all statistically significant. More competition increases efficiency.

Even though it goes beyond the purpose of this chapter, some considerations about the occurrence of collusive behavior in our markets can be made. In a similar Cournot setting, Huck et al. [2004] study how the number of firms affects the competitiveness of the market. They find that the larger the market size, the more competitive the market is. In particular, by comparing the observed aggregate output with theoretical predictions, they classify each market according to its degree of competitiveness (collusive, Nash or rivalistic) and show that duopolies are mostly collusive, while markets with four or more firms never are.

We compare the actual aggregate output sold with theoretical predictions we derived by using the OLS estimates of the wage coefficients $(\widehat{\gamma})$. More specifically, in order to determine the Nash equilibrium for each market, we substitute the values $\widehat{\gamma}_{M}, \widehat{\gamma}_{D}$ and $\widehat{\gamma}_{Q}$ that we obtained with the OLS panel estimations (Table 3.2, column (4)) in $Q_{n}=\bar{Q}_{n}=\frac{n\left(400 \gamma_{n}-10\right)}{(n+1) \gamma_{n}}$ (recall Equation 3.11) for $n=1,2$, and 4 respectively. One alternative solution is the symmetric collusive output, which we derive for Duopoly and Quadropoly by applying $\widehat{\gamma}_{D}$ and $\widehat{\gamma}_{Q}$ to the Monopoly quantity ( $n=1$ in the expression above). Finally, the competitive outcome is derived by equating the price to the marginal cost (which equals 
$\left.\frac{1}{20 \gamma_{n}}\right)$. Results are shown in Table 3.5. We find that, on average, collusion does not occur. Wilcoxon two-sided tests show a statistically significant difference between the observed quantity sold and the collusive output ( $p=0.0022$ in the Duopoly treatment, and $p=0.0117$ in the Quadropoly). All markets sell, on average, more than the Cournot equilibrium would predict, but this difference is significant only in the Duopoly and Quadropoly treatments (Wilcoxon test, $p=0.1627$ in Monopoly, $p=0.0029$ in Duopoly, and $p=0.0117$ in Quadropoly). Not unexpectedly, Duopoly and Quadropoly markets are not perfectly competitive (Wilcoxon test significant at $1 \%$ in Monopoly and Duopoly, and at $5 \%$ in Quadropoly).

Table 3.5: Average aggregate quantities

\begin{tabular}{lcccc}
\hline \hline & $Q^{\text {Sold }}$ & $Q^{\text {Nash }}$ & $Q^{\text {Collusive }}$ & $Q^{\text {Competitive }}$ \\
\cline { 2 - 5 } Monopoly & 137.6 & 125.4 & - & 399.3 \\
Duopoly & 203.2 & 159.1 & 119.4 & 399.2 \\
Quadropoly & 256.5 & 217.4 & 135.9 & 399.4 \\
\hline
\end{tabular}

\subsection{Discussion and conclusions}

Dozens of gift-exchange lab experiments show that employers are willing to offer wages higher than the prevailing minimum to elicit higher effort, and consistently succeed in doing so. Interestingly, these results are all obtained in settings where firms are assumed to operate in isolation as monopolists on the output market.

In this chapter, we experimentally investigate the interaction between labor market gift-exchange and output market competition by varying the competitiveness of the output market in three treatments. In all treatments, a firmworker pair produces output of a homogeneous good that the firm can sell on the output market, and the firm-worker relation is characterized by incomplete contracts with the possibility of wage-effort gift-exchange. In the Monopoly treatment, the firm does not face any competitors when selling her products. In the Duopoly treatment two firms compete in a Cournot fashion on the output market, and in the Quadropoly treatment four firms compete on the output market.

Our experimental data show that wages and effort are substantially above zero and both decrease with the number of firms in the market, supporting the predictions of a gift-exchange model. More importantly, the wage-effort rela- 
tion is not affected by the increased competitiveness of the output market and seems to be rather independent of it, proving that gift-exchange is a persistent behavioral pattern.

Similarly, results relative to market outcomes show that the reduced form gift-exchange model fits better our empirical data. We find that larger markets are characterized, on average, by a greater amount of quantity produced and sold, which translates into lower prices. Therefore, higher output market competition results in enhanced efficiency. Moreover, as the output market becomes more competitive, firms' share of the total surplus considerably decreases, while workers and especially consumers are able to capture most of the generated surplus.

Bowles [1998]'s idea that other-regarding inclinations mitigate in more competitive market environments does not seem to be supported by our data. Conversely, we find that the extent to which fairness considerations, in the form of gift-exchange, play a role in the principal-agent relationship is robust to varying market conditions.

One explanation for the relatively stable degree of reciprocity across treatments might relate to the relationship between social identity, group membership and the enforcement of altruistic norms. Akerlof and Kranton [2005] argue that the more the worker identifies him/herself with the firm, the more s/he acts in the interest of the firm and chooses the high-effort over the low-effort action. Several experiments have subsequently shown that group identity can have a significant influence on prosocial behavior, in the form of more altruism or cooperation towards members of the same group (Bernhard et al. [2006], Goette et al. [2006], Charness et al. [2007], Chen and Li [2009]). This recalls the dichotomy between intergroup competition and in-group cooperation, widely studied in economics and social psychology. Indeed, intergroup competition has been shown to increase performance/productivity (Nalbantian and Schotter [1997], Gneezy and Rustichini [2004], Tauer and Harackiewicz [2004]), to lead to a better group coordination (Bornstein et al. [2002]), and to foster within-group cooperation (Tan and Bolle [2007], Puurtinen and Mappes [2009], Markussen et al. [2014b]). Our design might favor, through repeated interactions, the emergence of a sort of group identity. By repeatedly playing with the same firm, it is possible that a social tie forms within the firm-worker pair: workers might develop a sense of belonging that leads them to fairly reciprocate wage offers independently of the market structure the firm operates in.

Another interpretation might be that workers understand the constraints 
that different market conditions impose upon firms (namely, that higher competition drives profits down). A low wage in a relatively highly competitive market is therefore not perceived as unfair; quite the opposite. The same (low) wage paid in a monopoly and in a quadropoly might be regarded as more unjust in the less competitive context, as it might reveal a firm's intention to exploit her employees. In the quadropoly, then, we should expect that workers would not punish low wage offers with lower effort. However, in our setting participants do not observe wage offers in any of the other markets. A comparison between wages in different competitive markets that could help to delineate a common view of what is a fair or unfair wage is therefore not possible.

This study contributes to the dispute on the potential erosion of fairness considerations that competitive markets would cause. In our experimental markets, even though competition drives profits and wages down, there is no adverse effect of increased competition on the intensity of reciprocity manifested towards firms. Workers do not extremely lower their effort provision in response to what might be seen as a low wage, when considering the whole wage range firms can choose from. Our findings show that the importance of fairness concerns as a driving force in determining both principals' and agents' behaviors is not deteriorated by the introduction of competition among firms. 


\section{Appendix}

\section{A Saliency of payoffs}

Here we present the results of the one session (with 24 subjects, yielding 6 independent observations) of the Monopoly treatment we ran without lump sum but with a higher exchange rate of ECU into Euros (100 ECU = 1 euro) and a show-up fee of 5 euro. We compare the results of this session with the original Monopoly treatment to assess whether the reduced saliency caused by the lump sum earnings of 70 has unduly affected outcomes. In this appendix, we label the original Monopoly treatment with lump sum "Low Saliency", while we use the label "High Saliency" to refer to the Monopoly treatment with show-up fee. Results show that the level of saliency does not significantly affect behavior.

\section{A.1 Gift-exchange}

Figure 3.1 shows the evolution of average wage (panel 3.1a) and effort (panel 3.1b) over time in the two treatments. Both wage offers and effort levels are substantially above zero. Wages in High Saliency are a bit below those in Low Saliency, and more volatile. Effort levels are also lower in High Saliency in the first half of the experiment, but they appear to be quite similar from period 15 onwards. A fall in wages and effort is observed in the last period of both treatments, with this drop being sharper in High Saliency.

Table 3.1 reports wages and the effort levels in each treatment, averaged over markets. The average wage in Low Saliency is higher than that in High Saliency. However, this difference is not significant (Mann-Whitney (MW): $p=0.6583$ ). Similarly, differences in effort between the two Monopoly treatments are not statistically significant (MW: $p=0.6583$ ).

Figure 3.2 depicts the average effort for different wage intervals in the two treatments. A positive wage-effort relation is observed: in each treatment, higher wage offers elicit higher effort levels, on average. In High Saliency, average effort is lower in the wage interval $0-20$ and higher in the wage interval 21-40 than in the same wage intervals of Low Saliency. 


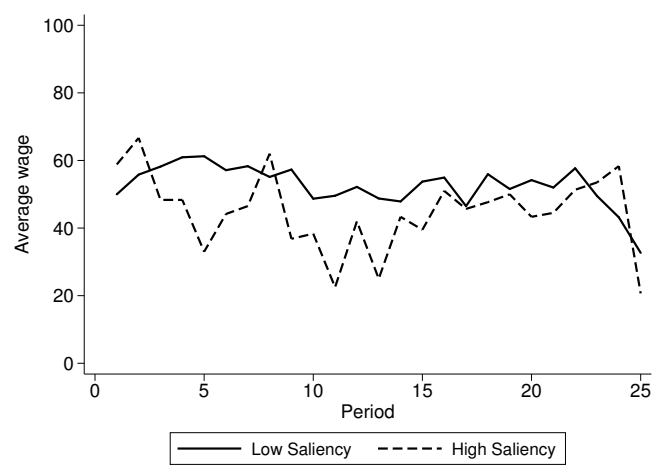

(a) Average wage

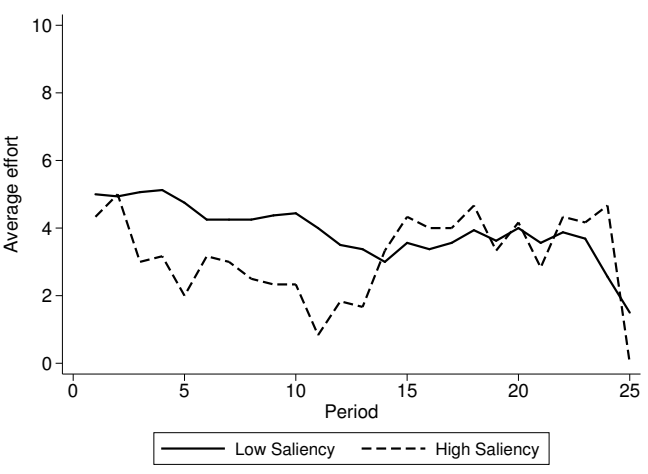

(b) Average effort

Figure 3.1: Average wage and effort over time

Table 3.1: Average wages and effort

\begin{tabular}{lcc}
\hline \hline & High Saliency & Low Saliency \\
\cline { 2 - 3 } Average wage & 44.9 & 52.5 \\
Average effort & 3.2 & 3.9 \\
\hline
\end{tabular}

All averages are taken over markets. Since each market represents one independent observation, averages are calculated over samples of 6 observations for High Saliency and 16 observations for Low Saliency.

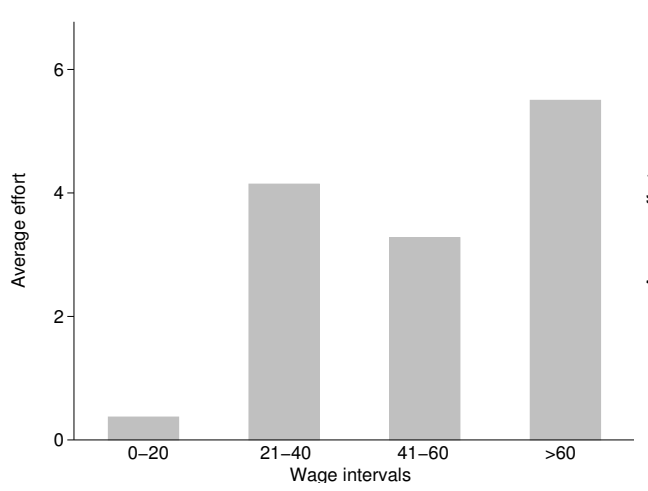

(a) High Saliency

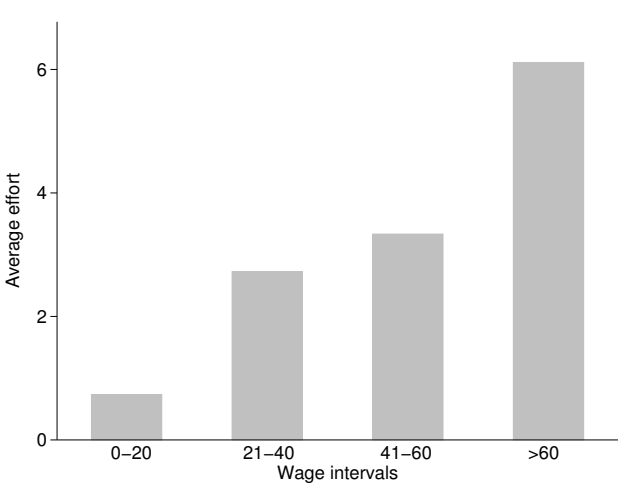

(b) Low Saliency

Figure 3.2: Average effort for different wage intervals

To formally test for reciprocity, we use a panel OLS regression model, with bootstrapped cluster-robust standard errors, where resampling clusters are defined over markets. Main results are shown in Table 3.2, column (1). We also control for period effects and whether the wage and effort chosen in the previous period have any influence on current effort levels (Table 3.2, columns (2) and $(3))$. 
Table 3.2: Wage-effort relation

\begin{tabular}{|c|c|c|c|}
\hline Effort in period $t$ & (1) & $(2)$ & (3) \\
\hline Constant & $\begin{array}{c}-0.409 \\
(0.441)\end{array}$ & $\begin{array}{c}0.451 \\
(0.522)\end{array}$ & $\begin{array}{c}0.367 \\
(0.409)\end{array}$ \\
\hline High Saliency & $\begin{array}{c}0.746 \\
(0.631)\end{array}$ & $\begin{array}{c}-0.477 \\
(0.737)\end{array}$ & $\begin{array}{c}-0.462 \\
(1.107)\end{array}$ \\
\hline Wage $_{t}$ & $\begin{array}{l}0.082^{* * *} \\
(0.007)\end{array}$ & $\begin{array}{l}0.079^{* * *} \\
(0.007)\end{array}$ & $\begin{array}{l}0.075^{* * *} \\
(0.010)\end{array}$ \\
\hline High Saliency $\times$ Wage $_{t}$ & $\begin{array}{r}-0.019^{*} \\
(0.009)\end{array}$ & $\begin{array}{c}-0.015 \\
(0.009)\end{array}$ & $\begin{array}{c}-0.019 \\
(0.011)\end{array}$ \\
\hline Period $t$ & & $\begin{array}{c}-0.053^{* *} \\
(0.020)\end{array}$ & $\begin{array}{c}-0.017 \\
(0.009)\end{array}$ \\
\hline High Saliency $\times$ Period $t$ & & $\begin{array}{c}0.079^{*} \\
(0.039)\end{array}$ & $\begin{array}{c}0.034 \\
(0.027)\end{array}$ \\
\hline Effort $_{t-1}$ & & & $\begin{array}{l}0.628^{* * *} \\
(0.077)\end{array}$ \\
\hline High Saliency $\times$ Effort $_{t-1}$ & & & $\begin{array}{c}-0.317^{* *} \\
(0.108)\end{array}$ \\
\hline Wage $_{t-1}$ & & & $\begin{array}{c}-0.051^{* * *} \\
(0.011)\end{array}$ \\
\hline High Saliency $\times$ Wage $_{t-1}$ & & & $\begin{array}{r}0.040^{*} \\
(0.020)\end{array}$ \\
\hline Number of observations & 550 & 550 & 528 \\
\hline
\end{tabular}

In specification (1), the treatment dummy (High Saliency) is not significant, indicating that the effort level chosen when the offered wage is zero is quite similar across treatments. The coefficient for wage is positive and highly statistically significant (at $0.1 \%$ level). As the reciprocity hypothesis maintains, the higher the wage offered the higher the effort level chosen. The wage-effort relation seems to be steeper in Low Saliency: a $1 \%$ increase in wages increases effort by 0.082 points in Low Saliency, and by 0.063 in High Saliency. This difference is significant at $5 \%$ level.

Specifications (2) and (3) add control variables. The wage-effort relation is again steeper in Low Saliency, with no significant difference with High Saliency. Effort somewhat decreases over time in Low Saliency, while it exhibits a slightly positive trend in High Saliency. The wage received in the previous period is statistically significant and correlates negatively with the effort exerted in the current period. This effect is present, significantly smaller, in High Saliency 
as well. Effort in the previous period, instead, positively affects effort in the current period, with this effect being significantly smaller in High Saliency.

\section{A.2 Markets performance}

Table 3.3 presents total quantities produced and sold, averaged over all periods and markets, in both Monopoly treatments. The average generated waste (quantities that firms produce but do not sell) is also reported. Both the average quantity produced and sold are not significantly different across the two treatments (MW: $p=0.6583$ and $p=0.8828$, respectively).

Table 3.3: Average quantities produced and sold

\begin{tabular}{lcc}
\hline \hline & High Saliency & Low Saliency \\
\cline { 2 - 3 } Average quantities produced & 143.2 & 158.1 \\
Average quantities sold & 135.5 & 137.6 \\
Average waste (\%) & 3.2 & 10.2 \\
\hline
\end{tabular}

All averages are taken over markets. Since each market represents one independent observation, averages are calculated over samples of 6 observations for High Saliency and 16 observations for Low Saliency.

Table 3.4 reports market averages of firms' profits and workers' earnings, and of the total welfare (which also takes into account consumers' surplus) generated in each treatment.

Table 3.4: Efficiency measures (averages)

\begin{tabular}{lcc}
\hline \hline & High Saliency & Low Saliency \\
\cline { 2 - 3 } Firms surplus & 122.4 & 115.7 \\
Workers surplus & 38.5 & 44.7 \\
Total surplus & 212.8 & 213.9 \\
\hline
\end{tabular}

In each market of Low Saliency, firms', workers' and total surpluses are calculated by subtracting the lump sum of 70 from both firms' and workers' payoff functions.

Firm profits are highest in High Saliency. The opposite holds true for workers' earnings. However, the hypotheses of equality of average firms' and workers' surpluses can not be rejected (MW: $p=0.5553$ and $p=0.7124$, respectively). Overall, average total surpluses are not significantly different (MW: $p=0.9412$ ). 


\section{B Additional regressions}

Table 3.5: Wage-effort relation in each treatment - OLS panel regressions

\begin{tabular}{|c|c|c|c|c|c|c|c|c|c|c|c|c|}
\hline \multirow{2}{*}{ Effort in period $t$} & \multicolumn{4}{|c|}{ Monopoly } & \multicolumn{4}{|c|}{ Duopoly } & \multicolumn{4}{|c|}{ Quadropoly } \\
\hline & $(1)$ & $(2)$ & (3) & (4) & (1) & $(2)$ & (3) & (4) & (1) & (2) & (3) & (4) \\
\hline Constant & $\begin{array}{c}-0.415 \\
(0.454)\end{array}$ & $\begin{array}{c}0.447 \\
(0.613)\end{array}$ & $\begin{array}{c}0.367 \\
(0.426)\end{array}$ & $\begin{array}{c}0.571 \\
(0.475)\end{array}$ & $\begin{array}{c}0.180 \\
(0.271)\end{array}$ & $\begin{array}{c}0.175 \\
(0.367)\end{array}$ & $\begin{array}{c}0.268 \\
(0.206)\end{array}$ & $\begin{array}{c}0.552^{* *} \\
(0.202)\end{array}$ & $\begin{array}{l}0.400^{* * *} \\
(0.118)\end{array}$ & $\begin{array}{l}0.578^{* * *} \\
(0.214)\end{array}$ & $\begin{array}{c}0.557^{* * *} \\
(0.112)\end{array}$ & $\begin{array}{l}0.701^{\text {*** }} \\
(0.138)\end{array}$ \\
\hline Wage $_{t}$ & $\begin{array}{l}0.082^{* * *} \\
(0.006)\end{array}$ & $\begin{array}{l}0.079^{* * *} \\
(0.007)\end{array}$ & $\begin{array}{l}0.075^{* * *} \\
(0.008)\end{array}$ & $\begin{array}{l}0.067^{* * *} \\
(0.009)\end{array}$ & $\begin{array}{l}0.075^{* * *} \\
(0.004)\end{array}$ & $\begin{array}{l}0.075^{* * *} \\
(0.004)\end{array}$ & $\begin{array}{l}0.077^{* * *} \\
(0.007)\end{array}$ & $\begin{array}{l}0.062^{* * *} \\
(0.006)\end{array}$ & $\begin{array}{l}0.072^{* * *} \\
(0.004)\end{array}$ & $\begin{array}{l}0.072^{* * *} \\
(0.005)\end{array}$ & $\begin{array}{l}0.086^{* * *} \\
(0.011)\end{array}$ & $\begin{array}{c}0.078^{* * *} \\
(0.012)\end{array}$ \\
\hline Period $t$ & & $\begin{array}{c}-0.053^{* *} \\
(0.019)\end{array}$ & $\begin{array}{c}-0.017 \\
(0.009)\end{array}$ & $\begin{array}{r}-0.018^{*} \\
(0.009)\end{array}$ & & $\begin{array}{c}0.000 \\
(0.012)\end{array}$ & $\begin{array}{c}-0.001 \\
(0.007)\end{array}$ & $\begin{array}{c}-0.004 \\
(0.006)\end{array}$ & & $\begin{array}{c}-0.013 \\
(0.011)\end{array}$ & $\begin{array}{c}-0.015^{* *} \\
(0.006)\end{array}$ & $\begin{array}{c}-0.017^{* *} \\
(0.006)\end{array}$ \\
\hline Wage $_{t-1}$ & & & $\begin{array}{c}-0.051^{* * *} \\
(0.010)\end{array}$ & $\begin{array}{c}-0.044^{* * *} \\
(0.009)\end{array}$ & & & $\begin{array}{c}-0.050^{* * *} \\
(0.008)\end{array}$ & $\begin{array}{c}-0.034^{* * *} \\
(0.007)\end{array}$ & & & $\begin{array}{c}-0.050^{* * *} \\
(0.011)\end{array}$ & $\begin{array}{c}-0.042^{* * *} \\
(0.012)\end{array}$ \\
\hline Effort $_{t-1}$ & & & $\begin{array}{l}0.628^{* * *} \\
(0.086)\end{array}$ & $\begin{array}{l}0.615^{* * *} \\
(0.083)\end{array}$ & & & $\begin{array}{l}0.585^{* * *} \\
(0.104)\end{array}$ & $\begin{array}{l}0.597^{* * *} \\
(0.097)\end{array}$ & & & $\begin{array}{l}0.447^{* * *} \\
(0.062)\end{array}$ & $\begin{array}{l}0.443^{* * *} \\
(0.059)\end{array}$ \\
\hline Disappointment & & & & $\begin{array}{c}-0.467 \\
(0.306)\end{array}$ & & & & $\begin{array}{c}-1.040^{\text {*** }} \\
(0.144)\end{array}$ & & & & $\begin{array}{c}-0.435^{* *} \\
(0.134)\end{array}$ \\
\hline $\mathrm{Nr}$ of obs. & 40 & 00 & 38 & 34 & & & 57 & 76 & & & & 8 \\
\hline
\end{tabular}

*** $p<0.001$; ${ }^{* *} p<0.01 ;{ }^{*} p<0.05$. Disappointment $=1$ if 1 if $w_{t}<w_{t-1}, 0$ otherwise. Bootstrapped robust standard errors, clustered over markets, in parentheses. 
Table 3.6: Wage-effort relation in each treatment - Tobit panel regressions

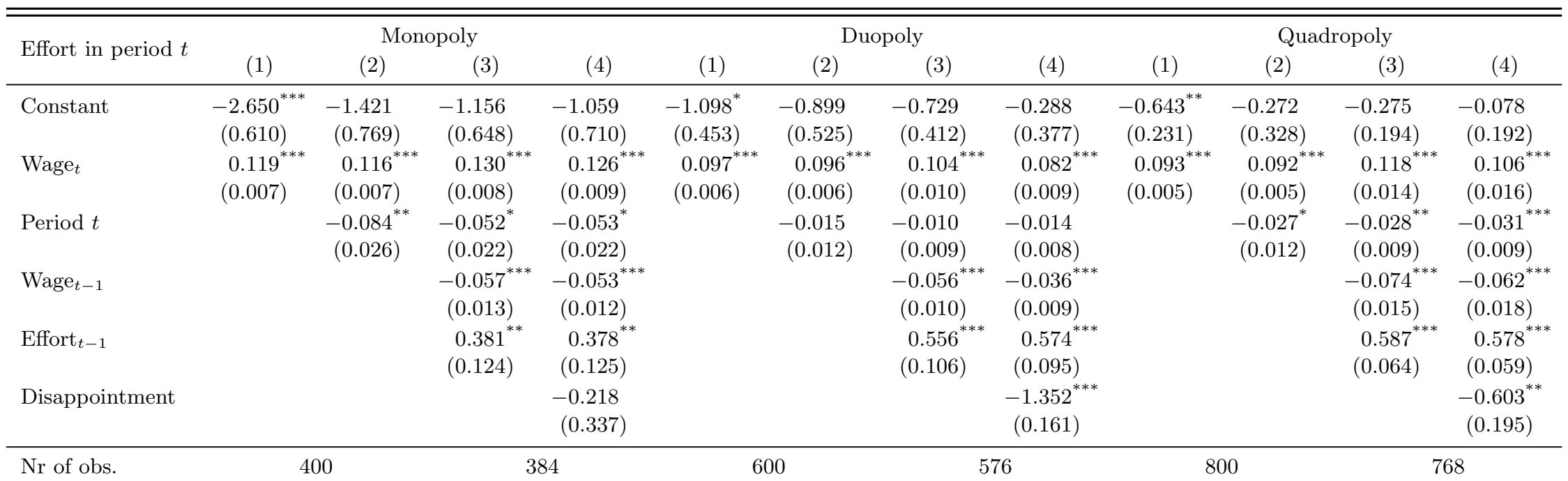

*** $p<0.001 ;{ }^{* *} p<0.01 ;{ }^{*} p<0.05$. Disappointment $=1$ if 1 if $w_{t}<w_{t-1}, 0$ otherwise. Bootstrapped robust standard errors, clustered over markets, in parentheses. 
Table 3.7: Wage-effort relation across output market conditions - Tobit

\begin{tabular}{|c|c|c|c|c|}
\hline Effort in period $t$ & (1) & $(2)$ & (3) & (4) \\
\hline Constant & $\begin{array}{c}-2.372^{* * *} \\
(0.637)\end{array}$ & $\begin{array}{l}-1.246 \\
(0.749)\end{array}$ & $\begin{array}{l}-0.936 \\
(0.636)\end{array}$ & $\begin{array}{l}-0.816 \\
(0.676)\end{array}$ \\
\hline Duopoly & $\begin{array}{c}1.198 \\
(0.863)\end{array}$ & $\begin{array}{c}0.294 \\
(0.964)\end{array}$ & $\begin{array}{c}0.136 \\
(0.835)\end{array}$ & $\begin{array}{c}0.453 \\
(0.860)\end{array}$ \\
\hline Quadropoly & $\begin{array}{l}1.664^{*} \\
(0.727)\end{array}$ & $\begin{array}{c}0.930 \\
(0.866)\end{array}$ & $\begin{array}{c}0.586 \\
(0.672)\end{array}$ & $\begin{array}{c}0.685 \\
(0.718)\end{array}$ \\
\hline Wage $_{t}$ & $\begin{array}{c}0.114^{* * *} \\
(0.007)\end{array}$ & $\begin{array}{c}0.112^{* * *} \\
(0.009)\end{array}$ & $\begin{array}{c}0.124^{* * *} \\
(0.011)\end{array}$ & $\begin{array}{c}0.119^{* * * *} \\
(0.010)\end{array}$ \\
\hline 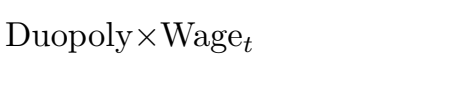 & $\begin{array}{l}-0.016 \\
(0.009)\end{array}$ & $\begin{array}{l}-0.015 \\
(0.011)\end{array}$ & $\begin{array}{l}-0.019 \\
(0.014)\end{array}$ & $\begin{array}{c}-0.035^{* *} \\
(0.013)\end{array}$ \\
\hline 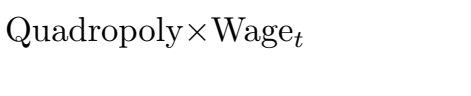 & $\begin{array}{c}-0.020^{*} \\
(0.010)\end{array}$ & $\begin{array}{l}-0.019 \\
(0.011)\end{array}$ & $\begin{array}{l}-0.004 \\
(0.019)\end{array}$ & $\begin{array}{l}-0.011 \\
(0.020)\end{array}$ \\
\hline Period $t$ & & $\begin{array}{c}-0.081^{* *} \\
(0.026)\end{array}$ & $\begin{array}{c}-0.048^{* *} \\
(0.019)\end{array}$ & $\begin{array}{c}-0.049^{* *} \\
(0.019)\end{array}$ \\
\hline Duopoly $\times$ Period $t$ & & $\begin{array}{l}0.065^{*} \\
(0.029)\end{array}$ & $\begin{array}{c}0.037 \\
(0.019)\end{array}$ & $\begin{array}{c}0.033 \\
(0.020)\end{array}$ \\
\hline Quadropoly $\times$ Period $t$ & & $\begin{array}{c}0.033 \\
(0.029)\end{array}$ & $\begin{array}{c}0.019 \\
(0.021)\end{array}$ & $\begin{array}{c}0.017 \\
(0.022)\end{array}$ \\
\hline Effort $_{t-1}$ & & & $\begin{array}{c}0.414^{* *} \\
(0.134)\end{array}$ & $\begin{array}{l}0.406^{* *} \\
(0.134)\end{array}$ \\
\hline Wage $_{t-1}$ & & & $\begin{array}{c}-0.058^{* * *} \\
(0.016)\end{array}$ & $\begin{array}{c}-0.054^{* * *} \\
(0.013)\end{array}$ \\
\hline Duopoly $\times$ Effort $_{t-1}$ & & & $\begin{array}{c}0.124 \\
(0.182)\end{array}$ & $\begin{array}{c}0.153 \\
(0.175)\end{array}$ \\
\hline Quadropoly $\times$ Effort $_{t-1}$ & & & $\begin{array}{c}0.171 \\
(0.155)\end{array}$ & $\begin{array}{c}0.170 \\
(0.153)\end{array}$ \\
\hline Duopoly $\times$ Wage $_{t-1}$ & & & $\begin{array}{c}0.003 \\
(0.020)\end{array}$ & $\begin{array}{c}0.019 \\
(0.017)\end{array}$ \\
\hline${\text { Quadropoly } \times \text { Wage }_{t-1}}$ & & & $\begin{array}{l}-0.016 \\
(0.024)\end{array}$ & $\begin{array}{l}-0.008 \\
(0.024)\end{array}$ \\
\hline Disappointment & & & & $\begin{array}{l}-0.218 \\
(0.357)\end{array}$ \\
\hline Duopoly $\times$ Disappointment & & & & $\begin{array}{c}-1.146^{* *} \\
(0.391\end{array}$ \\
\hline Quadropoly $\times$ Disappointment & & & & $\begin{array}{l}-0.419 \\
(0.385)\end{array}$ \\
\hline Number of observations & \multicolumn{2}{|c|}{1800} & \multicolumn{2}{|c|}{1728} \\
\hline
\end{tabular}

${ }^{*} p<0.05,{ }^{* *} p<0.01,{ }^{* * *} p<0.001$. Duopoly $=1$ for Duopoly treatment, 0 otherwise. Quadropoly $=1$ for Quadropoly treatment, 0 otherwise. Disappointment $=1$ if 1 if $w_{t}<w_{t-1}, 0$ otherwise. Bootstrapped robust standard errors, clustered over markets, in parentheses. 


\section{C Instructions for the Duopoly treatment}

You are going to participate in an economic experiment. You can earn money with the decisions you make. Please, read these instructions carefully. If you have any questions please raise your hand and one of us will come to you to answer your question in private.

In this experiment the amount of your earnings depends not only on your own decisions but also on the decisions of other participants you will interact with. During the experiment, your earnings will be calculated in experimental currency units (ECU). The experiment will consist of several periods. At the end of the session, your ECU earnings in each period will be summed up and converted into euros at the following rate:

$$
150 \mathrm{ECU}=1 \text { euro }
$$

During the experiment it might happen that you incur losses. That is, it might happen that you earn negative ECU amounts in a period. Eventual losses in a round will be subtracted from your accumulated earnings. In case of the highly unlikely event of an overall loss your earnings will be zero. Importantly, in each period, you can avoid losses through your own decisions.

At the end of the session you will be paid out your earnings in cash in private. All your earnings will be treated confidentially.

Important: During the experiment you are not allowed to communicate with other participants by any means other than those indicated in these instructions. If you are found violating these rules, you will both forfeit any earnings from this experiment, and may be excluded from future experiments as well.

\section{Roles, pairing and matching}

At the beginning of the session, each participant will be randomly assigned to one of two possible roles. Half of you will be firms and half will be workers. Your computer screen will inform you about your role.

Each firm and each worker will be randomly paired to form a firm-worker pair. You will never be informed about the identity of the participant you have been paired with. Likewise, your paired participant will never get to know your identity.

Finally, each firm will be randomly matched with one other firm in order to form a market where the two firms can sell the same product.

The experiment consists of 25 periods. Your role, the pair and the market you are in will stay fixed throughout the entire experiment. 


\section{Decision-making in each period}

Each period consists of three stages:

Stage 1: Each firm makes a wage offer to the worker s/he is paired with.

Stage 2: Workers have to accept the offered wage and, after having observed the offered wage, decide on their effort level. The chosen effort level determines the product stock size of the firm.

Stage 3: Firms get to know their stock size and choose how many units they want to sell on the market.

The details of the procedures in the three stages are explained below.

\section{Procedures}

1. At the beginning of each period, the firm offers a wage to the worker $\mathrm{s} /$ he has been paired with. Wage offers must be integer numbers and lie between 0 and 100 (inclusive). The wage has to be accepted by the worker.

2. Wage offers will only be transmitted to the worker a firm is paired with. No other worker and no other firm will get to know the wage offer a firm makes.

3. After $\mathrm{s} /$ he is informed about the wage offer, the worker decides on his/her effort level by choosing an integer number between (and including) 0 and 10 , where 0 is the lowest and 10 the highest effort level. Chosen effort levels will only be transmitted to the firm the worker is paired with. The effort level the worker chooses determines the firm's product stock size. The firm's stock size is larger the larger the worker's effort level and is calculated according to the following formula:

$$
\text { stock size }=40+20 \mathrm{x} \text { effort level }
$$

The following table shows for each effort level the corresponding stock size:

\begin{tabular}{lccccccccccc}
\hline Effort level & 0 & 1 & 2 & 3 & 4 & 5 & 6 & 7 & 8 & 9 & 10 \\
Stock size & 40 & 60 & 80 & 100 & 120 & 140 & 160 & 180 & 200 & 220 & 240 \\
\hline
\end{tabular}

Effort levels and associated stock sizes

4. After the worker has chosen his/her effort level, the firm will be informed about his/her stock size. Further, the firm will also be informed about the stock size of the other firm in the market.

5. Then, each firm independently and simultaneously decides on the individual 
number of units s/he sells on the market, by choosing an integer number between 0 and his/her stock size (inclusive). NB: A firm does not have to sell the full stock size.

6. The market price each firm receives for his/her units put on the market is determined by the total number of units put on the market. The total number of units on the market is the sum of units put on the market by each individual firm. The higher the total number of units put on the market, the lower the price that the firms receive for each unit sold. Specifically, the market price is given by the formula:

market price $=400$ - total number of units on the market

Negative prices are not allowed. Therefore, the price is fixed at zero when in total more than 400 units are put on the market.

\section{How the earnings in a period are calculated}

\section{A worker's earnings in a period}

1. In each period a worker has to provide effort. Providing effort is costly to the worker, and this cost is higher the higher the chosen effort level. Zero effort has no cost but each additional unit of effort costs 2 ECU. The schedule below shows how costs vary with chosen effort levels:

\begin{tabular}{llllllcccccc}
\hline Effort level & 0 & 1 & 2 & 3 & 4 & 5 & 6 & 7 & 8 & 9 & 10 \\
Cost of effort & 0 & 2 & 4 & 6 & 8 & 10 & 12 & 14 & 16 & 18 & 20 \\
\hline
\end{tabular}

Effort levels and associated costs

2. In each period, a worker will receive the offered wage. To calculate his/her earnings a worker has to subtract the cost of the effort from the wage. His/her earnings in a period are therefore given by:

Worker's earnings $=$ wage offered - cost of effort $+\mathbf{7 0}$

During the experiment, a worker can use an on-screen calculator to calculate his/her earnings.

\section{A firm's earnings in a period}

1. In each period, the revenue of a firm equals the individual number of units sold on the market multiplied by the market price and divided by 200 . That is,

\section{Firm's revenue $=($ market price $\mathrm{x}$ individual number of units sold) $/ 200$}

During the experiment, a firm can use an on-screen calculator to calculate his/her revenues. 
2. The following table presents the resulting market price and revenue for three hypothetical numbers of units sold by the own firm and the other firm, respectively:

\begin{tabular}{|c|c|c|c|c|}
\hline & \multicolumn{3}{|c|}{ Number of units sold by the other firm } \\
\hline & & 58 & 174 & 273 \\
\hline \multirow{3}{*}{ 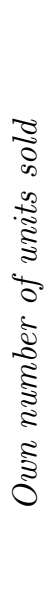 } & 63 & $\begin{array}{l}400-(63+58)=279 \\
\text { market price }=279 \\
\text { own revenue }=87.9\end{array}$ & $\begin{array}{l}400-(63+174)=163 \\
\text { market price }=163 \\
\text { own revenue }=51.3\end{array}$ & $\begin{array}{c}400-(63+273)=64 \\
\text { market price }=64 \\
\text { own revenue }=20.2\end{array}$ \\
\hline & 132 & $\begin{array}{c}400-(132+58)=210 \\
\text { market price }=210 \\
\text { own revenue }=138.6\end{array}$ & $\begin{array}{c}400-(132+174)=94 \\
\text { market price }=94 \\
\text { own revenue }=62\end{array}$ & $\begin{aligned} 400-(132+273) & =-5 \\
\text { market price } & =0 \\
\text { own revenue } & =0\end{aligned}$ \\
\hline & 221 & $\begin{array}{c}400-(221+58)=121 \\
\text { market price }=121 \\
\text { own revenue }=133.7\end{array}$ & $\begin{array}{c}400-(221+174)=5 \\
\text { market price }=5 \\
\text { own revenue }=5.5\end{array}$ & $\begin{aligned} 400-(221+273) & =-94 \\
\text { market price } & =0 \\
\text { own revenue } & =0\end{aligned}$ \\
\hline
\end{tabular}

3. In each period, the earnings of a firm are the difference between his/her revenue and the wage s/he offers to his/her worker. Therefore, a firm's earnings in a period are given by:

\section{Firm's earnings $=$ firm's revenue - offered wage $+70=$ (market price $\mathrm{x}$ individual number of units sold)/200 - offered wage +70}

\section{Information at the end of a period}

At the end of each period, each firm and each worker receive information on the decisions that are relevant for their earnings.

Each firm is informed about:

- the wage $\mathrm{s} /$ he offered to the worker $\mathrm{s} /$ he is paired with

- the effort level that is chosen by his/her worker

- the own stock size and that of the other firm in the same market

- the own number of units sold on the market and that of the other firm on the same market

- the market price in the own market

- own earnings

- earnings of the worker $\mathrm{s} /$ he is paired with 
Each worker is informed about:

- the wage offered by the firm s/he is paired with

- the effort level s/he has chosen

- the cost associated with the chosen effort level

- stock size of the firm s/he is paired with

- number of units sold on the market by the firm the worker is paired with

- the market price in the own market

- own earnings

- earnings of the firm $\mathrm{s} /$ he is paired with 


\title{
Chapter 4
}

\section{Gift-exchange under market liberalization}

\begin{abstract}
In this chapter, we study experimentally whether market liberalization, which increases competition among firms on the product market, affects reciprocal relationships within firms in a labor market characterized by incomplete contracts. We implement a within-subject design where firms and workers experience output markets with different degrees of competitiveness, while competition in the labor market remains unchanged. In one treatment, firms interact first in a monopoly and then in a duopoly. In the second treatment, the monopoly condition is followed by a quadropoly. We also study the removal of competition in two additional treatments, where market conditions change from duopoly to monopoly, and from quadropoly to monopoly. In concordance with a reduced form labor market gift exchange model, we find that wages and effort respond to the intensity of output market competition, and increase with market liberalization, while decrease when competition is removed. Therefore, more competitive markets generate higher total surplus. All markets are characterized by a positive relationship between wage and effort. This relationship is not affected by market liberalization, and is rather constant across market institutions when competition increases. Similarly, reciprocity between firm and worker does not significantly change when the market conditions change from duopoly or quadropoly to monopoly.
\end{abstract}

Based on a joint work with Ronald Peeters and Arno Riedl. 


\subsection{Introduction}

Recent decades have witnessed a gradual reduction in barriers to trade, as most developed countries have gone through deregulation programs in state-owned sectors or regulated monopolies (e.g., airlines, telecommunications, railroads). The main argument in favor of liberalization policies is based on the conventional wisdom that increased competition leads to lower prices and higher (consumer) welfare. This prediction finds support in the experimental literature in industrial organization. Several studies deal with how the number of firms in the market affects collusion and market prices. An established result is that collusion is frequently observed in duopolies, but almost never in markets with four or more firms. ${ }^{1}$ This leads to the conclusion that, by driving prices down, (more) competition improves efficiency. Although the theoretical literature has long recognized the importance of embedding incomplete contracts into industrial organization, ${ }^{2}$ prior oligopoly experiments implicitly assume that contracts are complete, and ignore potential interaction effects between product and labor markets.

In the context of labor markets, on the other hand, numerous experiments have taken contractual incompleteness into account and have shown that reciprocity between employers and employees is enough to enhance efficiency in such markets. ${ }^{3}$ However, by treating firms as monopolists in the product market, this literature too fails to account for spillover effects between product and labor markets. Casoria et al. [2018] fill this gap by analyzing the impact of output market competition on reciprocity norms in the context of a contractually incomplete labor relationship. The authors compare three treatments that only vary in the competitiveness of output market (monopoly, duopoly, and quadropoly), and find that the employer-employee reciprocal relationship is not affected by the increased competition of the output market, proving giftexchange as a quite stable behavioral pattern. The between-subject design used in Casoria et al. [2018], however, does not capture the effects on behavior of the change in the market structure implied by an increased competition.

In this chapter, we present the results of a laboratory experiment performed to study whether and how market liberalization leading to an increased compe-

\footnotetext{
1 See, among others, Dufwenberg and Gneezy [2000], Huck et al. [2004], Abbink and Brandts [2005], Brandts and Guillen [2007], Abbink and Brandts [2008], Fonseca and Normann [2012]; for recent surveys see Potters and Suetens [2013], Brandts and Potters [2018].

${ }^{2}$ See Grossman and Hart [1986] and subsequent literature.

${ }^{3}$ See Fehr et al. [1993, 1997, 1998b,a] and following literature; for recent surveys on giftexchange experiments, see Fehr et al. [2009], Charness and Kuhn [2011], Casoria and Riedl [2013].
} 
tition among firms affects reciprocal relationships within firms in a labor market characterized by incomplete contracts. We study firms and workers' behavior when output market conditions change from a setting where competition is absent to a setting characterized by the presence of competition, with all the other aspects of the economic environment being held constant. In particular, we implement two main treatments where product markets with different degrees of competitiveness follow one another, while competition in the labor market remains unchanged. In both treatments, pairs of subjects with roles of firms and workers are matched for a number of periods, forming a market. In one treatment, firms go from being monopolists on the product market to having to compete in a Cournot fashion with one other firm (duopoly). In the second treatment, we increase the size of the output market so that firms interact first under monopoly conditions and then compete on the output market with three other firms (quadropoly). We use duopoly and quadropoly markets to compare the fierceness of competition, since in a similar Cournot setting Huck et al. [2004] show that while duopolies manage to collude, markets with four firms never do. In both treatments, by design the increase in competition generates an increase in the market demand. This reflects the fact that market liberalization gives firms the opportunity to enter new markets and, therefore, to face a larger base of consumers. In two additional treatments, we check whether the order in which market environments follow one another has any impact on (product and labor) market outcomes. In these treatments, market conditions change from duopoly to monopoly, and from quadropoly to monopoly.

From a firm's perspective, the increase in competition induced by the market liberalization has two opposing effects. On the one hand, it implies a higher market demand, which requires higher production levels and, consequently, higher effort of the firm's workers to maximize its profits. Therefore, firms may want to increase wages to elicit the effort levels necessary to adjust to the new market conditions. On the other hand, higher competition means lower prices and profits; it also introduces some degree of interdependence with the other firms in the market, which in turn leads to more strategic uncertainty. These factors might push wages downward in more competitive markets.

From a worker's perspective, behavior can be sensitive to both wage offers and the market procedures that lead to them. The idea that the same outcome can be judged differently depending on the procedure behind it is central in Kahneman et al. [1986], who provide survey evidence that there are situations in which market mechanisms are deemed unfair (like price increases not justified 
by increased costs, or wage cuts by a firm that is not losing money). In a more recent paper, Bartling et al. [2015a] analyze experimentally the impact of a competitive price mechanism on counterproductive behavior in response to an unequal distribution of outcomes. The authors find that, compared to a situation where prices are determined unilaterally, the competitive procedure triggers less inefficient reactions and increases - the authors argue - justification for economic inequality. ${ }^{4}$ In our setting, workers experience different market conditions and their responses to the wage received might be influenced by how fair or unfair the wage offer is perceived to be in such different market environments. This, in turn, potentially determines whether or not markets operate efficiently. A more general argument is put forward by Bowles [1998]. In the author's view, as preferences are endogenous to market institutions, different institutions can shape or induce different social norms and behaviors. In particular, he argues that competitive markets make interactions anonymous, impersonal and ephemeral, which hinders the evolution and diffusion of nice traits like trust or generosity. It can be the case, therefore, that in our markets competition crowds out reciprocity while favoring the emergence of more selfregarding behaviors. ${ }^{5}$

We derive theoretical predictions from a reduced form gift-exchange model with Cournot output market competition that assumes a linear relation between wages and effort. Given a constant and sufficient level of reciprocity across market structures, the model predicts that wages and effort increase with the level of product market competition. Market liberalization, moreover, induces higher production levels and fosters efficiency (in terms of total generated surplus).

Our main experimental result is that in our markets increasing competition appears as a positive force. Wages and effort respond to the competitiveness of the product market and significantly increase with market liberalization. As a consequence, the more competitive a market is, the higher is the total generated surplus. Most importantly, the positive relationship between wage offers and effort levels, present in all markets, is robust to the different market institutions we implement. We interpret these findings as evidence that reciprocal firm-worker relationships can survive in competitive, liberalized output markets. Interestingly, we find significant sequencing effects only when few firms are involved. Wages and effort in monopolies that follow a duopoly drop, on

\footnotetext{
${ }^{4}$ Previous experimental work suggests that individuals care about procedural fairness. See, for instance, Bolton et al. [2005], Krawczyk and Le Lec [2010], Brock et al. [2013], Linde and Sonnemans [2015].

${ }^{5}$ See Cai and Liu [2009], Brandts et al. [2009], Falk and Szech [2013a], Brandts and Riedl [2016], among others, for further discussions on the detrimental effects of market interaction.
} 
average, more than they increase in duopolies that follow a monopoly. In the quadropoly case, instead, the decrease in wages and effort when going from quadropoly to monopoly is similar in value and significance to their increase when going from monopoly to quadropoly. We do not find consistent and significant differences in reciprocity across markets when competition is removed.

\subsection{Experimental design}

We study the effects of market liberalization and increasing competitiveness on gift-exchange labor relationships and market outcomes in four treatments. In both treatments each firm can hire exactly one worker and the firm-worker relationship is characterized by incomplete contracts with the possibility of wageeffort gift-exchange. A firm-worker pair produces output of a homogeneous good that can be sold on the output market by the firm.

Three different market structures are implemented. In the Monopoly, the firm does not face any competitors when selling her products. In the Duopoly, two firms compete in a Cournot fashion on the output market, and in the Quadropoly four firms compete on the output market.

Each treatment is characterized by two different market institutions, with each of them representing a phase. In the first treatment (Monopoly to Duopoly, MtoD), subjects interact in a monopolistic market in the first phase, whereas in the second phase interactions take place in a Duopoly. In the second treatment (Monopoly to Quadropoly, MtoQ), a Monopoly in the first phase is followed by a Quadropoly in the second.

We check for order effects in two additional treatments, which differ from the previous ones exclusively with respect to the sequencing of market environments. Therefore, in the third treatment (Duopoly to Monopoly, DtoM), firms operate first in a duopolistic market and then in a Monopoly. Lastly, in the fourth treatment (Quadropoly to Monopoly, QtoM), market conditions change from Quadropoly to Monopoly.

\subsubsection{Procedures and parameters}

In each treatment, subjects are randomly assigned the roles of either firm or worker and matched to form firm-worker pairs, and interact for several rounds. ${ }^{6}$ A partner matching mechanism is used to proxy an ongoing labor relationship, which is a distinctive feature of many economic firms. Roles and pairs are thus

\footnotetext{
${ }^{6}$ In the experiment we only have firms and workers, and no active consumers are involved. For welfare comparisons we will also provide predictions and results on consumer surplus.
} 
not changed during the experiment. In the Monopoly phase, each firm operates alone in her output market. In the Duopoly and Quadropoly phases, firms are randomly matched in order to compete on the output market. Once formed, markets are kept fixed during the experiment; that is, each firm faces the same competitor(s) throughout. This is common in standard oligopoly experiments (see Huck et al. [2004]). Each phase within each treatment lasts 15 periods, so that the whole experimental session runs over 30 periods.

Participants know, at the beginning of the experiment, that there will be two phases, and that the first phase consists of 15 periods. However, they do not know what the second phase looks like until right before the phase starts: participants receive new instructions at the beginning of each new phase. ${ }^{7}$ They are also asked to correctly answer a series of comprehension questions at the beginning of each phase. Each phase of the experiment starts only after all subjects correctly answered all comprehension questions. Subjects have access to an on-screen calculator during the experiment.

Each period of a phase consists of three stages. In the first stage, each firm makes a wage offer to the worker with whom she has been paired. Wages have to be integers in the set $w_{i} \in\{0,1, \ldots, 100\}$.

In the second stage, workers are informed on their own wage $w_{i}$ and choose their effort level $e_{i} \in\{0,1, \ldots, 10\}$. Higher effort implies higher cost for the worker, according to the linear cost function

$$
c\left(e_{i}\right)=2 e_{i}
$$

The effort level chosen by the worker determines the quantity produced by the firm, with higher effort levels producing more output. The production function is given by

$$
\bar{q}_{i}=80+20 e_{i}
$$

where the constant term makes sure that, even with the lowest possible effort level, firms always produce a positive amount of the homogeneous good so to be able to compete on the output market. ${ }^{8}$

In the third stage, firms choose how many of the produced units they want to bring to the market: $q_{i} \in\left[0, \bar{q}_{i}\right]$. The market price is determined according to the inverse demand function

$$
p(Q)=\max \left\{400-\frac{1}{n} Q, 0\right\},
$$

\footnotetext{
${ }^{7}$ A copy of the instructions for the MtoD treatment can be found in Appendix 4.C.

${ }^{8}$ This feature also reflects the fact that, outside the laboratory, firms would be able to produce a positive amount of units even if workers exert a rather low level of effort.
} 
where $Q=\sum_{i} q_{i}$ is the total quantity brought to the market and, depending on the market structure, $n \in\{1,2,4\}$ is the total number of firms active in the market. Dividing the aggregate quantity produced in the market by the number of active firms ensures that the market demand increases with $n .{ }^{9}$

In each period, a firm's payoff is given by:

$$
\pi_{i}=\frac{p(Q) q_{i}}{200}-w_{i}
$$

Firms revenues are discounted by $\frac{1}{200}$ in order to bring payoffs of firms and workers closer to each other, so to minimize inequity aversion issues that might arise in case of large payoff differences. A worker's payoff depends on the wage $\mathrm{s} /$ he is paid and the cost associated with the effort level chosen:

$$
u_{i}=w_{i}-2 e_{i}+90 .
$$

The lump sum of 90 in the worker's payoff function is introduced to avoid the possibility that behavior is influenced by loss aversion.

In all sessions, the number of firms and workers in the market, the matching mechanism and all market parameters and functions are public knowledge. Actual payoffs, wages paid and effort levels are known only to the involved firm-worker pair. The quantity each firm produces is public knowledge in her market: at the end of the second stage, firms receive information about their own quantity produced and the quantity produced by each competitor in a fixed order. At the end of each period, firms also learn the quantity sold by each firm in their market (in a fixed order) and the market price. This information regime makes sure that the information on market performances available to firms is constant across treatments. A worker is only informed about the market performance of the firm s/he has been paired with.

The computerized experiment was conducted at the BEElab of Maastricht University using z-Tree (Fischbacher [2007]). Students were recruited through ORSEE (Greiner [2015]), and each of them took part in only one treatment. We ran 16 sessions overall, 4 per treatment, with a total of 216 students. Each session took approximately 90 minutes. Participants were paid privately at the end of the experimental session. Earnings were converted into real money at the exchange rate of 200 ECU (Experimental Currency Unit) $=1$ euro. Subjects earned, on average, $€ 19.5$ in the MtoD and DtoM treatment, and $€ 20$ in the MtoQ and QtoM treatment. The experiment ended with a questionnaire,

\footnotetext{
${ }^{9}$ We use a standard symmetric Cournot model with linear demand and cost functions, which is widely used in the experimental industrial organization literature (see Huck et al. [2004]).
} 
where we collected demographics and elicited participants' reciprocity and risk attitudes, in order to later check for heterogeneity across participants in different treatments. ${ }^{10}$

\subsubsection{Predictions and hypotheses}

Under the standard assumptions of rational and narrowly selfish agents, workers will always provide the minimum level of effort irrespective of the wage offered, because effort is costly and unenforceable. Firms anticipate this behavior, and offer the lowest possible wage. Since our game is finitely repeated, the one-shot theoretical predictions extend to the repeated game, and the subgame perfect Nash equilibrium is zero effort, zero wage and no (positive) relationship between wage offers and effort levels. This prediction on wages and effort levels holds for all degrees of competition on the output market.

Given the implemented production function and a predicted effort level of zero, the total equilibrium output increases with market competition. The market price is the same across market structures, and the total surplus increases with competition.

Table 4.1 summarizes the standard theory predictions in terms of market performance. $^{11}$

On the basis of these predictions we formulate the following null hypotheses:

Hypothesis 1 (Standard theory).

(i) Wages and effort levels are equal to zero, both before and after market liberalization.

(ii) There is no (positive) relation between wage offers and effort levels.

(iii) Besides workers' surplus, which equals 0, firms and consumers' surpluses are increasing with the level of competition. Consequently, market liberalization induces higher total surplus.

\footnotetext{
${ }^{10}$ To assess individual reciprocal inclinations, we asked six questions about positive and negative reciprocity. As in Dohmen et al. [2008, 2009], subjects indicated on a 7-step scale (where 1 means "fully applies to me" and 7 "does not apply to me at all") to what extent each of the following statements accurately describes them: 1) If someone does me a favor, I am prepared to return it; 2) If I suffer a serious wrong, I will take revenge as soon as possible, no matter what the costs; 3) If somebody puts me in a difficult position, I will do the same to him/her; 4) I go out of my way to help somebody who has been kind to me before; 5) If somebody offends me, I will offend him/her back; 6) I am ready to undergo personal costs to help somebody who helped me before. To measure risk attitudes we use answers to the question: How do you see yourself: Are you generally a person who is fully prepared to take risks or do you try to avoid taking risks? Please tick a box on the scale, where the value 0 means: "not at all willing to take risks" and the value 10 means: "very willing to take risks".

${ }^{11}$ We subtracted 90 from workers' earnings to make sure workers surplus is not inflated by the lump sum. See Appendix 4.B for the formal derivation of the model predictions.
} 
Table 4.1: Standard theory equilibrium predictions

\begin{tabular}{lccc}
\hline \hline & Monopoly & Duopoly & Quadropoly \\
\cline { 2 - 4 }$q_{i}=\bar{q}_{i}$ & 80 & 80 & 80 \\
$Q=\bar{Q}$ & 80 & 160 & 320 \\
$p(Q)$ & 320 & 320 & 320 \\
Workers surplus & 0 & 0 & 0 \\
Firms surplus & 128 & 256 & 512 \\
Consumer surplus & 16 & 32 & 64 \\
Total surplus & 144 & 288 & 576 \\
\hline
\end{tabular}

${ }^{1}$ Consumer surplus is calculated and provided in the table for completeness. There are no consumers involved in the experiment.

The partial gift exchange version of the efficiency wage hypothesis (Akerlof [1982]) postulates that wage and effort are positively related, and predicts that wage offers above workers' reference wage are reciprocated by above minimum effort levels. Experimental literature on gift-exchange has provided vast evidence in support of this assumption. ${ }^{12}$

We use a reduced form gift-exchange model in order to develop benchmark theoretical predictions, and assume for simplicity that in every firm $i$ a linear relation exists between wage and effort:

$$
e_{i}\left(w_{i}\right)=\gamma_{n} w_{i}
$$

where $\gamma_{n}$ is a reciprocity parameter when $n$ firms compete on the market, with $n \in\{1,2,4\}$. We thus allow reciprocity to be dependent on the output market conditions.

The predictions of the model are formally derived in Appendix 4.B. For convenience, we report here only the equilibrium outcomes. The symmetric Nash equilibrium wage is given by

$$
w_{i}^{*}=\frac{32 n \gamma_{n}-8 \gamma_{n}-n}{2(n+1) \gamma_{n}^{2}}
$$

and is strictly positive if and only if $\gamma_{n}>\frac{n}{32 n-8}$. So, $\gamma_{n}>\frac{1}{24}$ is a sufficient condition for strictly positive wages (and hence effort levels) for all levels of output market competition we analyze. ${ }^{13}$ Results from previous gift-exchange

\footnotetext{
${ }^{12}$ See Fehr et al. [2009], Charness and Kuhn [2011], Casoria and Riedl [2013], and Cooper and Kagel [2016] for surveys on gift-exchange experimental results. The results reported in Casoria et al. [2018] provide support for this model in a similar market setup.

${ }^{13}$ The symmetry assumption guarantees that this is the unique equilibrium wage of the
} 
experiments without output market competition allow us to assume that this condition on $\gamma$ is likely satisfied. ${ }^{14}$

Equation 4.7 implies that the equilibrium wage is increasing in $\gamma_{n}$ up to $\widetilde{\gamma}_{n} \leq$ $\frac{n}{16 n-4}$ and decreases in $\gamma_{n}$ beyond that level. So, $\gamma_{n}>\frac{1}{12}$ is a sufficient condition for equilibrium wages to be decreasing in $\gamma_{n}$ for all levels of competition in the output market.

From the equilibrium wage we obtain the following equilibrium effort levels and production capacities and sales:

$$
e_{i}^{*}=\frac{32 n \gamma_{n}-8 \gamma_{n}-n}{2(n+1) \gamma_{n}} \quad \text { and } \quad q_{i}^{*}=\bar{q}_{i}^{*}=\frac{400 n \gamma_{n}-10 n}{(n+1) \gamma_{n}},
$$

and the following equilibrium market quantities and prices:

$$
Q_{n}^{*}=\bar{Q}_{n}=\frac{400 n^{2} \gamma_{n}-10 n^{2}}{(n+1) \gamma_{n}} \quad \text { and } \quad p_{n}^{*}=\frac{400 \gamma_{n}+10 n}{(n+1) \gamma_{n}} .
$$

It is easily shown that effort levels, individual and aggregate quantities (capacity and sales) are increasing in $\gamma_{n}$, while prices are declining in $\gamma_{n}$.

The resulting surpluses for, respectively, workers, firms and consumers are as follows:

$$
\begin{aligned}
W S_{n} & =\frac{-64 n^{2} \gamma_{n}^{2}+16 n \gamma_{n}^{2}+34 n^{2} \gamma_{n}-8 n \gamma_{n}-n^{2}}{2(n+1) \gamma_{n}^{2}}, \\
F S_{n} & =\frac{n}{(n+1)^{2}} \frac{1600 n \gamma_{n}^{2}+8 n^{2} \gamma_{n}-64 n \gamma_{n}+8 \gamma_{n}+n}{2 \gamma_{n}^{2}} \\
C S_{n} & =\frac{n}{(n+1)^{2}} \frac{1600 n^{2} \gamma_{n}^{2}-80 n^{2} \gamma_{n}+n^{2}}{4 \gamma_{n}^{2}}
\end{aligned}
$$

The total surplus equals:

$$
T S_{n}=\frac{1472 \gamma_{n}^{2} n^{3}+3104 \gamma_{n}^{2} n^{2}+32 \gamma_{n}^{2} n+4 \gamma_{n} n^{3}-76 \gamma_{n} n^{2}-n^{3}}{4(n+1)^{2} \gamma_{n}^{2}} .
$$

The workers' surplus is increasing in $\gamma_{n}$ up to $\widehat{\gamma}_{n}=\frac{n}{17 n-4}$ and is declining afterward. On the contrary, the firms' surplus decreases up to $\widehat{\widehat{\gamma}}_{n}=\frac{n}{4\left(-n^{2}+8 n-1\right)}$, and it increases in $\gamma_{n}$ beyond that level. Consumer surplus and total surplus are unambiguously increasing in $\gamma_{n}$ for all levels of output market competition.

finitely repeated game. Relaxing the symmetry assumption might result in a multiplicity of equilibria.

${ }^{14}$ In the gift-exchange experimental literature, regression results of effort on wage show that values for $\gamma$ generally lie in the range [0.04,0.1] (see Casoria and Riedl [2013] for a review). Moreover, the results reported in Casoria et al. [2018] provide evidence for this condition to be met in a similar market environment. 
Assuming an identical wage-effort relationship across all levels of output market competition (i.e., $\gamma_{n}=\gamma$ for all $n$ ), the comparative statics predictions with respect to the level of competition are unambiguous for wages and effort levels. For all $\gamma$ 's such that wages are strictly positive (i.e. $\gamma>\frac{1}{24}$ ) and for all levels of competition we implemented (i.e., $n=1,2,4$ ), Monopoly always produces lower wages and effort levels than Duopoly and Quadropoly. Individual, and aggregate, quantities increase in $n$, while market prices decline in $n$. Similarly, all aggregate surpluses (firms', workers', consumer and total) are increasing in $n$.

Assuming an identical level of reciprocity over all levels of output market competition, ${ }^{15}$ and for reciprocity levels high enough $\left(\gamma>\frac{1}{24}\right)$, we thus hypothesize the following:

Hypothesis 2 (Reciprocity).

(i) Wages and effort levels are positive.

(ii) In all studied markets, there is a positive relation between wage offers and effort levels (by model assumption).

(iii) Market liberalization increases both wages and effort.

(iv) Market liberalization increases aggregate surpluses (workers', firms', consumer and total).

\subsection{Results}

We start with analyzing the impact of market liberalization, and will therefore focus on the treatments MtoD and MtoQ. We first describe labor market outcomes, and then proceed to the description of the results for the product market. Thereafter, we discuss the effects of removing competition.

\subsubsection{Effects of market liberalization}

44 subjects participated in the MtoD treatment, resulting in 22 markets for the Monopoly phase. Since markets in the Monopoly phase do not interact with each other, each of them constitutes one independent observation. Hence, for the Monopoly phase we have 22 independent observations. As two markets of the Monopoly phase are merged into one in the subsequent Duopoly phase, here the number of independent observations is 11 . Similarly, 64 participants in the

\footnotetext{
${ }^{15}$ In the specific setting under study, relaxing the assumption of a constant $\gamma$ across all levels of output market competition does not affect the comparative statics predictions with respect to surpluses. Monopoly always yields the lowest aggregate workers', firms', consumer and total surpluses, and Quadropoly always the highest.
} 
MtoQ treatments yield 32 independent observations for the Monopoly phase and 8 for the Quadropoly phase, since four monopoly markets are matched into one in the Quadropoly phase.

Subjects in MtoD and MtoQ do not differ in their (average) positive and negative reciprocal attitudes (Mann-Whitney (MW) tests, $p$-value $=0.1102$ for positive reciprocity, and $p$-value $=0.5637$ for negative reciprocity). As for risk preferences, participants in MtoD report, on average, marginally significantly lower willingness to take risks than participants in MtoQ (6.36 vs. 7.16; MW test $p$-value $=0.0814)$.

\section{Labor market outcomes}

Our first result is that the experimental markets under study exhibit efficiencywage characteristics. Wages and efforts are substantially above the minimum level, efforts are positively related to wages, and both workers and firms earn rents (as compared to the case with no gift-exchange).

Table 4.2 reports averages of wages and effort over markets and periods, disaggregated by phase of each treatment. In MtoD and MtoQ treatments, wages and effort are clearly above zero. In the Monopoly phases, wages and effort levels are lower than in the corresponding Duopoly or Quadropoly phase.

Table 4.2: Average wages and effort

\begin{tabular}{cccccc}
\hline \hline & \multicolumn{2}{c}{ MtoD } & & \multicolumn{2}{c}{ MtoQ } \\
\cline { 2 - 3 } \cline { 5 - 6 } \cline { 5 - 6 } & Monopoly & Duopoly & & Monopoly & Quadropoly \\
\hline Wage & 45.6 & 50.1 & & 51.9 & 66.7 \\
& $(16.67)$ & $(14.20)$ & & $(13.55)$ & $(2.07)$ \\
Effort & 3.8 & 4.6 & & 4.6 & 6.4 \\
& $(1.76)$ & $(2.08)$ & & $(1.22)$ & $(0.68)$ \\
\hline
\end{tabular}

All averages and standard deviations (in parentheses) are taken over markets and periods.

Our main interest is in differences between phases within a treatment. For that, we regress individual wage and effort on a phase dummy for market liberalization (Phase 2). ${ }^{16}$ In MtoD, the variable Phase 2 takes value one if the observation comes from the Duopoly phase and zero otherwise; similarly, in MtoQ, it takes value one if the observation comes from the Quadropoly phase and zero otherwise. In all regressions the reference group is the correspond-

\footnotetext{
${ }^{16}$ Non-parametric test results are reported in Appendix 4.A.1. We report on any differences between the parametric and non-parametric analyses.
} 
ing Monopoly phase. ${ }^{17}$ Results are reported in Table 4.3. In both treatments, the coefficients of the constant indicate that wages and effort in the Monopoly phase are strictly positive. For both wage and effort, the coefficients associated to the phase dummy are also positive. In MtoD, the positive effect of market liberalization is not significant, while in MtoQ the within-treatment differences in both wages and effort are highly significant. ${ }^{18}$

Table 4.3: Effects on wages and effort of market liberalization

\begin{tabular}{lccccc}
\hline \hline & \multicolumn{2}{c}{ MtoD } & & \multicolumn{2}{c}{ MtoQ } \\
\cline { 2 - 3 } \cline { 5 - 6 } & Wage & Effort & & Wage & Effort \\
\hline \multirow{2}{*}{ Constant } & $44.250^{* * *}$ & $3.300^{* * *}$ & & $51.710^{* * *}$ & $4.431^{* * *}$ \\
& $(4.128)$ & $(0.531)$ & & $(2.608)$ & $(0.264)$ \\
\multirow{2}{*}{ Phase 2 } & 4.900 & 1.088 & & $15.706^{* * *}$ & $2.159^{* * *}$ \\
& $(6.915)$ & $(1.043)$ & & $(2.810)$ & $(0.377)$ \\
\hline $\mathrm{N}$ & 660 & 660 & & 960 & 960 \\
\hline
\end{tabular}

*** $p<0.001$. Bootstrapped robust standard errors, clustered over independent observations, in parentheses. In the MtoD treatment, Phase 2 takes value 1 if the observation comes from the Duopoly phase and 0 otherwise. In the MtoQ treatment Phase 2 takes value 1 if the observation comes from the Quadropoly phase and 0 otherwise.

Figure 4.1 shows the cumulative distribution functions (CDF) of wages in the two treatments under study. In the MtoD condition (left panel), the probability of having higher wages is slightly lower in the monopoly markets. The StuartMaxwell tests for marginal homogeneity ${ }^{19}$, performed by crossing wage quartiles and number of firms in the market (4 categories in total, see Table 4.4), reveals significant differences in the distributions of wage offers across phases ( $p$-value $<0.001)$. More specifically, in the Monopoly phase $41 \%$ of the observations lie in the first quartile while only $9 \%$ of the wage offers are in fourth quartile. In the Duopoly phase, $36 \%$ of the wage offers belong to the lowest quartile and $19 \%$ to the highest.

\footnotetext{
${ }^{17}$ Unless specified differently, all regressions are panel Tobit with bootstrapped clustered robust standard errors, where resampling clusters are defined over independent observations. The number of clusters is therefore 33 in MtoD (22+11 independent observations) and 40 in MtoQ (32+8 independent observations).

${ }^{18}$ These results are consistent with non-parametric Wilcoxon test results, reported in Appendix 4.A.1 Table 4.19.

${ }^{19}$ The Stuart-Maxwell test for marginal homogeneity generalizes the McNemar's test to the case where variables are classified into more than two categories. Analogously to the McNemar's test, the marginal homogeneity test is used to determine whether frequencies are equal across categories.
} 
In the MtoQ treatment (Figure 4.1, right panel), the difference in the two cumulative distributions of wage offers is evident and becomes larger for higher wage offers, indicating that high wages are more probable in the Quadropoly phase. In the Monopoly phase, $27 \%$ of the wage offers lie in the first and $11 \%$ lie in the fourth quartile; these shares are reversed in the Quadropoly phase, where $11 \%$ of the wage offers belong to the first quartile and $37 \%$ to the last one. These between-phase differences are highly significant (Stuart-Maxwell test, $p$-values $<0.001)$.

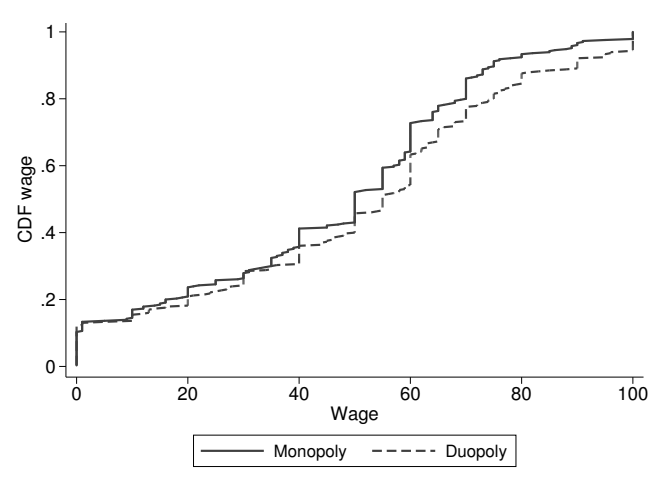

(a) MtoD

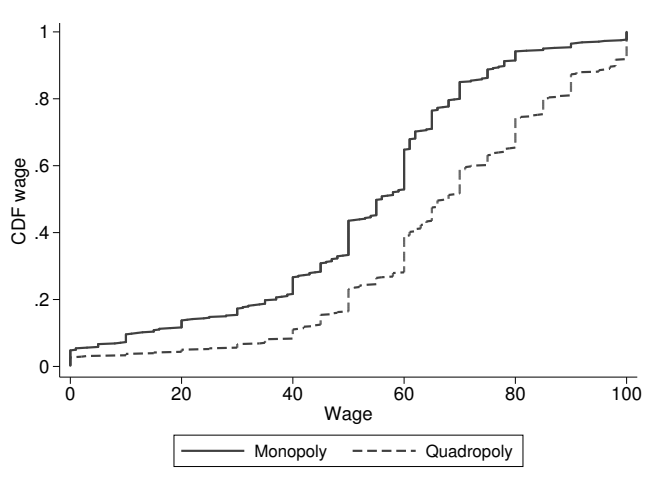

(b) MtoQ

Figure 4.1: Cumulative distribution functions of wage offers

Table 4.4: Contingency tables I - Wage

\begin{tabular}{lcclcc}
\hline \hline & \multicolumn{2}{c}{ MtoD } & & \multicolumn{2}{c}{ MtoQ } \\
\cline { 2 - 3 } \cline { 6 - 7 } Quartile (Wage offers) & Monopoly & Duopoly & & Monopoly & Quadropoly \\
\hline 1st (0-40) & $41.2(136)$ & $36.0(119)$ & & $26.7(128)$ & $11.0(53)$ \\
2nd (41-60) & $31.5(104)$ & $27.3(90)$ & & $38.1(183)$ & $28.0(134)$ \\
3rd (61-75) & $18.5(61)$ & $18.2(60)$ & & $24.0(115)$ & $24.1(116)$ \\
4th (76-100) & $8.8(29)$ & $18.5(61)$ & & $11.2(54)$ & $36.9(177)$ \\
Total & $100.0(330)$ & $100.0(330)$ & & $100.0(480)$ & $100.0(480)$ \\
\hline Stuart-Maxwell test & \multicolumn{3}{c}{$p<0.001$} & & \multicolumn{2}{c}{$p<0.001$} \\
\hline
\end{tabular}

Numbers in the table are percentages; frequencies are in parentheses.

A similar pattern can be found for effort levels. Figure 4.2 shows the CDFs of effort levels chosen in MtoD and MtoQ. In both cases, the distance between the two distributions gets larger for higher effort levels, suggesting that the probability of choosing higher effort is larger in the Duopoly and Quadropoly phases than in the corresponding Monopoly phase. In the Monopoly phase of MtoD, most of the observations lie within the first two quartiles, while only 
$9 \%$ belong to the fourth quartile (see Table 4.5). While the percentage of effort choices in the first quartile is more or less similar, in the Duopoly phase $23 \%$ of effort choices belong to the highest quartile. The Stuart-Maxwell test yields a $p$-value $<0.001$, which indicates that the distribution of effort levels is statistically significantly different between the two phases. The differences are larger in the MtoQ treatment: in the Monopoly phase, $23 \%$ of effort choices are in the first and $11 \%$ in the fourth quartile; in the Quadropoly, the respective shares are $11 \%$ and $38 \%$. Also in this case, the Stuart-Maxwell test results yield a $p$-value $<0.001$.

Therefore, in line with the reciprocity hypothesis, we find that wages and effort levels are positive and respond to the intensity of output market competition by an increase when markets are liberalized.

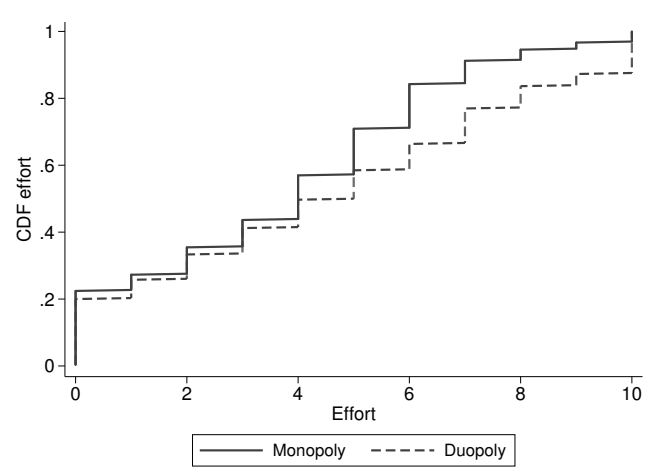

(a) MtoD

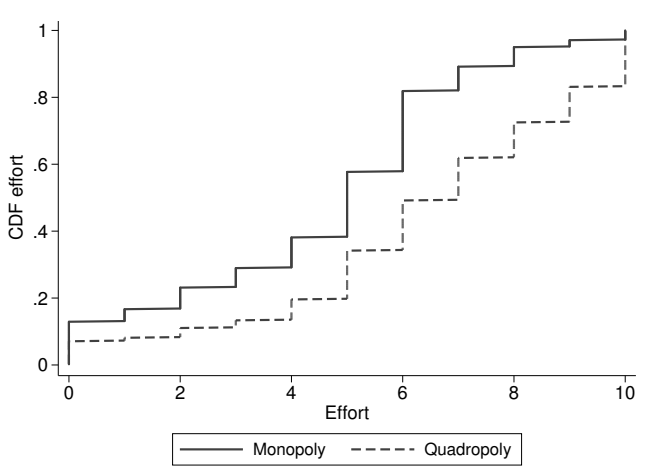

(b) MtoQ

Figure 4.2: Cumulative distribution functions of effort levels

Table 4.5: Contingency tables II - Effort

\begin{tabular}{lcclcc}
\hline \hline & \multicolumn{2}{c}{ MtoD } & & \multicolumn{2}{c}{ MtoQ } \\
\cline { 2 - 3 } \cline { 5 - 6 } Quartile (Effort levels) & Monopoly & Duopoly & & Monopoly & Quadropoly \\
\hline 1st (0-2) & $35.5(117)$ & $33.3(110)$ & & $23.1(111)$ & $11.1(53)$ \\
2nd (3-5) & $35.5(117)$ & $25.2(83)$ & & $34.6(166)$ & $23.1(111)$ \\
3rd (6-7) & $20.3(67)$ & $18.5(61)$ & & $31.5(151)$ & $27.7(133)$ \\
4th (8-10) & $8.7(29)$ & $23.0(76)$ & & $10.8(52)$ & $38.1(183)$ \\
Total & $100.0(330)$ & $100.0(330)$ & & $100.0(480)$ & $100.0(480)$ \\
\hline Stuart-Maxwell test & \multicolumn{3}{c}{$p<0.001$} & & \multicolumn{2}{c}{$p<0.001$} \\
\hline
\end{tabular}

Numbers in the table are percentages; frequencies are in parentheses. 
Next, we study wage dynamics. In all treatment phases, wages remain steadily positive over time but appear to follow different patterns in monopolistic and in liberalized markets (Figure 4.3). In both treatments, the monopolistic markets are characterized by a gradual decrease in wages over time. Conversely, in the competitive markets wages increase in the initial periods and tend to head downward only in the final periods. ${ }^{20}$

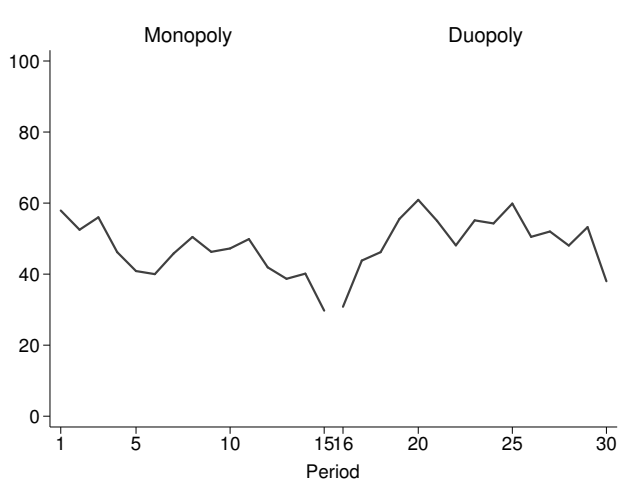

(a) MtoD

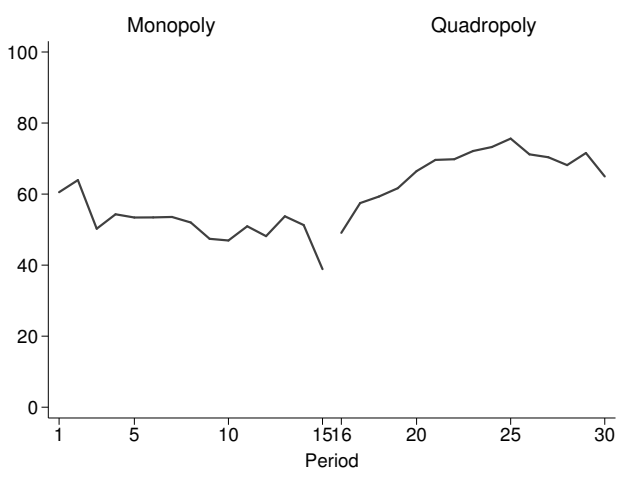

(b) MtoQ

Figure 4.3: Average wage over time

We analyze the evolution of wages over time by means of a Tobit regression of wages on a time variable, Period $t$, which takes values from 1 to 15 . We include a squared time variable, Period $t^{2}$, to control for non-linear dynamics. Results are reported in Table 4.6.

In both treatments, the average wage in period 1 of Phase 2 is lower than the average wage in period 1 of the Monopoly phase. This suggests that there might be spillover effects across market institutions: in more competitive markets, firms need to learn that higher wages are necessary to induce higher effort and output, and therefore to increase profits. The difference is significant only when controlling for non-linear time dynamics.

Consistent with the impressions one gets from Figure 4.3, in the Monopoly phase of both treatments (MtoD and MtoQ) wages decrease over time, as it is shown by the negative coefficient associated to Period $t$. This negative trend is statistically significant in specification (1), but it decreases in size and significance when we add quadratic terms. In both Monopoly phases, there is no significant non-linear time trend. In the Duopoly and Quadropoly phases wages do not evolve linearly over time, but tend to increase and then decrease

\footnotetext{
${ }^{20}$ When not considering the end-game effect in the last period of each phase, where both wage and effort decrease.
} 
as the concave shape in Figure 4.3 suggests. This is shown by the positive coefficient associated to Period $t \times$ Phase 2 , and by the negative coefficient of Period $t^{2} \times$ Phase $2 .^{21}$

Table 4.6: Time dynamics - Wages

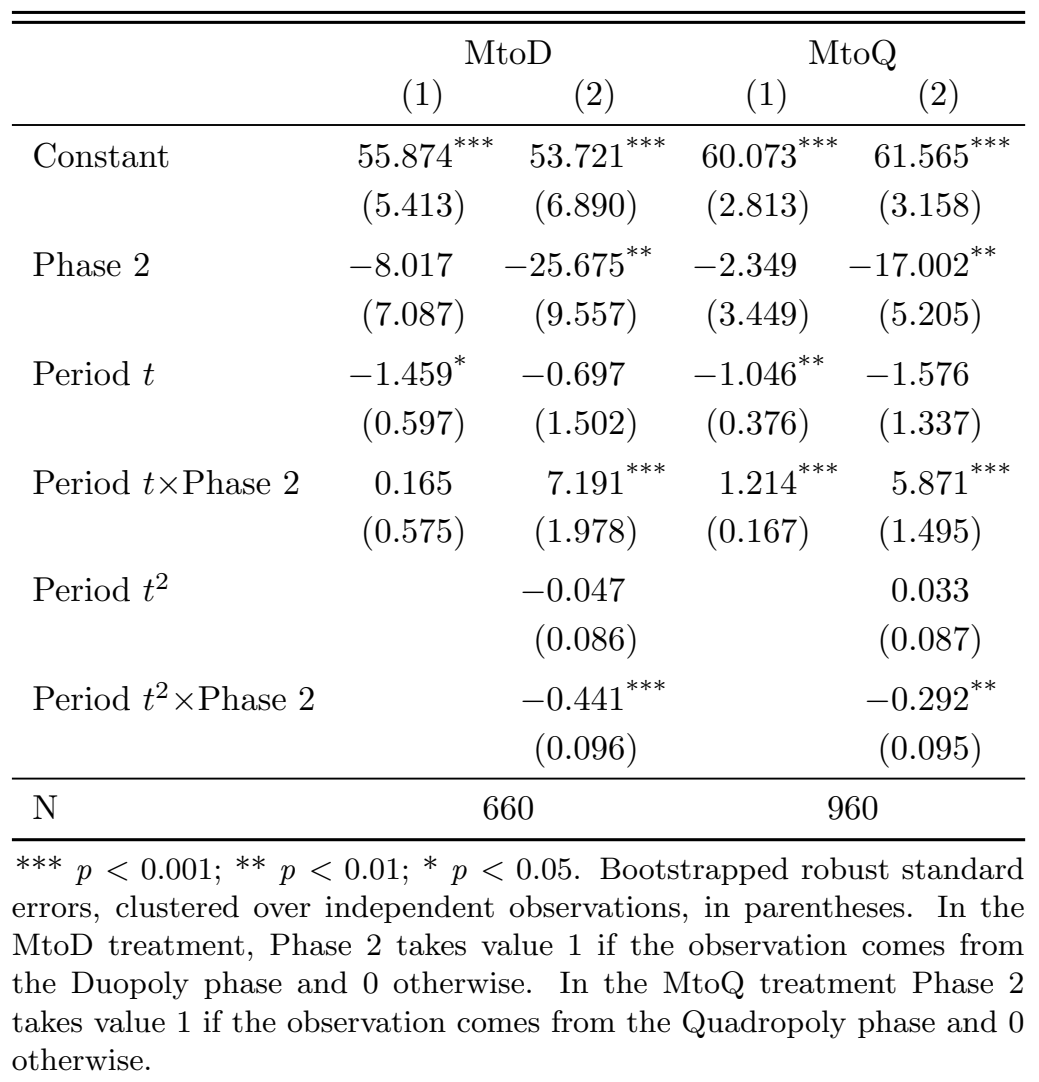

\section{Wage-effort relationship}

An important question is how effort choices depend on the offered wage and whether this relationship changes across the different market structures within a treatment. Before presenting regression results, it is informative to look at scatter plots of wage and effort in each phase of the two treatments under study. Figures $4.4 \mathrm{a}$ and $4.4 \mathrm{~b}$ show such scatter plots, where each dot is a single observation. $^{22}$ There is a clear positive relationship between the wage paid

\footnotetext{
${ }^{21}$ According to non-parametric Jonckheere-Terpstra (JT) tests, average wages in the Monopoly phases of MtoD and MtoQ significantly decrease over time. No significant trend is detected in the Duopoly phase of MtoD, while wages significantly increase in the Quadropoly phase of MtoQ. See Appendix 4.A.1.

${ }^{22}$ In Figures $4.4 \mathrm{a}$ and $4.4 \mathrm{~b}$ we do not include the last period of each phase (period 15 for the Monopoly phases, and period 30 for the Duopoly and Quadropoly phases) since, due to an end-game effect, they contain generally more zero wage and/or zero effort observations at the end of a phase.
} 
and the effort provided, and this relationship appears to be quite stable across all phases: workers respond to higher wages with higher effort in each phase of both treatments. There is, however, some heterogeneity as there are cases where low (high) effort is chosen in response to high (low) wage offers.

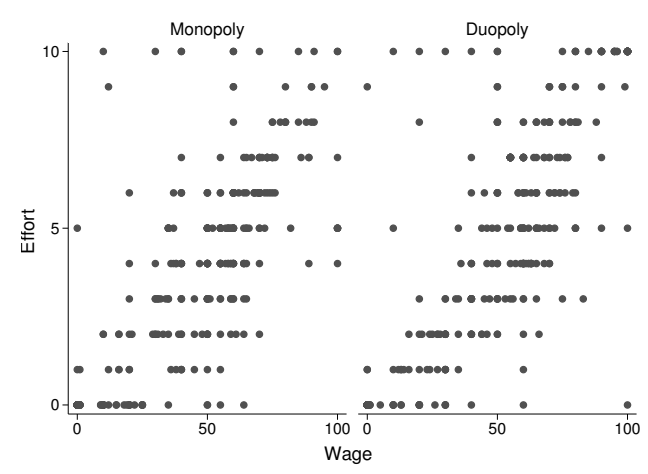

(a) MtoD

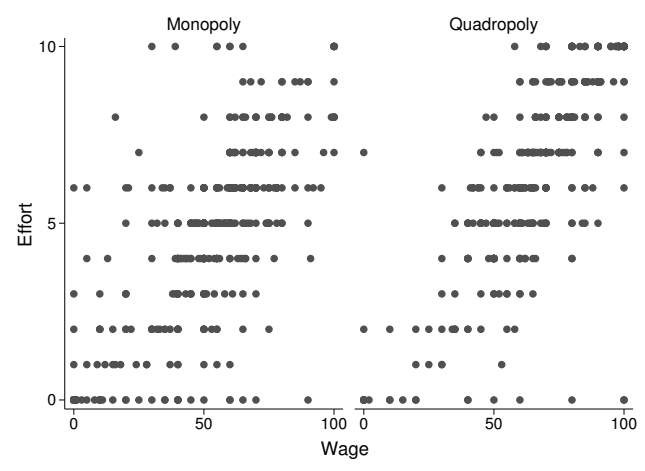

(b) MtoQ

Figure 4.4: Relation between wage offers and effort levels

We test for difference in reciprocity across phases by means of a panel Tobit regression of effort on wages and a series of control variables. In both the regressions presented in Tables 4.7 and 4.8, the reference group is the Monopoly phase. Table 4.7 shows the results for the MtoD treatment. In the first model specification (column (1)) we only consider wage, a phase dummy (Duopoly, which takes value 1 if the observation comes from the Duopoly phase of MtoD, and zero otherwise) and an interaction between the two. There is a positive and highly significant relationship between the wage received and the effort level chosen, and this relation remains equally strong after competition is introduced: the coefficient of the interaction term of wage and phase dummy is not significant ( $p$-value $=)$. In columns (2) and (3) we additionally control for time and lagged wage and effort. None of these variables has a significant effect on effort choices. The only exception is the time variable in the Monopoly phase, which is significantly and negatively correlated with effort once we control for lagged wage and effort. The highly significant and positive relationship between wage and effort is robust to the different model specifications. More importantly, we do not find any difference in reciprocity between the two phases of MtoD.

Table 4.8 presents regression results for the MtoQ treatment. Also in this case, we see a strong relationship between the wage offered and the effort level chosen in the Monopoly phase. The coefficient for the interaction term of wage and phase dummy (Quadropoly, which takes value 1 if the observation comes 
from the Quadropoly phase of MtoQ, and zero otherwise) is not significant, indicating that the wage-effort relation is stable across the two market structures. Adding time variables (specification (2)) shows a significantly decreasing trend of effort levels in the Monopoly phase, which becomes non significant once we control for lagged wage and effort. In specification (3), the negative trend of effort is significantly stronger in Quadropoly than in Monopoly. Moreover, there is a significant and negative correlation between the wage received in the previous period and the effort chosen in the current period. This effect persists in the Quadropoly phase. In both phases the effort level chosen in the previous period positively and significantly correlates with the effort exerted in the current period, with this effect being stronger in Quadropoly. Again, the positive wage coefficient remains highly significant across the different specifications, and we do not find any difference in the wage-effort relationship between Monopoly and Quadropoly markets. ${ }^{23}$

Our second set of results can be summarized as follows: in line with the reciprocity hypothesis, a positive wage-effort relationship emerges in all phases within a treatment; the higher output market competition implied by market liberalization does not significantly affect this relationship, and gift-exchange labor relations persist under a higher competitive pressure on the output market.

\footnotetext{
${ }^{23}$ For both treatments, we also used as control variables the reciprocity and risk attitudes reported by subjects in the final questionnaire, but did not find any significant effect, nor does adding these controls alter the significance reported in Tables 4.7 and 4.8.
} 
Table 4.7: Wage-effort relation - MtoD

\begin{tabular}{|c|c|c|c|}
\hline Dep. var.: Effort in $t$ & (1) & $(2)$ & $(3)$ \\
\hline Constant & $\begin{array}{c}-1.831^{* * *} \\
(0.496)\end{array}$ & $\begin{array}{r}-1.276 \\
(0.719)\end{array}$ & $\begin{array}{c}-1.127^{*} \\
(0.517)\end{array}$ \\
\hline Duopoly & $\begin{array}{c}0.783 \\
(1.165)\end{array}$ & $\begin{array}{c}0.483 \\
(1.032)\end{array}$ & $\begin{array}{c}0.295 \\
(0.753)\end{array}$ \\
\hline Wage $_{t}$ & $\begin{array}{l}0.111^{* * *} \\
(0.009)\end{array}$ & $\begin{array}{l}0.109^{* * *} \\
(0.010)\end{array}$ & $\begin{array}{l}0.115^{\text {*** }} \\
(0.013)\end{array}$ \\
\hline Wage $_{t} \times$ Duopoly & $\begin{array}{c}-0.003 \\
(0.018)\end{array}$ & $\begin{array}{c}-0.000 \\
(0.020)\end{array}$ & $\begin{array}{c}0.011 \\
(0.022)\end{array}$ \\
\hline Period $t$ & & $\begin{array}{r}-0.062 \\
(0.042)\end{array}$ & $\begin{array}{r}-0.063^{*} \\
(0.030)\end{array}$ \\
\hline Period $t \times$ Duopoly & & $\begin{array}{r}-0.040 \\
(0.088)\end{array}$ & $\begin{array}{r}-0.088 \\
(0.062)\end{array}$ \\
\hline Wage $_{t-1}$ & & & $\begin{array}{r}-0.035 \\
(0.022)\end{array}$ \\
\hline Wage $_{t-1} \times$ Duopoly & & & $\begin{array}{c}-0.045 \\
(0.029)\end{array}$ \\
\hline Effort $_{t-1}$ & & & $\begin{array}{c}0.316 \\
(0.210)\end{array}$ \\
\hline Effort $_{t-1} \times$ Duopoly & & & $\begin{array}{c}0.437 \\
(0.269)\end{array}$ \\
\hline $\mathrm{N}$ & 660 & 660 & 616 \\
\hline
\end{tabular}

*** $p<0.001$; $p<0.05$. Bootstrapped robust standard errors, clustered over independent observations, in parentheses. Duopoly takes value 1 if the observation comes from phase 2 of the MtoD treatment, and 0 otherwise. 
Table 4.8: Wage-effort relation - MtoQ

\begin{tabular}{lccc}
\hline \hline Dep. var.: Effort in t & $(1)$ & $(2)$ & $(3)$ \\
\hline Constant & -0.756 & -0.271 & 0.378 \\
& $(0.464)$ & $(0.498)$ & $(0.556)$ \\
Quadropoly & -0.626 & -1.030 & $-1.834^{*}$ \\
& $(0.772)$ & $(0.796)$ & $(0.742)$ \\
Wage $t$ & $0.100^{* * *}$ & $0.098^{* * *}$ & $0.104^{* * *}$ \\
& $(0.008)$ & $(0.008)$ & $(0.009)$ \\
Wage $t_{t} \times$ Quadropoly & 0.019 & 0.022 & 0.003 \\
& $(0.012)$ & $(0.013)$ & $(0.015)$ \\
Period $t$ & & $-0.049^{*}$ & -0.038 \\
& & $(0.025)$ & $(0.022)$ \\
Period $t \times$ Quadropoly & & -0.016 & $-0.065^{* *}$ \\
Wage \\
\end{tabular}




\section{Product market outcomes}

Table 4.9 reports average aggregate market outcomes in both experimental treatments where competition increases. As previously explained, in MtoD two markets of the Monopoly phase are matched into one in the Duopoly phase. Therefore, for a clean comparison, in the Monopoly phase we take averages over the sum of the two markets that will be merged in the Duopoly phase. In the Duopoly phase, averages are taken within a market. The same procedure is followed for the MtoQ treatment: averages are taken over the sum of the four markets that will be merged in the Monopoly phase, and within a market in the Quadropoly phase.

Aggregate outputs increase when the competitiveness of the output market increases. In both treatments, due to the labor market gift-exchange relation, output considerably exceeds the standard theory predictions (cf. Table 4.1).

Table 4.9: Average market outcomes

\begin{tabular}{lccccc}
\hline \hline & \multicolumn{2}{c}{ MtoD } & & \multicolumn{2}{c}{ MtoQ } \\
\cline { 2 - 3 } \cline { 5 - 6 } & Monopoly & Duopoly & & Monopoly & Quadropoly \\
\hline $\bar{Q}$ & 310.67 & 342.91 & & 687.50 & 832.00 \\
& $(43.26)$ & $(83.18)$ & & $(35.30)$ & $(54.72)$ \\
$Q^{s}$ & 282.64 & 337.41 & & 643.65 & 821.97 \\
& $(37.58)$ & $(80.94)$ & & $43.64)$ & $(57.78)$ \\
Firms surplus & 247.98 & 260.00 & & 517.41 & 514.65 \\
& $(18.17)$ & $(13.87)$ & & $(33.55)$ & $(13.40)$ \\
Workers surplus & 76.07 & 81.90 & & 170.93 & 215.65 \\
& $(15.26)$ & $(21.83)$ & & $(24.31)$ & $(8.68)$ \\
Total surplus & 437.13 & 499.21 & & 969.44 & 1161.52 \\
& $(46.73)$ & $(84.04)$ & & $(55.08)$ & $(50.87)$ \\
\hline $\bar{Q}$ & & &
\end{tabular}

$\bar{Q}$ indicates aggregate quantity produced, $Q^{s}$ indicates aggregate quantity sold. All averages are taken over periods and markets. In the Monopoly phase of MtoD, averages are taken over the sum of the two markets that will be merged in the Duopoly phase. In the Monopoly phase of MtoQ, averages are taken over the sum of the four markets that will be merged in the Quadropoly phase. In the Duopoly and Quadropoly phases averages are taken within a market. Standard deviations in parentheses. 
Table 4.10 reports the results of panel regressions of quantities produced and sold on the phase dummy for market liberalization (Phase 2). It shows that market liberalization has a positive effect on both the quantity produced and the quantity sold by the firms. In MtoD, this effect is statistically significant only for the latter. ${ }^{24}$

Table 4.10: Effects on quantity produced and sold of market liberalization

\begin{tabular}{|c|c|c|c|c|}
\hline & \multicolumn{2}{|c|}{ MtoD } & \multicolumn{2}{|c|}{ MtoQ } \\
\hline & Q produced & Q sold & Q produced & Q sold \\
\hline Constant & $\begin{array}{c}310.67^{* * *} \\
(9.142)\end{array}$ & $\begin{array}{c}282.64^{* * *} \\
(8.183)\end{array}$ & $\begin{array}{c}687.50^{* * *} \\
(6.196)\end{array}$ & $\begin{array}{c}643.65^{\text {*** }} \\
(7.747)\end{array}$ \\
\hline Phase 2 & $\begin{array}{c}32.24 \\
(27.776)\end{array}$ & $\begin{array}{c}54.76^{*} \\
(26.711)\end{array}$ & $\begin{array}{l}144.50^{* * *} \\
(20.665)\end{array}$ & $\begin{array}{l}178.32^{* * *} \\
(21.919)\end{array}$ \\
\hline $\mathrm{N}$ & 660 & 660 & 960 & 960 \\
\hline \multicolumn{5}{|c|}{$\begin{array}{l}{ }^{* * *} p<0.001 ;{ }^{*} p<0.05 \text {. Bootstrapped robust standard errors, } \\
\text { clustered over independent observations, in parentheses. In MtoD, } \\
\text { Phase } 2 \text { takes value } 1 \text { if the observation comes from the Duopoly phase } \\
\text { and } 0 \text { otherwise. In MtoQ, Phase } 2 \text { takes value } 1 \text { if the observation } \\
\text { comes from the Quadropoly phase and } 0 \text { otherwise. The reference } \\
\text { group is the aggregate quantity produced and sold by two monopolies } \\
\text { in MtoD, and by four monopolies in MtoQ. }\end{array}$} \\
\hline
\end{tabular}

Figure 4.5 displays market averages of quantities produced and sold over time, and provides a graphical representation of the increase in quantity after market liberalization. It also shows that in all phases only a small share of the produced quantity is "wasted", as firms tend to sell almost everything that is produced.

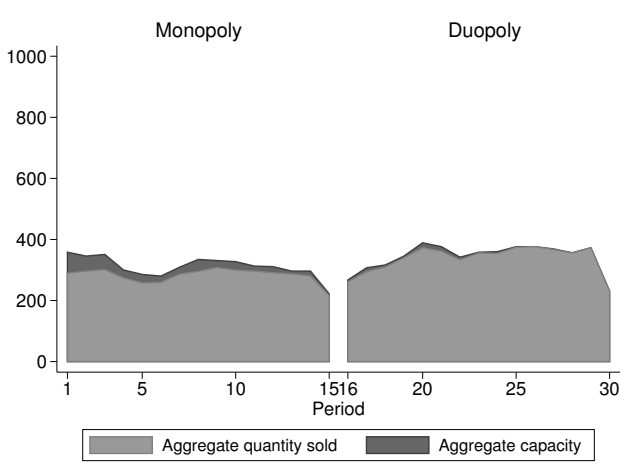

(a) MtoD

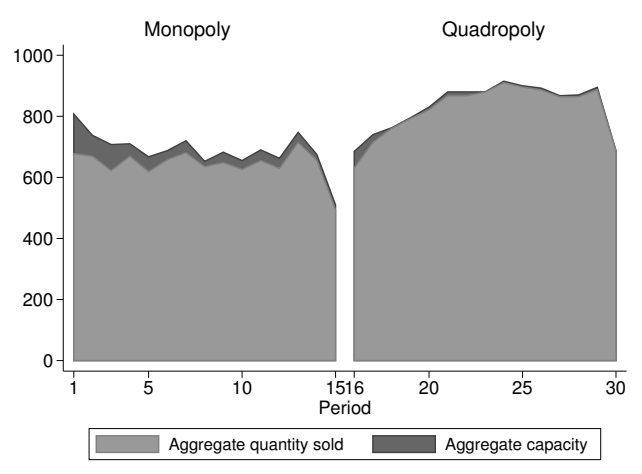

(b) MtoQ

Figure 4.5: Average quantities produced and sold over time

\footnotetext{
${ }^{24}$ These results are consistent with non-parametric Wilcoxon test results (see Appendix 4.A.1 Table 4.19).
} 
In line with the predictions of our reciprocity model, both firms and workers earn more in duopoly markets than under monopoly (see Table 4.9), an effect that the standard theory hypothesis predicts only for firms. As shown in the top panel of Table 4.11, which reports estimates of panel regressions of firm, worker and total surpluses on a dummy for the Duopoly phase (Duopoly), the difference is statistically significant for the firm and the total surplus. The bottom panel of Table 4.11 shows the results of regressions of firm, worker and total surpluses on a dummy for the Quadropoly phase. The coefficient associated to the phase dummy is positive and highly significant for worker and total surplus. Firms earn somewhat less in quadropoly markets, with this difference not being statistically significant.

Table 4.11: Effects on surpluses of market liberalization

\begin{tabular}{|c|c|c|c|}
\hline MtoD & Firm surplus & Worker surplus & Total surplus \\
\hline Constant & $\begin{array}{c}247.975^{* * *} \\
(4.050)\end{array}$ & $\begin{array}{l}76.073^{* * *} \\
(3.213)\end{array}$ & $\begin{array}{l}437.133^{* * *} \\
(10.197)\end{array}$ \\
\hline Duopoly & $\begin{array}{l}12.022^{*} \\
(6.012)\end{array}$ & $\begin{array}{c}5.824 \\
(7.861)\end{array}$ & $\begin{array}{c}62.075^{*} \\
(28.485)\end{array}$ \\
\hline $\mathrm{N}$ & 660 & 660 & 660 \\
\hline MtoQ & Firm surplus & Worker surplus & Total surplus \\
\hline Constant & $\begin{array}{c}517.409^{* * *} \\
(5.876)\end{array}$ & $\begin{array}{c}170.925^{* * *} \\
(4.230)\end{array}$ & $\begin{array}{c}969.442^{* * *} \\
(9.765)\end{array}$ \\
\hline Quadropoly & $\begin{array}{r}-2.759 \\
(7.977)\end{array}$ & $\begin{array}{l}44.725^{* * *} \\
(5.209)\end{array}$ & $\begin{array}{l}192.074^{* * *} \\
(20.262)\end{array}$ \\
\hline $\mathrm{N}$ & 960 & 960 & 960 \\
\hline \multicolumn{4}{|c|}{$\begin{array}{l}{ }^{* *} p<0.001{ }^{*} p<0.05 \text {. Bootstrapped robust standard errors, clus- } \\
\text { tered over independent observations, in parentheses. } \\
\text { Top panel: Duopoly takes value } 1 \text { if the observation comes from phase } \\
2 \text { of the MtoD treatment, and } 0 \text { otherwise. The reference group is the } \\
\text { aggregate (firm, worker, total) surplus of two monopolies. } \\
\text { Lower panel: Quadropoly takes value } 1 \text { if the observation comes from } \\
\text { phase } 2 \text { of the MtoQ treatment, and } 0 \text { otherwise. The reference group } \\
\text { is the aggregate (firm, worker, total) surplus of four monopolies. }\end{array}$} \\
\hline
\end{tabular}

Table 4.12 reports the observed average surplus shares. Firms are able to capture most of the total surplus before and after markets are liberalized. Their shares slightly decrease after market liberalization, mostly due to the increase in the consumers' share of total surplus. Workers appear to reap more or less the same share of surplus in the monopoly, the duopoly and the quadropoly markets. 
Table 4.12: Average surplus shares (in \%)

\begin{tabular}{lcclcc}
\hline \hline & \multicolumn{2}{c}{ MtoD } & & \multicolumn{2}{c}{ MtoQ } \\
\cline { 2 - 3 } \cline { 5 - 6 } & Monopoly & Duopoly & & Monopoly & Quadropoly \\
\hline Firms & 56.73 & 52.08 & & 53.37 & 44.31 \\
Workers & 17.40 & 16.41 & & 17.63 & 18.57 \\
Consumers & 25.87 & 31.51 & & 29.00 & 37.13 \\
\hline
\end{tabular}

Numbers in the table are percentages.

Our third result can be summarized as follows. Market liberalization induces an increase in the quantity produced and sold. Workers' surplus is positive, contrary to standard theory predictions, and increases after market liberalization. This increase is sizable and statistically significant only in the MtoQ treatment. On the other hand, firms' surplus significantly increases in MtoD, while there is a non significant decrease in MtoQ. Workers' share of total surplus does not substantially increase after market are liberalized, but there is some redistribution of surplus from firms to consumers. Results regarding the total generated surplus go along with the predictions of both the standard theory and the reciprocity hypotheses, since total surplus is significantly larger in liberalized markets.

\subsubsection{Effects of removing competition}

In this section, we study the effects on wages, effort and market outcomes when competition is removed rather than introduced. In particular, we will focus on whether treatment effects are symmetric. Since the phases within a treatment are identical in all exogenous parameters, regardless of the order in which they follow one another, we should observe the reverse changes with the removal of competition as we did with its introduction.

44 subjects took part in the DtoM treatment and 64 in the QtoM treatment. Therefore, in DtoM there were 11 markets in the Duopoly phase and 22 in the Monopoly phase; in QtoM, we had 8 markets in the Quadropoly phase and 36 in the Monopoly phase. However, since markets in the monopolies that followed a duopoly or a quadropoly cannot be seen as independent of each other, the number of independent observations is defined over markets of bigger size. Therefore, we have 11 and 8 independent observations per treatment, respectively. 


\section{Labor market outcomes}

Labor markets in the DtoM and QtoM treatments exhibit, overall, patterns that are opposite to those that characterize economies in the MtoD and MtoQ treatments. Indeed, while wages and effort increase due to market liberalization, we observe a decrease in average wages and effort after the removal of competition (see Table 4.13).

While the wage increase in MtoD was modest and not significant (from 45.6 to 50.1), average wages in the Monopoly markets of DtoM are significantly lower than those in the Duopoly markets (from 68.4 to 39.9). Similarly, the decrease in effort in DtoM (5.9 to 3.2) is larger and more significant than the effort increase in MtoD (from 3.8 to 4.6). In QtoM, instead, the decrease in average wages and effort (from 62.5 to 46.8 , and from 5.6 to 4.1 , respectively) is similar in value and significance to their increase in MtoQ (from 51.9 to 66.7 for wages, and from 4.6 to 6.4 for effort). ${ }^{25}$

Table 4.13: Average wages and effort

\begin{tabular}{|c|c|c|c|c|c|c|}
\hline & \multicolumn{3}{|c|}{ DtoM } & \multicolumn{3}{|c|}{ QtoM } \\
\hline & Duopoly & & Monopoly & Quadropoly & & Monopoly \\
\hline Wage & $\begin{array}{c}68.4 \\
(10.38)\end{array}$ & $>* * *$ & $\begin{array}{c}39.9 \\
(17.07)\end{array}$ & $\begin{array}{c}62.5 \\
(5.69)\end{array}$ & $>* * *$ & $\begin{array}{c}46.8 \\
(6.65)\end{array}$ \\
\hline Effort & $\begin{array}{c}5.9 \\
(1.55)\end{array}$ & $>* * *$ & $\begin{array}{c}3.2 \\
(1.46)\end{array}$ & $\begin{array}{c}5.6 \\
(0.93)\end{array}$ & $>^{* * *}$ & $\begin{array}{c}4.1 \\
(0.33)\end{array}$ \\
\hline
\end{tabular}

All averages and standard deviations (in parentheses) are taken over periods and independent observations. ${ }^{* * *} p<0.001$. See footnote 25 .

Figure 4.6 provides further support for this result. The top and bottom panels display, respectively, the cumulative distribution functions of wages and effort in DtoM and QtoM, and indicate that in both treatments the probability of higher wage offers and effort levels is lower in the Monopoly phase. ${ }^{26}$ The CDFs of wages and effort in DtoM lie further apart as compared to those in MtoD. On the contrary, differences between CDFs in QtoM and MtoQ are barely noticeable.

\footnotetext{
${ }^{25}$ Statistical significance is assessed using panel Tobit regressions, using the Monopoly phase of DtoM or QtoM as reference group, and a dummy variable for the Phase 2 of each treatment. Bootstrapped standard errors are clustered over independent observations. Wilcoxon nonparametric test results are reported in Appendix 4.A.3 Table 4.22 and confirm the statistically significant decrease in wages and effort in both treatments.

${ }^{26}$ Results from marginal homogeneity tests applied to wage and effort quartiles confirm that the distributions are statistically significantly different between phases of a treatment ( $p<0.001$ in all cases). See Tables 4.23 and 4.24 in Appendix 4.A.3.
} 


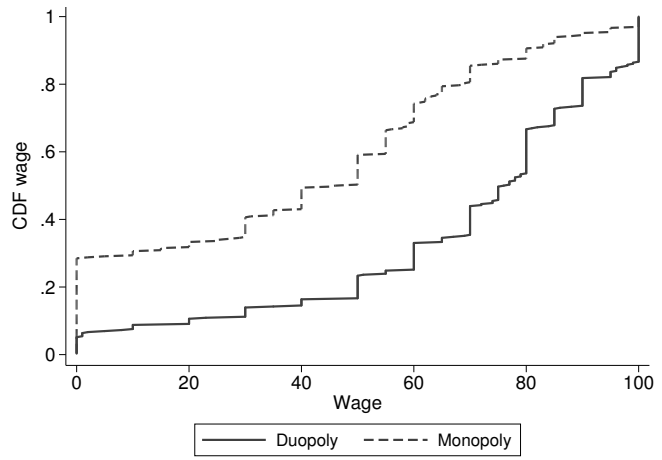

(a) DtoM

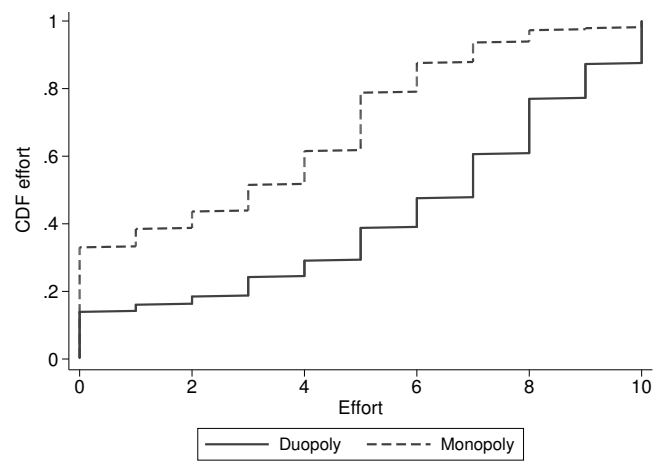

(c) DtoM

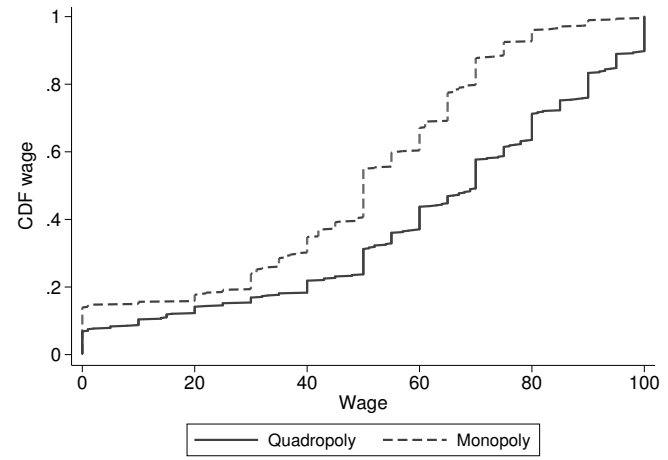

(b) QtoM

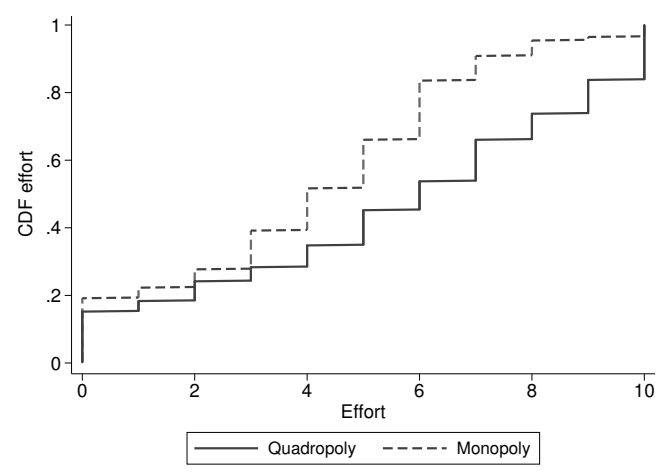

(d) QtoM

Figure 4.6: Cumulative distribution functions of wage offers (top panels) and effort levels (bottom panels)

Figure 4.7 shows the development of average wages over time. Wages in the Duopoly and Quadropoly phases appear quite stable, and tend to decrease in both the Monopoly phases.

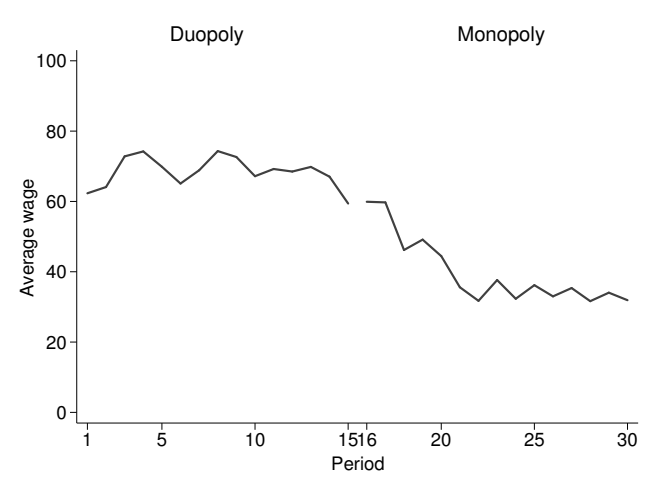

(a) DtoM

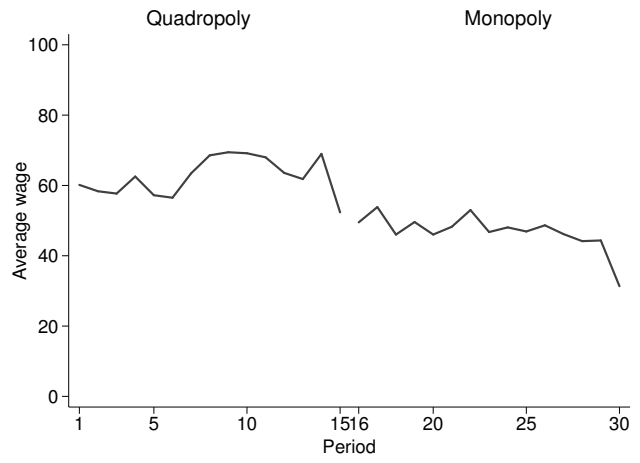

(b) QtoM

Figure 4.7: Average wage over time 
Table 4.14 shows regressions of wage over a time variable (Period $t$, taking values from 1 to 15) and its square, for both DtoM and QtoM. The Monopoly phase serves as reference category.

There is a negative and highly statistically significant time trend in Monopoly of DtoM, but no significant trend in Duopoly. This is shown by the coefficients of Period $t$ and Period $t \times$ Phase 1 in columns (1) and (2). Moreover, wages in the Monopoly phase of MtoD exhibit a significant non-linear trend. In the Monopoly phase of the QtoM treatment, the significant and negative time effects disappear once we control for non linear trends. Wages in the Quadropoly phase exhibit a significantly positive time trend. ${ }^{27}$

Wages decrease over time in the Monopoly phases of both MtoD and DtoM, and of both MtoQ and QtoM. This trend remains highly significant only in the Monopoly of DtoM. While in the Duopoly and Quadropoly phases of MtoD and MtoQ wages exhibit a significant non linear trend (by increasing in the initial periods and decreasing in the final ones), in the same phases of DtoM and QtoM wages appear rather stable over time.

Table 4.14: Time dynamics - Wages

\begin{tabular}{|c|c|c|c|c|}
\hline & \multicolumn{2}{|c|}{ DtoM } & \multicolumn{2}{|c|}{ QtoM } \\
\hline & (1) & $(2)$ & (3) & (4) \\
\hline Constant & $\begin{array}{l}53.677^{* * *} \\
(5.223)\end{array}$ & $\begin{array}{l}67.437^{* * *} \\
(6.498)\end{array}$ & $\begin{array}{l}52.887^{* * *} \\
(2.733)\end{array}$ & $\begin{array}{l}45.660^{* * *} \\
(4.864)\end{array}$ \\
\hline Phase 1 & $\begin{array}{l}17.148^{*} \\
(7.006)\end{array}$ & $\begin{array}{l}-6.902 \\
(11.439)\end{array}$ & $\begin{array}{c}6.757^{* *} \\
(1.997)\end{array}$ & $\begin{array}{c}5.686 \\
(7.234)\end{array}$ \\
\hline Period $t$ & $\begin{array}{c}-2.406^{\text {*** }} \\
(0.598)\end{array}$ & $\begin{array}{c}-7.319^{* * *} \\
(1.772)\end{array}$ & $\begin{array}{r}-1.005^{*} \\
(0.463)\end{array}$ & $\begin{array}{c}1.559 \\
(1.307)\end{array}$ \\
\hline Period $t \times$ Phase 1 & $\begin{array}{c}-0.055 \\
(0.563)\end{array}$ & $\begin{array}{c}3.589 \\
(2.542)\end{array}$ & $\begin{array}{c}0.463^{*} \\
(0.215)\end{array}$ & $\begin{array}{c}3.412^{*} \\
(1.672)\end{array}$ \\
\hline Period $t^{2}$ & & $\begin{array}{l}0.309^{* * *} \\
(0.090)\end{array}$ & & $\begin{array}{c}-0.161 \\
(0.089)\end{array}$ \\
\hline Period $t^{2} \times$ Phase 1 & & $\begin{array}{c}-0.228 \\
(0.154) \\
\end{array}$ & & $\begin{array}{c}-0.185 \\
(0.107) \\
\end{array}$ \\
\hline $\mathrm{N}$ & 66 & 60 & & 50 \\
\hline $\begin{array}{l}* p<0.001 ;{ }^{* *} p \\
\text { ors, clustered over } \\
\text { oM treatment, Ph } \\
\text { e Duopoly phase a } \\
\text { kes value } 1 \text { if the ob } \\
\text { herwise. }\end{array}$ & $0.01 ;{ }^{*} p<$ & $\begin{array}{l}0.05 \text {. Boots } \\
\text { observations } \\
\text { lue } 1 \text { if the } \\
\text { se. In the Q } \\
\text { les from the }\end{array}$ & $\begin{array}{l}\text { trapped ro } \\
\text {, in paren } \\
\text { observatio }\end{array}$ & $\begin{array}{l}\text { ust standard } \\
\text { eses. In the } \\
\text { comes from } \\
\text { ent Phase } 1 \\
\text { phase and } 0\end{array}$ \\
\hline
\end{tabular}

${ }^{27}$ Non-parametric JT test results are reported in Appendix 4.A.3. 


\section{Wage-effort relationship}

We have seen that market liberalization leaves the reciprocal firm-worker relationship mostly unchanged when going from Monopoly to Duopoly, and from Monopoly to Quadropoly (see Tables 4.7 and 4.8). Here we test if the same holds when moving from more to less liberalized markets.

Table 4.15 reports the results of a panel Tobit regression of effort levels on wages and other explanatory variables for the DtoM treatment. The Monopoly phase serves as reference group. All specifications show a strong relationship between the wage received and the effort level chosen. As in the MtoD treatment, no difference in the wage-effort relationship across phases exists in DtoM. Specifically, the coefficient of Wage $_{t} \times$ Duopoly shows that reciprocity in the Duopoly phase is insignificantly higher than in the Monopoly phase, and this result is robust to the different model specifications. Effort tends to decrease over time in both phases, and these period effects are stronger in the Duopoly. Wages received in the previous period negatively affect effort in the current period, similarly in the Duopoly and the Monopoly phases. In both phases, the impact of the effort chosen in the previous period is positive, and not significantly higher in the Duopoly phase.

Table 4.16 shows regression results for the QtoM treatment. Also in this case, the Monopoly phase serves as reference group. Again, we find a positive and highly significant relationship between effort and wage in the three specifications we consider. Moreover, we do not find any significant difference in the wageeffort relationship between the Quadropoly and the subsequent Monopoly phase in specifications (1) and (2). Reciprocity is significantly lower in Quadropoly when controlling for lagged wage and effort. Effort significantly decreases in the Monopoly, while no significant time trend is found in the Quadropoly. In both phases, wage offers received in the previous period are negatively correlated with effort choices in the current period. Previous period effort choices have a positive impact on current ones, significant only in Monopoly. There are no differences in this effect between the Quadropoly and the Monopoly phase.

Overall, it is clear that both wages and effort respond to the intensity of output market competition. However, the effects of the market liberalization and those of the removal of competition are not symmetric for the Duopoly case: both wages and effort decrease much more when competition is removed than they increase when markets are liberalized. On the other hand, the effects of introducing and removing competition on the wage-effort relation are quite symmetric. 
Table 4.15: Wage-effort relation - DtoM

\begin{tabular}{|c|c|c|c|}
\hline Dep. var.: Effort in $t$ & (1) & $(2)$ & $(3)$ \\
\hline Constant & $\begin{array}{c}-1.472^{* * *} \\
(0.425)\end{array}$ & $\begin{array}{r}-0.244 \\
(0.346)\end{array}$ & $\begin{array}{r}-0.100 \\
(0.375)\end{array}$ \\
\hline Duopoly & $\begin{array}{c}-0.618 \\
(0.833)\end{array}$ & $\begin{array}{r}-1.328 \\
(0.932)\end{array}$ & $\begin{array}{c}-1.685^{* *} \\
(0.323)\end{array}$ \\
\hline Wage $_{t}$ & $\begin{array}{l}0.096^{* * *} \\
(0.007)\end{array}$ & $\begin{array}{c}0.091^{* * *} \\
(0.007)\end{array}$ & $\begin{array}{l}0.095^{\text {*** }} \\
(0.014)\end{array}$ \\
\hline Wage $_{t} \times$ Duopoly & $\begin{array}{c}0.019 \\
(0.014)\end{array}$ & $\begin{array}{c}0.024 \\
(0.014)\end{array}$ & $\begin{array}{c}0.025 \\
(0.018)\end{array}$ \\
\hline Period $t$ & & $\begin{array}{c}-0.128^{* *} \\
(0.048)\end{array}$ & $\begin{array}{c}-0.117^{* * *} \\
(0.032)\end{array}$ \\
\hline Period $t \times$ Duopoly & & $\begin{array}{c}-0.070 \\
(0.036)\end{array}$ & $\begin{array}{c}-0.083^{* *} \\
(0.031)\end{array}$ \\
\hline Wage $_{t-1}$ & & & $\begin{array}{r}-0.048^{*} \\
(0.021)\end{array}$ \\
\hline Wage $_{t-1} \times$ Duopoly & & & $\begin{array}{c}-0.024 \\
(0.019)\end{array}$ \\
\hline Effort $_{t-1}$ & & & $\begin{array}{l}0.495^{* *} \\
(0.165)\end{array}$ \\
\hline Effort $_{t-1} \times$ Duopoly & & & $\begin{array}{c}0.312 \\
(0.172) \\
\end{array}$ \\
\hline $\mathrm{N}$ & $(660)$ & $(660)$ & $(616)$ \\
\hline
\end{tabular}


Table 4.16: Wage-effort relation - QtoM

\begin{tabular}{|c|c|c|c|}
\hline Dep. var.: Effort in $t$ & (1) & $(2)$ & $(3)$ \\
\hline Constant & $\begin{array}{c}-1.676^{* * *} \\
(0.430)\end{array}$ & $\begin{array}{c}-0.904 \\
(0.478)\end{array}$ & $\begin{array}{r}-0.684 \\
(0.553)\end{array}$ \\
\hline Quadropoly & $\begin{array}{c}0.293 \\
(0.556)\end{array}$ & $\begin{array}{r}-0.615 \\
(0.794)\end{array}$ & $\begin{array}{r}-0.621 \\
(0.786)\end{array}$ \\
\hline Wage $_{t}$ & $\begin{array}{l}0.114^{* * *} \\
(0.010)\end{array}$ & $\begin{array}{l}0.113^{* * *} \\
(0.010)\end{array}$ & $\begin{array}{l}0.124^{* * *} \\
(0.010)\end{array}$ \\
\hline Wage $_{t} \times$ Quadropoly & $\begin{array}{c}-0.003 \\
(0.010)\end{array}$ & $\begin{array}{c}-0.002 \\
(0.010)\end{array}$ & $\begin{array}{c}-0.027^{*} \\
(0.013)\end{array}$ \\
\hline Period $t$ & & $\begin{array}{c}-0.090^{* * *} \\
(0.025)\end{array}$ & $\begin{array}{c}-0.091^{* * *} \\
(0.024)\end{array}$ \\
\hline Period $t \times$ Quadropoly & & $\begin{array}{c}0.021 \\
(0.035)\end{array}$ & $\begin{array}{c}-0.003 \\
(0.035)\end{array}$ \\
\hline Wage $_{t-1}$ & & & $\begin{array}{c}-0.058^{* * *} \\
(0.015)\end{array}$ \\
\hline Wage $_{t-1} \times$ Quadropoly & & & $\begin{array}{c}0.044^{*} \\
(0.018)\end{array}$ \\
\hline Effort $_{t-1}$ & & & $\begin{array}{c}0.480^{*} \\
(0.191)\end{array}$ \\
\hline Effort $_{t-1} \times$ Quadropoly & & & $\begin{array}{c}-0.186 \\
(0.212)\end{array}$ \\
\hline $\mathrm{N}$ & $(960)$ & $(960)$ & $(896)$ \\
\hline
\end{tabular}

*** $p<0.001$; ${ }^{*} p<0.05$. Bootstrapped robust standard errors, clustered over independent observations, in parentheses. Quadropoly takes value 1 if the observation comes from phase 1 of the QtoM treatment, and 0 otherwise. 


\section{Product market outcomes}

The statistically significant differences in wages and effort between phases of DtoM and QtoM translate into capacities and quantities sold that significantly differ across these phases. As shown in Table 4.17, average quantities produced and sold significantly decrease when markets become less competitive. Workers and total surplus are lower in the monopoly phase of both treatments DtoM and QtoM, while firms surplus is slightly higher. ${ }^{28}$

Table 4.17: Average market outcomes

\begin{tabular}{|c|c|c|c|c|c|c|}
\hline & \multicolumn{3}{|c|}{ DtoM } & \multicolumn{3}{|c|}{ QtoM } \\
\hline & Duopoly & & Monopoly & Quadropoly & & Monopoly \\
\hline $\bar{Q}$ & $\begin{array}{l}394.79 \\
(61.80)\end{array}$ & $>* * *$ & $\begin{array}{l}286.67 \\
(58.48)\end{array}$ & $\begin{array}{l}765.33 \\
(74.51)\end{array}$ & $>* * *$ & $\begin{array}{l}646.17 \\
(26.69)\end{array}$ \\
\hline$Q^{s}$ & $\begin{array}{l}374.88 \\
(66.77)\end{array}$ & $>* * *$ & $\begin{array}{l}275.35 \\
(51.91)\end{array}$ & $\begin{array}{l}736.60 \\
(88.54)\end{array}$ & $>^{* * *}$ & $\begin{array}{l}614.99 \\
(26.21)\end{array}$ \\
\hline Firms surplus & $\begin{array}{l}239.55 \\
(19.36)\end{array}$ & $<^{*}$ & $\begin{array}{l}255.53 \\
(22.08)\end{array}$ & $\begin{array}{l}516.87 \\
(22.42)\end{array}$ & $<$ & $\begin{array}{l}521.30 \\
(22.37)\end{array}$ \\
\hline Workers surplus & $\begin{array}{l}113.24 \\
(16.48)\end{array}$ & $>^{* * *}$ & $\begin{array}{c}67.17 \\
(29.89)\end{array}$ & $\begin{array}{l}205.53 \\
(16.61)\end{array}$ & $>^{* * *}$ & $\begin{array}{l}154.75 \\
(25.84)\end{array}$ \\
\hline Total surplus & $\begin{array}{l}539.54 \\
(65.60)\end{array}$ & $>^{* * *}$ & $\begin{array}{l}430.37 \\
(62.70)\end{array}$ & $\begin{array}{c}1075.53 \\
(90.09)\end{array}$ & $>^{* * *}$ & $\begin{array}{l}936.71 \\
(31.31)\end{array}$ \\
\hline
\end{tabular}

All averages and standard deviations (in parentheses) are taken over periods and independent observations. In the Monopoly phase of DtoM, averages are taken over the sum of the two markets that were merged in the Duopoly phase. In the Monopoly phase of QtoM, averages are taken over the sum of the four markets that were merged in the Quadropoly phase. In the Duopoly and Quadropoply phases averages are taken within a market.

*** $p<0.001 ;{ }^{*} p<0.05$. Statistical significance is assessed using panel fixed effects linear regressions, using the Monopoly phase of DtoM or QtoM as reference group, and a dummy variable for the Phase 1 of each treatment. Bootstrapped standard errors are clustered over independent observations.

Table 4.18 reports average surplus shares. Workers' share of total surplus decreases strongly when going from duopoly to monopoly markets, while its reduction in the QtoM treatment is milder. The share of surplus going to firms increases in the Monopoly phases of both treatments, whereas consumers surplus tends to decrease.

In sum, the removal of output market competition, leads to a decrease in the quantity produced and sold, which results in lower total surplus. Workers earn less after the removal of competition, and firms surplus increases. The

\footnotetext{
${ }^{28}$ These results are in line with the Wilcoxon non-parametric test results reported in Appendix 4.A.3 Table 4.22.
} 
Table 4.18: Average surplus shares

\begin{tabular}{lcclcc}
\hline \hline & \multicolumn{2}{c}{ DtoM } & & \multicolumn{2}{c}{ QtoM } \\
\cline { 2 - 3 } \cline { 5 - 6 } & Duopoly & Monopoly & & Quadropoly & Monopoly \\
\hline Firms & 44.40 & 59.38 & & 48.06 & 55.65 \\
Workers & 20.99 & 15.61 & & 19.11 & 16.52 \\
Consumers & 34.61 & 25.02 & & 32.83 & 27.82 \\
\hline
\end{tabular}

Numbers in the table are percentages.

effects on product market outcomes of the market liberalization and those of the removal of competition are rather symmetric, with the exception of the workers' share of total surplus. The latter remains largely unchanged under market liberalization, but decreases after the removal of competition.

\subsection{Summary and conclusions}

In this chapter, we investigated how market liberalization, which increases simultaneously competition between firms on the product market and consumers demand, interacts with reciprocal relationships within firms in a labor market characterized by incomplete contracts. We implemented a within-subject design where firms and workers experienced different market institutions. In one treatment, subjects interacted first in a monopoly and then in a duopoly. In a second treatment, the monopoly condition was followed by a quadropoly. We also studied the removal of competition in two additional treatments, which differed from the previous ones exclusively with respect to the order in which market environments followed one another. Therefore, in these treatments market conditions changed from duopoly to monopoly, and from quadropoly to monopoly. In all treatments, each firm was paired with one worker, so that competition in the labor market remained unchanged.

We find that wages and effort are highly responsive to the market environment. Firms in our experiments offer higher wages after markets are liberalized, as a response to the positive demand shock, and this induces higher effort levels of workers. The opposite pattern is observed when competition is removed: wages, and effort, decrease when the market size and competition are reduced. Our experimental labor markets respond asymmetrically to output market liberalization and to the removal of competition, but only when few firms are involved. In particular, following a duopoly the drop in wage and effort is larger, on average, than their increase following a monopoly. 
Competitive markets produce and sell more due to market liberalization, generating higher total surplus. The removal of competition, instead, causes a drop in the output produced and sold, so that monopoly markets that follow a duopoly or a quadropoly are characterized by lower total surplus. This corroborates the results of experimental studies on oligopoly markets with complete contracts showing that increased competition leads to lower prices and higher generated surplus (Dufwenberg and Gneezy [2000], Huck et al. [2004], Abbink and Brandts [2005], Brandts and Guillen [2007], Abbink and Brandts [2008], Fonseca and Normann [2012]).

An important result is that the increased competition resulting from market liberalization does not diminish reciprocity between firms and workers. A positive wage-effort relationship appears in all markets independent of their size, as previously shown in the gift-exchange experimental literature. Moreover, we find that reciprocal behavior is quite stable across markets characterized by different levels of competitiveness. This holds both when a monopoly is followed by a duopoly, and when a major increase in competition is introduced bringing the number of firms in the market from one to four. Also in the treatments where competition is removed we do not find consistent significant differences in the reciprocal firm-worker relationship. This finding is not in line with the view of Bowles [1998] mentioned in the introduction, nor with the stream of experimental research documenting the detrimental effects of market experience on other-regarding inclinations.

One interpretation of our results is that workers simply respond to the wage offer they receive, independent of the mechanism that led to them (competitive or not). Alternatively, following Kahneman et al. [1986], workers might take into account the effects of competition on market demand, profits and, therefore, wages when choosing their effort. The introduction of competition exposes workers to higher wages than those received in the past, which might help sustain reciprocity. On the other hand, the lower wages received after competition is removed might not trigger hostile reactions because not perceived as unfair. In our setting, the removal of competition leads, at the same time, to higher profits and a lower market demand. Therefore, lower effort is required in a monopoly than in a more competitive market, which may justify the decrease in wages.

Our experiment shows that the unexpected exposure to market interactions does not fundamentally alter our subjects' pro-social behavior. We interpret these findings as evidence that reciprocal firm-worker relationships can survive 
under market liberalization. Our experimental data provide support for the welfare enhancing effect of liberalization in a setting where labor relations are characterized by incomplete contracts. Clearly, our evidence does not shed light on every aspect of the interaction between labor market gift-exchange and output market competition. Other settings and institutional environments should be investigated. 


\section{Appendix}

\section{A Additional statistical analyses}

\section{A.1 Market liberalization - Non-parametric analysis}

\section{Differences between phases within a treatment}

For the Wilcoxon tests in this subsection we will use market averages as unit of observation. Since we have 22 (32) independent observations in the Monopoly phase and 11 (8) in the Duopoly (Quadropoly) phase of MtoD (MtoQ), in the former averages are taken over two (four) markets.

Table 4.19: Wilcoxon tests - $p$-values

\begin{tabular}{lll}
\hline \hline & MtoD & MtoQ \\
\hline Wage & 0.1549 & 0.0117 \\
Effort & 0.1422 & 0.0116 \\
Capacities & 0.1422 & 0.0116 \\
Quantity sold & 0.0619 & 0.0117 \\
Firms surplus & 0.0040 & 0.4838 \\
Workers surplus & 0.2860 & 0.0117 \\
Total surplus & 0.0262 & 0.0117 \\
\hline
\end{tabular}

Wilcoxon tests are two-sided and take market averages as the unit of observation.

\section{Trend analysis}

The impression of opposite wage dynamics in small and large markets (Figure 4.3) is (partially) corroborated by Jonckheere-Terpstra (JT) tests. ${ }^{29}$ The

\footnotetext{
${ }^{29}$ The Jonckheere-Terpstra test is a nonparametric test for ordered differences among classes. Here, we test the null hypothesis that average wage and effort do not differ among periods, against the alternative hypothesis that there is an ordered difference among periods. In particular, being $\bar{w}_{t}$ and $\bar{e}_{t}$ the average wage and effort in period $t$, we test whether $\bar{w}_{1} \geq$ $\bar{w}_{2} \geq \ldots \geq \bar{w}_{15}$ in the Monopoly phases, and whether $\bar{w}_{16} \leq \ldots \leq \bar{w}_{30}$ in the Duopoly and Quadropoly phases (similarly, for effort: $\bar{e}_{1} \geq \bar{e}_{2} \geq \ldots \geq \bar{e}_{15}$, and $\bar{e}_{16} \leq \ldots \leq \bar{e}_{30}$ ), with at least one strict inequality.
} 
tests show that in the Monopoly phase of both MtoD and MtoQ average wages are significantly decreasing over time (MtoD: $p=0.0011$; MtoQ: $p=0.0009$ ). The increasing trend of average wage in competitive markets is not statistically significant in the Duopoly phase $(p=0.1630)$, while it is so in the Quadropoly phase $(p<0.001)$.

As for effort levels, JT test results show a significant decreasing trend in the Monopoly phase of both MtoD $(p=0.0005)$ and MtoQ $(p=0.0002)$. Effort levels do not exhibit any significant trend in the Duopoly phase of MtoD $(p=0.1683)$, while they do increase over time in the Quadropoly phase of MtoQ $(p=0.0005)$.

Note that, while all the JT results hold despite the endgame effect, in the Duopoly phase of MtoD the increasing wage and effort dynamics become significant once we exclude the last period: $p=0.0182$ for wage and $p=0.0034$ for effort. 


\section{A.2 Additional regressions}

Table 4.20: Wage-effort relation - MtoD, control for risk and reciprocity attitudes

\begin{tabular}{lccc}
\hline \hline Dep. var.: Effort in t & $(1)$ & $(2)$ & $(3)$ \\
\hline Constant & -3.246 & -2.742 & -1.348 \\
& $(2.419)$ & $(2.592)$ & $(1.814)$ \\
Duopoly & 0.673 & 0.381 & 0.294 \\
& $(1.277)$ & $(1.132)$ & $(0.827)$ \\
Wage $_{t}$ & $0.111^{* * *}$ & $0.109^{* * *}$ & $0.115^{* * *}$ \\
& $(0.009)$ & $(0.010)$ & $(0.013)$ \\
Wage $_{t} \times$ Duopoly & -0.001 & 0.002 & 0.011 \\
& $(0.020)$ & $(0.023)$ & $(0.023)$ \\
Period $t$ & & -0.061 & -0.062 \\
& & $(0.043)$ & $(0.031)$ \\
Period $t \times$ Duopoly & & -0.041 & -0.088 \\
Wage \\
\end{tabular}


Table 4.21: Wage-effort relation - MtoQ, control for risk and reciprocity attitudes

\begin{tabular}{|c|c|c|c|}
\hline Dep. var.: Effort in $\mathrm{t}$ & (1) & $(2)$ & $(3)$ \\
\hline Constant & $\begin{array}{r}-0.441 \\
(0.875)\end{array}$ & $\begin{array}{c}0.040 \\
(0.909)\end{array}$ & $\begin{array}{c}0.333 \\
(0.732)\end{array}$ \\
\hline Quadropoly & $\begin{array}{r}-0.558 \\
(0.766)\end{array}$ & $\begin{array}{c}-0.975 \\
(0.790)\end{array}$ & $\begin{array}{r}-1.901^{*} \\
(0.751)\end{array}$ \\
\hline Wage $_{t}$ & $\begin{array}{l}0.100^{* * *} \\
(0.008)\end{array}$ & $\begin{array}{c}0.098^{* * *} \\
(0.008)\end{array}$ & $\begin{array}{c}0.104^{* * *} \\
(0.009)\end{array}$ \\
\hline Wage $_{t} \times$ Quadropoly & $\begin{array}{c}0.018 \\
(0.013)\end{array}$ & $\begin{array}{c}0.021 \\
(0.013)\end{array}$ & $\begin{array}{c}0.004 \\
(0.016)\end{array}$ \\
\hline Period $t$ & & $\begin{array}{r}-0.049^{*} \\
(0.025)\end{array}$ & $\begin{array}{c}-0.039 \\
(0.022)\end{array}$ \\
\hline Period $t \times$ Quadropoly & & $\begin{array}{r}-0.016 \\
(0.023)\end{array}$ & $\begin{array}{c}-0.066^{* * *} \\
(0.015)\end{array}$ \\
\hline Wage $_{t-1}$ & & & $\begin{array}{c}-0.038^{* * *} \\
(0.011)\end{array}$ \\
\hline Wage $_{t-1} \times$ Quadropoly & & & $\begin{array}{c}0.006 \\
(0.023)\end{array}$ \\
\hline Effort $_{t-1}$ & & & $\begin{array}{c}0.187^{*} \\
(0.086)\end{array}$ \\
\hline Effort $_{t-1} \times$ Quadropoly & & & $\begin{array}{c}0.365 \\
(0.200)\end{array}$ \\
\hline Risk & $\begin{array}{r}-0.118 \\
(0.095)\end{array}$ & $\begin{array}{r}-0.116 \\
(0.095)\end{array}$ & $\begin{array}{r}-0.029 \\
(0.057)\end{array}$ \\
\hline Positive reciprocity & $\begin{array}{r}-0.017 \\
(0.218)\end{array}$ & $\begin{array}{c}-0.024 \\
(0.218)\end{array}$ & $\begin{array}{r}-0.106 \\
(0.126)\end{array}$ \\
\hline Negative reciprocity & $\begin{array}{c}0.158 \\
(0.161)\end{array}$ & $\begin{array}{c}0.161 \\
(0.161)\end{array}$ & $\begin{array}{c}0.129 \\
(0.082)\end{array}$ \\
\hline $\mathrm{N}$ & 960 & 960 & 896 \\
\hline
\end{tabular}




\section{A.3 Removal of competition - Non-parametric analysis Differences between phases within a treatment}

Table 4.22: Wilcoxon tests - $p$-values

\begin{tabular}{lll}
\hline \hline & DtoM & QtoM \\
\hline Wage & 0.0033 & 0.0117 \\
Effort & 0.0033 & 0.0117 \\
Capacities & 0.0033 & 0.0116 \\
Quantity sold & 0.0044 & 0.0173 \\
Firms surplus & 0.0912 & 0.8886 \\
Workers surplus & 0.0033 & 0.0173 \\
Total surplus & 0.0033 & 0.0117 \\
\hline
\end{tabular}

Wilcoxon tests are two-sided and take averages over independent observations (markets of bigger size) as the unit of observation.

Table 4.23: Contingency tables I - Wage

\begin{tabular}{lcclcc}
\hline \hline & \multicolumn{2}{c}{ DtoM } & & \multicolumn{2}{c}{ QtoM } \\
\cline { 2 - 3 } \cline { 5 - 6 } Quartile (Wage offers) & Monopoly & Duopoly & & Monopoly & Quadropoly \\
\hline 1st (0-40) & $49.4(163)$ & $16.5(54)$ & & $34.8(167)$ & $21.9(105)$ \\
2nd (41-60) & $24.8(82)$ & $16.6(55)$ & & $32.3(155)$ & $21.9(105)$ \\
3rd (61-75) & $13.0(43)$ & $16.6(55)$ & & $25.4(122)$ & $17.7(85)$ \\
4th (76-100) & $12.8(42)$ & $50.3(166)$ & & $7.5(36)$ & $38.5(185)$ \\
Total & $100.0(330)$ & $100.0(330)$ & & $100.0(480)$ & $100.0(480)$ \\
\hline Stuart-Maxwell test & \multicolumn{3}{c}{$p<0.001$} & & \multicolumn{2}{c}{$p<0.001$} \\
\hline
\end{tabular}

Numbers in the table are percentages; frequencies are in parentheses.

Table 4.24: Contingency tables II - Effort

\begin{tabular}{lcclccc}
\hline \hline & \multicolumn{2}{c}{ DtoM } & & \multicolumn{2}{c}{ QtoM } \\
\cline { 2 - 3 } \cline { 6 - 7 } Quartile (Effort levels) & Monopoly & Duopoly & & Monopoly & Quadropoly \\
\hline 1st (0-2) & $43.6(144)$ & $18.5(61)$ & & $27.7(133)$ & $24.2(116)$ \\
2nd (3-5) & $35.2(116)$ & $20.3(67)$ & & $38.3(184)$ & $21.1(101)$ \\
3rd (6-7) & $14.8(49)$ & $21.8(72)$ & & $24.8(119)$ & $20.8(100)$ \\
4th (8-10) & $6.4(21)$ & $39.4(130)$ & & $9.2(44)$ & $33.9(163)$ \\
Total & $100.0(330)$ & $100.0(330)$ & & $100.0(480)$ & $100.0(480)$ \\
\hline Stuart-Maxwell test & \multicolumn{2}{c}{$p<0.001$} & & \multicolumn{2}{c}{$p<0.001$} \\
\hline
\end{tabular}

Numbers in the table are percentages; frequencies are in parentheses. 


\section{Trend analysis}

JT tests applied to averages over independent observations of wages and effort yield the following results: in the Duopoly phase of DtoM, neither wages nor effort show significant time trends ( $p=0.9425$ for wage, $p=0.5010$ for effort), while the Monopoly phase is characterized by wage offers and effort levels that significantly decrease over time ( $p<0.001$ for both variables); in QtoM, instead, wages and effort significantly increase over time in the Quadropoly phase ( $p=0.0312$ for wage, $p=0.0502$ for effort) and significantly decrease in the Monopoly phase ( $p=0.0024$ for wage, $p<0.001$ for effort). These results hold also when we exclude from the analysis the last period of both phases.

\section{Correlation wage-effort}

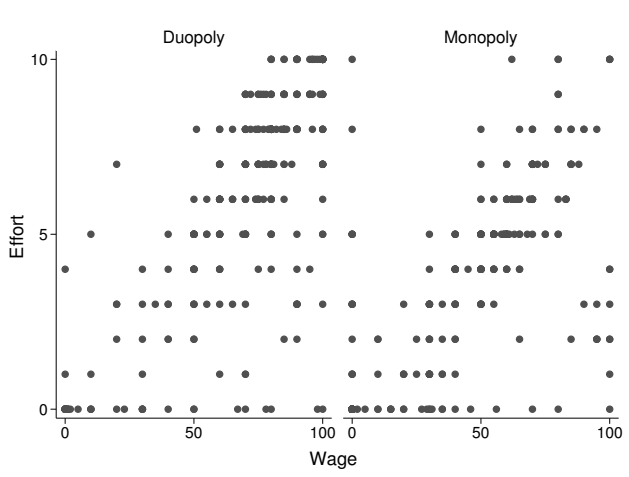

(a) DtoM

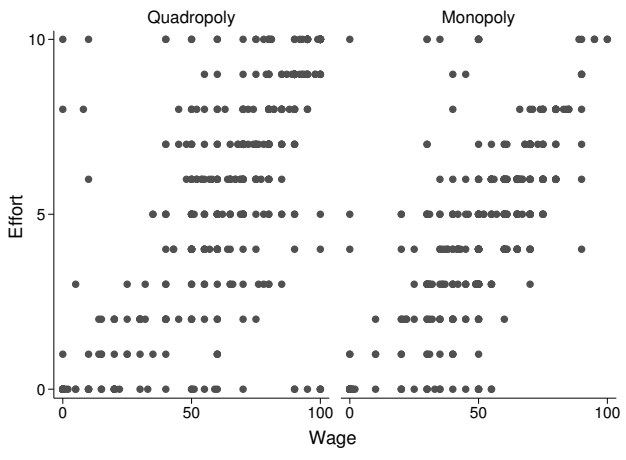

(b) QtoM

Figure 4.8: Relation between wage offers and effort levels 


\section{B Theoretical background}

In this section we formally derive the predictions of the standard theoretical model, and those of the reduced form gift-exchange model presented in Section 4.2 .2 .

Under the standard assumptions of rational and narrowly selfish agents, the subgame perfect Nash equilibrium is zero effort, zero wage and no relationship between wage offers and effort levels. Given the implemented production function $\left(\bar{q}_{i}=80+20 e_{i}\right)$, this implies that the individual equilibrium output is $q i=\bar{q}_{i}=80$ in all markets. The total equilibrium output is $Q_{1}=\bar{Q}_{1}=80$, $Q_{2}=\bar{Q}_{2}=160$ and $Q_{4}=\bar{Q}_{4}=320$, respectively in Monopoly, Duopoly and Quadropoly. Consequently, the equilibrium market price is $p_{n}=320$, with $n \in\{1,2,4\}$. The equilibrium surpluses are calculated as follows:

$$
\begin{aligned}
W S_{n} & =n\left(w_{i}^{*}-2 e_{i}^{*}\right), \\
F S_{n} & =n\left(\frac{p_{i}^{*} q_{i}^{*}}{200}-w_{i}^{*}\right) \\
C S_{n} & =\frac{1}{2}\left[\left(400-p_{i}^{*}\right) Q^{*}\right] .
\end{aligned}
$$

This yields $W S_{n}=0$ with $n \in\{1,2,4\}$ for the workers; $F S_{1}=128, F S_{2}=256$ and $F S_{4}=512$ for firms; $C S_{1}=16, C S_{2}=32$ and $C S_{4}=64$ for consumers. The total surplus is simply the sum of $W S_{n}, F S_{n}$ and $C S_{n}$, and equals $T S_{1}=$ $144, T S_{2}=288$ and $T S_{4}=576$.

The alternative view of the gift-exchange hypothesis, instead, assumes that for all firms in the market

$$
e_{i}\left(w_{i}\right)=\gamma_{n} w_{i}
$$

where $\gamma_{n}$ is a reciprocity parameter when $n$ firms compete on the market. In equilibrium, firms bring full capacity to the market (i.e., $\left.q_{i}=\bar{q}_{i}\right) .{ }^{30}$ Assuming symmetry among rival firms, firm $i$ 's profit function is given by

$\pi_{i}=\frac{\left[400-\frac{1}{n}\left(80+20 \gamma_{n} w_{i}\right)-(n-1)\left(\frac{1}{n}\left(80+20 \gamma_{n} w_{j}\right)\right)\right]\left[80+20 \gamma_{n} w_{i}\right]}{200}-w_{i}$.

Solving for the profit maximizing wage $w_{i}$, yields the reaction function

$$
w_{i}\left(w_{j}\right)=\frac{32 \gamma_{n} n-8 \gamma_{n}-2(n-1) \gamma_{n}^{2} w_{j}-n}{4 \gamma_{n}^{2}} .
$$

\footnotetext{
${ }^{30}$ Since all firms know the prevailing conditions in their market, each firm is able to calculate the quantity that maximizes her profit. Given that the relations $\bar{q}_{i}=80+20 e_{i}\left(w_{i}\right)$ and $e_{i}\left(w_{i}\right)=\gamma_{n} w_{i}$ are common knowledge, each firm is also able to exactly calculate what effort needs to be elicited, and thus what wage to offer, for the equilibrium quantity to be produced. This implies that, in equilibrium, there is no excess capacity.
} 
Assuming symmetry among firms (i.e., $w_{i}=w_{j}, i \neq j$ ) gives the unique symmetric Nash equilibrium wage:

$$
w_{i}^{*}=\frac{32 n \gamma_{n}-8 \gamma_{n}-n}{2(n+1) \gamma_{n}^{2}} .
$$

By plugging $w_{i}^{*}$ into (4.4), we obtain the equilibrium effort level:

$$
e_{i}^{*}=\frac{32 n \gamma_{n}-8 \gamma_{n}-n}{2(n+1) \gamma_{n}}
$$

and substituting $e_{i}^{*}$ in the production function $\bar{q}_{i}=80+20 e_{i}$ gives the equilibrium production capacities and sales:

$$
q_{i}^{*}=\bar{q}_{i}^{*}=\frac{400 n \gamma_{n}-10 n}{(n+1) \gamma_{n}} .
$$

Given $Q_{n}^{*}=n q_{i}^{*}$, the equilibrium market quantities and prices are given by:

$$
Q_{n}^{*}=\bar{Q}_{n}=\frac{400 n^{2} \gamma_{n}-10 n^{2}}{(n+1) \gamma_{n}} \quad \text { and } \quad p_{n}^{*}=\frac{400 \gamma_{n}+10 n}{(n+1) \gamma_{n}} .
$$

Lastly, the surpluses for, respectively, workers, firms and consumers are calculated according to the formulae in 4.1, 4.2 and 4.3. 


\section{C Instructions for the MtoD treatment}

You are going to participate in an economic experiment. You can earn money with the decisions you make. Please, read these instructions carefully. If you have any questions please raise your hand and one of us will come to you to answer your question in private.

In this experiment the amount of your earnings depends not only on your own decisions but also on the decisions of other participants you will interact with. During the experiment, your earnings will be calculated in experimental currency units (ECU). The experiment will consist of several periods. At the end of the experiment, your ECU earnings in each period will be summed up and converted into euros at the following rate:

$200 \mathrm{ECU}=1$ euro

During the experiment it might happen that you incur losses. That is, it might happen that you earn negative ECU amounts in a period. Eventual losses in a round will be subtracted from your accumulated earnings. In case of the highly unlikely event of an overall loss your earnings will be zero. Importantly, in each period, you can avoid losses through your own decisions.

At the end of the experiment you will be paid out your earnings in cash in private. All your earnings will be treated confidentially.

The experiment consists of two parts. You are now receiving instructions for part 1. At the end of the first part, you will receive instructions for part 2.

Important: During the experiment you are not allowed to communicate with other participants by any means other than those indicated in these instructions. If you are found violating these rules, you will both forfeit any earnings from this experiment, and may be excluded from future experiments as well. 


\section{Instructions for part 1}

\section{Roles and pairing}

At the beginning of the session, each participant will be randomly assigned to one of two possible roles. Half of you will be firms and half will be workers. Your computer screen will inform you about your role.

Each firm and each worker will be randomly paired to form a firm-worker pair. You will never be informed about the identity of the participant you have been paired with. Likewise, your paired participant will never get to know your identity.

Your role and the pair you are in will stay fixed throughout the entire first part of the experiment. This part of the experiment consists of 15 periods.

\section{Decision-making in each period}

Each period consists of three stages:

Stage 1: Each firm makes a wage offer to the worker s/he is paired with.

Stage 2: After having observed the wage, workers decide on their effort level. The chosen effort level determines the product stock size of the firm.

Stage 3: Firms get to know their stock size and choose how many units they want to sell on the market.

The details of the procedures in the three stages are explained below.

\section{Procedures}

1. At the beginning of each period, the firm offers a wage to the worker $\mathrm{s} /$ he has been paired with. Wage offers must be integer numbers and lie between 0 and 100 (inclusive). The wage has to be accepted by the worker.

2. Wage offers will only be transmitted to the worker a firm is paired with. No other worker and no other firm will get to know the wage offer a firm makes.

3. After $\mathrm{s} /$ he is informed about the wage offer, the worker decides on his/her effort level by choosing an integer number between (and including) 0 and 10 , where 0 is the lowest and 10 the highest effort level. Chosen effort levels will only be transmitted to the firm the worker is paired with. The effort level the worker chooses determines the firm's product stock size. The firm's stock size is larger the larger the worker's effort level and is calculated according to the following formula:

$$
\text { stock size }=80+20 \times \text { effort level }
$$


The following table shows for each effort level the corresponding stock size:

\begin{tabular}{lccccccccccc}
\hline Effort level & 0 & 1 & 2 & 3 & 4 & 5 & 6 & 7 & 8 & 9 & 10 \\
Stock size & 80 & 100 & 120 & 140 & 160 & 180 & 200 & 220 & 240 & 260 & 280 \\
\hline
\end{tabular}

Effort levels and associated stock sizes

4. After the worker has chosen his/her effort level, the firm will be informed about his/her stock size.

5. Then, the firm decides on the number of units $\mathbf{s} /$ he sells on the market, by choosing an integer number between 0 and his/her stock size (inclusive). NB: A firm does not have to sell the full stock size.

6. The market price the firm receives for his/her units put on the market is determined by the number of units put on the market. The higher the number of units put on the market, the lower the price that the firm receives for each unit sold. Specifically, the market price is given by the formula:

market price $=400$ - total number of units on the market

\section{How the earnings in a period are calculated}

\section{A worker's earnings in a period}

1. In each period a worker has to provide effort. Providing effort is costly to the worker, and this cost is higher the higher the chosen effort level. Zero effort has no cost but each additional unit of effort costs 2 ECU. The schedule below shows how costs vary with chosen effort levels:

\begin{tabular}{llllllcccccc}
\hline Effort level & 0 & 1 & 2 & 3 & 4 & 5 & 6 & 7 & 8 & 9 & 10 \\
Cost of effort & 0 & 2 & 4 & 6 & 8 & 10 & 12 & 14 & 16 & 18 & 20 \\
\hline
\end{tabular}

Effort levels and associated costs

2. In each period, a worker will receive the offered wage. To calculate his/her earnings a worker has to subtract the cost of the effort from the wage. His/her earnings in a period are therefore given by:

\section{Worker's earnings $=$ wage offered - cost of effort $+\mathbf{7 0}$}

During the experiment, a worker can use an on-screen calculator to calculate his/her earnings.

\section{A firm's earnings in a period}

1. In each period, the revenue of a firm equals the number of units sold on the market multiplied by the market price and divided by 200 . That is, 
Firm's revenue $=($ market price $\mathrm{x}$ number of units sold $) / 200$

During the experiment, a firm can use an on-screen calculator to calculate his/her revenues.

2. The following table presents the resulting market price and revenue for three hypothetical numbers of units sold by the firm:

\begin{tabular}{|c|c|c|}
\hline \multicolumn{3}{|c|}{ Number of units sold } \\
\hline 63 & 132 & 221 \\
\hline $400-63=337$ & $400-132=268$ & $400-221=179$ \\
market price $=337$ & market price $=268$ & market price $=179$ \\
own revenue $=106.2$ & own revenue $=176.9$ & own revenue $=197.8$ \\
& & \\
\hline
\end{tabular}

3. In each period, the earnings of a firm are the difference between his/her revenue and the wage s/he offers to his/her worker. Therefore, a firm's earnings in a period are given by:

\section{Firm's earnings $=$ firm's revenue - offered wage $=$ (market price $\mathrm{x}$ number of units sold)/200 - offered wage}

\section{Information at the end of a period}

At the end of each period, each firm and each worker receive information on the decisions that are relevant for their earnings.

Each firm is informed about:

- the wage $\mathrm{s} /$ he offered to the worker $\mathrm{s} /$ he is paired with

- the effort level that is chosen by his/her worker

- the own stock size

- the own number of units sold on the market

- the market price in the own market

- own earnings

- earnings of the worker $\mathrm{s} /$ he is paired with

Each worker is informed about:

- the wage offered by the firm $\mathrm{s} /$ he is paired with

- the effort level s/he has chosen

- the cost associated with the chosen effort level

- stock size of the firm s/he is paired with

- number of units sold on the market by the firm the worker is paired with

- the market price in the own market

- own earnings

- earnings of the firm $\mathrm{s} / \mathrm{he}$ is paired with 


\section{Instructions for part 2}

This part of the experiment is the same as the first part, with one exception: now there are two firms in the market that can sell the same product.

\section{Roles, pairing and matching}

You keep the same role as in part 1.

Your partner (either firm, if you are a worker, or worker, if you are a firm) is the same as in part 1.

Each firm now will be randomly matched with one other firm in order to form a market where the two firms can sell the same product.

The market you are in will stay fixed throughout the entire second part of the experiment.

This part of the experiment also consists of 15 periods.

Procedures Procedures are the same as in part 1.

\section{Summary - firms:}

1. Stock size:

$$
\text { stock size }=80+20 \times \text { effort level }
$$

The following table shows for each effort level the corresponding stock size:

\begin{tabular}{lccccccccccc}
\hline Effort level & 0 & 1 & 2 & 3 & 4 & 5 & 6 & 7 & 8 & 9 & 10 \\
Stock size & 80 & 100 & 120 & 140 & 160 & 180 & 200 & 220 & 240 & 260 & 280 \\
\hline
\end{tabular}

Effort levels and associated stock sizes

2. The market price each firm receives for his/her units put on the market is determined by the total number of units put on the market. The total number of units on the market is the sum of units put on the market by each individual firm. The higher the total number of units put on the market, the lower the price that the firms receive for each unit sold. Specifically, the market price is now given by the formula:

market price $=400$ - total number of units on the market $/ 2$

\section{Summary - workers:}

1. Zero effort has no cost but each additional unit of effort costs 2 ECU. The schedule below shows how costs vary with chosen effort levels:

\begin{tabular}{llllllcccccc}
\hline Effort level & 0 & 1 & 2 & 3 & 4 & 5 & 6 & 7 & 8 & 9 & 10 \\
Cost of effort & 0 & 2 & 4 & 6 & 8 & 10 & 12 & 14 & 16 & 18 & 20 \\
\hline
\end{tabular}

Effort levels and associated costs 


\section{How the earnings in a period are calculated}

\section{A worker's earnings in a period}

In each period, a worker will receive the offered wage. To calculate his/her earnings a worker has to subtract the cost of the effort from the wage. His/her earnings in a period are therefore given by:

\section{Worker's earnings $=$ wage offered cost of effort +90}

During the experiment, a worker can use an on-screen calculator to calculate his/her earnings.

\section{A firm's earnings in a period}

1. In each period, the revenue of a firm equals the individual number of units sold on the market multiplied by the market price and divided by 200 . That is,

\section{Firm's revenue $=($ market price $\mathrm{x}$ individual number of units sold) $/ 200$}

During the experiment, a firm can use an on-screen calculator to calculate his/her revenues.

2. The following table presents the resulting market price and revenue for three hypothetical numbers of units sold by the own firm and the other firm, respectively:

\begin{tabular}{|c|c|c|c|c|}
\hline & \multicolumn{3}{|c|}{ Number of units sold by the other firm } \\
\hline & & 58 & 174 & 280 \\
\hline \multirow{3}{*}{ 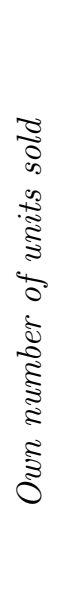 } & 64 & $\begin{array}{c}400-(64+58) / 2=339 \\
\text { market price }=339 \\
\text { own revenue }=108.5\end{array}$ & $\begin{array}{c}400-(64+174) / 2=281 \\
\text { market price }=281 \\
\text { own revenue }=89.9\end{array}$ & $\begin{array}{c}400-(64+280) / 2=228 \\
\text { market price }=228 \\
\text { own revenue }=73\end{array}$ \\
\hline & 132 & $\begin{array}{c}400-(132+58) / 2=305 \\
\text { market price }=305 \\
\text { own revenue }=201.3\end{array}$ & $\begin{array}{c}\text { 400- }(132+174) / 2=247 \\
\text { market price }=247 \\
\text { own revenue }=163\end{array}$ & $\begin{array}{c}\text { 400- }(132+280) / 2=194 \\
\text { market price }=194 \\
\text { own revenue }=128\end{array}$ \\
\hline & 278 & $\begin{array}{c}400-(278+58) / 2=232 \\
\text { market price }=232 \\
\text { own revenue }=322.5\end{array}$ & $\begin{array}{c}400-(278+174) / 2=174 \\
\text { market price }=174 \\
\text { own revenue }=241.9\end{array}$ & $\begin{array}{c}400-(278+280) / 2=121 \\
\text { market price }=121 \\
\text { own revenue }=168.2\end{array}$ \\
\hline
\end{tabular}

3. In each period, the earnings of a firm are the difference between his/her revenue and the wage s/he offers to his/her worker. Therefore, a firm's earnings in a period are given by: 


\section{Firm's earnings $=$ firm's revenue - offered wage $=$ (market price $\mathrm{x}$ individual number of units sold)/200 - offered wage}

\section{Information at the end of a period}

At the end of each period, each firm and each worker receive information on the decisions that are relevant for their earnings.

Each firm is informed about:

- the wage $\mathrm{s} /$ he offered to the worker $\mathrm{s} /$ he is paired with

- the effort level that is chosen by his/her worker

- the own stock size and that of the other firm in the same market

- the own number of units sold on the market and that of the other firm on the same market

- the market price in the own market

- own earnings

- earnings of the worker $\mathrm{s} /$ he is paired with

Each worker is informed about:

- the wage offered by the firm $\mathrm{s} /$ he is paired with

- the effort level s/he has chosen

- the cost associated with the chosen effort level

- stock size of the firm $\mathrm{s} /$ he is paired with

- number of units sold on the market by the firm the worker is paired with

- the market price in the own market

- own earnings

- earnings of the firm $\mathrm{s} / \mathrm{he}$ is paired with 


\title{
Chapter 5
}

\section{Do upfront investments increase cooperation? An experimental approach}

\begin{abstract}
A vast literature in economics and the social sciences has investigated institutions that foster cooperation, and has shown that a policy is more successful at increasing cooperation when it is endogenously chosen than when it is exogenously imposed. In this literature, it has always been implicitly assumed the presence of an enforcement mechanism. We investigate whether voluntary, decentralized upfront investments increase cooperation in settings where there is no enforcement mechanism and cooperation is not easily sustained voluntarily. We study whether this effect depends on the investments being endogenous or exogenous. Such investments are a cost that individuals have to incur before deciding whether to cooperate or not, and increase the payoff resulting from the choice to cooperate. We find that cooperation rarely emerges in treatments where investments are not possible. Introducing endogenous investment opportunities boosts overall cooperation levels. If low investments are implemented endogenously, cooperation is lower than when the same investments are exogenous. When investments are high, cooperation is not significantly different between the endogenous and the exogenous conditions. This is consistent with low investments being interpreted as a signal for unwillingness to cooperate, triggering non-cooperative choices.
\end{abstract}

Based on a joint work with Alice Ciccone and Christine Gutekunst. 


\subsection{Introduction}

The tension between opportunistic and cooperative behavior, resulting from a misalignment of individual and group interests, is pervasive in human interactions. A vast literature in economics and the social sciences has therefore investigated institutions that foster cooperation. ${ }^{1}$ Part of this literature has experimentally analyzed the effects on cooperative behavior of exogenous and endogenous institutions, and has shown that a given policy is more successful at increasing cooperation when it is endogenously chosen than when it is exogenously imposed (Tyran and Feld [2006], Dal Bó et al. [2010], Sutter et al. [2010], Markussen et al. [2014a], Kamei [2016]).

In these prior experiments, subjects are presented with different institutions and decide, through voting, on the rules governing their interactions. Putting an institution to the vote, however, does not imply it will be adopted. ${ }^{2}$ Moreover, the focus has been mostly on formal and informal sanctions (so that subjects choose whether and how much to punish free-riders), and it has been implicitly assumed the presence of an enforcement mechanism. However, in many circumstances agents cannot choose or vote for an enforcement institution. Even if institutional arrangements exist, cooperation is not always easily enforced. This is the case, for instance, for groups where agents, even though willing to cooperate, are not willing to punish, ${ }^{3}$ or when there is no institution with coercive power. A prominent example is given by international environmental agreements. Environmental treaties lack behind in their effectiveness in reducing global greenhouse gas emissions, and this is thought to be associated with the lack of a functioning enforcement mechanism capable of mitigating the inherent free-rider problem. This is the kind of situations that we address in this chapter.

We investigate whether voluntary decentralized upfront investments help promoting cooperation in a social dilemma, and whether this effect depends on the investments being endogenous (chosen by the participants) or exogenous (imposed by the experimenter). Such investments are a cost agents have to incur before deciding whether to cooperate or not, and increase the payoff re-

\footnotetext{
${ }^{1}$ Examples of such institutions include peer punishment (Fehr and Gächter [2000], Noussair and Tucker [2005]), competition (Markussen et al. [2014b]), communication (Isaac and Walker [1988]), re-distribution (Sausgruber and Tyran [2007]), group member selection (Gunnthorsdottir et al. [2010]) and advice (Chaudhuri et al. [2006a]), among others.

${ }^{2}$ In Botelho et al. [2005], for instance, most of the experimental subjects voted against the punishment institution, and in Dal Bó et al. [2010], nearly half of the subjects voted against a policy that could foster cooperation.

${ }^{3}$ See for instance Sutter et al. [2010].
} 
sulting from the choice to cooperate. Differently from previous studies, we do not ask whether agents would vote for an institution with coercive power that fosters cooperation, and whether this eventually increases cooperation. We ask whether agents themselves are able to create situations that are conducive to cooperation in settings where there is no enforcement mechanism and cooperation is not easily sustained voluntarily.

The social dilemma situation we consider is an infinitely repeated prisoners' dilemma (PD), which captures the tension at the heart of social dilemmas in a simple form. To test whether the possibility of voluntary upfront investments increases cooperation levels, we compare a condition without investments (NoInv) with a condition where participants can choose how much to invest (Endo). In the treatments with no investment opportunities, subjects just play a two-player repeated PD game for 12 matches, where each match lasts for a randomly determined number of periods. In the investment treatments, subjects decide, at the beginning of each match, how much of a given endowment they want to invest. Then, they learn each others' investment choices and choose between cooperation and defection. To determine whether it matters if investments are chosen or exogenously imposed, we compare the Endo condition with a condition where participants are presented with pre-determined investments (Exo). This also allows us to explore whether participants use investments to signal the intention to cooperate.

Theory and previous empirical work suggest that the discount factor plays an important role in the decision to cooperate. We therefore study whether changes in the discount factor, translated into the probability of continuation of a game, affect cooperation rates in the investigated context. In particular, each of the explored treatments (NoInv, Endo and Exo) is implemented using a low probability of continuation of 0.35 (labeled Short) and a high probability of continuation of 0.75 (labeled Long), which are exogenously imposed. When $\delta=0.35$, cooperation can never be supported as a subgame perfect Nash equilibrium in the NoInv treatment. In Endo and Exo, investments have the potential to transform a game where mutual defection is the only subgame perfect equilibrium into a game in which both mutual defection and mutual cooperation are equilibria, but only when investments are high enough. When $\delta=0.75$, both defection and cooperation are always sustainable in equilibrium.

Recent experiments on infinitely repeated prisoner's dilemma games have shown that individuals cooperate more when the probability of future interactions (i.e., the probability of continuation of the game) is high (Dal Bó [2005], 
Dal Bó and Fréchette [2011]), when cooperation is risk dominant (Blonski et al. [2011]), and when both continuation probabilities and cooperation payoff are sufficiently high (Dal Bó and Fréchette [2011]). Our experiment is inspired by Dal Bó and Fréchette [2011]. They exogenously vary the payoff from mutual cooperation and the probability of continuation $\delta$ of an indefinitely repeated PD to study how cooperation depends on whether mutual cooperation can be supported in a subgame perfect equilibrium, and in a risk dominant equilibrium. Differently from Dal Bó and Fréchette [2011], the (cooperation) payoffs in our repeated $\mathrm{PD}$ game are not exogenously given, but endogenously determined by participants' choice of an investment.

Our results can be summarized as follows. Cooperation rarely emerges in treatments where investments are not possible, for both low and high probabilities of continuation. Moreover, we find that when investments are possible but low, cooperation levels are not different from those observed in the no investment condition, but significantly lower than when the same investments are exogenous. This result holds both in the Short and in the Long treatments. When high investments are endogenous, cooperation is significantly higher than when investments are not possible, but not significantly different from cooperation in the exogenous conditions. This suggests that low investments signal unwillingness to cooperate, which triggers non-cooperative choices. On the other hand, high investments seem not to serve as signal for willingness to cooperate, as they increase cooperation independent of the mode of implementation.

Even though investments have the potential to foster cooperation, participants in our experiment frequently choose not to invest (in about 40 percent of the cases), or low investments (slightly more than 20 percent of the cases). The investment decision entails a coordination problem, in that individuals would like to invest if others invest as well. One explanation for the observed investment behavior is that our subjects are not able to solve such coordination problem. In most cases, indeed, and especially in the beginning of the experiment, subjects who choose high investments have opponents who choose low investments. This results in the former switching to low investments (especially 0 ) throughout the experiment, which always guarantees the mutual defection payoff in every period. In our game, not investing and defecting is, in fact, the risk dominant equilibrium. This finding is in line with empirical results on coordination problems, which show a tendency to select the risk-dominant equilibrium (Camerer [2003], Brandts and Cooper [2006a,b], Blume and Ortmann [2007], Chaudhuri et al. [2006b]). 
In line with the experimental literature on infinitely repeated $\mathrm{PD}$, we find that higher cooperation payoffs together with a high probability of continuation increase cooperation. In contrast to previous results, we find relatively high levels of cooperation also when $\delta$ is rather low, and no significant differences in cooperation rates between Short and Long treatments.

\subsection{Experimental design}

The experiment is structured as a $2 \times 3$ design and thus consists of six treatments. Two treatments are without investment opportunities (NoInvShort and NoInvLong), in two treatments players could invest before playing an indefinitely repeated PD game (EndoShort and EndoLong) and in two treatments investments were exogenously imposed (ExoShort and ExoLong). The suffixes "Short" and "Long" refer to the probability of continuation used in the corresponding treatment: matches continued from period to period with probability $\delta=0.35$ in the Short treatments, and with probability $\delta=0.75$ in the Long treatments.

In all treatments, subjects were randomly paired within matching groups of 8 participants and played a sequence of 12 matches. In each match, subjects were initially endowed with $w_{i}=8$ Experimental Currency Units (ECU) and played a repeated PD for a randomly determined number of periods. In each period, players chose between two actions, either cooperate or defect. ${ }^{4}$ The stage PD game is displayed in Table 5.1.

Table 5.1: Prisoner's dilemma game payoff matrix

\begin{tabular}{lcc}
\hline \hline & Cooperate & Defect \\
\hline Cooperate & $32+2 r_{i}, 32+2 r_{j}$ & $4+2 r_{i}, 50$ \\
Defect & $50,4+2 r_{j}$ & 25,25 \\
\hline
\end{tabular}

The parameters are calibrated following Dal Bó and Fréchette [2011], who exogenously vary the payoff from mutual cooperation and the probability of continuation $\delta$ of an indefinitely repeated PD to study how cooperation depends on whether mutual cooperation can be supported in a subgame perfect equilibrium (SPE). ${ }^{5}$ In our PD game, both the payoff from mutual cooperation

\footnotetext{
${ }^{4}$ We used a neutral language throughout the experiment, with players choosing between option "A" (cooperate) and option "B" (defect).

${ }^{5}$ Dal Bó and Fréchette [2011] also study whether risk dominance determines cooperation choices. In their experiment, the payoff from mutual cooperation $(R)$ takes one of three possible values: 32,40 , and 48 , while the sucker payoff is constant and equal to $12 ; \delta$ is equal
} 
and the sucker payoff increase with investment levels $r_{i}, r_{j}$, which are integers in $\{0,1, \ldots, 8\}$. When $r_{i}=0$, the cooperation payoff is 32 and the sucker payoff is 4. When $r_{i}=8$, the cooperation payoff is 48 , and the sucker payoff is 20 . This guarantees the conditions for cooperation to switch from not being sustainable in equilibrium to being supported as SPE as the investments increase. Under $\delta=0.35$, cooperation is not supported as SPE for $r_{i}, r_{j} \leq 4$, while it is for $r_{i}, r_{j}>4$. The equilibrium conditions will be derived and explained in detail in Section 5.3.

In the treatments with endogenous investments (EndoShort and EndoLong), participants could decide in the beginning of each match how much of their endowment they wish to invest, by choosing a number in $\{0,1, \ldots, 8\}$. Players within a pair were informed of the investment decision made by their partner before the PD started. Any non-invested unit produced one unit of direct private benefit, while the invested units were doubled and added to the payoff from cooperation in the subsequent PD game. Once a match ended, the new match began with a new investment decision. Hence, the investment decision was made once at the beginning of each match, and subjects were bound by that decision for the duration of that match. ${ }^{6}$

The only difference between the endogenous and the exogenous treatments (ExoShort and ExoLong) is that in the latter investments were not chosen by the participants. For each pair in the endogenous treatments, instead, we created a twin pair in the exogenous treatments, so that the participants in the exogenous condition were presented with the same sequence of investments as chosen by the participants in the endogenous condition. The purpose of the exogenous treatments is to disentangle the effect of the changes in the cooperation payoffs (induced by the investments) and the signaling effect implicit in the active choice of an investment level.

In the treatments without investment opportunity, the endowment of $w_{i}=8$ was added to the PD game payoff in every period. The resulting subgame is

to either 0.5 or 0.75 . Different combinations of $R$ and $\delta$ determine whether cooperation can be sustained as an SPE. In particular, for $R=32$ and $\delta=0.5$ cooperation is never sustainable in equilibrium, while for any other combination of $R$ and $\delta$, cooperation can always be supported in an SPE. Cooperation is risk dominant under $R=48$ and $\delta=0.5$, and under $R=40,48$ and $\delta=0.75$.

${ }^{6}$ As we are mainly interested in the role of investments in affecting cooperation levels, our primary concern is whether choices in the PD are responsive to investment decisions and, therefore, whether investments are used as a device to trigger future cooperation. If investment choices were to be revised in every period of a match, we could not rule out the possibility of them being used as a punishment device instead. Keeping investment decisions constant within matches, besides making the data more easily tractable, helps their interpretation to be less exposed to this confounding effect. 
then the same as the one induced by $r_{i}, r_{j}=0$ in the investment treatments.

In all treatments, pairs remained fixed throughout a match, and subjects were randomly paired with a new partner within their matching group at the end of a match. ${ }^{7}$ Since the matching groups consisted of 8 participants playing in 12 matches, subjects met the same partner 1.71 times on average. However, pairs were formed so that each participant would never play with the same partner two matches in a row. At the end of each PD stage game, subjects within a pair received information on their own and their partner's actions and payoffs. In the investment treatments, players were reminded of the investment levels as well. Earnings at the end of a match were the sum of the payoffs realized in each period. At the end of the experimental session, for each matching group one out of the 12 matches was randomly picked. Subjects in a matching group were paid in cash according to the earnings of that match.

\subsubsection{Procedures}

The instructions for the experiment were provided on paper, and participants had the opportunity to ask questions at any time during a session. All questions were asked and answered in private. Participants were asked to answer a series of comprehension questions to verify their full understanding of the game. The experiment started only after all participants had answered correctly all questions. The experiment ended with a questionnaire.

The experiment was conducted at the BEElab of Maastricht University using z-Tree (Fischbacher [2007]). Participants were recruited through ORSEE (Greiner [2015]), and each of them took part in only one session. In total 432 students participated in the experiment. We ran 18 sessions overall, 3 per treatment, with 3 matching groups per session. Each session took approximately 50 minutes for the Short treatments, and 80 minutes for the Long treatments.

Within a treatment, the length of a match differed across matches and matching groups. However, to ease the comparison between treatments with the same probability of continuation, the same random sequence of match lengths was used in treatments with equal $\delta$. That is, match lengths across matching groups in NoInvShort were the same as in EndoShort and ExoShort, and match lengths across matching groups in NoInvLong were the same as in EndoLong and ExoLong. ${ }^{8}$

\footnotetext{
${ }^{7}$ Rematching within the same group ensures that observations are independent at the matching group level.

${ }^{8}$ Table 5.6 in Appendix 5.A presents the sequences of match lengths for the different matching groups that were implemented in the three sets of treatments.
} 


\subsection{Theoretical background}

Table 5.2 shows a prisoner's dilemma payoff matrix, where: $c$ is the reward from mutual cooperation; $d$ is the payoff from mutual defection; $t$ is the temptation payoff, obtained from defecting when the other cooperates; and $s$ is the sucker payoff, obtained from cooperating when the other defects. The presentation in Table 5.2 allows for potentially asymmetric payoffs by using indexes $i$ and $j$. For a game to have the structure of a $\mathrm{PD}$, two conditions have to hold. First, $t_{k}>c_{k}>d_{k}>s_{k}$ for $k=i, j$. Second, it is also required that $c_{i}+$ $c_{j}>\max \left[t_{i}+s_{j}, s_{i}+t_{j}\right]$. This condition guarantees that cooperation is more profitable than alternating between cooperation and defection.

Table 5.2: Prisoner's dilemma payoff matrix

\begin{tabular}{ccc}
\hline \hline & $\mathrm{C}$ & $\mathrm{D}$ \\
\hline $\mathrm{C}$ & $c_{i}, c_{j}$ & $s_{i}, t_{j}$ \\
$\mathrm{D}$ & $t_{i}, s_{j}$ & $d_{i}, d_{j}$ \\
\hline
\end{tabular}

In a $\mathrm{PD}$ with asymmetric payoff parameters and common discount factor $\delta$, the critical value $\delta^{S P E}$ for which mutual cooperation is sustainable in a SPE is given by (see Blonski and Spagnolo [2015]):

$$
\delta^{S P E}=\max \left\{\delta_{i}^{S P E}, \delta_{j}^{S P E}\right\}=\max \left\{\frac{t_{i}-c_{i}}{t_{i}-d_{i}}, \frac{t_{j}-c_{j}}{t_{j}-d_{j}}\right\} .
$$

For our parameters, the critical value $\delta^{S P E}$ for which cooperation can be sustained in equilibrium is 0.72 when $r_{i}, r_{j}=0$ (or when investments are not allowed), and it is 0.08 when $r_{i}, r_{j}=8$. For other combinations of $r_{i}$ and $r_{j}$, $\delta^{S P E}$ lies within these two extremes, i.e. $0.08 \leq \delta^{S P E} \leq 0.72$, depending on the investment level chosen.

\subsubsection{Predictions and hypotheses}

In a setting where both mutual cooperation and mutual defection are sustainable as equilibrium outcomes ${ }^{9}$ investments could be 0 or 8 depending on the action expected to be chosen by the other player. Subjects that expect to coordinate on the cooperative equilibrium should invest 8 , in order to maximize payoffs. Conversely, subjects that expect defection to be selected as equilibrium outcome should not invest at all. Investing 8 and cooperating in the PD

\footnotetext{
${ }^{9}$ In the following, "cooperation (not) being sustainable in equilibrium" and "cooperation (not) being sustainable as equilibrium outcome" indicate that there are (no) strategies that support mutual cooperation as equilibrium outcome.
} 
is the payoff dominant equilibrium, while not investing and defecting is the risk dominant one. We formulate the following hypothesis.

H1: Investment levels $r_{i}, r_{j}$ are such that $r_{i}, r_{j} \in\{0,8\}$.

When $\delta=0.35$ and investments are not allowed (NoInvShort), defection is the only equilibrium outcome. When investment opportunities are introduced while keeping $\delta=0.35$ (EndoShort), three different cases need to be distinguished. If a) both players choose investment levels of 4 or less, or $b$ ) one player chooses an investment level in the interval $[5,8]$, while the other chooses to invest less, then cooperation cannot be supported as an equilibrium outcome. If, instead, c) both players choose investments in the interval [5,8], trigger strategies can sustain mutual cooperation as part of an SPE, while defection still constitutes an equilibrium outcome. Given these theoretical predictions, we expect no cooperation in NoInvShort. Moreover, we expect behavior in the first two cases of EndoShort $(a)$ and $b$ )) to be similar to NoInvShort, and cooperation rates to stabilize at a higher level in the last case of EndoShort $(c)$ ).

The comparison between NoInvShort and EndoShort allows us to study the effect of investments on cooperation, and whether cooperation levels depend on cooperation being sustainable in equilibrium. On the other hand, we do not expect any difference between NoInvLong and EndoLong $(\delta=0.75)$ as in both of these conditions cooperation is supported as equilibrium outcome, regardless of the possibility to invest and the specific investment choices. We hence formulate the following hypothesis.

H2: When $\delta=0.35$, then

(i) For $r_{i} \leq 4, r_{j} \in[0,8]$, there is no difference in cooperation rates between NoInvShort and EndoShort.

(ii) For $r_{i}, r_{j}>4$, cooperation rates in EndoShort are larger than in NoInvShort.

When $\delta=0.75$, then

(i) There is no difference in cooperation rates between NoInvLong and EndoLong, independent of $r_{i}$ and $r_{j}$.

Since the exogenous treatments are an exact replica of the endogenous treatments, SPE predictions do not differ between the Short investment treatments (EndoShort and ExoShort), and between the Long investment treatments (EndoLong and ExoLong). 
H3: For any $r_{i}, r_{j}$, there is no difference in cooperation rates between EndoShort and ExoShort, and between EndoLong and ExoLong.

However, investments might convey a signal regarding the action that will be chosen in the $\mathrm{PD}$, in which case cooperation levels might vary depending on whether investments have been endogenously chosen or exogenously imposed. ${ }^{10}$ Such signal might affect beliefs in two ways. First, investments might signal a player's (un)willingness to cooperate in the subsequent PD. Second, they might signal a player's beliefs on the opponent's (un)willingness to cooperate in the subsequent PD. ${ }^{11}$ Therefore, if low investment levels (i.e. below or at the threshold of 4) serve as signal of unwillingness to cooperate, we would expect cooperation in the Endo conditions to be lower than in Exo conditions. Similarly, if high investments (i.e. above the threshold) signal willingness to cooperate, we would expect higher cooperation rates in Endo than in Exo. For the case where investments diverge, signals are contrasting and it is not easy to predict which one will prevail, if any. On the one hand, if a high investment signal willingness to cooperate, the player who chose a low investment might cooperate after seeing the high investment of the opponent. If this effect is strong enough, we would observe higher cooperation in the Endo treatments. On the other hand, if a low investment signal unwillingness to cooperate, the player with high investment might decide to defect after seeing the low investment chosen by the opponent, which could result in lower cooperation rates in Endo than in Exo. These two effects might also offset each other, resulting in no difference in cooperation rates between Endo and Exo. We formulate the following alternative hypothesis.

\section{H4:}

(i) For $r_{i}, r_{j} \leq 4$, cooperation rates in Endo are smaller than in Exo.

(ii) For $r_{i}, r_{j}>4$, cooperation rates in Endo are larger than in Exo.

By comparing the two NoInv, the two Endo and the two Exo conditions across the two levels of $\delta$, we can assess the impact on cooperation levels of a higher probability of future interactions. Given previous experimental evidence, we expect that the higher probability of continuation leads to higher cooperation

\footnotetext{
${ }^{10}$ Selection effects might also play a role in our experiment. Such effects might arise if subjects choose to invest and cooperate because of unobservable characteristics (for example, preferences for cooperative behavior) that differ from those of subjects who choose to not invest and not cooperate. We will address this issue in Section 5.4.2.

${ }^{11}$ Disentangling these two effects goes beyond the scope of this chapter. Therefore, we use the term signal to include both effects.
} 
rates. ${ }^{12}$ For the NoInv conditions, this follows from the theoretical reasoning that cooperation is sustainable as an equilibrium action in NoInvLong but not in NoInvShort. In the investment conditions, we have seen that cooperation is always sustainable for the high probability of continuation, while it is so for the low probability of continuation only when $r_{i}, r_{j}>4$. Hence, if $r_{i} \leq 4$ in the Short treatments, we expect cooperation rates to be higher in the Long treatments. If $\delta$ plays a role in determining cooperation rates, we would expect higher cooperation in the Long conditions also when in the Short treatments investments are such that $r_{i}, r_{j}>4$. This leads to the following hypothesis.

H5: Cooperation in Long treatments is higher than in Short treatments.

\subsection{Results}

In this section we present the main results. We start with the presentation of the investment choices made in EndoShort and EndoLong. Thereafter, we describe the results on cooperation levels in the six treatments. For each treatment, we collected a sequence of decisions over twelve matches for nine different matching groups. This yields 9 independent observations per treatment. Therefore, for the data analysis we will use matching group averages as the primary unit of observation.

\subsubsection{Investments}

In this section we describe the investment choices made by subjects, and compare them across the two treatments with endogenous investment opportunities.

On average, investments do not differ between the EndoShort and EndoLong treatments. When looking at the first match only, the average investment is 4.08 in EndoShort and 4.49 in EndoLong. When aggregating data over all matches, average investments are 3.25 and 3.57, respectively. In neither case the difference is statistically significant according to two-sided Mann-Whitney $\mathrm{U}(\mathrm{MW})$ tests (Table 5.3).

H1 predicts that, in equilibrium, investments should be either 0 or 8 . Figure 5.1 shows histograms of the investments chosen in the treatments EndoShort (left panel) and EndoLong (right panel). The most frequent investment is 0 , which is chosen in both treatments in about 40 percent of the cases. In slightly more than 20 percent of the cases the chosen investments are 8. Investment

\footnotetext{
${ }^{12}$ A number of previous experiments (see for instance Dal Bó [2005], Dal Bó and Fréchette [2011], Blonski et al. [2011]) have provided evidence in favor of people being reactive to changes in the discount rate in laboratory experiments.
} 
Table 5.3: Average investments

\begin{tabular}{lccc}
\hline \hline & EndoShort & EndoLong & MW $p$-values \\
\hline First match & 4.08 & 4.49 & 0.2883 \\
All matches & 3.25 & 3.57 & 0.6267 \\
\hline
\end{tabular}

Averages are taken over matching groups. $p$-values are from two-sided Mann-Whitney tests which take averages over matching groups as unit of observation.

choices in the middle of the range occur much less frequently, and distribute differently across the two treatments. The two investment distributions are indeed statistically different, according to a Kolmogorov-Smirnov test $(p=0.017)$. While subjects do not exclusively invest either 0 or 8 , they largely behave according to the predictions of $\mathrm{H} 1$.

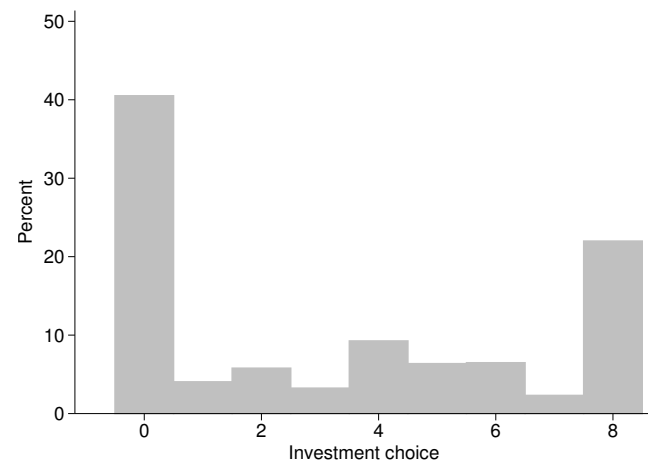

(a) EndoShort

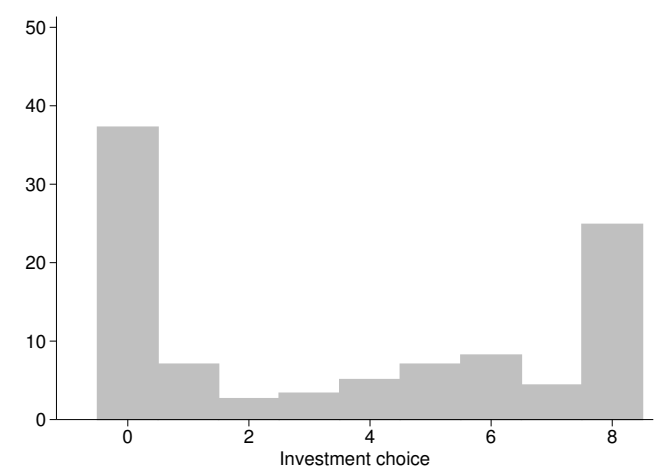

(b) EndoLong

Figure 5.1: Distribution of investments

\subsubsection{Cooperation}

Introducing an investment possibility gives players the opportunity to influence the payoff received from the cooperation action. We are specifically interested in the changes in cooperation rates that are induced by the introduction of the opportunity to invest and by the actual investment level chosen. We first describe the effects on cooperation of introducing investments, and how the level of investment affects cooperation, by comparing treatments without investment opportunities and treatments with endogenous investment choices. Thereafter, we test whether the endogeneity of the investment choices induces cooperation by comparing treatments with endogenous and exogenous investments. In both cases, we keep the probability of continuation $(\delta)$ constant. In the last subsec- 
tion, we discuss whether and how changes in the probability of future interactions affect cooperation. We will hence compare treatments across the Short and the Long conditions while keeping the investment dimension constant.

\section{The effect of endogenous investments on cooperation}

Subjects' cooperation rates in each treatment are shown in Figure 5.2, averaged over the first period of each match and over all periods. ${ }^{13}$ According to MW tests, cooperation rates are significantly higher in treatments with investment opportunities, both in the Short and Long conditions. ${ }^{14}$

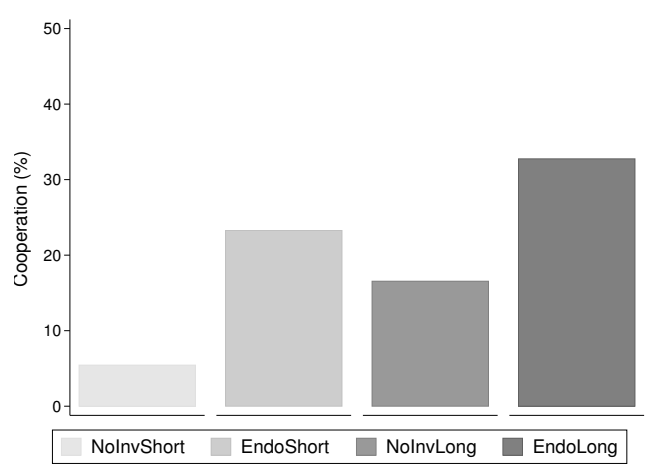

First periods

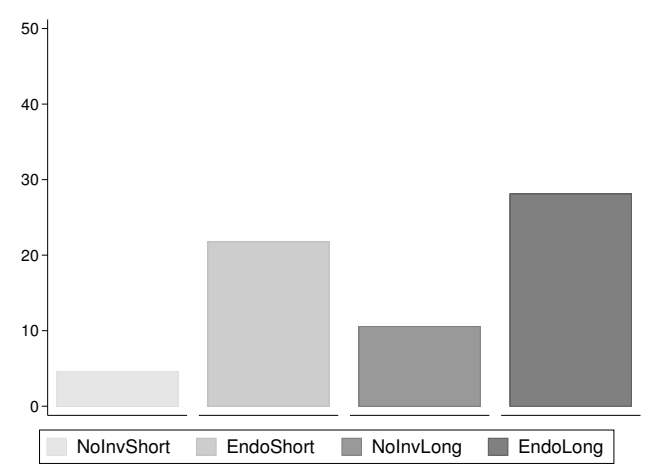

All periods

Figure 5.2: Average cooperation by treatment

Next, we analyze how different levels of investment affect cooperation rates. We look at the three following cases (see also Section 5.3): both players invested at most 4 , one player invested at most 4 and the other invested (strictly) more than 4, and both invested (strictly) more than 4. In the Short treatments, cooperation is sustainable in an SPE in the last case, while defection is the only equilibrium in the first two cases. For simplicity and clarity of exposition, the data in the Long treatments are organized according to the same categories, even though cooperation is always sustainable in an SPE independent of the investment level.

Figure 5.3 shows cooperation rates by treatment, and considers the three above-mentioned cases separately for the treatments with investment opportu-

\footnotetext{
${ }^{13}$ Looking separately at first periods is important since matches have a different number of periods and cooperation rates might vary across periods. Moreover, choices in the first periods indicate how subjects start playing, which potentially affects how they play in the next periods.

${ }^{14} \mathrm{MW}$ test results are reported in Table 5.8 in Appendix 5.C.2, and are consistent with the regression results shown in Table 5.9.
} 
nities. Figure 5.3 clearly shows that investments do not always trigger high(er) cooperation. For instance, first period cooperation rates are about 6 percent both in NoInvShort and in EndoShort when both investments are below 4 .

First periods

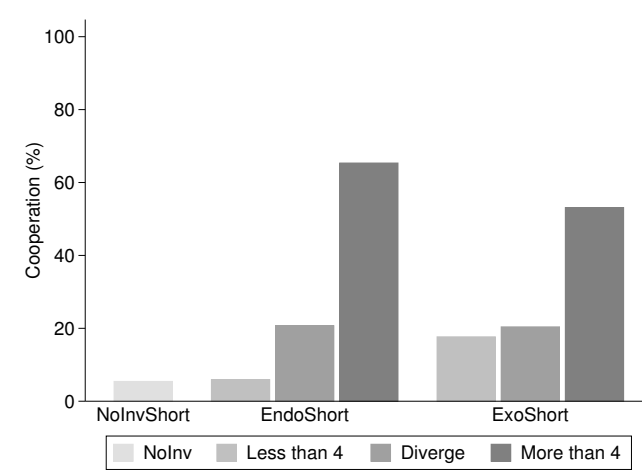

Short

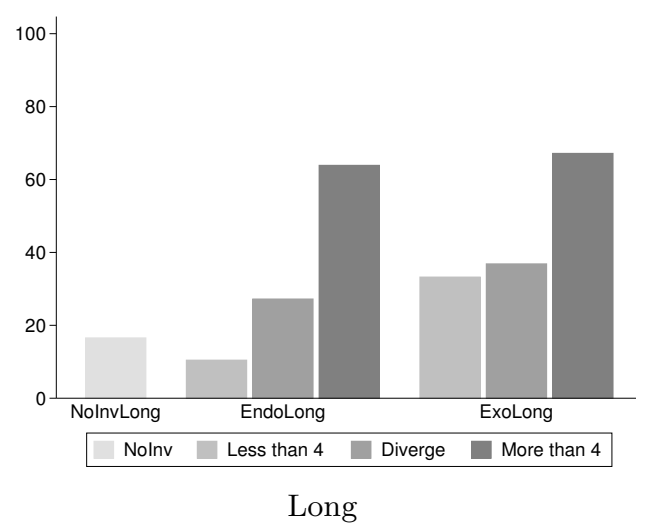

All periods

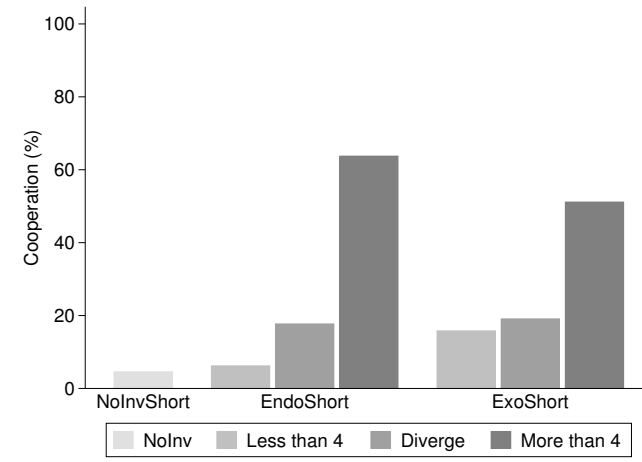

Short

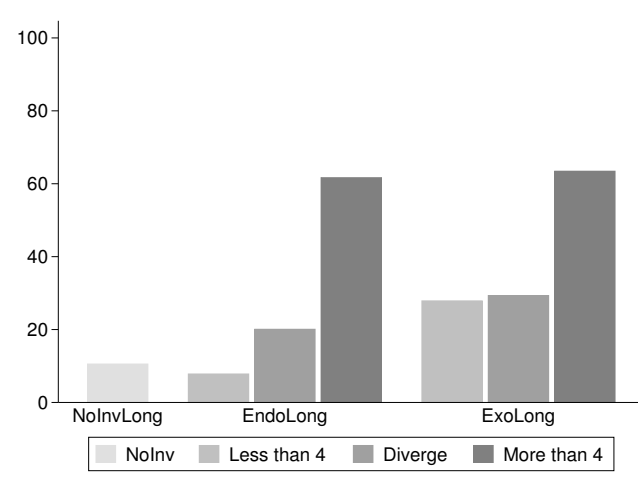

Long

Figure 5.3: Average cooperation by treatment and investment category

According to $\mathrm{H} 2$, we should observe no differences in cooperation rates between NoInvShort and EndoShort when investment levels are such that cooperation cannot be supported in equilibrium ( $r_{i} \leq 4$ for at least one $i \in\{1,2\}$ ), while cooperation rates should be larger in EndoShort when investment levels are such that cooperation is sustainable in an $\operatorname{SPE}\left(r_{i}, r_{j}>4\right)$. To test this hypothesis, therefore, we compare average cooperation rates in NoInvShort with those in EndoShort when $r_{i} \leq 4$ for at least one player, and with those in EndoShort when $r_{i}, r_{j}>4$. According to MW tests, average cooperation is not statistically different between NoInvShort and EndoShort when $r_{i}, r_{j} \leq 4$, 
both when looking at the first period of each match $(p=0.5623)$ and when aggregating data over all periods $(p=0.2482)$. In contrast, when subjects' investments diverge or when both investments are strictly larger than 4 , cooperation is higher in EndoShort - this difference is highly significant at $0.1 \%$ level for first periods cooperation rates $(p=0.0009$ for divergent investments, $p=0.0008$ for investments strictly larger than 4) and for cooperation rates averaged over all periods ( $p=0.0009$ in both cases). ${ }^{15}$

$\mathrm{H} 2$ predicts no difference in cooperation rates between NoInvLong and EndoLong, since cooperation is sustainable in an SPE in both treatments. However, we find that in EndoLong investments do have an effect on cooperation. Disaggregating data in the EndoLong treatment in the same way as for EndoShort reveals that behavior is quite similar across the Short and the Long conditions (see Figure 5.3). In particular, while there are no significant differences in cooperation rates between NoInvLong and EndoLong with $r_{i}, r_{j} \leq 4$ (first periods: $p=0.4013$, all periods: $p=0.6272$ ), average cooperation is significantly higher in EndoLong when $r_{i}, r_{j}>4$ (first periods: $p=0.0013$, all periods: $p=0.0007$ ). Cooperation rates when investments diverge are higher than when investments are not allowed, but significantly so only when considering data aggregated over all periods (first periods: $p=0.1022$, all periods: $p=0.0243$ ).

We find that investment opportunities have no effect on cooperation rates when both investments are below the threshold level for cooperation to be sustainable in an SPE, while they positively affect cooperation as compared to the no investments condition when investments are above the threshold. This is in line with $\mathrm{H} 2$. However, contrary to $\mathrm{H} 2$, one player investing above the threshold for cooperation to be an equilibrium action is sufficient for cooperation to significantly increase. When the probability of continuation is high, we find similar results, even though this effect is not predicted by subgame perfection.

\section{Endogenous versus exogenous investments}

The comparison NoInv-Endo serves as baseline to examine cooperative behavior with and without the investment institution, but does not permit to pin down the mechanism behind the observed cooperation rates. The comparison between Endo and Exo treatments, instead, allows us to disentangle whether cooperation rates are determined by changes in the PD payoffs, or by the very act of choosing a specific investment level. If payoff is what drives cooperation rates, then we

\footnotetext{
${ }^{15}$ See Table 5.10 for MW test results, and Table 5.11 for regression results, both in Appendix 5.C.2.
} 
should observe, for given investment levels, the same cooperation rates in Endo and Exo treatments. This is what $\mathrm{H} 3$ states. If investments provide information on whether a subject is going to defect or cooperate in the PD game, we should instead observe that the same investments induce different cooperation rates in Endo and Exo. As H4 states, cooperation rates in Endo should be lower for investment levels of 4 or less, and larger for investments strictly higher than 4 .

Using Figure 5.3 again, we see that when both players invest at most 4, cooperation is significantly lower in the Endo treatments according to MW tests, both in Long and Short conditions, and both when looking only at first periods (Short: $p=0.0135$, Long: $p=0.0080$ ) and when aggregating data over all periods (Short: $p=0.0274$, Long: $p=0.0193$ ). In contrast, when both investments are above 4, cooperation in EndoShort is around 10 percentage points higher than in ExoShort, while cooperation rates are quite similar in EndoLong and ExoLong. In neither case, however, the difference is statistically significant (MW $p>0.1$ in all cases). ${ }^{16}$ If investments diverge, cooperation tends to be higher in the Exo treatments, both in the Short and in the Long conditions. Also in this case, however, the difference is not statistically significant (MW $p>0.1$ in all cases). ${ }^{17}$

One interpretation is that choosing low investments signals unwillingness to cooperate, while the increase in cooperation is mostly induced by the high payoffs associated with high investments. A second interpretation might be that selection effects play a role in the endogenous treatments. In this case, cooperation rates might be due not to the investment level chosen, but to some unobservable characteristics (for example, preferences for (un)cooperative behavior) that differ across subjects. For instance, assuming that cooperative subjects choose high investments, if two cooperative subjects are randomly paired, investments and cooperation rates will be high in this pair. High cooperation would then result from selection effects, and not from the investment chosen.

To control for selection effects, we consider separately cooperation rates of subjects who chose investments above 4 , and those of subjects who chose investments below or at 4 . If selection effects affect results, then subjects who invest $r_{i}>4\left(r_{i} \leq 4\right)$ would cooperate (not cooperate) irrespective of the investment chosen by their opponents. Table 5.4 shows that both subjects who choose $r_{i}>4$ and subjects who choose $r_{i} \leq 4$ cooperate more when the

\footnotetext{
${ }^{16}$ See Tables 5.12 and 5.13 in Appendix 5.C.2.

${ }^{17}$ In this case, we further split the data into two sub-categories: one for $r_{i} \leq 4$ and $r_{j}>4$, the other for $r_{i}>4$ and $r_{j} \leq 4$. In both cases, we do not find any differences in cooperation rates between Endo and Exo treatments, according to MW tests.
} 
opponents choose $r_{j}>4$, both in EndoShort and in EndoLong. This difference is statistically significant according to MW tests only for subjects who invest more than $4 .{ }^{18}$

Table 5.4: Average cooperation rates by a subject's and opponent's investment categories

\begin{tabular}{lcccc}
\hline \hline & \multicolumn{2}{c}{ EndoShort } & \multicolumn{2}{c}{ EndoLong } \\
& $r_{i} \leq 4$ & $r_{i}>4$ & $r_{i} \leq 4$ & $r_{i}>4$ \\
\hline$r_{j} \leq 4$ & 5.56 & 24.96 & 8.50 & 26.70 \\
$r_{j}>4$ & 11.77 & 63.27 & 14.41 & 61.85 \\
$p$-value & 0.3865 & 0.0009 & 0.1711 & 0.0041 \\
\hline
\end{tabular}

Averages are taken over all periods. $p$-values are from twosided Mann-Whitney tests.

We interpret these results as indicating that cooperation rates are not determined by selection effects, but by the signaling effect implied by the choice of an investment level. Investments seem to work as a (negative) signal of willingness to cooperate only when they are low: when both players invest at most 4, we do find lower cooperation rates in the Endo than in the Exo treatments, as $\mathrm{H} 4$ predicts. In line with $\mathrm{H} 3$, we do not find statistically significant differences between Endo and Exo treatments when investments are high, suggesting that, at least in the Long condition, the increased payoffs are the main driving force behind the higher cooperation levels observed in this case.

\section{The effect of time horizon on cooperation}

Early experiments on the infinitely repeated PD have shown that cooperation tends to increase with the probability of continuation, but only marginally, as subjects often fail in fully exploiting the possibility to cooperate (Murnighan and Roth [1978, 1983], Feinberg and Husted [1993]). Recent experiments, by allowing subjects to play more repeated games and gain experience, suggest instead that the effect of repetition on cooperation is substantial (Dal Bó [2005], Dal Bó and Fréchette [2011]; see Dal Bó and Fréchette [forthcoming] for a survey). Given these results, we expect that subjects cooperate more when the probability of future interactions is high.

According to $\mathrm{H} 5$, we should then observe higher cooperation rates in the Long treatments than in the Short treatments. In the NoInv treatments, cooperation averaged over the first period of each match is higher in the Long

\footnotetext{
${ }^{18}$ We find similar patterns in the exogenous treatments. None of the differences in this case is statistically significant.
} 
condition, but this difference is marginally statistically significant only when averaging over the first period of each match. ${ }^{19}$ Similarly, in the Endo condition, cooperation rates do not significantly differ between Short and Long treatments. In the Exo condition, cooperation levels are higher in the Long treatments; however, the hypothesis of equality of cooperation rates between Long and Short treatments is not rejected. Only exceptions are cooperation rates averaged over the first period of each match when investments are less than 4, and when investments diverge: in both cases, cooperation is marginally significantly higher in ExoLong.

In our experiment, increasing the probability of continuation does not substantially affect cooperation rates. This result partly contradicts H5. We will discuss this result further in Section 5.5.2.

\subsection{Discussion}

\subsubsection{Investments as coordination problem}

Investments boost overall cooperation levels, independent of whether they are endogenously chosen or exogenously imposed. Yet, in 60 percent of the cases subjects choose low investments, between 0 and 4 (recall Figure 5.1). In the following, we focus on subjects' investment decisions and discuss a potential explanation for the observed investment behavior. We therefore restrict our attention to the endogenous treatments (EndoShort and EndoLong).

The investment decision entails a coordination problem, in that individuals would like to invest if others invest as well. Figure 5.4 shows the distribution of investments in the first and in the last match, by treatment. The frequency of investments below or at 4 increases from 53 to 73 percent in EndoShort, and from 42 to 63 percent in EndoLong. This seems to be mostly due to a shift of investment choices from the middle of the range toward 0. Indeed, by comparing first match (upper panels) and last match (lower panels) investment choices, we see that, in both treatments, the percentage of 8 investments does not change much (it remains around 20 percent), the frequency of choices in the middle of the range decreases while the frequency of 0 investments increases substantially (reaching almost 60 percent).

The observed shift toward 0 might be due to the inability of our subjects to solve such coordination problem. Figure 5.5 shows the proportion of pairs who succeed at coordinating on the same investment category (either both players

\footnotetext{
${ }^{19}$ In this section we refer to results from MW tests reported in Table 5.15 in Appendix 5.C.2. Results from probit regressions are in Tables 5.16 and 5.17 .
} 
First match
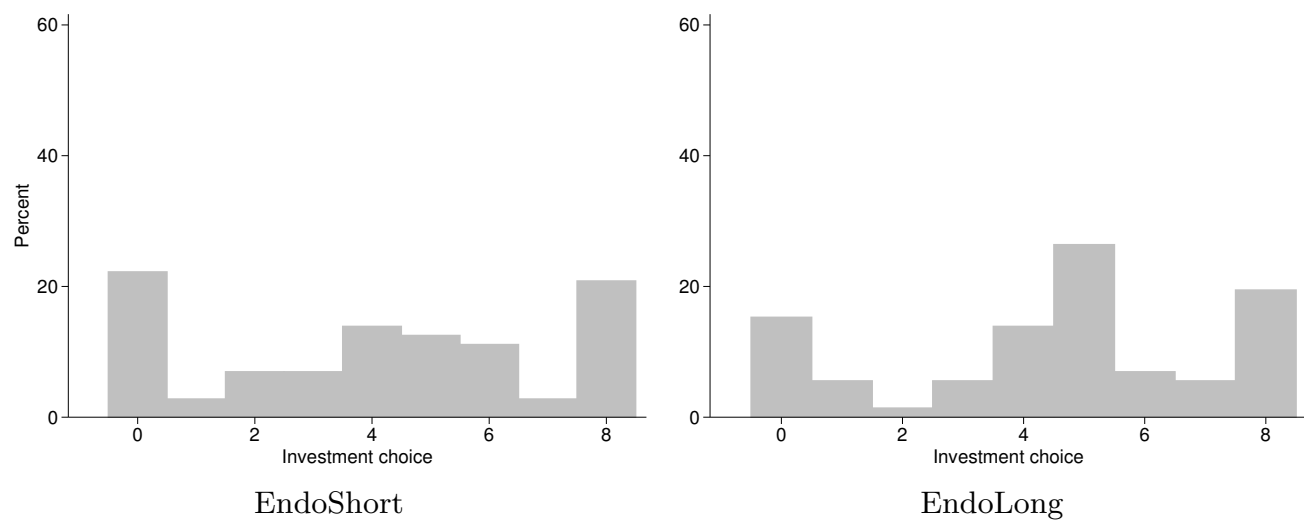

Last match

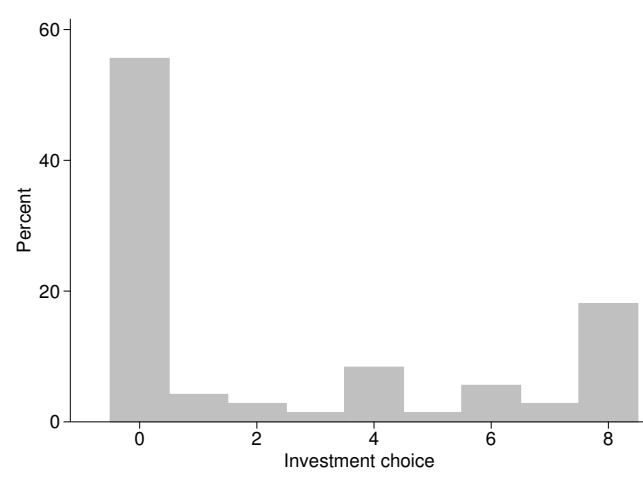

EndoShort

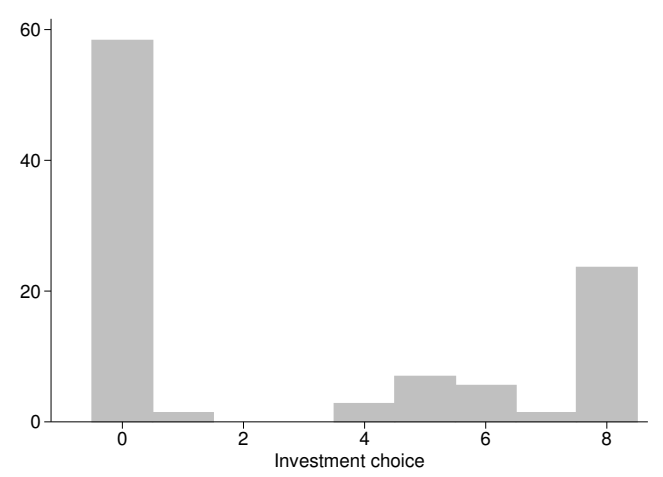

EndoLong

Figure 5.4: Distribution of investments

invest less than 4 , or both strictly more than 4) and the proportion of pairs who do not. ${ }^{20}$ In the first match, the "miscoordination rate" is relatively high: in roughly 60 percent of the cases in EndoShort and 40 percent of the cases in EndoLong, subjects who chose high investments had opponents who chose low investments. By the end of the experiment, in match 12, the miscoordination rate is lower in both treatments, while the percentage of pairs that coordinates on low investments rises. ${ }^{21}$

\footnotetext{
${ }^{20}$ Choosing different investment levels, though in the same category, might also lead to the unravelling of investments. However, for the sake of consistency of exposition throughout the chapter, and keeping in mind the threshold at 4 for cooperation to be supported in equilibrium in the Short treatments, we focus on investment categories rather than investment levels.

${ }^{21}$ Jonckheere-Terpstra (JT) test results show that in both treatments coordination on investments lower than 4 significantly increases over matches (EndoShort: $p=0.0010$, EndoLong: $p=0.0005$ ), while there is no significant trend for coordination on investments larger than 4 ( $p>0.1$ in both treatments). The miscoordination rate significantly decreases over matches (EndoShort: $p=0.0006$, EndoLong: $p=0.0033$ ). The JT test is a nonparametric test for ordered differences among classes. Here, we test the null hypothesis that average (mis)coordination rates do not differ among matches, against the alternative hypothesis that there is an ordered difference among matches.
} 

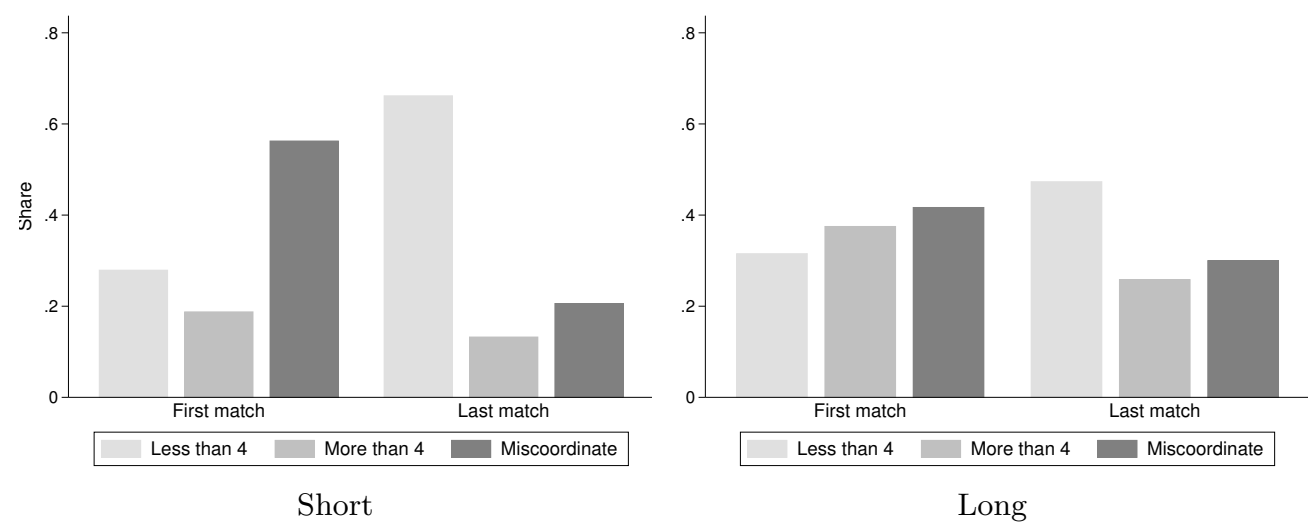

Figure 5.5: Coordination on the same investment category

Figure 5.6 shows the percentage of subjects who, after experiencing miscoordination in the previous match, switch to a different investment category (i.e. shift from investments choices in the Low category $\left(r_{i} \leq 4\right)$ to investments in the High category $\left(r_{i}>4\right)$, and vice versa) and the percentage of subjects who do not. It additionally shows, among the subjects who switch, the proportion of subjects who lower their investments (i.e., who switch to the Low category) and, among the subjects who do not switch, the percentage of those who keep choosing investments in Low. In the Short condition, one third of the subjects switch investment category, while in the Long condition this percentage is slightly lower. In most cases, those subjects who switch lower their investments. In both treatments, in more than 60 percent of the cases subjects move to the Low category, where in about 40 percent of the cases they invest nothing. This finding is in line with previous experimental results on coordination games, which show a convergence toward the risk-dominant equilibrium (Camerer [2003], Brandts and Cooper [2006a,b], Blume and Ortmann [2007], Chaudhuri et al. [2006b]).

The highlighted coordination problem explains the shift to lower investments over time, but it only provides a partial explanation for low investments. As mentioned before, only about one third of the subjects decide to switch category. Among the majority of those who do not, the larger percentage (over 55 percent) invest and keep investing in the Low category (Figure 5.6). Figure 5.7 provides further insights into why players choose low investments so often. It shows the individual payoff averaged over matches, separately for the following cases: both players invest less than 4 (Low, Low), player $i$ invests less and player $j$ invests strictly more than 4 (Low, High), and vice versa (High, Low), both 

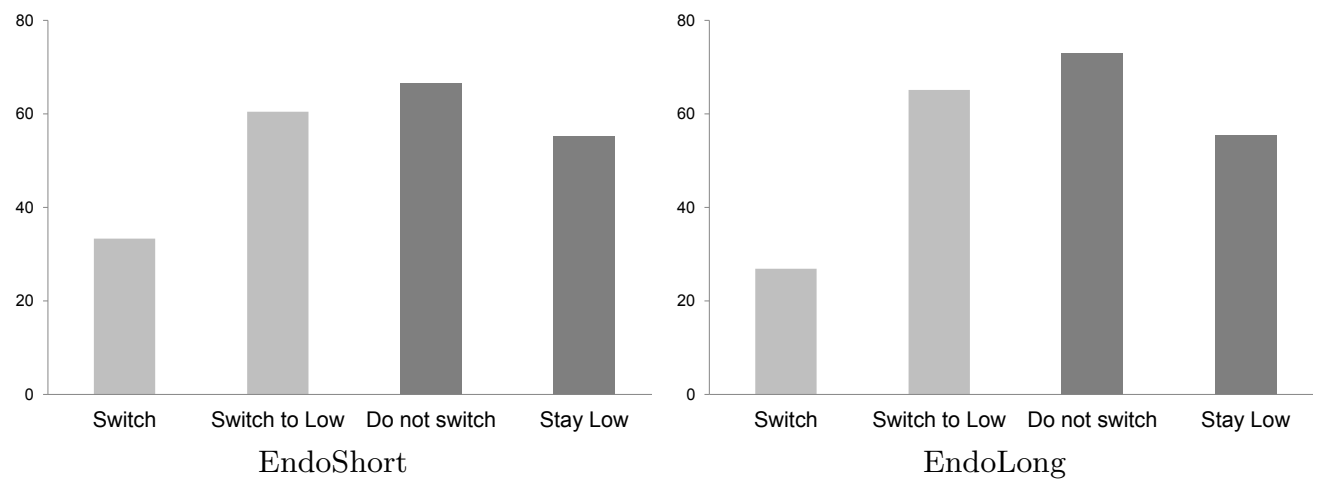

Figure 5.6: Investment choices given miscoordination in previous match

players invest strictly more than 4 (High, High). Comparing the two darker bars (High, Low and High, High) shows that, in both treatments, choosing investments in the High category yields a relatively high payoff only if both players do so. Given the potential miscoordination, instead, ending up with somebody who chose in Low yields the lowest payoff on average. Moreover, even if both players choose investments in the High category (darkest bars), there is a larger variability in the payoffs than when they both choose investments in the Low category (lightest bars). Therefore, choosing a low investment is the safest option, as it at least guarantees the mutual defection payoff in every period.

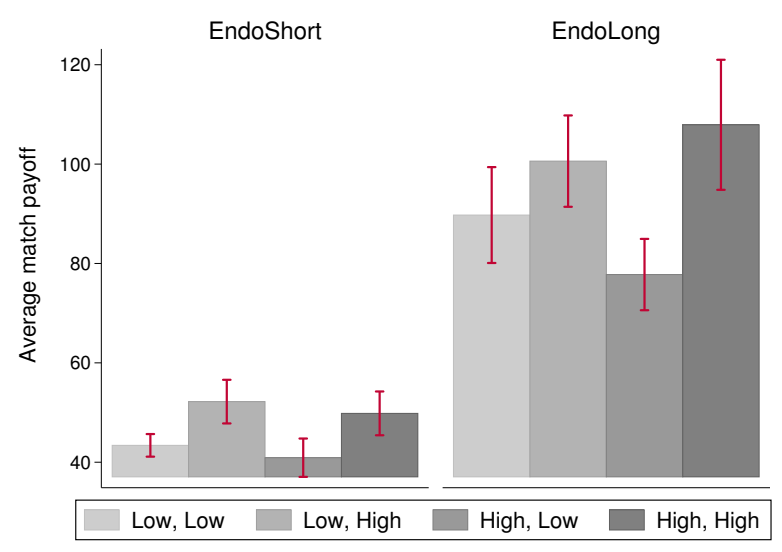

Figure 5.7: Individual average payoffs 


\subsubsection{Cooperation}

We find a higher cooperation rate when players can invest than when they cannot. Specifically, when both players choose high investment levels, cooperation rates are highest in the investment treatments.

By comparing endogenous and exogenous investment treatments, we investigated whether the higher cooperation levels are due to a signaling effect, embodied in the choice of an investment, or to greater payoffs, induced by the investments. While low investments seem to be interpreted as signals of unwillingness to cooperate and induce low cooperation rates, high investments are associated with high cooperation levels, independent of whether they are endogenously chosen or exogenously imposed. Payoffs in this case might be large enough to induce as much cooperation in the exogenous as in the endogenous treatments. Differently from previous experiments, we find that a higher probability of continuation does not substantially increases cooperation rates. ${ }^{22}$

In the theoretical and experimental literature on indefinitely repeated PD, Subgame Perfection (SPE), Risk Dominance (RD) and Size of the Basin of attraction of the Always Defect strategy (SizeBAD) have been used as possible explanations for cooperation rates. In the following we discuss if these concepts provide an explanation for our results.

Experiments on the indefinitely repeated PD suggest that SPE fails to predict cooperative behavior, mostly because it does not recognize the importance of the risk that cooperating entails. The lower bound $\delta^{S P E}$ that equalizes shortrun gains and long-run losses from defecting does not take into account that the sucker payoff as well may influence a player's propensity to cooperate. To capture this effect, Blonski and Spagnolo [2015] introduce a measure for the riskiness of cooperation, and use it to define the critical discount factor $\delta^{R D}$ for which cooperation is risk dominant. ${ }^{23}$ The authors experimentally show

\footnotetext{
${ }^{22}$ For the purpose of providing a benchmark, we compare our results with those in Dal Bó and Fréchette [2011]. The best comparable treatments are our NoInvLong and ExoLong with $r_{i}=r_{j}=0,4,8$ and $\delta=0.75$, and their games with cooperation payoffs of $R=32,40$ and 48 and $\delta=0.75$. Compared to our games, their sucker payoff is higher when $R=32$, which would suggest lower cooperation in our treatments. We do find substantially lower cooperation rates in our NoInvLong, but similar levels of cooperation in ExoLong (averaged over all periods in all matches). When $R=48$, our sucker payoff is higher, which would suggest higher cooperation in our games. Indeed, we find greater cooperation rates in ExoLong. We do not have any observations in ExoLong where $r_{i}=r_{j}=4$. When comparing games in EndoLong with the games in Dal Bó and Fréchette [2011], we find lower cooperation in our games when $R=32$, and higher when $R=48$.

${ }^{23}$ Blonski and Spagnolo [2015] transpose Harsanyi and Selten [1988]'s concept of RD from symmetric coordination games with two strategies to indefinitely repeated PD by focusing on only two strategies, the Grim ( $G$, that starts by cooperating, and cooperates as long as the other player does so, but defects forever if the other player defects) and the Always Defect
} 
that changes in the sucker payoff affect cooperation rates, so that the smaller the sucker payoff, the riskier it is to cooperate (and vice versa), and provide evidence that RD explains cooperation better than SPE alone does.

Dal Bó and Fréchette [2011] show that cooperation is on average higher when it is risk dominant, but they also find that a relatively large number of subjects still fail to coordinate on a cooperative equilibrium when it is risk dominant. They suggest a different index to explain cooperation: SizeBAD, defined as the largest set of beliefs that make the Always Defect strategy optimal against Grim. Values of SizeBAD close to one predict that cooperation would hardly emerge, since a player needs to have an extremely strong belief that the partner will cooperate for her to cooperate as well. The opposite holds for values of SizeBAD close to zero. ${ }^{24}$ Dal Bó and Fréchette [2011] find that the likelihood of choosing a cooperative action significantly and negatively correlates with SizeBAD. ${ }^{25}$

In our experiment, cooperation is not risk dominant in the treatments without investments, NoInvShort and NoInvLong (though it is an SPE in the latter). Moreover, SizeBAD is 1 in NoInvShort, since cooperation is never an equilibrium in this treatment, while SizeBAD is 0.875 in NoInvLong. This might explain why we find low cooperation rates in these treatments, and only a slightly and not statistically significantly higher cooperation in NoInvLong.

Investments, instead, make cooperation choices less risky by increasing the sucker payoff, so that cooperation becomes part of a risk dominant equilibrium for investments beyond a given level. ${ }^{26}$ In the Short treatments, cooperation is risk dominant for $r_{i}, r_{j} \geq 7$. In the Long condition, the higher $r_{j}$, the lower

(AD). Hence, cooperation is said to be risk dominant if playing $\mathrm{G}$ is the best response to the other player choosing $\mathrm{G}$ or $\mathrm{AD}$ with probability one half.

${ }^{24}$ The size of the basin of attraction is calculated as follows:

$$
\text { Size } B A D= \begin{cases}1 & \text { if } \delta<\frac{g}{1+g} \\ \frac{(1-\delta) \ell}{(1-(1-\delta)(1+g-\ell))} & \text { otherwise }\end{cases}
$$

where $g=\frac{t-c}{c-d}$ and $\ell=-\frac{s-d}{c-d}$. If cooperation cannot be supported as an SPE, SizeBAD is 1 .

${ }^{25}$ In Dal Bó and Fréchette [forthcoming] the authors report the results of a meta-study of experiments on infinitely repeated PD games. The analysis shows that, while SPE is not enough to understand cooperation levels, cooperation rates are also relatively low when cooperation can be supported by a risk dominant equilibrium. Cooperation rates decrease with SizeBAD, especially when cooperation is risk dominant.

${ }^{26}$ Since different investments imply different cooperation payoffs, the resulting PD might be asymmetric depending on the investment chosen by the players. We take this potential asymmetry into account when determining the critical value $\delta^{R D}$ for which cooperation is risk dominant (see Blonski and Spagnolo [2015]). The condition for cooperation to be part of a risk dominant equilibrium is presented in Appendix 5.B. 
is the investment $r_{i}$ required for cooperation to be risk dominant. ${ }^{27}$ Moreover, investments decrease SizeBAD. More precisely, in the Short condition Size $B A D$ is 1 as long as at least one player invests $r_{i} \leq 4$, and it decreases with investments when $r_{i}, r_{j}>4$. In the Long condition, SizeBAD is never 1 (cooperation is always sustainable as equilibrium). ${ }^{28}$

Table 5.5 presents the results from a linear probability model of the effects of SPE, RD, SizeBAD, and their interaction with the investment level, on cooperation. $S P E$ is a dummy variable that takes value 1 if cooperation is sustainable in a subgame perfect equilibrium, and 0 otherwise. $R D$ takes value 1 if cooperation is sustainable in a risk dominant equilibrium, and 0 otherwise. Table 5.5 shows that the fact that cooperation is sustainable in an SPE or an $\mathrm{RD}$ equilibrium does not increase, per se, the likelihood of choosing the cooperative action. Investments, instead, have a positive and significant effect on cooperation, both when cooperation is an SPE and when it is not. Investments increase cooperation also when cooperation is $\mathrm{RD}$, with this effect being significant only in the Long treatments. This might be due to the fact that in the Short treatments very high investment levels are required for cooperation to be RD. Similarly, investments have a positive and significant effect on cooperation when it is not RD only in the Short treatments. In the Long treatments this effect disappears possibly because cooperation is not RD only for rather low investment levels. We find that cooperation significantly increases when the size of the basin of attraction decreases. Also in this case, investments have a positive impact on cooperation rates, indicating that, for a given SizeBAD, the higher the investment the higher the cooperation rates. This suggests that, even when SizeBAD is too large for cooperation to emerge, cooperation would be increasing in the investment level. ${ }^{29}$

\footnotetext{
${ }^{27}$ This implies that cooperation is risk dominant also in cases where, for example, $r_{i}=8$ and $r_{j}=0$.

${ }^{28}$ Note that, since the PD might be asymmetric, SizeBAD might differ between players in a

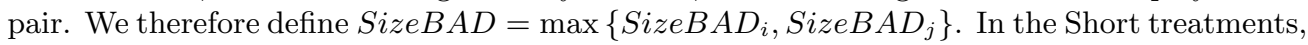
$0.33 \leq$ Size $B A D \leq 0.91$ for $r_{i}, r_{j}>4$. In the Long treatments, $0.07 \leq$ SizeBAD $\leq 0.88$.

${ }^{29}$ These effects are visible in Figures 5.8, 5.9 and 5.10 in Appendix 5.C.2. Figure 5.8 shows that cooperation rates increase in the investment level even when cooperation is not RD. Figures 5.9 and 5.10 show that, overall, cooperation decreases with SizeBAD, but also that, given SizeBAD, cooperation might increase with the investment level.
} 
Table 5.5: Effects on cooperation of SPE, RD, SizeBAD and investments

\begin{tabular}{|c|c|c|c|c|c|c|}
\hline & Short & Long & Short & Long & Short & Long \\
\hline SPE & $\begin{array}{r}-0.343 \\
(0.355)\end{array}$ & & & & & \\
\hline Investment $\times \mathrm{SPE}$ & $\begin{array}{c}0.106^{*} \\
(0.051)\end{array}$ & $\begin{array}{l}0.052^{* * *} \\
(0.007)\end{array}$ & & & & \\
\hline Investment $\times$ Not_SPE & $\begin{array}{l}0.023^{* * *} \\
(0.004)\end{array}$ & & & & & \\
\hline $\mathrm{RD}$ & & & $\begin{array}{r}-1.139 \\
(1.823)\end{array}$ & $\begin{array}{c}-0.011 \\
(0.028)\end{array}$ & & \\
\hline Investment $\times \mathrm{RD}$ & & & $\begin{array}{c}0.211 \\
(0.228)\end{array}$ & $\begin{array}{l}0.052^{* * *} \\
(0.006)\end{array}$ & & \\
\hline Investment $\times$ Not_RD & & & $\begin{array}{l}0.029^{* * *} \\
(0.004)\end{array}$ & $\begin{array}{r}-0.015 \\
(0.015)\end{array}$ & & \\
\hline SizeBAD & & & & & $\begin{array}{c}-0.718^{\text {*** }} \\
(0.131)\end{array}$ & $\begin{array}{c}-0.695^{* * *} \\
(0.090)\end{array}$ \\
\hline Investment $\times S i z e B A D$ & & & & & $\begin{array}{l}0.024^{* * *} \\
(0.004)\end{array}$ & $\begin{array}{c}0.010^{*} \\
(0.005)\end{array}$ \\
\hline Constant & $\begin{array}{l}0.079^{* * *} \\
(0.021)\end{array}$ & $\begin{array}{l}0.111^{* * *} \\
(0.032)\end{array}$ & $\begin{array}{c}0.076^{* * *} \\
(0.021)\end{array}$ & $\begin{array}{c}0.123^{* * *} \\
(0.035)\end{array}$ & $\begin{array}{c}0.796^{\text {*** }} \\
(0.131)\end{array}$ & $\begin{array}{c}0.708^{* * *} \\
(0.064)\end{array}$ \\
\hline Nr of obs. & 2976 & 7744 & 2976 & 7744 & 2976 & 7744 \\
\hline
\end{tabular}

*** $p<0.001 ; * * p<0.01 ; * p<0.05$. All results are from linear probability model regressions. Bootstrapped robust standard errors, clustered over matching groups, in parentheses. SPE takes value 1 if cooperation is sustainable in a subgame perfect equilibrium, and 0 otherwise. $\mathrm{RD}$ takes value 1 if cooperation is sustainable in an risk dominant equilibrium, and 0 otherwise.

Taken together, these results help understand why we observe similar cooperation patterns in Short and Long treatments. In both cases, investments lower the minimum $\delta$ necessary for cooperation to be an SPE and an RD, and decrease the SizeBAD, making it easier for cooperation to emerge. This suggests that investments affect and explain cooperation behavior beyond the equilibrium refinement used. 


\subsection{Summary and conclusions}

In this chapter we ask whether individuals are able to create situations that are conducive to cooperation in settings where there is no enforcement mechanism and cooperation is not easily sustained voluntarily. We introduce upfront investment opportunities and investigate whether they help promoting cooperation in a social dilemma, and whether this effect depends on the investments being endogenous or exogenous. Such investments are a cost that individuals have to incur before deciding whether to cooperate or not, and increase the payoff resulting from the choice to cooperate.

We compare a condition without investments with an endogenous condition where participants can choose their investment level, to test whether investments increase cooperation levels. To determine whether the endogeneity of the investment decision matters for cooperation to increase, we compare the endogenous treatment with a condition where participants are presented with pre-determined investment levels. Finally, we ask how the probability of continuation of the PD game interacts with the investment decision, and study whether changes in this probability affect cooperation rates in this specific context.

We find low cooperation levels in treatments where investments are not allowed, and in treatments where investments are low. When high investments are chosen, cooperation is significantly higher than when investments are not allowed. Moreover, we find that when players choose low investments, cooperation rates are lower in the endogenous than in the exogenous treatments. Cooperation levels are instead not significantly higher in the endogenous treatments when investments are large. This suggests that, while low investments signal unwillingness to cooperate, high investments do not necessarily signal the opposite. In our experiment, a higher probability of continuation is not necessarily associated with higher cooperation rates.

We find that cooperation may not prevail when it is sustainable in a subgame perfect equilibrium, and that it does emerge when it is risk dominant or when the the size of the basin of attraction of AD decreases. However, cooperation increases with the investment level also under unfavorable conditions (for instance, a large SizeBAD). This suggests that investments affect and explain cooperation behavior irrespective of the equilibrium refinement used. While investments boost overall cooperation levels, independent of the mode of implementation, we do observe that our participants do not always fully exploit the possibility to create situations favorable to cooperation, and frequently choose 
low to no investments. We show that this is due to the lack of coordination, which makes choosing a high investment riskier (in terms of earned payoffs) than choosing a low investment.

Our results show that requiring individuals to invest upfront generates cooperative behavior in situations where a functioning enforcement mechanism lacks. Combining endogenous and exogenous elements, such as requiring a minimum investment level, might help overcome the coordination problem embedded in the investment decision. This result seems to provide preliminary support to a theoretical finding in the environmental economics literature. There, the idea is that environmental treaties should focus on investments in green technology rather than on emission limits, arguing that such upfront investments, by reducing a country's temptation to defect, make future cooperation credible and the treaty self-enforcing (Harstad et al. [2016]).

We would like to conclude by pointing out directions for future research. We let the investments increase not only the cooperation payoff, but the sucker payoff as well. Moreover, we focus on selfish investments, i.e. investments that only affect a player's payoff from cooperation. Our intention was to capture the effect of investments per se, isolated from free-riding and other regarding concerns that might play a role if own decisions affect others' payoffs. This obviously does not reflect many real-life situations, where investments are lost once the other party opts for defection, or where investments are directly beneficial to the other party. We pointed out that the underinvestment we find is mostly due to miscoordination. An interesting question is how to induce agents to overcome this coordination problem. Settings where investment choices are sequential, or where agents can communicate and negotiate over investments might help in this regard. 


\section{Appendix}

\section{A Design - number of periods per match}

Table 5.6: Number of periods across matching groups

(a) NoInvShort and InvShort

\begin{tabular}{cccccccccccccc}
\hline \hline $\begin{array}{c}\text { Matching } \\
\text { group }\end{array}$ & 1 & 2 & 3 & 4 & 5 & 6 & 7 & 8 & 9 & 10 & 11 & 12 & Total \\
\hline 1 & 1 & 2 & 3 & 2 & 1 & 1 & 1 & 1 & 2 & 1 & 3 & 2 & 20 \\
2 & 1 & 2 & 5 & 7 & 1 & 1 & 1 & 2 & 2 & 1 & 1 & 2 & 26 \\
3 & 3 & 1 & 1 & 1 & 1 & 1 & 1 & 1 & 4 & 1 & 4 & 3 & 22 \\
4 & 1 & 6 & 1 & 2 & 1 & 2 & 1 & 1 & 1 & 2 & 2 & 2 & 22 \\
5 & 2 & 2 & 1 & 1 & 2 & 1 & 1 & 3 & 1 & 1 & 4 & 1 & 20 \\
6 & 1 & 1 & 2 & 2 & 1 & 2 & 1 & 1 & 2 & 1 & 2 & 1 & 17 \\
7 & 1 & 1 & 1 & 1 & 1 & 2 & 2 & 1 & 1 & 3 & 2 & 1 & 17 \\
8 & 1 & 1 & 5 & 1 & 2 & 1 & 2 & 2 & 1 & 2 & 1 & 1 & 20 \\
9 & 1 & 1 & 2 & 5 & 1 & 2 & 1 & 1 & 1 & 1 & 2 & 4 & 22 \\
\hline
\end{tabular}

(b) NoInvLong and InvLong

\begin{tabular}{cccccccccccccc}
\hline \hline $\begin{array}{c}\text { Matching } \\
\text { group }\end{array}$ & 1 & 2 & 3 & 4 & 5 & 6 & 7 & 8 & 9 & 10 & 11 & 12 & Total \\
\hline 1 & 1 & 2 & 1 & 1 & 7 & 7 & 1 & 5 & 4 & 1 & 2 & 1 & 33 \\
2 & 1 & 11 & 7 & 3 & 8 & 7 & 3 & 6 & 2 & 2 & 2 & 5 & 57 \\
3 & 1 & 1 & 8 & 7 & 6 & 5 & 15 & 9 & 7 & 2 & 5 & 3 & 69 \\
4 & 3 & 1 & 4 & 1 & 7 & 5 & 1 & 4 & 2 & 10 & 4 & 3 & 45 \\
5 & 6 & 1 & 8 & 4 & 2 & 8 & 14 & 10 & 4 & 1 & 6 & 5 & 69 \\
6 & 8 & 8 & 17 & 3 & 1 & 2 & 5 & 1 & 2 & 2 & 1 & 3 & 53 \\
7 & 7 & 4 & 2 & 4 & 3 & 1 & 2 & 1 & 9 & 9 & 2 & 3 & 47 \\
8 & 11 & 7 & 1 & 1 & 9 & 2 & 5 & 1 & 9 & 12 & 3 & 2 & 63 \\
9 & 4 & 5 & 2 & 1 & 3 & 2 & 8 & 6 & 3 & 1 & 8 & 5 & 48 \\
\hline
\end{tabular}




\section{B Theoretical background}

In this section we describe the condition for cooperation to be part of a risk dominant equilibrium in a PD with asymmetric payoff parameters and symmetric discount factor $\delta$. The critical value $\delta^{R D}$ for which cooperation is risk dominant is given by (see Blonski and Spagnolo [2015]):

$$
\delta^{R D}=\frac{Y+Z}{2 W}+\sqrt{\left(\frac{Y+Z}{2 W}\right)^{2}-\frac{X}{W}}
$$

where

$$
\begin{aligned}
X & =\left(d_{i}-s_{i}\right)\left(d_{j}-s_{j}\right)-\left(t_{i}-c_{i}\right)\left(t_{j}-c_{j}\right), \\
Y & =\left(d_{i}-s_{i}\right)\left(d_{j}-s_{j}\right)-\left(t_{i}-d_{i}\right)\left(t_{j}-c_{j}\right), \\
Z & =\left(d_{i}-s_{i}\right)\left(d_{j}-s_{j}\right)-\left(t_{i}-c_{i}\right)\left(t_{j}-d_{j}\right) \text { and } \\
W & =\left(d_{i}-s_{i}\right)\left(d_{j}-s_{j}\right)-\left(t_{i}-d_{i}\right)\left(t_{j}-d_{j}\right) .
\end{aligned}
$$

\begin{tabular}{|c|c|c|}
\hline & \multicolumn{2}{|c|}{ Investment } \\
\hline & First periods & All periods \\
\hline \multirow[t]{2}{*}{ Long } & 0.321 & 0.288 \\
\hline & $(0.88)$ & $(0.90)$ \\
\hline \multirow[t]{2}{*}{ Constant } & $3.252^{* * *}$ & $3.219^{* * *}$ \\
\hline & $(0.69)$ & $(0.72)$ \\
\hline $\mathrm{Nr}$ of obs. & 1728 & 5360 \\
\hline \multicolumn{3}{|c|}{$\begin{array}{l}\text { Results are from OLS regressions. }{ }^{* * *} p \\
<0.001 \text {. Bootstrapped standard errors, clus- } \\
\text { tered over matching groups, in parentheses. } \\
\text { Long takes value } 1 \text { if the observation comes } \\
\text { from the EndoLong treatment and } 0 \text { other- } \\
\text { wise. }\end{array}$} \\
\hline
\end{tabular}

\section{C Additional statistical analyses}

\section{C.1 Investments}

Table 5.7: Treatment effects, investments 


\section{C.2 Cooperation}

\section{The effect of endogenous investments on cooperation}

\section{Non-parametric analysis}

Table 5.8: Percentage of cooperation by treatment

\begin{tabular}{lccccccc}
\hline \hline & \multicolumn{3}{c}{ Short } & & \multicolumn{3}{c}{ Long } \\
\cline { 2 - 4 } \cline { 6 - 8 } & NoInv & Endo & $p$ & & NoInv & Endo & $p$ \\
\hline First periods & 5.44 & 23.26 & 0.0115 & & 16.55 & 32.75 & 0.0301 \\
All periods & 4.58 & 21.75 & 0.0091 & & 10.55 & 28.08 & 0.0092 \\
\hline Nr of obs. & \multicolumn{3}{c}{18} & & & \multicolumn{1}{c}{18} \\
\hline
\end{tabular}

Averages are taken over matching groups. $p$-values are from two-sided Mann-Whitney tests which take averages over matching groups as unit of observation.

\section{Regression analysis}

A probit regression of the probability of choosing the cooperative action is used to assess the impact of introducing the opportunity to invest. ${ }^{30}$ Table 5.9 reports the results for both the treatments with $\delta=0.35$ and the treatments with $\delta=0.75$. The reference group in both cases is the treatment NoInv.

Table 5.9: Effects of investment treatment on the probability to cooperate

\begin{tabular}{lccccc}
\hline \hline & \multicolumn{2}{c}{$\delta=0.35$} & & \multicolumn{2}{c}{$\delta=0.75$} \\
\cline { 2 - 3 } \cline { 5 - 6 } \cline { 5 - 6 } Investment & First periods & All periods & & First periods & All periods \\
\cline { 5 - 6 } Constant & $0.873^{* * *}$ & $0.913^{* * *}$ & & $0.525^{*}$ & $0.728^{* *}$ \\
& $(0.22)$ & $(0.24)$ & & $(0.24)$ & $(0.24)$ \\
& $-1.604^{* * *}$ & $-1.771^{* * *}$ & & $-0.972^{* * *}$ & $-1.389^{* * *}$ \\
\hline
\end{tabular}

\begin{tabular}{l} 
Nr of obs. $1728 \quad 2976 \quad 1728$ \\
\hline$* * * p<0.001 ;{ }^{* *} p<0.01 ;{ }^{*} p<0.05$. Bootstrapped standard errors, clustered \\
over matching groups, in parentheses. Investment takes value 1 if the observation \\
comes from EndoShort or EndoLong, and 0 otherwise. In each regression, the \\
reference group is the treatment without investments.
\end{tabular}

\footnotetext{
${ }^{30}$ All reported regressions use cluster-robust bootstrapped standard errors, corrected for potential correlations at the matching group level.
} 
Table 5.10: Differences in cooperation between NoInv and Endo

\begin{tabular}{lccccccc}
\hline \hline & & $(1)$ & $(2)$ & $(3)$ & \multicolumn{3}{c}{ NoInv vs } \\
& NoInv & $r_{i}, r_{j} \leq 4$ & $r_{i} \leq 4, r_{j}>4$ & $r_{i}, r_{j}>4$ & $(1)$ & $(2)$ & $(3)$ \\
\hline $\begin{array}{l}\text { Short } \\
\text { First periods }\end{array}$ & 5.44 & 5.93 & 20.71 & 65.34 & 0.5623 & 0.0009 & 0.0008 \\
All periods & 4.58 & 6.21 & 17.71 & 63.74 & 0.2482 & 0.0009 & 0.0009 \\
\hline Nr of obs. & & & & 17 & 18 & 16 \\
\hline Long & & & & & & & \\
First periods & 16.55 & 10.45 & 27.22 & 63.89 & 0.4013 & 0.1022 & 0.0013 \\
All periods & 10.55 & 7.81 & 20.08 & 61.67 & 0.6272 & 0.0243 & 0.0007 \\
\hline Nr of obs. & & & & 18 & 18 & 18 \\
\hline
\end{tabular}

Averages are taken over matching groups. $p$-values are from two-sided Mann-Whitney tests which take averages over matching groups as unit of observation.

Table 5.11: Effects of investments on the probability to cooperate, by investment category

\begin{tabular}{|c|c|c|c|c|}
\hline & \multicolumn{2}{|c|}{$\delta=0.35$} & \multicolumn{2}{|c|}{$\delta=0.75$} \\
\hline & First periods & All periods & First periods & All periods \\
\hline$r_{i}, r_{j} \leq 4$ & $\begin{array}{c}-0.048 \\
(0.14)\end{array}$ & $\begin{array}{c}0.019 \\
(0.12)\end{array}$ & $\begin{array}{r}-0.186 \\
(0.28)\end{array}$ & $\begin{array}{c}0.032 \\
(0.29)\end{array}$ \\
\hline$r_{i} \leq 4, r_{j}>4$ & $\begin{array}{l}0.865^{* * *} \\
(0.16)\end{array}$ & $\begin{array}{l}0.854^{* * *} \\
(0.16)\end{array}$ & $\begin{array}{c}0.383 \\
(0.23)\end{array}$ & $\begin{array}{c}0.337 \\
(0.21)\end{array}$ \\
\hline$r_{i}, r_{j}>4$ & $\begin{array}{l}1.966^{* * *} \\
(0.21)\end{array}$ & $\begin{array}{l}1.977^{* * *} \\
(0.21)\end{array}$ & $\begin{array}{l}1.499^{* * *} \\
(0.25)\end{array}$ & $\begin{array}{l}1.848^{* * *} \\
(0.26)\end{array}$ \\
\hline Constant & $\begin{array}{l}-1.604^{* * *} \\
(0.10)\end{array}$ & $\begin{array}{l}-1.771^{\text {*** }} \\
(0.08)\end{array}$ & $\begin{array}{c}-0.972^{* * *} \\
(0.19)\end{array}$ & $\begin{array}{c}-1.389^{* * *} \\
(0.19)\end{array}$ \\
\hline Nr of obs. & 1728 & 2976 & 1728 & 7744 \\
\hline
\end{tabular}




\section{Endogenous versus exogenous treatments}

\section{Non-parametric analysis}

Table 5.12: Differences in cooperation between Endo and Exo

\begin{tabular}{|c|c|c|c|c|c|c|c|c|c|}
\hline & \multicolumn{3}{|c|}{$r_{i}, r_{j} \leq 4$} & \multicolumn{3}{|c|}{$r_{i} \leq 4, r_{j}>4$} & \multicolumn{3}{|c|}{$r_{i}, r_{j}>4$} \\
\hline & Endo & Exo & $p$ & Endo & Exo & $p$ & Endo & Exo & $p$ \\
\hline \multicolumn{10}{|l|}{ Short } \\
\hline First periods & 5.93 & 17.67 & 0.0135 & 20.71 & 20.40 & 0.8945 & 65.34 & 53.12 & 0.4428 \\
\hline All periods & 6.21 & 15.80 & 0.0274 & 17.71 & 19.08 & 0.7573 & 63.74 & 51.13 & 0.3706 \\
\hline $\mathrm{Nr}$ of obs. & \multicolumn{3}{|c|}{16} & \multicolumn{3}{|c|}{18} & \multicolumn{3}{|c|}{14} \\
\hline \multicolumn{10}{|l|}{ Long } \\
\hline First periods & 10.45 & 33.25 & 0.0080 & 27.22 & 36.87 & 0.2888 & 63.89 & 67.17 & 0.6272 \\
\hline All periods & 7.81 & 27.87 & 0.0193 & 20.08 & 29.33 & 0.4529 & 61.67 & 63.44 & 0.6272 \\
\hline Nr of obs. & \multicolumn{3}{|c|}{18} & \multicolumn{3}{|c|}{18} & \multicolumn{3}{|c|}{18} \\
\hline
\end{tabular}

Averages are taken over matching groups. $p$-values are from two-sided Mann-Whitney tests which take averages over matching groups as unit of observation.

\section{Regression analysis}

In addition, a probit regression of the probability of choosing the cooperative action is used to assess treatment differences between Endo and Exo. Table 5.13 reports the results for the treatments with $\delta=0.35$ and $\delta=0.75$, both for the first period of each match and all periods. The reference groups in each specification are the corresponding investment category in the Exo treatment. 
Table 5.13: Endo versus Exo

\begin{tabular}{|c|c|c|c|c|c|c|}
\hline & \multicolumn{6}{|c|}{$\delta=0.35$} \\
\hline & 1st periods & All & 1st periods & All & 1st periods & All \\
\hline$r_{i}, r_{j} \leq 4 \times$ Endo & $\begin{array}{c}-0.736^{* * *} \\
(0.17)\end{array}$ & $\begin{array}{c}-0.667^{* * *} \\
(0.16)\end{array}$ & & & & \\
\hline$r_{i}, r_{j}>4 \times$ Endo & & & $\begin{array}{l}0.403 \\
(0.34)\end{array}$ & $\begin{array}{l}0.334 \\
(0.32)\end{array}$ & & \\
\hline$r_{i} \leq 4, r_{j}>4 \times$ Endo & & & & & $\begin{array}{l}0.062 \\
(0.18)\end{array}$ & $\begin{array}{l}-0.007 \\
(0.17)\end{array}$ \\
\hline Constant & $\begin{array}{c}-0.916^{* * *} \\
(0.14)\end{array}$ & $\begin{array}{c}-1.085^{* * *} \\
(0.13)\end{array}$ & $\begin{array}{l}-0.041 \\
(0.28)\end{array}$ & $\begin{array}{l}-0.128 \\
(0.26)\end{array}$ & $\begin{array}{c}-0.801^{* * *} \\
(0.13)\end{array}$ & $\begin{array}{c}-0.910^{* * *} \\
(0.09)\end{array}$ \\
\hline Nr of obs. & 812 & 1352 & 368 & 588 & 548 & 1036 \\
\hline
\end{tabular}

\begin{tabular}{lcccccc}
\hline \hline & & \multicolumn{5}{c}{$\delta=0.75$} \\
& 1st periods & All & 1st periods & All & 1st periods & All \\
\hline$r_{i}, r_{j} \leq 4 \times$ Endo & $-0.583^{*}$ & -0.348 & & & & \\
& $(0.28)$ & $(0.32)$ & & & & \\
$r_{i}, r_{j}>4 \times$ Endo & & & -0.215 & 0.006 & & \\
& & $(0.33)$ & $(0.33)$ & & -0.300 & $-0.460^{*}$ \\
$r_{i} \leq 4, r_{j}>4 \times$ Endo & & & & $(0.23)$ & $(0.23)$ \\
Constant & $-0.576^{* *}$ & $-1.009^{* * *}$ & $0.742^{*}$ & 0.453 & -0.290 & $-0.593^{* *}$ \\
& $(0.20)$ & $(0.21)$ & $(0.30)$ & $(0.29)$ & $(0.19)$ & $(0.21)$ \\
\hline Nr of obs. & 616 & 2724 & 428 & 1876 & 684 & 3144 \\
\hline
\end{tabular}

*** $p<0.001 ;{ }^{* *} p<0.01 ;{ }^{*} p<0.05$. Bootstrapped standard errors, clustered over matching groups, in parentheses. In each regression, the reference group is the corresponding category in the exogenous treatment. 
Table 5.14: Within treatment differences in cooperation rates, across investment category

\begin{tabular}{|c|c|c|c|c|}
\hline & \multicolumn{4}{|c|}{$\delta=0.35$} \\
\hline & \multicolumn{2}{|c|}{ Endo } & \multicolumn{2}{|c|}{ Exo } \\
\hline & 1st periods & All periods & 1 st periods & All periods \\
\hline$r_{i}, r_{j} \leq 4$ & $\begin{array}{c}-0.913^{* * *} \\
(0.10)\end{array}$ & $\begin{array}{c}-0.834^{* * *} \\
(0.13)\end{array}$ & $\begin{array}{r}-0.116 \\
(0.09)\end{array}$ & $\begin{array}{r}-0.175 \\
(0.14)\end{array}$ \\
\hline$r_{i}, r_{j}>4$ & $\begin{array}{l}1.101^{* * *} \\
(0.22)\end{array}$ & $\begin{array}{l}1.123^{* * *} \\
(0.18)\end{array}$ & $\begin{array}{l}0.760^{* * *} \\
(0.18)\end{array}$ & $\begin{array}{l}0.782^{* * *} \\
(0.20)\end{array}$ \\
\hline Constant & $\begin{array}{c}-0.739^{* * *} \\
(0.12)\end{array}$ & $\begin{array}{c}-0.917^{* * *} \\
(0.14)\end{array}$ & $\begin{array}{c}-0.801^{* * *} \\
(0.13)\end{array}$ & $\begin{array}{c}-0.910^{* * *} \\
(0.09)\end{array}$ \\
\hline \multirow[t]{4}{*}{$\mathrm{Nr}$ of obs. } & 864 & 1488 & 864 & 1488 \\
\hline & \multicolumn{4}{|c|}{$\delta=0.75$} \\
\hline & \multicolumn{2}{|c|}{ Endo } & \multicolumn{2}{|c|}{ Exo } \\
\hline & 1st periods & All periods & 1st periods & All periods \\
\hline$r_{i}, r_{j} \leq 4$ & $\begin{array}{c}-0.569^{* *} \\
(0.20)\end{array}$ & $\begin{array}{c}-0.305 \\
(0.22)\end{array}$ & $\begin{array}{c}-0.286 \\
(0.20)\end{array}$ & $\begin{array}{c}-0.417^{*} \\
(0.17)\end{array}$ \\
\hline$r_{i}, r_{j}>4$ & $\begin{array}{l}1.117^{* * *} \\
(0.11)\end{array}$ & $\begin{array}{l}1.512^{* * *} \\
(0.17)\end{array}$ & $\begin{array}{l}1.032^{* * *} \\
(0.26)\end{array}$ & $\begin{array}{l}1.046^{* * *} \\
(0.29)\end{array}$ \\
\hline Constant & $\begin{array}{c}-0.589^{* * *} \\
(0.12)\end{array}$ & $\begin{array}{c}-1.052^{* * *} \\
(0.08)\end{array}$ & $\begin{array}{r}-0.290 \\
(0.20)\end{array}$ & $\begin{array}{c}-0.593^{* *} \\
(0.22)\end{array}$ \\
\hline Nr of obs. & 864 & 3872 & 864 & 3872 \\
\hline
\end{tabular}


The effect of time horizon on cooperation

Non-parametric analysis

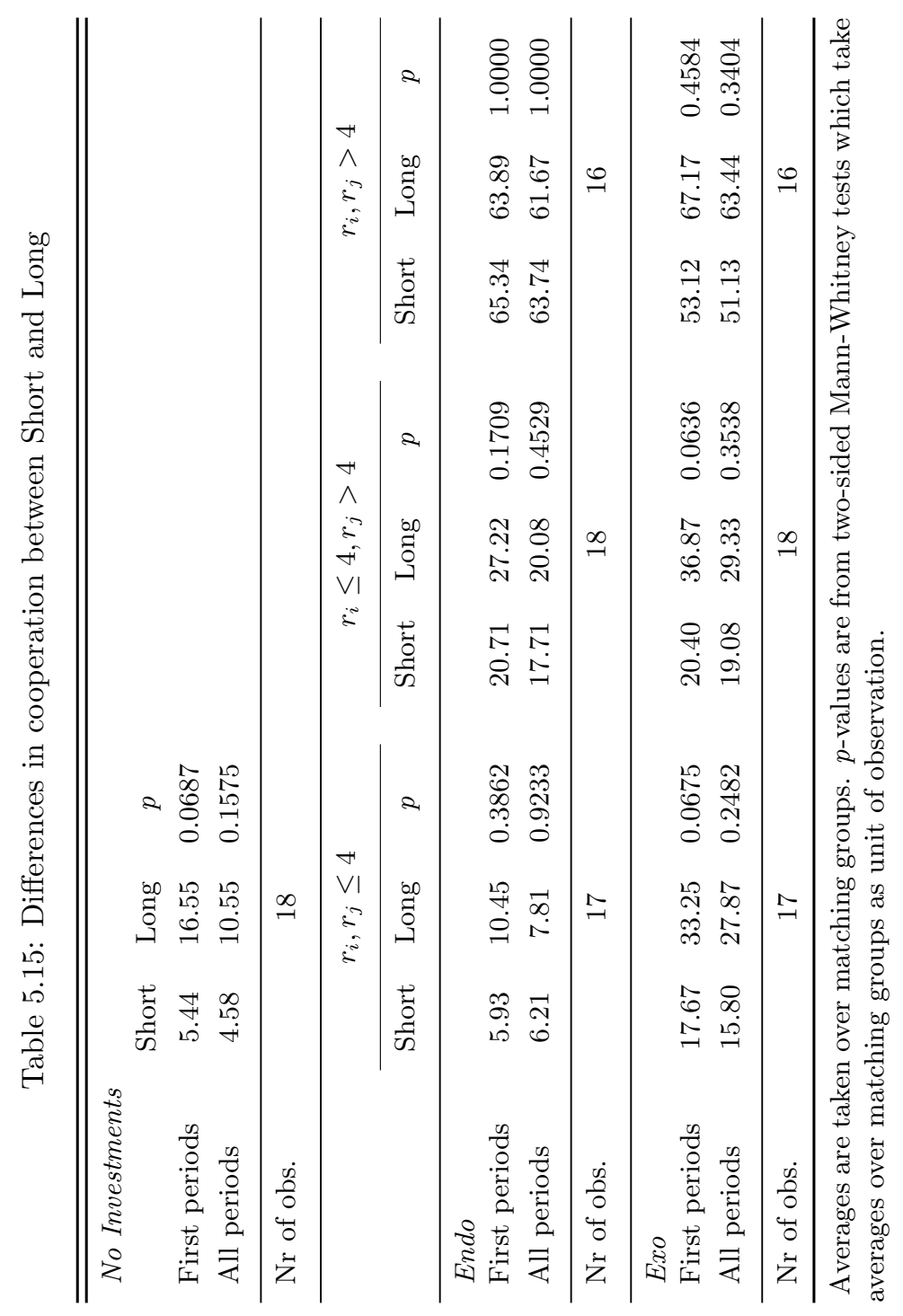




\section{Regression analysis}

We regress the probability to cooperate over a dummy for $\delta$ being high (see Tables 5.16 and 5.17). Results confirm that, in our experiment, increasing the probability of continuation does not necessarily increase the probability of a cooperative outcome.

Table 5.16: Effects of $\delta$ on the probability to cooperate

\begin{tabular}{|c|c|c|}
\hline & \multicolumn{2}{|c|}{ No Investments } \\
\hline & First periods & All periods \\
\hline \multirow[t]{2}{*}{ Long } & $0.632^{* *}$ & 0.381 \\
\hline & $(0.22)$ & $(0.21)$ \\
\hline \multirow[t]{2}{*}{ Constant } & $-1.604^{* * *}$ & $-1.771^{* * *}$ \\
\hline & $(0.10)$ & $(0.08)$ \\
\hline Nr of obs. & 1728 & 5360 \\
\hline \multicolumn{3}{|c|}{$\begin{array}{l}\text { *** } p<0.001 ;{ }^{* *} p<0.01 ; * p<0.05 \text {. } \\
\text { Bootstrapped standard errors, clustered over } \\
\text { matching groups, in parentheses. Long takes } \\
\text { value } 1 \text { if the observation comes from a treat- } \\
\text { ment with } \delta=0.75 \text { and } 0 \text { otherwise. In each } \\
\text { regression, the reference category is the Short } \\
\text { treatment. }\end{array}$} \\
\hline
\end{tabular}


Table 5.17: Effects of $\delta$ on the probability to cooperate

\begin{tabular}{lcccccc}
\hline \hline & \multicolumn{3}{c}{ First periods } & & \multicolumn{3}{c}{ All periods } \\
\hline & $r_{i}, r_{j} \leq 4$ & $r_{i} \leq 4, r_{j}>4$ & $r_{i}, r_{j}>4$ & $r_{i}, r_{j} \leq 4$ & $r_{i} \leq 4, r_{j}>4$ & $r_{i}, r_{j}>4$ \\
\hline \multirow{2}{*}{ Long } & $0.494^{*}$ & 0.150 & 0.165 & 0.394 & -0.135 & 0.253 \\
& $(0.21)$ & $(0.18)$ & $(0.24)$ & $(0.25)$ & $(0.16)$ & $(0.26)$ \\
Constant & $-1.652^{* * *}$ & $-0.739^{* * *}$ & 0.362 & $-1.751^{* * *}$ & $-0.917^{* * *}$ & 0.206 \\
& $(0.10)$ & $(0.12)$ & $(0.19)$ & $(0.09)$ & $(0.14)$ & $(0.19)$ \\
\hline \multirow{2}{*}{ Nr of obs. } & 714 & 616 & 398 & 2038 & 2090 & 1232 \\
\hline
\end{tabular}

\begin{tabular}{lcccccc}
\hline \hline & & & \multicolumn{2}{c}{ Exogenous } \\
& & First periods & & \multicolumn{3}{c}{ All periods } \\
\hline \multirow{2}{*}{ Long } & $r_{i}, r_{j} \leq 4$ & $r_{i} \leq 4, r_{j}>4$ & $r_{i}, r_{j}>4$ & $r_{i}, r_{j} \leq 4$ & $r_{i} \leq 4, r_{j}>4$ & $r_{i}, r_{j}>4$ \\
\hline \multirow{2}{*}{ Constant } & 0.341 & $0.511^{*}$ & 0.165 & 0.075 & 0.317 & 0.582 \\
& $(0.24)$ & $(0.23)$ & $(0.24)$ & $(0.26)$ & $(0.23)$ & $(0.37)$ \\
& $-0.916^{* * *}$ & $-0.801^{* * *}$ & 0.362 & $-1.085^{* * *}$ & $-0.910^{* * *}$ & -0.128 \\
& $(0.14)$ & $(0.13)$ & $(0.19)$ & $(0.14)$ & $(0.09)$ & $(0.23)$ \\
\hline Nr of obs. & 714 & 616 & 398 & 2038 & 2090 & 1232 \\
\hline
\end{tabular}

*** $p<0.001$; $^{* *} p<0.01$ * $^{*} p<0.05$. Bootstrapped standard errors, clustered over matching groups, in parentheses. Long takes value 1 if the observation comes from a treatment with $\delta=0.75$ and 0 otherwise. In each regression, the reference category is the Short treatment. 


\section{C.3 Discussion - Cooperation}
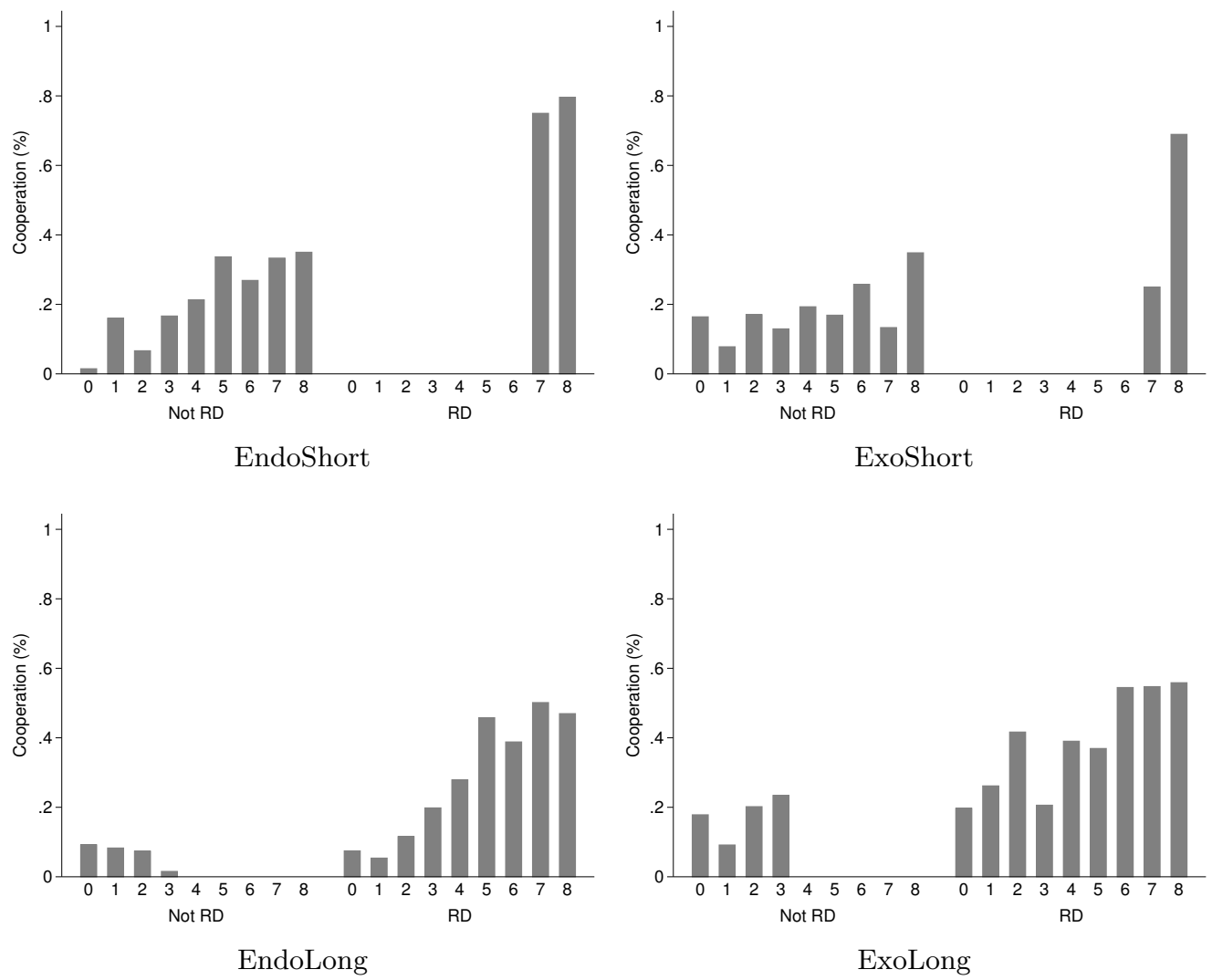

Figure 5.8: Risk dominance and cooperation, by investment level
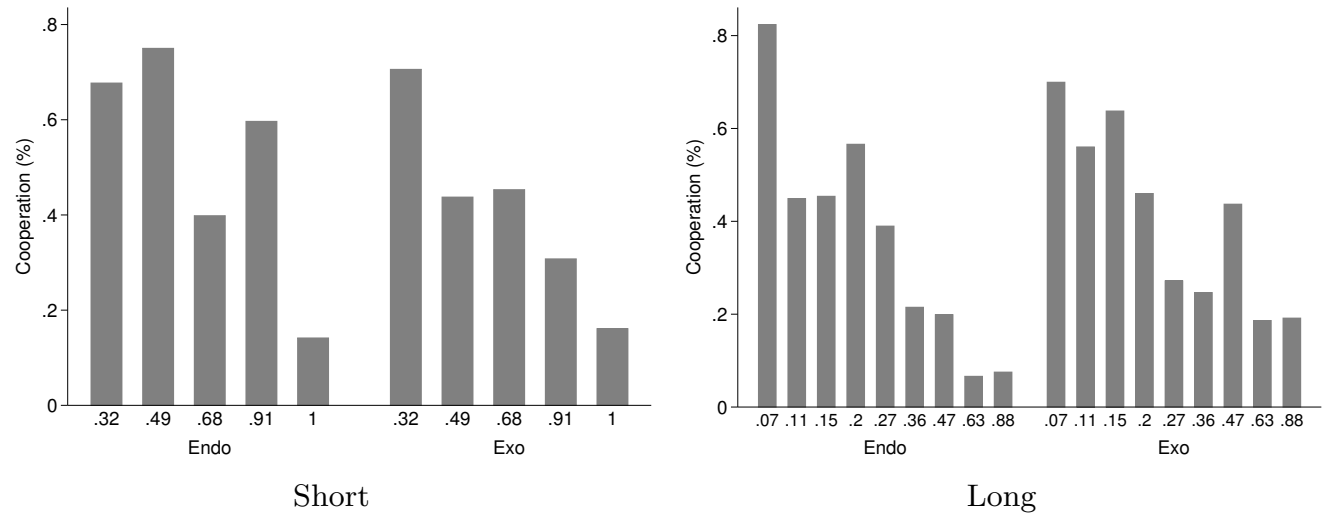

Figure 5.9: Cooperation and SizeBAD 

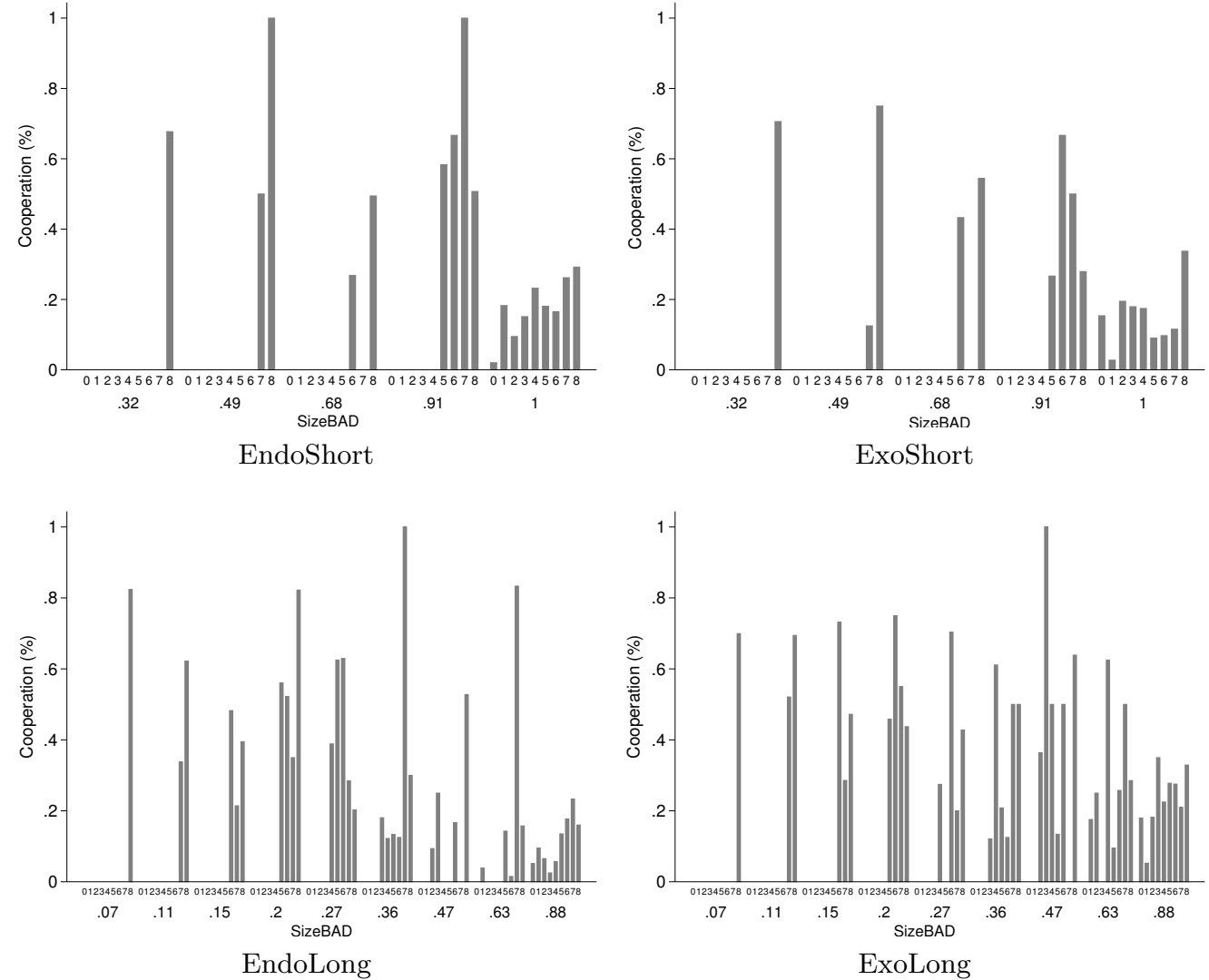

Figure 5.10: Cooperation, investments and SizeBAD 




\section{Valorization Addendum}

To a large extent, public policy choices strongly rely on traditional economic assumptions of behavior, such as perfect rationality and narrow self-interest. For example, reforms aiming at increasing competition (as in the railway, airline, electricity and gas industries) are often based on the conventional wisdom that competition increases (consumer) welfare. This argument assumes that contracts are complete, and that individuals' preferences are exogenous to, and therefore unaffected by, the institutional environment in which individuals make their decisions. Yet, empirical studies have yielded mixed results on the impact of pro-competition reforms on economic performance, and recent experiments have reported on the deteriorating effects of competition on social orientation and subjective well-being. This indicates that preferences and behavior are, at least in part, shaped by the institutional arrangements in place, and casts doubts on the solely positive effects of more competition. Given the importance of reciprocity as a driver of incomplete-contracts labor market outcomes, shown both in the lab and (to some extent) in the field, potential consequences of increased competition on workers' (other-regarding) preferences should not be ignored when designing competition policy reforms.

Chapters 3 and 4 provide controlled evidence on whether more competition leads to higher welfare, while acknowledging the interaction effects between product market, labor market and individuals' (reciprocal) preferences. They are intended to be an informative first step in the assessment of the effects of output market competition for incomplete labor markets. We brought the laboratory environment closer to real life contexts by abandoning the unnatural features of complete contracts, common in the industrial organization literature, and of monopolistic product markets, common in the gift-exchange literature. However, there are other rather relevant aspects we left out. For instance, in our experiments, we limit each employer to hire at most one worker. Clearly, most labor relationships involve more workers per employer. It remains to be seen whether our findings can be generalized to this more realistic context, where 
also horizontal fairness considerations might play a role. Would reciprocity survive if competition leads to an unequal increase or decrease in wages across workers? Or if some workers are laid off? In this sense, our studies pave the way for more research on the interaction of labor market gift-exchange and output market competition. Adding complexity in a systematic way will allow for a clearer identification of patterns of behavior, which in turn will permit to accurately inform public policy and help designing effective reforms.

Human cooperation has been praised as beneficial in numerous settings. For instance, cooperation in teams boosts team performance; international cooperation helps curb environmental degradation, or further scientific research. In many cases, cooperation requires some prior (coordination on) investments. Working efficiently on an interdisciplinary project, for instance, might require researchers to get familiar with each others' methods or literature. Long-term employment relationships are often facilitated by investments, such as retirement programs. Chapter 5 captures this aspect, and shows that those individuals who invest, and manage to coordinate on relatively high investments, are those who cooperate more. It also shows, however, that most individuals do not invest or choose low investments. This suggests that investments can be an important tool to enforce cooperation, but one cannot solely rely on voluntary investments.

This result has important policy implications. For instance, discussions on how to reduce greenhouse gas emissions have recently moved their focus from emission limits to investments in green technologies. Setting investment levels is argued to be more effective at inducing compliance to environmental agreements, since investments reduce the incentive to deviate and make cooperation credible. Our results provide support for the introduction of this kind of policies. The "2020 Climate and Energy package" adopted by the European Union seems to go in this direction: the agreement requires countries to set emission targets, and, at the same time, to develop renewable energy sources. Our results might be also informative to competition policy. While mergers and acquisitions are thoroughly scrutinized, governments usually encourage firms cooperative investments, especially in $\mathrm{R} \& \mathrm{D}$, because of the potential benefits resulting, for instance, from spillover effects or cost reduction. However, our results suggest that investments might facilitate collusion in the product market. Therefore, authorities should evaluate firms' co-investments with attention, and investigate the possibility of price collusion in presence of relatively high investments. 


\section{Bibliography}

K. Abbink and J. Brandts. Price competition under cost uncertainty: a laboratory analysis. Economic Inquiry, 43:636-648, 2005.

K. Abbink and J. Brandts. 24. Pricing in Bertrand competition with increasing marginal costs. Games and Economic Behavior, 63:1-31, 2008.

J. Abeler, S. Altmann, S. Kube, and M. Wibral. Gift exchange and workers' fairness concerns: when equality is unfair. Journal of the European Economic Association, 8:1299-1324, 2010.

J. Abeler, A. Falk, L. Goette, and D. Huffman. Reference points and effort provision. American Economic Review, 101:470-492, 2011.

G. Akerlof. Labor contracts as partial gift exchange. The Quarterly Journal of Economics, 97:543-569, 1982.

G. Akerlof and R. Kranton. Identity and the economics of organizations. Journal of Economic Perspectives, 19:9-32, 2005.

G. Akerlof and J. Yellen. Fairness and unemployment. American Economic Review, 78:44-49, 1988.

G. Akerlof and J. Yellen. The fair wage-effort hypothesis and unemployment. The Quarterly Journal of Economics, 105:255-283, 1990.

R. Axelrod. The evolution of cooperation. New York: Basic Books, 1984.

R. Axelrod and W. D. Hamilton. The evolution of cooperation. Science, 211: 1390-1396, 1981.

L. Balafoutas, K. Grechenig, and N. Nikiforakis. Third-party punishment and counter-punishment in one-shot interactions. Economics Letters, 122:308$310,2014$. 
N. Bardsley. Dictator game giving: altruism or artefact? Experimental Economics, 11:122-133, 2008.

B. Bartling, M. Grieder, and C. Zehnder. Does competition justify inequality? CESifo Working Paper 5651, 2015a.

B. Bartling, R. Weber, and L. Yao. Do markets erode social responsibility? The Quarterly Journal of Economics, 130:219-266, 2015b.

S. Bauernschuster, O. Falck, and N. Große. When trustors compete for the favour of a trustee - A laboratory experiment. Journal of Economic Psychology, 34:133-147, 2013.

H. Bernhard, E. Fehr, and U. Fischbacher. Group affiliation and altruistic norm enforcement. American Economic Review, 96:217-221, 2006.

T. Bewley. Why wages don't fall during a recession. Cambridge, MA: Harvard University Press, 1999.

P. Blau. Exchange and power in social life. New York: Wiley, 1964.

M. Blonski and G. Spagnolo. Prisoners' other dilemma. International Journal of Game Theory, 44:61-81, 2015.

M. Blonski, P. Ockenfels, and G. Spagnolo. Equilibrium selection in the repeated prisoner's dilemma: axiomatic approach and experimental evidence. American Economic Journal: Microeconomics, 3:164-192, 2011.

S. Blount. When social outcomes aren't fair: the effect of causal attributions on preferences. Organizational Behavior and Human Decision Processes, 63: 131-144, 1995.

A. Blume and A. Ortmann. The effects of costless pre-play communication: experimental evidence from games with pareto-ranked equilibria. Journal of Economic Theory, 132:274-290, 2007.

T. Blumkin, B. Ruffle, and Y. Ganun. Are income and consumption taxes ever really equivalent? Evidence from a real-effort experiment with real goods. European Economic Review, 56:1200-1219, 2012.

G. E. Bolton and A. Ockenfels. A theory of equity, reciprocity and competition. American Economic Review, 100:166-193, 2000. 
G. E. Bolton, J. Brandts, and A. Ockenfels. Fair procedures: evidence from games involving lotteries. The Economic Journal, 115:1054-1076, 2005.

J. Bone, B. Wallace, R. Bshary, and N. Raihani. Power asymmetries and punishment in a prisoner's dilemma with variable cooperative investment. PLoS ONE, 11:1-16, 2016.

G. Bornstein, U. Gneezy, and R. Nagel. The effect of intergroup competition on group coordination: an experimental study. Games and Economic Behavior, 41:1-25, 2002.

A. Botelho, G. W. Harrison, L. Costa Pinto, and E. Rutstrom. Social norms and social choice. NIMA Working Papers 30, 2005.

S. Bowles. Endogenous preferences: the cultural consequences of markets and other economic institutions. Journal of Economic Literature, 36:75-111, 1998.

S. Bowles. Is liberal society a parasite on tradition? Philosophy and Public Affairs, 39:746-81, 2011.

J. Brandts and G. Charness. Do labour market conditions affect gift exchange? Some experimental evidence. The Economic Journal, 114:684-708, 2004.

J. Brandts and D. J. Cooper. A change would do you good ... An experimental study on how to overcome coordination failure in organizations. The American Economic Review, 96:669-693, 2006a.

J. Brandts and D. J. Cooper. Observability and overcoming coordination failure in organizations: an experimental study. Experimental Economics, 9:407-423, 2006b.

J. Brandts and P. Guillen. Collusion and fights in an experiment with pricesetting firms and advance production. Journal of Industrial Economics, 55: 453-473, 2007.

J. Brandts and J. Potters. Experimental Industrial Organization. In L. Corchón and M. Marini, editors, Handbook of Game Theory and Industrial Organization, volume II, pages 453-474. Edward Elgar Publishing, 2018.

J. Brandts and A. Riedl. Market competition and efficient cooperation. Research Memoranda 006, Maastricht University, Graduate School of Business and Economics, 2016. 
J. Brandts, A. Riedl, and F. van Winden. Competitive rivalry, social disposition, and subjective well-being: an experiment. Journal of Public Economics, 93: 1158-1167, 2009.

J. Brandts, K. Gërxhani, A. Schram, and J. Ygosse-Battisti. Size doesn't matter! Gift exchange in experimental labor markets. Journal of Economic Behavior and Organization, 76:544-548, 2010.

J. Brock, A. Lange, and E. Ozbay. Dictating the risk: experimental evidence on giving in risky environments. The American Economic Review, 103:415-437, 2013.

M. Brown, A. Falk, and E. Fehr. Relational contracts and the nature of market interactions. Econometrica, 72:747-780, 2004.

M. Brown, A. Falk, and E. Fehr. Competition and relational contracts: the role of unemployment as a disciplinary device. Journal of the European Economic Association, 10:887-907, 2012.

T. Burnham. Public goods with high-powered punishment: high cooperation and low efficiency. Journal of Bioeconomics, 17:173-187, 2015.

H. Cai and Q. Liu. Competition and corporate tax avoidance: evidence from Chinese industrial firms. The Economic Journal, 119:764-795, 2009.

C. Camerer. Behavioral game theory: experiments in strategic interaction. Princeton University Press, 2003.

F. Casoria and A. Riedl. Experimental labor markets and policy considerations: incomplete contracts and macroeconomic aspects. Journal of Economic Surveys, 27:398-420, 2013.

F. Casoria, R. Peeters, and A. Riedl. Labor market gift-exchange and output market competition. 2018.

G. Charness. Attribution and reciprocity in an experimental labor market. Journal of Labor Economics, 22:665-688, 2004.

G. Charness and P. Kuhn. Does pay inequality affect worker effort? Experimental evidence. Journal of Labor Economics, 25:693-723, 2007.

G. Charness and P. Kuhn. Lab labor: what can labor economists learn from the lab? In O. Ashenfelter and D. Card, editors, Handbook of Labor Economics, volume 4A, pages 229-330. Elsevier B.V., 2011. 
G. Charness, G. Fréchette, and J. Kagel. How robust is laboratory gift exchange? Experimental Economics, 7:189-205, 2004.

G. Charness, L. Rigotti, and A. Rustichini. Individual behavior and group membership. American Economic Review, 97:1340-1352, 2007.

A. Chaudhuri, S. Graziano, and P. Maitra. Social learning and norms in a public goods experiment with inter-generational advice. Review of Economic Studies, 73(2):357-380, 2006a.

A. Chaudhuri, A. Schotter, and B. Sopher. Talking ourselves to efficiency: coordination in inter-generational minimum effort games with private, almost common and common knowledge of advice. The Economic Journal, 119:91122, 2006b.

Y. Chen and S. Li. Group identity and social preferences. American Economic Review, 99:431-457, 2009.

R. Chetty, A. Looney, and K. Kroft. Salience and taxation: theory and evidence. American Economic Review, 99:1145-1177, 2009.

M. Cinyabuguma, T. Page, and L. Putterman. Can second-order punishment deter perverse punishment? Experimental Economics, 9:265-279, 2006.

D. J. Cooper and J. H. Kagel. Other regarding preferences: a selective survey of experimental results. In J. Kagel and A. E. Roth, editors, Handbook of Experimental Economics, volume 2. Princeton University Press, 2016.

P. Dal Bó. Cooperation under the shadow of the future: experimental evidence from infinitely repeated games. American Economic Review, 95:1591-1604, 2005 .

P. Dal Bó and G. R. Fréchette. The evolution of cooperation in infinitely repeated games: experimental evidence. American Economic Review, 101: 411-429, 2011.

P. Dal Bó and G. R. Fréchette. On the determinants of cooperation in infinitely repeated games: a survey. Journal of Economic Literature, forthcoming.

P. Dal Bó, A. Foster, and L. Putterman. Institutions and behavior: experimental evidence on the effects of democracy. American Economic Review, 100: 2205-2229, 2010. 
D. Davis and C. Holt. Experimental Economics. Princeton University Press, 1993.

T. Dohmen, A. Falk, D. Huffman, and U. Sunde. Representative trust and reciprocity: prevalence and determinants. Economic Inquiry, 46:84-90, 2008.

T. Dohmen, A. Falk, D. Huffman, and U. Sunde. Homo reciprocans: survey evidence on behavioural outcomes. The Economic Journal, 119:592-612, 2009.

A. Dreber, D. G. Rand, D. Fudenberg, and M. A. Nowak. Winners dont punish. Nature, 452:348-351, 2008.

P. Duersch, J. Oechssler, and R. Vadovic. Sick pay provision in experimental labor markets. European Economic Review, 56:1-19, 2012.

M. Dufwenberg and U. Gneezy. Price competition and market concentration: an experimental study. International Journal of Industrial Organization, 18: $7-22,2000$.

M. Dufwenberg and G. Kirchsteiger. A theory of sequential reciprocity. Games and Economic Behavior, 47:268298, 2004.

M. Egas and A. Riedl. The economics of altruistic punishment and the maintenance of cooperation. Proceedings of the Royal Society B - Biological Sciences, 275:871-878, 2008.

A. Ertan, T. Page, and L. Putterman. Who to punish? Individual decisions and majority rule in mitigating the free-rider problem. European Economic Review, 53:495-51, 2009.

A. Falk and U. Fischbacher. A theory of reciprocity. Games and Economic Behavior, 54:293-315, 2006.

A. Falk and N. Szech. Morals and markets. Science, 340:707-711, 2013a.

A. Falk and N. Szech. Organizations, diffused pivotality and immoral outcomes. CEPR Discussion Papers 9522, 2013b.

A. Falk, E. Fehr, and C. Zehnder. Fairness perceptions and reservation wages. The behavioral effects of minimum wage laws. The Quarterly Journal of Economics, 121:1347-1381, 2006.

A. Falk, E. Fehr, and U. Fischbacher. Testing theories of fairness - intentions matter. Games and Economic Behavior, 62:287-303, 2008. 
E. Fehr and A. Falk. Wage rigidity in a competitive incomplete contract market. Journal of Political Economy, 107:106-134, 1999.

E. Fehr and U. Fischbacher. Third-party punishment and social norms. Evolution and Human Behavior, 25:63-87, 2004.

E. Fehr and S. Gächter. Cooperation and punishment in public goods experiments. American Economic Review, 90:980-994, 2000.

E. Fehr and S. Gächter. Do incentive contracts crowd out voluntary cooperation? IEW - Working Papers iewwp034, 2002a.

E. Fehr and S. Gächter. Altruistic punishment in humans. Nature, 415:137-140, 2002b.

E. Fehr and H. Gintis. Human motivation and social cooperation: experimental and analytical foundations. Annual Review of Sociology, 33:4364, 2007.

E. Fehr and K. M. Schmidt. A theory of fairness, competition, and cooperation. The Quarterly Journal of Economics, 114:817-868, 1999.

E. Fehr and K. M. Schmidt. Adding a stick to the carrot? The interaction of bonuses and fines. American Economic Review, 97:177-181, 2007.

E. Fehr and J.-R. Tyran. Does money illusion matter? American Economic Review, 91:1239-1262, 2001.

E. Fehr, G. Kirchsteiger, and A. Riedl. Does fairness prevent market clearing? An experimental investigation. The Quarterly Journal of Economics, 108: 437-460, 1993.

E. Fehr, G. Kirchsteiger, and A. Riedl. Involuntary unemployment and noncompensating wage differentials in an experimental labour market. The Economic Journal, 106:106-121, 1996.

E. Fehr, S. Gächter, and G. Kirchsteiger. Reciprocity as a contract enforcement device: experimental evidence. Econometrica, 65:833-860, 1997.

E. Fehr, E. Kirchler, A. Weichbold, and S. Gchter. When social norms overpower competition: gift exchange in experimental labor markets. Journal of Labor Economics, 16:324-351, 1998a.

E. Fehr, G. Kirchsteiger, and A. Riedl. Gift exchange and reciprocity in competitive experimental markets. European Economic Review, 42:1-34, 1998b. 
E. Fehr, A. Klein, and K. Schmidt. Fairness and contract design. Econometrica, 75:121-154, 2007.

E. Fehr, L. Goette, and C. Zehnder. A behavioral account of the labor market: the role of fairness concerns. Annual Review of Economics, 1:355-384, 2009.

E. Fehr, E. Tougareva, and U. Fischbacher. Do high stakes and competition undermine fair behaviour? Evidence from Russia. Journal of Economic Behavior and Organization, 108:354-363, 2014.

R. M. Feinberg and T. A. Husted. An experimental test of discount-rate effects on collusive behaviour in duopoly markets. Journal of Industrial Economics, 41:153-160, 1993.

U. Fischbacher. z-tree: Zurich toolbox for ready-made economic experiments. Experimental Economics, 10:171-178, 2007.

M. Fonseca and H.-T. Normann. Explicit vs. tacit collusion - The impact of communication in oligopoly experiments. European Economic Review, 56: 1759-1772, 2012.

B. Frey, F. Oberholzer-Gee, and R. Eichenberger. The old lady visits your backyard: a tale of morals and markets. Journal of Political Economy, 104: 1297-1313, 1996.

D. Fudenberg and E. Maskin. The folk theorem in repeated games with discounting or with incomplete information. Econometrica, 54:533-554, 1986.

D. Fudenberg, D. K. Levine, and E. Maskin. The folk theorem with imperfect public information. Econometrica, 62:997-1039, 1994.

S. Gächter and A. Falk. Reputation and reciprocity: consequences for the labour relation. The Scandinavian Journal of Economics, 104:1-26, 2002.

S. Gächter and B. Herrmann. Reciprocity, culture and human cooperation: previous insights and a new cross-cultural experiment. Philosophical Transactions of the Royal Society B: Biological Sciences, 364:791-806, 2009.

S. Gächter and C. Thöni. Social comparison and performance: experimental evidence on the fair wageeffort hypothesis. Journal of Economic Behavior and Organization, 76:531-543, 2010.

S. Gächter, E. Renner, and M. Sefton. The long-run benefits of punishment. Science, 322:1510, 2008. 
S. Gächter, D. Nosenzo, and M. Sefton. The impact of social comparisons on reciprocity. The Scandinavian Journal of Economics, 114:1346-1367, 2012.

H. Gintis. Strong reciprocity and human sociality. Journal of Theoretical Biology, 206:169-179, 2000.

U. Gneezy and J. List. Putting behavioral economics to work: testing for gift exchange in labor markets using field experiments. Econometrica, 74:1365$1384,2006$.

U. Gneezy and A. Rustichini. Gender and competition at a young age. American Economic Review, 94:377-381, 2004.

L. Goette, D. Huffman, and S. Meier. The impact of group membership on cooperation and norm enforcement: evidence using random assignment to real social groups. American Economic Review, 96:212-216, 2006.

B. Greiner. Subject pool recruitment procedures: organizing experiments with orsee. Journal of the Economic Science Association, 1:114-125, 2015.

S. Grossman and O. Hart. The costs and benefits of ownership: a theory of vertical and lateral integration. The Journal of Political Economy, 94:691$719,1986$.

A. Gunnthorsdottir, R. Vragov, S. Seifert, and K. McCabe. Near-efficient equilibria in contribution-based competitive grouping. Journal of Public Economics, 94:987-994, 2010.

W. Güth, R. Schmittberger, and B. Schwarze. An experimental analysis of ultimatum bargaining. Journal of Economic Behavior and Organization, 3: 367-388, 1982.

R. Hannan, J. Kagel, and D. Moser. Partial gift exchange in an experimental labor market: impact of subject population differences, productivity differences, and effort requests on behavior. Journal of Labor Economics, 20: 923-951, 2002.

J. Harsanyi and R. Selten. A general theory of equilibrium selection in games. MIT Press, Boston, 1988.

B. Harstad, F. Lancia, and A. Russo. Compliance technology and self-enforcing agreements. CESifo Working Paper Series 5562, 2016. 
H. Hennig-Schmidt, Z.-Y. Li, and C. Yang. Why people reject advantageous offers - Non-monotonic strategies in ultimatum bargaining evaluating a video experiment run in PR China. Journal of Economic Behavior and Organization, 65:373-384, 2008.

H. Hennig-Schmidt, B. Rockenbach, and K. Sadrieh. In search of workers' real effort reciprocity - A field and a laboratory experiment. Journal of the European Economic Association, 8:817-837, 2010.

J. Henrich, R. Boyd, S. Bowles, C. Camerer, E. Fehr, H. Gintis, and R. McElreath. In search of homo economicus: behavioral experiments in 15 smallscale societies. American Economic Review, 91:73-78, 2001.

J. Henrich, J. Ensminger, R. McElreath, A. Barr, C. Barrett, A. Bolyanatz, J. Cardenas, M. Gurven, E. Gwako, N. Henrich, C. Lesorogol, F. Marlowe, D. Tracer, and J. Ziker. Markets, religion, community size, and the evolution of fairness and punishment. Science, 327:1480-1484, 2010.

G. Homans. Social behavior as exchange. American Journal of Sociology, 63: 597-606, 1958.

A. Hopfensitz and E. Reuben. The importance of emotions for the effectiveness of social punishment. The Economic Journal, 119:1534-1559, 2009.

S. Huck, H. Norman, and J. Oechssler. Two are few and four are many: number effects in experimental oligopolies. Journal of Economic Behavior and Organization, 53:435-446, 2004.

S. Huck, A. Seltzer, and B. Wallace. Deferred compensation in multiperiod labor contracts: an experimental test of Lazear's model. American Economic Review, 101:819-843, 2011.

S. Huck, G. Lünser, and J.-R. Tyran. Competition fosters trust. Games and Economic Behavior, 76:195-209, 2012.

B. Irlenbusch and D. Sliwka. Transparency and reciprocal behavior in employment relations. Journal of Economic Behavior and Organization, 56:383-403, 2005.

R. Isaac and J. Walker. Communication and free-riding behavior: the voluntary contribution mechanism. Economic Inquiry, 26:585-608, 1988. 
D. Kahneman and A. Tversky. Prospect theory: an analysis of decision under risk. Econometrica, 47:263-292, 1979.

D. Kahneman, J. Knetsch, and R. Thaler. Fairness as a constraint on profit seeking: entitlements in the market. The American Economic Review, 76: 728-741, 1986.

K. Kamei. Democracy and resilient pro-social behavioral change: an experimental study. Social Choice and Welfare, 47:359-378, 2016.

K. Kamei, L. Putterman, and J.-R. Tyran. State or nature? Endogenous formal versus informal sanctions in the voluntary provision of public goods. Experimental Economics, 18:38-65, 2015.

R. Kerschbamer and G. Kirchsteiger. Theoretically robust but empirically invalid? An experimental investigation into tax equivalence. Economic Theory, 16:719-734, 2000.

M. Krawczyk and F. Le Lec. 'give me a chance!' An experiment in social decision under risk. Experimental Economics, 13:500-511, 2010.

S. Kube, M. Maréchal, and C. Puppe. The currency of reciprocity - Giftexchange in the workplace. American Economic Review, 102:1644-1662, 2012.

S. Kube, M. Maréchal, and C. Puppe. Do wage cuts damage work morale? Evidence from a natural field experiment. Journal of the European Economic Association, 11:853-870, 2013.

E. Lazear. Why is there mandatory retirement? Journal of Political Economy, $87: 1261-1284,1979$

V. Lei and C. Noussair. Equilibrium selection in an experimental macroeconomy. Southern Economic Journal, 74:448-482, 2007.

D. Levine. Modeling altruism and spitefulness in experiments. Review of Economic Dynamics, 1:593-622, 1998.

J. Linde and J. Sonnemans. Decisions under risk in a social and individual context: the limits of social preferences? Journal of Behavioral and Experimental Economics, 56:62-71, 2015.

J. List. On the interpretation of giving in dictator games. Journal of Political Economy, 115:482-493, 2007. 
I. Marcin, P. Robalo, and F. Tausch. Institutional endogeneity and third-party punishment in social dilemmas. Preprints of the max planck institute for research on collective goods bonn 2016/6, 2016 .

T. Markussen, L. Putterman, and J.-R. Tyran. Self-organization for collective action: an experimental study of voting on sanction regimes. Review of Economic Studies, 81:301-324, 2014a.

T. Markussen, E. Reuben, and J. Tyran. Competition, cooperation, and collective choice. The Economic Journal, 124:F163-F195, 2014b.

D. Masclet, C. Noussair, S. Tucker, and M. C. Villeval. Monetary and nonmonetary punishment in the voluntary contributions mechanism. American Economic Review, 93:366-380, 2003.

S. Maximiano, R. Sloof, and J. Sonnemans. Gift exchange in a multi-worker firm. The Economic Journal, 117:1025-1050, 2007.

S. Maximiano, R. Sloof, and J. Sonnemans. Gift exchange and the separation of ownership and control. Games and Economic Behavior, 77:41-60, 2013.

J. K. Murnighan and A. E. Roth. Equilibrium behavior and repeated play of the prisoner's dilemma. Journal of Mathematical Psychology, 17:189-198, 1978.

J. K. Murnighan and A. E. Roth. Expecting continued play in prisoner's dilemma games: a test of several models. The Journal of Conflict Resolution, 27:279-300, 1983.

H. R. Nalbantian and A. Schotter. Productivity under group incentives: an experimental study. American Economic Review, 87:314-341, 1997.

N. Nikiforakis. Punishment and counter-punishment in public good games: can we really govern ourselves? Journal of Public Economics, 92:91-112, 2008.

N. Nikiforakis and D. Engelmann. Altruistic punishment and the threat of feuds. Journal of Economic Behavior and Organization, 78:319-332, 2011.

D. Nosenzo. Pay secrecy and effort provision. Economic Inquiry, 51:1779-1794, 2013.

C. Noussair and S. Tucker. Combining monetary and social sanctions to promote cooperation. Economic Inquiry, 43:649-660, 2005. 
C. Noussair, C. Plott, and R. Riezman. An experimental investigation of the patterns of international trade. American Economic Review, 85:462-491, 1995.

C. Noussair, C. Plott, and R. Riezman. Production, trade and exchange rates in large experimental economies. European Economic Review, 51:46-76, 2007.

G. Ortona, S. Ottone, F. Ponzano, and F. Scacciati. Labour supply in presence of taxation financing public services. An experimental approach. Journal of Economic Psychology, 29:619-631, 2008.

E. Ostrom, J. Walker, and R. Gardner. Covenants with and without a sword: self-governance is possible. American Political Science Review, 86:404-417, 1992.

M. Owens and J. Kagel. Minimum wage restrictions and employee effort in incomplete labor markets: an experimental investigation. Journal of Economic Behavior and Organization, 73:317-326, 2010.

P. Pereira, N. Silva, and J. Silva. Positive and negative reciprocity in the labor market. Journal of Economic Behavior and Organization, 59:406-422, 2006.

J. Potters and S. Suetens. Oligopoly experiments in the current millennium. Journal of Economic Surveys, 27:439-460, 2013.

L. Putterman, J.-R. Tyran, and K. Kamei. Public goods and voting on formal sanction schemes. Journal of Public Economics, 95:1213-1222, 2011.

M. Puurtinen and T. Mappes. Between-group competition and human cooperation. Proceedings of the Royal Society B, 276:355-360, 2009.

M. Rabin. Incorporating fairness into game theory and economics. American Economic Review, 83:1281-1302, 1993.

E. Reuben and A. Riedl. Enforcement of contribution norms in public good games with heterogeneous populations. Games and Economic Behavior, 77: 122-137, 2013.

A. Riedl and J. Tyran. Tax liability side equivalence in gift-exchange labor markets. Journal of Public Economics, 89:2369-2382, 2005.

A. Riedl and F. Van Winden. Does the wage tax system cause budget deficits? A macro-economic experiment. Public Choice, 109:371-394, 2001. 
A. Riedl and F. Van Winden. An experimental investigation of wage taxation and unemployment in closed and open economies. European Economic Review, 51:871-900, 2007.

A. Riedl and F. Van Winden. Input versus output taxation in an experimental international economy. European Economic Review, 56:216-232, 2012.

A. Roth, V. Prasnikar, M. Okuno-Fujiwara, and S. Zamir. Bargaining and market behavior in Jerusalem, Ljubljana, Pittsburgh, and Tokyo: an experimental study. American Economic Review, 81:1068-1095, 1991.

R. Sausgruber and J.-R. Tyran. Pure redistribution and the provision of public goods. Economics Letters, 95:334-338, 2007.

K. Schmidt. Social preferences and competition. Journal of Money, Credit and Banking, 43:207-231, 2011.

C. Shapiro and J. Stiglitz. Equilibrium unemployment as a worker discipline device. American Economic Review, 74:433-444, 1984.

A. Shleifer. Does competition destroy ethical behavior? American Economic Review, 94:414-418, 2004.

C. Siang, T. Requate, and I. Waichman. On the role of social wage comparisons in gift-exchange experiments. Economics Letters, 112:75-78, 2011.

V. Smith. An experimental study of competitive market behavior. Journal of Political Economy, 70:111-137, 1962.

M. Sutter, S. Haigner, and M. Kocher. Choosing the carrot or the stick? Endogenous institutional choice in social dilemma situations. Review of Economic Studies, 77:1540-1566, 2010.

J. Tan and F. Bolle. Team competition and the public goods game. Economic Letters, 96:133-139, 2007.

J. Tauer and J. Harackiewicz. The effects of cooperation and competition on intrinsic motivation and performance. Journal of Personality and Social Psychology, 86:849-861, 2004.

R. L. Trivers. The evolution of reciprocal altruism. Quarterly Review of Biology, 46:35-57, 1971. 
J.-R. Tyran and L. Feld. Achieving compliance when legal sanctions are nondeterrent. Scandinavian Journal of Economics, 108:135-156, 2006.

K. Vohs, N. Mead, and M. Goode. The psychological consequences of money. Science, 314:1154-1156, 2006.

T. Yamagishi. The provision of a sanctioning system as a public good. Journal of Personality and Social Psychology, 51:110-116, 1986. 